\title{
Earthquake-induced hydrologic changes in the geoengineered schist landslides of Cromwell Gorge, Central Otago
}

\author{
Grant O'Brien
}

A thesis submitted in fulfilment of the requirements for the degree of Masters in Petroleum Geoscience

School of Geography, Environment and Earth Sciences

July 2014 

Dedicated to my family, friends and the late Rob Wenham 



\section{Abstract}

Geoengineered groundwater systems located within seven large ( $>100$ ha surface area), deep-seated, slow-creep schist landslides in Cromwell Gorge (Otago, New Zealand) are observed to respond systematically to 10 large $\left(>\mathrm{M}_{w} 6.2\right)$, regional earthquakes at epicentral distances of $130-630 \mathrm{~km}$. The permeabilities of the schist landslides have previously been reported to be c. $1 \times 10^{-17}-4 \times 10^{-6} \mathrm{~m}^{2}$ and the permeability structure is dominated by large fracture zones. Of the 315 hydrological instruments in the gorge for which data have been analysed, 21 monitoring well piezometers record repeated metreor centimetre-scale groundwater level changes, and 12 underground V-notch weirs record elevated flow rates induced by the same earthquakes. Groundwater level changes exhibit consistent temporal characteristics at all monitoring sites, namely a time to peak pressure change on the order of one month and a subsequent recovery period on the order of one year. Changes in weir flow rate are near-instantaneous with maximum flow rates reached within 0-6 hours, followed by recession periods on the order of one month. Hydrological responses to different earthquakes at each monitoring site are systematic in terms of polarity and amplitude. This comprehensive dataset enables consistent patterns in the amplitude, time to peak pressure change and recovery time of groundwater level changes, and elevated weir discharge volumes in response to earthquake shaking to be documented. Earthquakes inducing hydrological responses have been categorised into five categories based on shaking characteristics (duration, bandwidth and amplitude). Larger hydrological responses and proportionally shorter time to peak pressure change and recovery time are associated with long duration (25-50 s or longer), high-amplitude, broad bandwidth shaking. The larger amplitudes of hydrological response and proportionally shorter times to peak pressure change and recovery times, are interpreted to represent greater temporary enhancement of the landslides hydraulic properties, particularly permeability. Understanding how earthquakes can enhance or otherwise affect hydraulic properties such as permeability in fractured reservoirs is intrinsically important and may prove of economic utility for both the geothermal and hydrocarbon energy sectors. 



\section{Acknowledgements}

First and foremost, I would like to thank my project supervisors, John Townend and Simon C. Cox. Your help, guidance and enthusiasm have been most appreciated;

Euan G.C. Smith for help with the groundwater modelling and Matlab coding;

Neil Whitford from Contact Energy's Clyde Dam operations for supplying us with the outstanding dataset;

Adrian Benson, Belinda Smyth-Little and Mark Rodgers for help with coding, assembly of the data base and thought provoking discussions;

Lisa Williams, Caroline Holden, Phaedra Upton and my office mates Rory Hart, Claire Castellazzi, Brook Keats and Rachel Heckles for insightful discussions; and

last but by no means least, a sincere thank you to the organisations who provided funding for this project: The Earthquake Commission (EQC), OMV, GNS Sciences and Victoria University of Wellington. 



\section{Contents}

Abstract $\quad$ v

Acknowledgements vii

List of Figures $\quad$ xiii

List of Tables $\quad$ Xv

$\begin{array}{ll}\text { Abbreviations } & \text { xvii }\end{array}$

1 Introduction 1

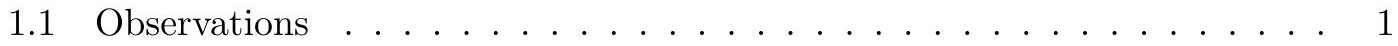

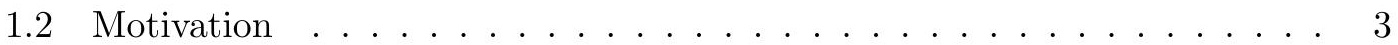

1.3 State of knowledge of earthquake-induced hydrologic phenomena . . . . . 5

1.4 Research objectives . . . . . . . . . . . . . . . . . . 7

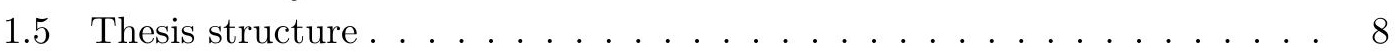

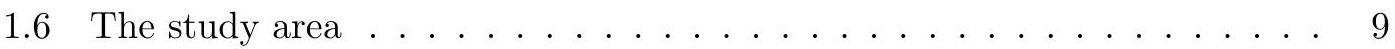

1.6.1 Geological setting . . . . . . . . . . . . . . . . 9 9

1.6.2 Rainfall and climate . . . . . . . . . . . . . . . . . . 12

1.6.3 Landslide distribution and extent . . . . . . . . . . . . . . . 13

1.6.4 Landslide characteristics . . . . . . . . . . . . . . . . . . 15

1.7 Geoengineering of Cromwell Gorge . . . . . . . . . . . . . . . . . . 17

1.8 Groundwater movement in the Cromwell Gorge area . . . . . . . . . . . . 19

1.8.1 Fluid sources and shallow circulation . . . . . . . . . . . . 20

1.8.2 Controls on permeability . . . . . . . . . . . . . . . . . . . . . 22

1.9 Hydrogeologic data set . . . . . . . . . . . . . . . . . . . . . 23

1.9.1 Borehole instrumentation: Piezometers . . . . . . . . . . . . . . 24

1.9.2 Tunnel instrumentation: V-notch weirs . . . . . . . . . . . . . 24

1.10 Seismological data set . . . . . . . . . . . . . . . . . . 27

2 Data and methodology $\quad 29$

2.1 Processing of hydrological data . . . . . . . . . . . . . . . . 29

2.1.1 Definition of an earthquake-induced hydrologic event . . . . . . . . 32

2.1.2 Identification of an earthquake-induced hydrologic event . . . . . . 33

2.2 Identification of other influences . . . . . . . . . . . . . . . . . . . 34 
2.3 Monitoring well parameters . . . . . . . . . . . . . . . . . . . . 40

2.4 Quantification of earthquake-induced hydrologic responses . . . . . . . . . 42

2.5 Processing of seismological data . . . . . . . . . . . . . . . . . 42

2.5.1 Treatment of changes in the seismic network . . . . . . . . . 43

2.5.2 Earthquake source characteristics . . . . . . . . . . . . . 43

2.5.3 Intensity and characteristics of shaking felt in Cromwell Gorge . . 47

3 Results 53

3.1 Hydrological responses to regional seismicity . . . . . . . . . . . . . . 53

3.1 .1 Amplitude of hydrologic fluctuations . . . . . . . . . . . . . 57

3.1.2 Duration of hydrologic fluctuations . . . . . . . . . . . . . 61

3.1.3 Distribution of hydrological responses . . . . . . . . . . . . . 64

3.1.4 Analysis of cycles within data . . . . . . . . . . . . . 66

3.1.5 Characteristic groundwater response in hydrological data . . . . . 69

3.1.6 Modelling of groundwater level fluctuations . . . . . . . . . . . . 74

3.2 Earthquakes that have induced hydrological responses . . . . . . . . . . 77

3.2.1 Source characteristics of earthquakes inducing hydrological responses 80

3.2.1.1 Earthquake take-off angles with respect to Cromwell Gorge 81

3.2.2 Earthquake shaking characteristics in Cromwell Gorge . . . . . . . 81

3.2.2.1 Measures of shaking intensity . . . . . . . . . . . 82

3.2 .2 .2 Seismic energy density . . . . . . . . . . . . 85

3.2.2.3 Shaking intensity and the amplitude of hydrologic response 85

3.2.2.4 Spectral characteristics . . . . . . . . . . . . . . . . 88

3.3 Summary of results . . . . . . . . . . . . . . . . . 93

$\begin{array}{llr}4 & \text { Discussion } & 97\end{array}$

4.1 Key observations . . . . . . . . . . . . . . . . . . . 97

4.2 Characteristic hydrological responses . . . . . . . . . . . . . . . . . . 99

4.3 Sensitivity to earthquake stimulation . . . . . . . . . . . . . . . . 100

4.4 What governs the response of the hydrological system? . . . . . . . . . . . 102

4.4.1 Summary of mechanisms . . . . . . . . . . . . . . . . . . . . . . . 103

4.4.2 Polarity of groundwater level responses . . . . . . . . . . . 107

4.4.3 Polarity of groundwater discharge in tunnels . . . . . . . . . . 108

4.4.4 Amplitude of hydrological response . . . . . . . . . . . . . . . . . 109

4.4.5 Duration of the hydrologic recovery . . . . . . . . . . . . . . 110

4.5 Conceptual model for groundwater movement . . . . . . . . . . . . . . 112

4.6 Geoengineering, landslide movement and earthquake-induced effects . . . 115

4.6.1 Monitoring well DL50C and rainfall . . . . . . . . . . . . 116

4.7 Shallow crustal permeability . . . . . . . . . . . . . . . . 117

4.8 Extraneous variables that may have contributed to the results . . . . . . . 118

5 Conclusions $\quad 121$

5.1 Main findings . . . . . . . . . . . . . . . . . . . . . . . 121

5.2 Directions for future research . . . . . . . . . . . . . . . 124 
B Piezometer and weir data: Cromwell Gorge landslides

C Removal of barometric effects: a test 137

D Assessment of uncertainties

Bibliography 



\section{List of Figures}

1.1 Central Otago, New Zealand location map . . . . . . . . . . . . . . . 10

1.2 Cromwell, Cromwell Gorge and Alexandra, Central Otago . . . . . . . . . 11

1.3 Extent of landslides in Cromwell Gorge . . . . . . . . . . . . . . . . . . 14

1.4 Vertical zoning within landslides . . . . . . . . . . . . . . 17

1.5 Schematic to illustrate the internal architecture of the schist landslides . . 18

1.6 Schematic to illustrate the complex hydrology within the schist landslides 20

1.7 Schematic to illustrate the groundwater movement within the landslides and the affect of drainage tunnels . . . . . . . . . . . . . . . . 21

1.8 Typical monitoring well setup . . . . . . . . . . . . . . . . 25

1.9 Location of the investigated monitoring sites in Cromwell Gorge . . . . . 26

1.10 Location of seismometers and strong motion sensors . . . . . . . . . 28

2.1 Piezometer record DL545a, Nine Mile Downstream monitoring area . . . . 30

2.2 Piezometer record DL1330a and Discharge record from weir 556W-01, Nine Mile Downstream monitoring area . . . . . . . . . . . . . . 31

2.3 Alignment of the earthquake catalogue with groundwater level and dis-

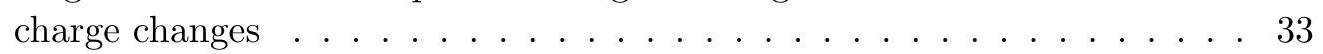

2.4 Quantification of hydrological responses . . . . . . . . . . . . . 36

2.5 Frequency analysis of barometer and piezometer data DL1330a, NMD . . 37

2.6 Example of how temperature may show a negative correlation to groundwater level . . . . . . . . . . . . . . . . . . . . 38 38

2.7 Example of a storm event in the Nine Mile Downstream tunnel systems . 39

2.8 Representative $\mathrm{M}_{w}>5$ earthquakes occurring since 1991 and the $2 \mathrm{D}$ velocity model boundaries, New Zealand region . . . . . . . . . . . . 44

2.9 Earthquake focal mechanisms and take-off angles . . . . . . . . . . . . . 47

2.10 A step-wise rotation of the $\mathrm{T}, \mathrm{N}$ and $\mathrm{P}$ axes and an earthquake Take-off angle with respect to Cromwell Gorge . . . . . . . . . . . . . 48

2.11 Example of a Morlet continuous wavelet transform performed on seismometer data . . . . . . . . . . . . . . . . . . . 5 52

3.1 Earthquake induced piezometer fluctuations, Nine Mile Creek Slide area . 54

3.2 Earthquake induced piezometer fluctuations Clyde Slide and No. 5 Slide areas . . . . . . . . . . . . . . . . . . 55

3.3 Earthquake-induced discharge data for tunnel systems in the Nine Mile Downstream and Nine Mile Upstream Slide areas . . . . . . . . . . . 56

3.4 Geographic distribution of the systematic hydrological responses in Cromwell Gorge shown by slide monitoring area . . . . . . . . . . . . 65

3.5 Changes in phase lag DL1330a Nine Mile Downstream slide area . . . . . 67 
3.6 Comparison of weir 537W-01 flow data, barometer pressure and local temperature data . . . . . . . . . . . . . . . 68 68

3.7 Offset in phase lag from 24 hour sinusoids, weir 537W-01, No. 5 Slide area 69

3.8 Earthquake-induce trends in the hydrological data recorded throughout Cromwell Gorge landslides . . . . . . . . . . . . . . . . . . . . . 71

3.9 Earthquake-induced trends in hydrological data, part 2 . . . . . . . . . . . 72

3.10 Characteristic groundwater level response to earthquakes . . . . . . . . . 73

3.11 Characterising the shape of groundwater level fluctuations using overdamped harmonic oscillation . . . . . . . . . . . 76

3.12 Geographic distribution of earthquakes that have induced hydrologic responses in Cromwell Gorge landslides . . . . . . . . . . . . . . . . 78

3.13 Rotated lower hemisphere focal mechanism showing calculated earthquake take-off angles with respect to Cromwell Gorge . . . . . . . . . . . 82

3.14 Interpolation of horizontal PGA, Arias intensity and seismic energy density 84

3.15 Comparison of earthquake shaking characteristics (PGA, Arias and seismic $e$ ) with the amplitude, time to peak pressure change and recovery time of hydrological responses . . . . . . . . . . . . . . . 86

3.16 Examples of seismographs for earthquakes recorded at EAZ and AXZ, east component . . . . . . . . . . . . . . . 89

3.17 CWT plots for six earthquakes recorded at EAZ, east component . . . . . 90

3.18 CWT plots for two earthquakes recorded at AXZ, east component . . . . 91

3.19 CWT plots for two earthquakes recorded at MSZ, east component . . . . 92

3.20 CWT plots for three earthquakes recorded at MSZ, east component . . . 93

3.21 Comparison of measured PGA, calculated PGA, seismic energy density and Arias intensity . . . . . . . . . . . . . . . . . 95

3.22 Spectral category and hydrological responses . . . . . . . . . . . . . 96

4.1 The characteristic groundwater level change . . . . . . . . . . . . . . . 99

4.2 Horizontal PGA measured at EAZ and calculated values pre 1994 . . . . . 102

4.3 Conceptual model to illustrate groundwater movement . . . . . . . . . . . 114

4.4 Piezometer DL50C and extensometer BRERX-01, Brewery Creek Slide Active Portion . . . . . . . . . . . . . . . 116

A.1 Continuous wavelet transform versus a conventional spectrogram . . . . . 130

B.1 Earthquake induced-discharge events Clyde Slide, No. 5 Slide and Cairnmuir Slide areas . . . . . . . . . . . . . . . . . . . . 132

B.2 Earthquake induced-piezometric fluctuations Brewery Creek Slide Area . 133

B.3 Earthquake induced-discharge events Brewery Creek Slide Area . . . . . . . 134

B.4 Earthquake induced-discharge events Cairnmuir Slide Area . . . . . . . . 135

B.5 Earthquake induced-piezometer level changes and discharge events Jackson Creek Slide Area . . . . . . . . . . . . . . . . . . . . . . 136

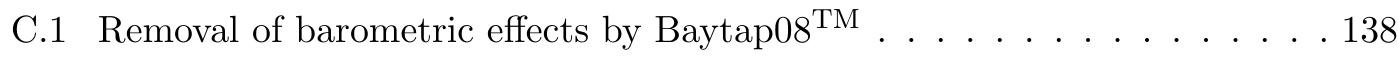

D.1 Log-likelihood plots for determining damping ratio angular frequency . . . 140

D.2 Log-likelihood plots for determining damping ratio angular frequency . . . 141 


\section{List of Tables}

1.1 Schist landslides in Cromwell Gorge: A summary . . . . . . . . . . . . . . 14

1.2 Landslide hydraulic conductivity and permeability measurements . . . . . 23

1.3 Hydrological monitoring sites used in this study . . . . . . . . . . . . . 27

2.1 Earth tides used in the analysis . . . . . . . . . . . . . . . 38

2.2 Summary of monitoring wells that have recorded earthquake-induce groundwater level changes and the well parameters . . . . . . . . . . . . 41

2.3 GeoNet stations within close proximity to Cromwell Gorge . . . . . . . . . 43

3.1 Weirs, tunnels and baseflow . . . . . . . . . . . . . . 58

3.2 Amplitude of earthquake-induced hydrologic fluctuations . . . . . . . . . . . 59

3.3 Piezometer rise and recovery timescales . . . . . . . . . . . . 62

3.4 Modelled damping ratios and angular frequencies . . . . . . . . . . . . 75

3.5 Summary of earthquakes that have induced hydrologic responses in Cromwell Gorge Landslides . . . . . . . . . . . . . . . . . . . . 79

3.6 Summary of shaking intensity for earthquakes inducing hydrological responses . . . . . . . . . . . . . . . . . 87

3.7 A summary of earthquake parameters and induced hydrologic responses . 94

4.1 Mechanisms evoked in the relevant literature to explain earthquake-induced hydrological changes . . . . . . . . . . . . . . . . 106

A.1 New Zealand 2D velocity models . . . . . . . . . . . . . . . . . . 127 



\title{
Abbreviations
}

\author{
Hydrological \\ BRE Brewery Creek Landslide \\ BRM Barometer \\ CAI Cairnmuir Landslide \\ CLY Clyde Landslide \\ DR A drainage tunnel (drive) drilled through and beneath a Landslide \\ FL Flow Bucket \\ JAC Jackson Creek Landslide \\ NMD Nine Mile Downstream Landslide \\ NMU Nine Mile Upstream Landslide \\ No. 5 Number 5 Landslide \\ PZ Standpipe Piezometer \\ PZWB Westbay Piezometer \\ RL Reduced Level; defined page 24 \\ WR V-notch Weir \\ Seismological \\ e Seismic Energy Density $\left(\mathrm{J} / \mathrm{m}^{3}\right)$; defined pages 50 and 82 \\ $\mathbf{I}_{a} \quad$ Arias Intensity $(\mathrm{m} / \mathrm{s})$; defined page 49 \\ $\mathbf{M}_{w} \quad$ Moment Magnitude \\ Obspy Observation Seismology tool box for Python; https://github.com/obspy/ \\ PGA Peak Ground Acceleration \% $\%$; defined page 48 \\ PGV Peak Ground Velocity $(\mathrm{m} / \mathrm{s})$ \\ $\mathbf{T}, \mathbf{P}$, and $\mathbf{N}$ The tensional, compressional, and null axes of a focal mechanism \\ Geographical \\ NZTM The New Zealand Transverse Mercator projection system \\ WGS84 World Geodetic System 1984
}





\section{Chapter 1}

\section{Introduction}

\subsection{Observations}

Following large earthquakes, a wide spectrum of coseismic and postseismic hydrologic responses is commonly observed. Hydrological responses to earthquakes occur in a variety of geological settings, from mountainous hard rock settings to low-lying soft sediment basins, as seen following the 2010 Darfield (Canterbury) earthquake (Cox et al., 2012). The characteristic time scales of hydrological responses also vary, being induced co-seismically or post-seismically, many being short-lived and lasting $10^{-5}-10^{0}$ days (seconds to days), whereas on the other hand, some hydrological responses are longlived, persisting on the order of $10^{2}$ days (years). Observations of earthquake-induced hydrological responses have been made at many distances, ranging from the immediate proximity of an earthquake, through to many 1000's of kilometres away, and can be divided into three categories after Wang and Manga (2010): the near-field (within one or two fault lengths ${ }^{1}$ ), the intermediate-field (up to 10 fault lengths), and the far-field (greater than 10 fault lengths). Observations include: soft sediment liquefaction, changes in groundwater level, changes in groundwater temperature and composition, increased discharge from streams, the emergence of new and the alteration of old springs, gas release, well-casing pressure changes, mud volcano and hydrothermal geyser activity (Wang et al., 2004; King et al., 2006; Wang and Manga, 2010; Cox et al., 2012). Changes in groundwater level parallel changes in subsurface fluid pressure and have been linked to the temporal and spatial distribution of earthquake aftershocks (Hill et al., 1993). Furthermore, large enough changes in fluid pressures from large-scale fluid flow, such

\footnotetext{
${ }^{1}$ In this context, a fault length is described as the length a fault ruptures during an earthquake, determined from surface deformation, or if no impression is left at the surface the aftershock sequence may illuminate the extent of the fault rupture plane.
} 
as fluid extraction and injection, have been shown to induce localised earthquakes and deformation (Segall, 1989; Hainzl et al., 2006).

This project is focused on observations of groundwater movement, made in hard, fractured rock (Otago Schist) in response to multiple large intermediate- and far-field earthquakes. These observations are recorded by one of the most extensive long-term groundwater monitoring systems presently available, that is part of the infrastructure for the Clyde Hydroelectric Dam, Cromwell Gorge, Central Otago, New Zealand.

The spectrum of far-field observations in mountainous hard-rock sites is to a degree limited, primarily due to population density and infrastructure. Some hydrological responses appear more prominent in hard rock sites, such as increases in stream discharge (Wang et al., 2004), changes in groundwater level (this study), temperature and composition (Manga and Rowland, 2009; Cox et al., 2010; Wang et al., 2012). Beneficially, monitoring equipment within mountainous regions may be associated with larger scale infrastructure for example: hydroelectric dams, transport tunnels and mining operations, in which monitoring networks may be highly sophisticated, although spatially concentrated. Furthermore, the natural groundwater systems within these engineered sites have often been altered to ensure safety and longevity of operations. This concept is fundamental to this research and raises two questions 1) In a geoengineered setting, has the alteration of the groundwater system(s) increased or decreased the sensitivity of the hydrologic system to respond to earthquake shaking? 2) How can observations at geoengineered sites be assessed and provide insight to the possible responses occurring within unmodified hydrologic settings?

Previous research into earthquake-induced hydrologic phenomena have utilised data that generally fall into one of two main categories, either focussing on data from a single monitoring site (e.g., well, stream or spring) that responds to multiple earthquakes (Roeloffs, 1998; Weingarten and Shemin, 2013), or on many sites recording responses to a single event (Wang et al., 2004; Cox et al., 2012). Few studies incorporate both categories and those that do (e.g., Jonsson et al. (2003); Elkhoury et al. (2006)) limit instrumentation type, possibly reflecting the availability of data. This study attempts to overcome this limitation and unravel the effects of different earthquake parameters, due to the unique hydrological monitoring infrastructure in the Cromwell Gorge, a dense network of monitoring wells and tunnel weirs in operation since early 1990. 


\subsection{Motivation}

New Zealand is an island nation situated on an active collision zone between the Australian and Pacific tectonic plates. Because of this setting New Zealanders endure frequent tectonic activity and are acutely aware of earthquakes and the immediate hazards they pose.

Engineering standards in place, such as those enveloped in modern building codes, have proven successful in minimising earthquake-induced loss of life and damage to infrastructure. However, despite these standards, the negative effect on lives and infrastructure from large earthquakes is an ongoing issue for many New Zealanders. This has been highlighted by seismicity in the Canterbury Region following the $2010 \mathrm{M}_{w} 7.1$ Darfield (Canterbury) Earthquake (Gledhill et al., 2011; Quigley et al., 2012), the more devastating 22 February $2011 \mathrm{M}_{w} 6.3$ Christchurch earthquake (Kaiser et al., 2012; Cubrinovski et al., 2011; Wotherspoon et al., 2012) and most recently, the $2013 \mathrm{M}_{w} 6.6$ Cook Strait earthquake sequence which caused damage in Wellington and Seddon.

Ground damage, resulting from liquefaction and lateral spreading during the Canterbury earthquake sequence of 2010-2012, occurred to levels previously unseen in New Zealand (Wotherspoon et al., 2012; Cubrinovski and Green, 2010; Cubrinovski et al., 2011). This not only hampered earthquake recovery strategies, but caused (ongoing) major political and insurance issues, especially regarding the suitability of land use. Liquefaction can occur in sediments during earthquake shaking, resulting from particle rearrangement and consolidation. The consolidation reduces the bulk volume of the sediment, causing an increase in pore pressure and subsequent ejection of liquefied sediment to the surface (Terzaghi, 1925).

Liquefaction propelled by changes in subsurface pore pressures had, to a degree, been previously anticipated (Brown and Weeber, 1992; CAE, 1997). This was done by producing 'first-generation' maps that indicated the potential of the hazard as a function of soil/shallow sediment type and its distribution. Surveys carried out by Beca Engineering (2004, 2005) included the soil strength and water table measurements in subsequent assessments. Despite this research the severity and enduring effects of the ground damage that occurred in 2010 - 2012 had not been foreseen. It has since become apparent that the depth to the groundwater, degree of shaking-induced changes to water pressures (i.e. deviation from a hydrostatic gradient) and groundwater flow might be of importance in enhancing liquefaction and ground damage (Cox et al., 2012; Wotherspoon et al., 2012).

The Darfield earthquake induced far-field hydrological fluctuations in many differing hydrological systems. For example, significant groundwater fluctuations were observed in a shallow borehole in Puriri Park, Northland, New Zealand (Cox et al., 2012) some 
$914 \mathrm{~km}$ away. Even a faint teleseismic signal from the earthquake was recorded in a sensitive groundwater monitoring borehole in Virginia, US (USGS, 2014). Interestingly some of the largest far-field fluctuations in the groundwater table were recorded in schist mountains of Central Otago. Here, an extensive groundwater monitoring network exists around the Clyde Dam, operating since early 1990, regularly recording hydrological effects of distal earthquakes (N. Whitford, personal communication 01/2013).

In the aftermath of the Canterbury earthquakes (2010-2012), there is a heightened need to understand why the seismicity caused so much more land damage than expected, and which other cities in New Zealand potentially face similar hazards. The Canterbury earthquakes not only highlighted the direct earthquake hazard of ground shaking, but also the indirect earthquake-induced hazards regarding alteration to the groundwater systems (Cox et al., 2012). Whether earthquakes will cause land damage by liquefaction, lateral spreading, emergence of springs or landslides, any information regarding the subsurface fluid pressure and groundwater regime, and how they may be altered, is vital in understanding and predicting severity of potential damage.

\section{Economic motivation}

Many subterranean fluids and gases are valuable resources, and the secure, consistent supply of these resources is of economic importance to many nations. Groundwater is a valuable commodity for many areas of the world where rainfall may be insufficient and demands exceed supply. Changes to groundwater reservoirs induced by earthquakes may affect the availability and quality of the groundwater. The degree of earthquakeinduced groundwater remobilisation that has been observed (e.g., Wang et al. 2004; Cox et al. 2012; Beresnev and Johnson 1994), suggests that subsurface fluid(s) or gas(es) or mixtures thereof, may be significantly affected by the passage of seismic waves under the right conditions, either directly or indirectly (Beresnev and Johnson, 1994). The implication of this may be significant to the economic production and sustainability of valued groundwater systems, hydrocarbon production, geothermal production, and carbon capture-storage systems. For example, production of oil and gas utilises pressure monitoring and production rates to aid in understanding reservoir behaviour, and what have been commonly observed as earthquake-induced responses are changes to the rate of production and pressures on the well casing (Beresnev and Johnson, 1994). Observed changes to oil production rates have not always been positive in response to earthquake shaking (Beresnev and Johnson, 1994). 
Economic production from geothermal fields and hydrocarbon reservoirs relies on the ability for fluids to flow through the reservoir rock. This flow is governed by the hydraulic properties of the reservoir rock such as permeability and porosity, and the fluid(s) properties e.g. viscosity (Manga et al., 2012; Dandekar, 2013). The hydraulic properties (e.g., permeability) of geothermal and hydrocarbon reservoir rocks are often insufficient to allow for economic production, and may be anthropogenically stimulated (e.g. hydraulic fracturing) to enhance flow of fluids and gases. Hydraulically fracturing a rock requires the fluids held within the pore space to undergo increasing fluid pressures, to the extent that the fluid pressures exceed the strength of the rock mass (Sibson, 2001). Large fluid pressures are required to surpass the strength of a rock mass: these pressures are of many orders of magnitude greater than that induced by intermediate and far-field earthquakes. The idea that the effect an earthquake may have on economic reservoirs, such as geothermal, hydrocarbon or carbon capture and storage systems could be predicted, is of great value.

\subsection{State of knowledge of earthquake-induced hydrologic phenomena}

A change in stress acting on a porous solid such as the earth's crust may cause it to deform if the stress is large enough to exceed the strength of the medium (Sibson, 2001), commonly reflected by the Mohr-Coulomb failure envelope. The deformation is partitioned between the solid (rock) and the fluids held within the pore space (Wang and Manga, 2010). Earthquakes generate changes to the crust's static stress and impart dynamic stresses through the passage of seismic waves (Roeloffs, 1998; Brodsky et al., 2003; Wang and Manga, 2010) that may exceed the failure threshold.

Both static and dynamic stresses decrease with distance, but at different rates (Kilb et al., 2002). Static stress changes decay in proportion to $1 / \mathrm{D}^{3}$ (where $\mathrm{D}$ is distance) and dynamic stresses proportional to $1 / \mathrm{D}^{1.66}$, based on the empirical relation between earthquake magnitude and the amplitude of surface-waves (Lay and Wallace, 1995; Kilb et al., 2002; Wang and Manga, 2010). This difference in the rate of decay is not universal, due to other earthquake and crustal parameters (e.g. density and anisotropy), but enables identification regarding which stress type (static or dynamic) may have the dominant effect on a hydrological system at different distances from the seismic source (Roeloffs, 1998; Brodsky et al., 2003). At far-field distances (>10 fault lengths) dynamic stresses outlast static changes, and are able to directly or indirectly induce changes to hydrological systems (Roeloffs, 1998; Weingarten and Shemin, 2013; Cox et al., 2012), more so than (greatly diminished) static stress changes. 
At far-field distances ( $>10$ fault lengths) earthquake-induced hydrologic changes are varied; forthcoming observations include: changes in groundwater levels (Roeloffs, 1998; Brodsky et al., 2003), changes in spring and stream discharge (Manga et al., 2003; Manga and Rowland, 2009), and changes in groundwater composition and temperature (Manga and Rowland, 2009; Wang et al., 2012). The duration and amplitude of these far-field hydrologic changes vary. Brodsky et al. (2003) observe $10^{-2}-10^{-1} \mathrm{~m}$ scale groundwater oscillations in a $91.4 \mathrm{~m}$ deep well mimicking a nearby seismometer (hydroseismographs) in Grants Pass, Oregon, responding to multiple distant earthquakes (e.g. $2002 \mathrm{M}_{w} 7.9$ Denali Earthquake $3100 \mathrm{~km}$ away). Hydroseismographs have been reported for many decades (Blanchard and Byerly, 1935), and are regularly observed world wide. For example, a shallow groundwater borehole in Puriri Park, Whangarei, Northland (Cox et al., 2012), and monitoring boreholes associated with the Deep Fault Drilling Project (DFDP) located near Whataroa, West Coast of New Zealand's South Island (Sutherland R., Cox S.C., personal communication, 2012, 2013). Changes in groundwater levels, stream discharge, and temperature and composition of groundwater are also observed (Manga et al., 2003; Elkhoury et al., 2006; Cox et al., 2010; Manga et al., 2012; Cox et al., 2012; Wang et al., 2012). These changes are often prolonged (even permanent), lasting months to years after the earthquake. Increases and decreases in petroleum production have been reported as far-field phenomena, also persisting for years after earthquake stimulation (Beresnev and Johnson, 1994).

The flow of fluids or gases through a saturated porous rock is described by Darcy's law, where the hydraulic property permeability $\left(\kappa\right.$ in $\left.\mathrm{m}^{2}\right)$ relates to the rate of fluid discharge per unit area of rock (fluid flux, $q$ ) to the hydraulic gradient $(\nabla h)$ by

$$
q=-\frac{\kappa g \rho}{\mu} \nabla h
$$

where $g$ is the acceleration due to gravity $(\mathrm{m} / \mathrm{s})$ and $\rho$ is fluid density. The equation is also simply related to a pressure gradient $(\nabla p)$ that may be induced by the passage of seismic waves, also prompting fluid flow by

$$
q=-\frac{\kappa}{\mu} \nabla p
$$

where $\mu$ is the fluid viscosity. Permeability of geologic media may be as low as $10^{-23}$ $\mathrm{m}^{2}$ in undisturbed crystalline rocks, yet may range up to $10^{-7} \mathrm{~m}^{2}$ in gravels (Manga et al., 2012). Many far-field observations show hydrological changes recovering after short (hours to days) or prolonged (months to years) periods of time, back to some pre-stimulated level (Elkhoury et al., 2006). This suggests any changes in hydraulic 
properties were temporary. Mechanisms that have been employed to explain observed groundwater level and discharge changes at far-field distances often centre around the enhancement of permeability (e.g. Roeloffs (1998); Brodsky et al. (2003); Elkhoury et al. (2006)), and differ from that used to explain liquefaction (e.g., Terzaghi 1925).

Mechanisms proposed to explain the observed earthquake-induced hydrologic responses have included permeability enhancement through the removal of colloidal material through small oscillations in stress imparted by seismic waves, with recovery governed by the reblocking of colloidal material (Roeloffs, 1998; Brodsky et al., 2003), an abrupt increase in pore pressure induced by seismic waves, where recovery may be governed by the diffusive properties of the rock mass (Roeloffs, 1998; Faoro et al., 2012), mobilisation of gaseous phases from a reduction in surface tension during shaking (Beresnev and Johnson, 1994; Manga et al., 2012). Micro-fracture generation and changes in hydraulic head have also been evoked (Manga and Rowland, 2009; Wang et al., 2004), but do not embody the concept of temporary change. Poroelastic processes are further considered to play a role (Faoro et al., 2012), but how far-field dynamic stresses induce and sustain elevated pressures remains as yet unknown (Manga et al., 2012).

How permeability recovers in different hydrological systems is often considered to be a combination of mechanical and geochemical processes (Wang and Manga, 2010). Geochemical processes e.g. cementation and disequilibrium reactions (Polak et al., 2004) can also change permeability, and may be more influential in fractured rocks with low porosity and permeability (Manga et al., 2012). Furthermore, the time needed for geochemical enhancement is too great to explain near-coseismic changes in permeability, although is suited to observed recovery periods of months to years (Manga et al., 2012).

The amplitude of hydrologic change has been compared to earthquake shaking intensity, such as seismic energy density (Wang, 2007) and peak ground acceleration (Cox et al., 2012), but observations of comparatively large hydrological changes at far-field distances (e.g. Cox et al. 2012) suggest other factors may be involved. Elkhoury et al. (2006) are able to associate peak ground velocity to permeability enhancement, through the utilisation of earth tides causing small yet predictable oscillatory stress changes in a shallow monitoring well. Laboratory experiments are able to relate shaking intensity (dynamic stress change) to the amplitude of pressure change (Faoro et al., 2012), which in turn are related to the degree of permeability enhancement (Elkhoury et al., 2011).

\subsection{Research objectives}

The primary objectives of this study are to: 
- Investigate links between the source parameters of earthquakes and the triggering of hydrological responses, and relationships between earthquake shaking characteristics at the site and variations in hydrological responses.

- Determine whether the hydrological response is determined by a triggered static stress change within the landslide groundwater systems, or a direct dynamic stress change associated with the passage of seismic waves.

- Assess the current mechanisms that may be used to explain the observed earthquakeinduced hydrologic responses, and conclude if there are temporal or permanent changes in the hydraulic properties (e.g. permeability) of the landslide groundwater systems.

- Address the two questions previously stated (Section 1.1) regarding how the geoengineering of the landslide groundwater systems may have altered the sensitivity of the groundwater systems to earthquake shaking, and if the findings can be viewed in the context of an unmodified hydrologic setting.

\subsection{Thesis structure}

Chapter 1 (this chapter) provides the motivation, objectives and background investigations regarding the field of research, and provides detail on the location and instrumentation used to record hydrological and seismological data.

Chapter 2 details the methodology used for hydrological and seismological data analysis.

Chapter 3 describes the results obtained from the hydrological and seismological data analysis, and characterises the hydrological responses observed in Cromwell Gorge landslides. Earthquakes are studied from the source characteristics, through to the degree of shaking felt at the site.

Chapter 4 discusses the results and observations obtained through the analysis of the large hydrological dataset and accompanied seismological data. Current mechanisms previously presented in the relevant literature regarding earthquake-induced hydrologic phenomena are discussed and likely candidates are selected to explain the observed hydrological responses within Cromwell Gorge landslides. A conceptual model is presented to explain the observations, and it is discussed if the findings may hold true under unmodified hydrological conditions. 
Chapter 5 outlines the conclusions from this study and provides a context for future directions of research into earthquake-induced hydrological phenomena in Cromwell Gorge.

\subsection{The study area}

Cromwell Gorge, the principal site for this study, is located in the heart of Central Otago (Figure 1.1). Located at the downstream extent of the gorge is New Zealand's largest hydroelectric power station, the Clyde Dam, and the neighbouring township of Clyde. Cromwell Gorge is approximately $20 \mathrm{~km}$ long and is surrounded by the rugged Dunstan Mountains to the Northeast, and the Cairnmuir Mountains to the Southwest. Two large rivers drain into the gorge from the north and west, the Clutha River and the Kawarau River. Both rivers become increasingly flooded downstream in response to the Clyde Dam. The gorge begins near the town of Cromwell, and cuts through the surrounding northeast-southwest trending mountain ranges in a southeast direction, curving progressively southward downstream. Residing at the downstream extent of Cromwell Gorge is the Clyde Dam, which controls the rate of lake discharge into the Clutha River, sending it past the neighbouring town of Clyde, before it spills out into an alluviated basin and meets the Manuherikia River at the township of Alexandra.

Cromwell Gorge was carefully flooded in increments during 1992 - 1993, generating the approximately $26 \mathrm{~km}^{2}$ Lake Dunstan, with a net head of $60 \pm 1 \mathrm{~m}$. The water head drives 4 Francis Turbine-generator units, generating 432 MW (installed capacity). During the investigations and development for the hydroelectric dam (1979-1993) it was uncovered that many of the hill slopes of Cromwell Gorge housed large, deep-seated, slow-creep landslides in the schist bedrock, as described by Turnbull (1987) and later by Gillon and Hancox (1991). Many of the toes of these landslides would be flooded or partially flooded during lake filling. At the time, the hazards these landslides presented were not

fully known. Large-scale, geological, geotechnical and geophysical investigations were undertaken to better understand landslide movement and the hydrological systems of the gorge, also determining the correct strategies for mitigation of the hazard(s) they pose. Section 1.7 outlines the geotechnical engineering works that were carried out to ensure stability of the landslides, and allow the hydroelectric dam to prosper.

\subsubsection{Geological setting}

The crust in the Central Otago region is dominated by a band of Otago Schist, which at around c. $150 \mathrm{~km}$ wide is a major feature of New Zealand's Eastern Province. The schist 


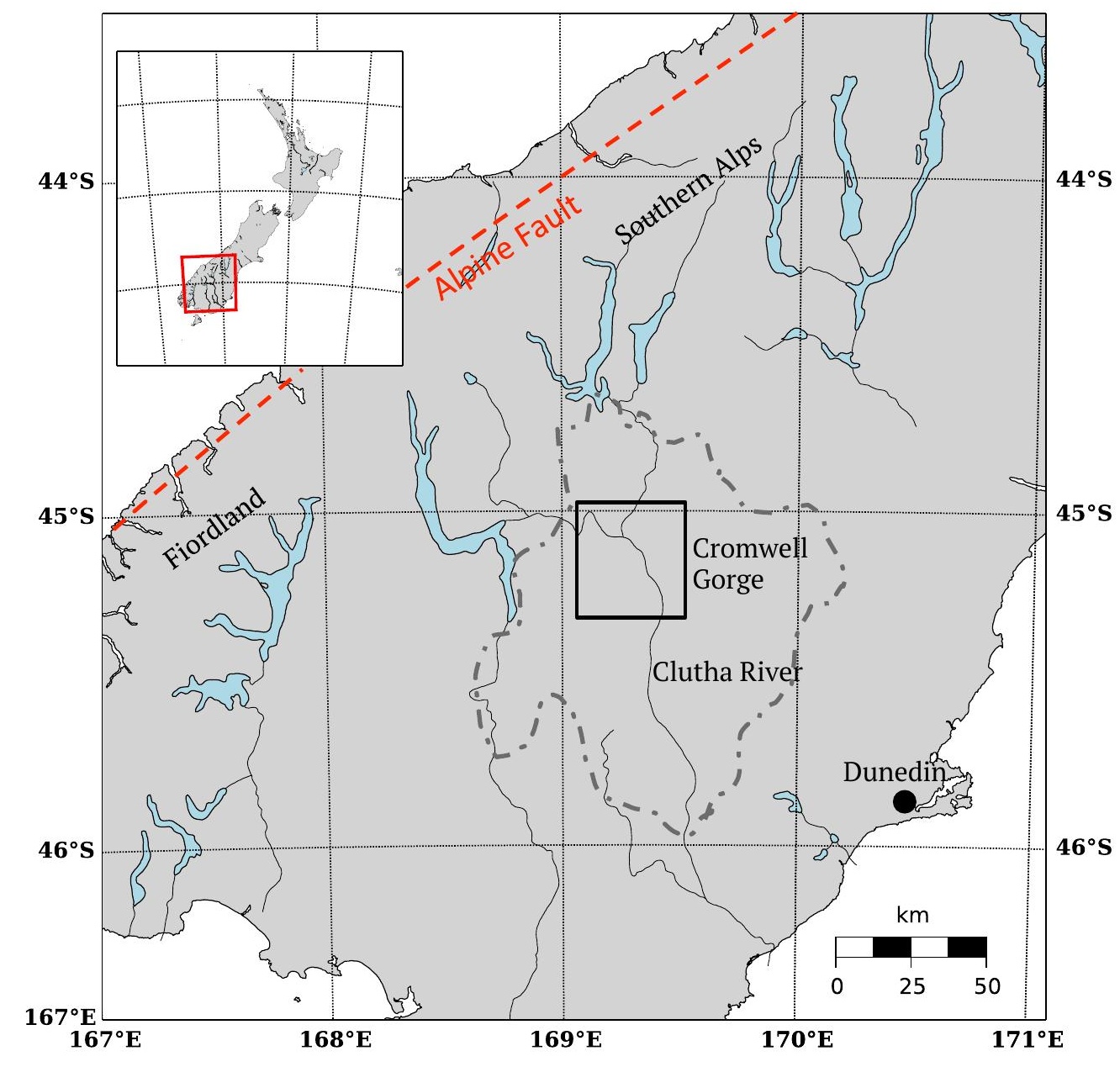

FiguRE 1.1: Map showing the location of the Cromwell Gorge, Central Otago, and surrounding features. The location of the Alpine Fault is approximate, sourced from GNS Sciences Active Faults Database (http://data.gns.cri.nz/af/ date accessed 10/03/2014), and the boundary for the Central Otago region is sourced from Central Otago District Council (http://www.codc.govt.nz/ date accessed 10/03/2014). The black square encompasses the study area, shown in more detail by Figure 1.2.

forms a large arch-like structure containing rocks of greenschist facies near the centre that were metamorphosed to peak pressures of $8-10 \mathrm{kbar}$ and temperature range $350-$ $400^{\circ} \mathrm{C}$, transitioning to lower-grade prehnite-pumpellyite facies, nonschistose greywackes on the flanks (Mortimer, 2000). Progressive development of foliation, textural zones and successive fold generations define an increase in deformation inline with the increase in metamorphism, towards the centre of the Otago Schist belt (Mortimer and Sibson, 2003). The schist formed during accretion of the Permian-Triassic Caples and Rakaia terranes in a Jurassic-Cretaceous accretionary wedge (Mortimer, 2000; Turnbull, 2000). The landscape of Central Otago consists of northeast-trending basins and flat topped ranges (Otago Peneplain). The basins are fault-angle depressions separated by large fault blocks tilting westward, above westerly dipping reverse faults (Turnbull, 2000). The majority of 


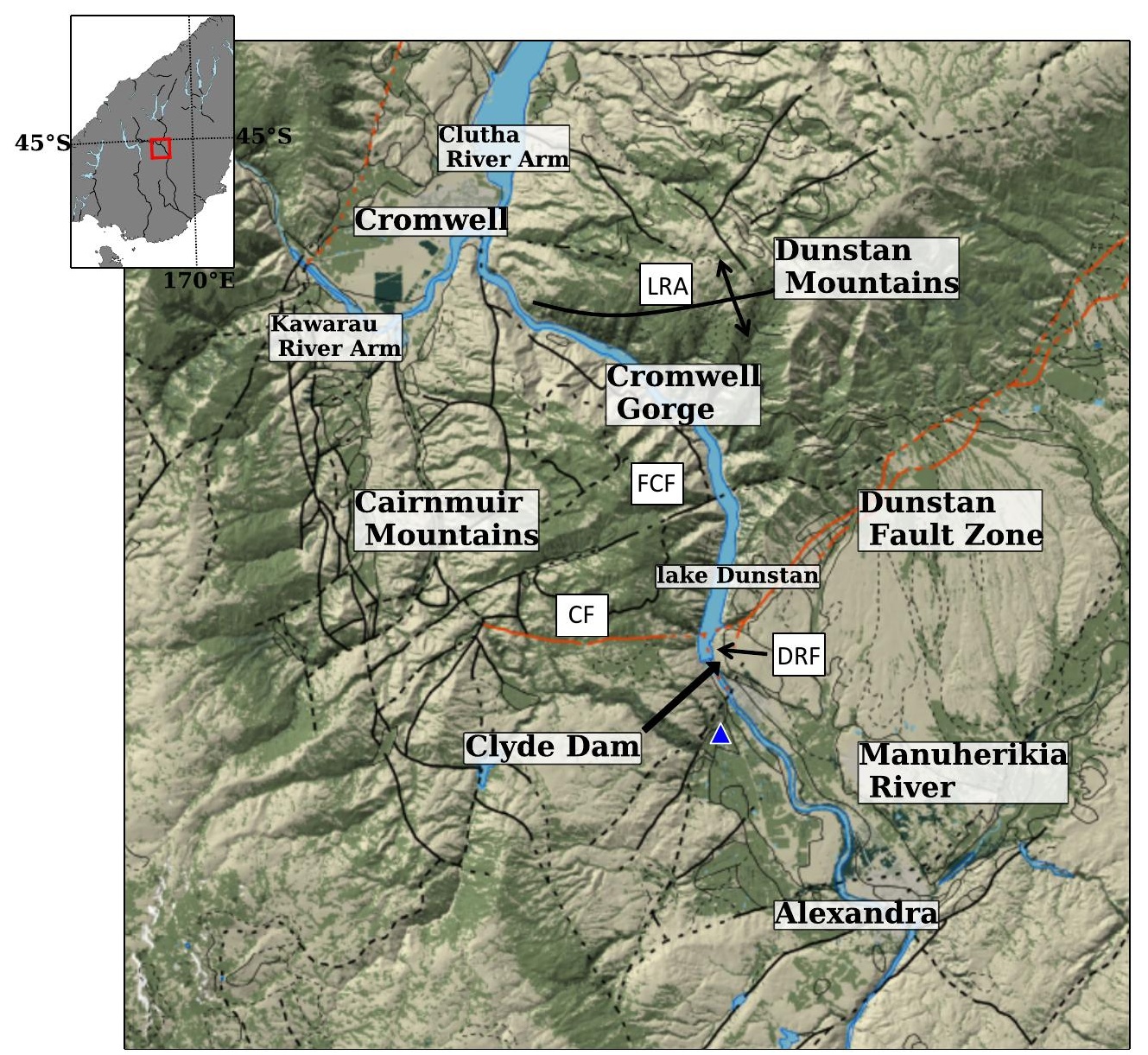

Figure 1.2: Map showing the extent of Cromwell Gorge through the Cairnmuir and Dunstan Mountain ranges. Known active faults are shown in red (Dunstan Fault system, DRF: Dry River Fault and CF: Cairnmuir Fault), other faults and features are shown in black, FCF: Fish Creek Fault, and LRA: Leaning Rock Antiform. The location of the Clyde electronic weather station is shown by the blue triangle. Map data sourced from LINZ, and geology data from GNS Sciences (2013).

Central Otago's mountain ranges have elevations up to $2000 \mathrm{~m}$ and arose mainly during the Late Tertiary-Pleistocene as a result of large-scale folding (Markley and Norris, 1999; Turnbull, 2000). Fault traces and offset structural markers associated with crush zones indicate there are areas of brittle deformation.

The dominant rock type in Cromwell Gorge is garnet-biotite-albite schist of the Rakaia Terrane, textural zones III-IV, with minor greenschist of the Caples Terrane, and rare banding comprised of metachert (Turnbull, 1987; Turnbull et al., 2001). The CaplesRakaia terrane boundary is located in the Cairnmuir Mountains southwest of Cromwell Gorge. Gillon and Hancox (1991) describe the schist as containing a large degree of structural defects, including foliation surfaces, jointing, crush and shear zones, which all play a directive role in the development and subsequent control of landslide movement. 
Located at the base of the gorge (now submerged) lie Late Quaternary outwash gravels, once forming a series of discontinuous terraces that flanked the old Clutha river. Early geological investigations (Beetham and Fergusson, 1990a,b) suggest these gravels are creating a natural buttress at the toes of some of the landslides, aided by a deep paleoriver channel. Major structural features present within or very near the gorge are the Leaning Rock Antiform, the Dunstan Fault, Cairnmuir Fault and Fish Creek Fault (Figure 1.2). Also present are a few low angle faults located on the west bank.

\subsubsection{Rainfall and climate}

Central Otago is one of New Zealand's driest regions, with Alexandra having on average the country's lowest annual rainfall of $340 \mathrm{~mm}$ (Wilson and Lu, 2011). Seasonality in Central Otago is sharply defined, and having a large mean temperature contrast between the summer and winter periods is, in New Zealand, considered by many to be a region of extremes. The soils found within the region reflect the dry climate and aid in understanding aspects of the hydrological system, such as groundwater infiltration and recharge (refer to section 1.8 for details). Hewitt and Fergusson (1990) outline the three main soil types found throughout Cromwell Gorge, forming as a function of precipitation and evaporation. From lake level $195 \mathrm{~m}$ asl to $\approx 400$ asl, where the least amount of rainfall occurs, the soils are semi-arid and free draining with a distinctive pale, powdery, calcium carbonate horizon found $1-2 \mathrm{~m}$ below the surface. Pallic soils are found from $\approx 400-700 \mathrm{~m}$ asl; these soils show some leaching in their profile due to being saturated during winter months, but drying out during summer months. Brown soils are present above $700 \mathrm{~m}$ asl, where soils are wet all year round and show intense leaching, due to the higher degrees of precipitation with increasing elevation in the region (Mark, 1965). The fact that Central Otago has a low annual rainfall is one of the most complementing factors in determining earthquake-induced responses within groundwater monitoring systems. This is due to a reduction in noise that rainfall creates within hydrological data, which potentially masks any earthquake-induced signals.

In the last 20 years, there have been periods of significant rainfall in the area, and of the ten largest rainfall events recorded in Cromwell since 1950, six have occurred post lake filling. Macfarlane (2009) summarises the rainfall recorded at Cromwell, dividing it into three distinct periods based on comparison to residual mass and long-term trends. 1) between 1950 - 1967 rainfall was notably less than the long-term monthly mean, and residual mass was on a negative trend, 2) a period drier than long-term means occurred between 1989 - 1993, but the general residual mass was maintained, 3) three prominent, extended rainfall events occurring from December 1993 to March 1994, September 1995 
to January 1996 and November 1999 to January 2000, brought the area into an atypical wet regime during this time (positive residual mass trend).

Rainfall has been shown by Macfarlane (2009) to have an effect on the movement rate for active portions of landslides in Cromwell Gorge, such as the Brewery Creek Active Portion. The Brewery Creek Active Portion is relatively thin $(30 \mathrm{~m})$ in comparison to the other slides $(>100 \mathrm{~m}$ ), also housing an identified perched groundwater system. This active section appears to be sensitive to rainfall, and accelerated creep has been recorded during storm events. The duration of increased landslide movement trails the rainfall-induced groundwater levels that recede on the order of months to a few years (Macfarlane, 2009). Monitoring well DL-50C, located in the Brewery Creek Active Portion, records perched groundwater levels: there is a clear relationship between heavy rainfall, piezometric levels, and accelerated slide creep (Macfarlane, 2009). When the piezometer level surpasses $280.9-281 \mathrm{~m}$ asl accelerated creep is triggered. This record is further discussed in relation to earthquake-induced effects in Chapter 4.

\subsubsection{Landslide distribution and extent}

Large, ancient, slow flexural creeping landslides are found throughout many of the schist mountain ranges of Central Otago, such as the Shotover, Kawarau, and Clutha Catchments (Turnbull, 1987; Halliday, 2010). Landslides are better developed where the topography is steeper and precipitation is higher (Wood, 1962; Turnbull, 1987; Halliday, 2010). In Cromwell Gorge the landslides are extensive, deep-seated, and formed predominately in schist bedrock, schist debris and colluvium (Beetham and Fergusson, 1990a; Gillon and Hancox, 1991). The landslides are more extensive and better developed on the eastern flank of the gorge, predominantly due to the underlying foliation where the southern limb of the Leaning Rock Antiform is providing a dipping, planar surface for the slide base to locate (Beetham and Fergusson, 1990a,b; Gillon and Hancox, 1991). The Nine Mile Creek Slide, the largest landslide in the gorge, encompasses a 1200 ha area, extending from below the present day lake level at $195 \mathrm{RL}$, across to Fairfax Spur and up Leaning Rock/Haehaeata $(1646 \mathrm{~m})$. The Nine Mile Creek Slide is associated with the Leaning Rock Antiform, and is divided based on the hill slope geomorphology (Beetham and Fergusson, 1990a) into Nine Mile Upstream and Nine Mile Downstream Slide areas. The geotechnical investigations have further subdivided each slide area into segments based on geomorphic character; these subdivisions are of little relevance to this study. Other major slides in the gorge are the Brewery Creek, No.5, Cairnmuir, Jackson Creek, and Clyde slides. There are smaller slides present in the gorge, and a handful are located north of the gorge on the Kawarau and Clutha River Arms of the greater Lake Dunstan. Data were not available for these smaller slides, are not discussed 


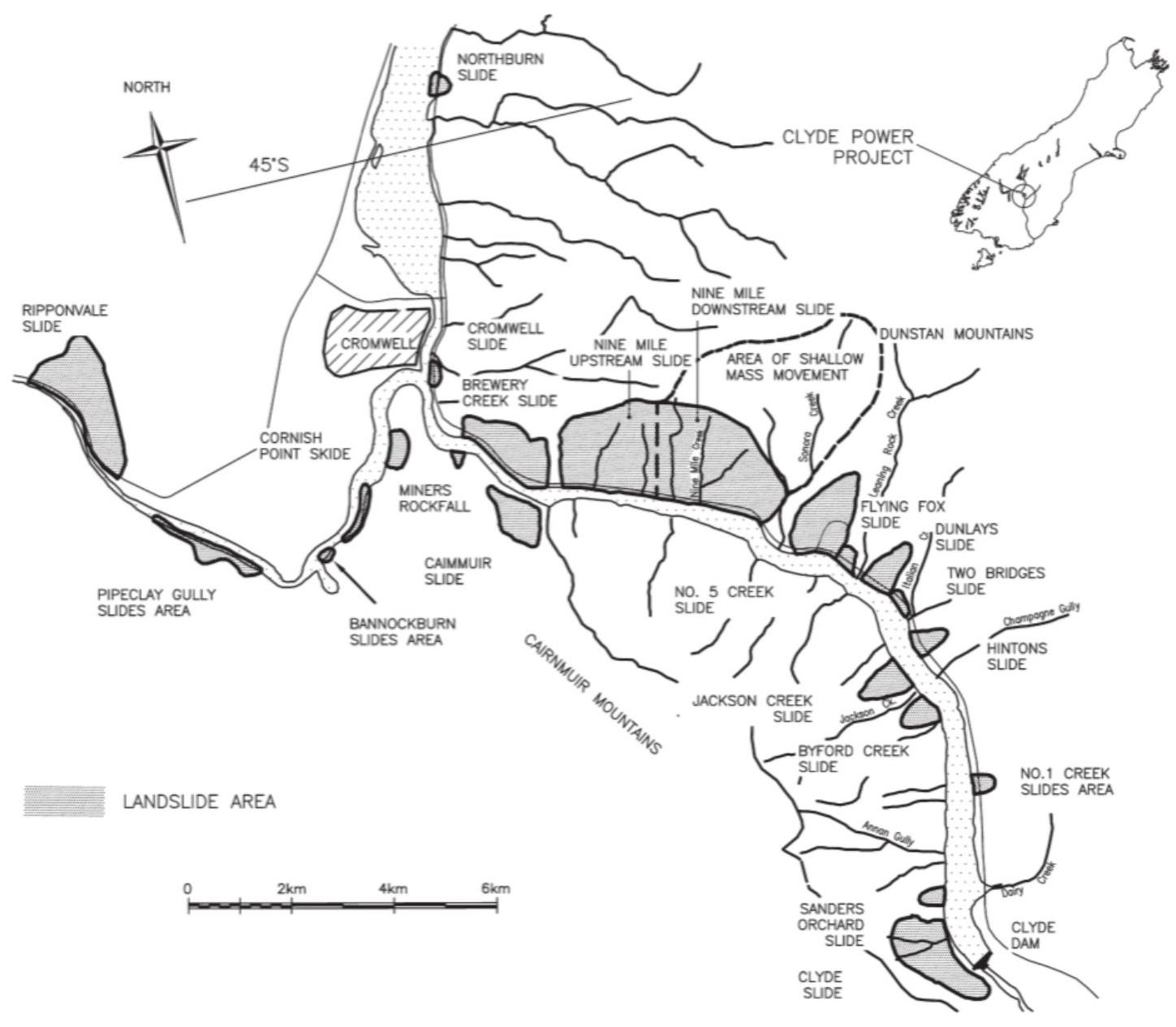

Figure 1.3: Figure from Macfarlane (2009) showing the extent of the slow-creep schist landslides (shaded grey) in Cromwell Gorge.

TABLE 1.1: A summary of the slow-creep, schist landslides identified in Cromwell Gorge, for which monitoring data was obtained. Measurements from Gillon and Hancox (1991); Beetham and Fergusson (1990a)

\begin{tabular}{|c|c|c|c|c|}
\hline Slide name & $\begin{array}{c}\text { Area } \\
(\mathbf{h a})\end{array}$ & $\begin{array}{c}\text { Volume } \\
\left(10^{6} \mathbf{m}^{3}\right)\end{array}$ & $\begin{array}{c}\text { Av. slope } \\
\left({ }^{\circ}\right)\end{array}$ & $\begin{array}{c}\text { Thickness } \\
\text { max (m) }\end{array}$ \\
\hline Cairnmuir Slide & 100 & 10 & 25 & 83 \\
Clyde Slide & 120 & 50 & $22-28$ & 70 \\
Jackson Creek Slide & 23 & 5 & $28-30$ & 46 \\
Brewery Creek Slide & 200 & 175 & 26 & 140 \\
Nine Mile Upstream area & 300 & 240 & $19-25$ & 180 \\
Nine Mile Downstream area & 900 & $>1000$ & $16-27$ & 270 \\
No. 5 Slide & 126 & 60 & $19-35$ & 100 \\
\hline
\end{tabular}

further. Table 1.1 provides a summary of landslide extent and location for the seven landslides where monitoring data were obtained. 


\subsubsection{Landslide characteristics}

The hill slopes of the Cromwell Gorge are rugged and undulating, with numerous deeply incised streams draining steeply into Lake Dunstan. Streams have eroded V-shaped gullies, some showing up to $150 \mathrm{~m}$ of incision and exposing subsurface slide material (Beetham and Fergusson, 1990a). Trench studies ( $\geq 7 \mathrm{~m}$ deep), drill cores (deepest $310 \mathrm{~m}$ ) and tunnelling operations also provide detail on the subsurface, whilst extensive surface mapping has characterised surface features.

\section{Surface morphology}

Some landslides have more prominent surface features than others, but most are ancient features exhibiting a rather subdued morphology (Gillon and Hancox, 1991). This subdued nature due to the widespread mantling by loess and solifluction deposits, is also indicative of very slow slide movement (Beetham and Fergusson, 1990a). The schist landslides are interpreted as a result of slow, deep-seated creep or bedrock flow, in response to the tectonic (uplift) and erosional (downcutting of the Clutha River) processes forming Cromwell Gorge (Gillon and Hancox, 1991). The angle of the hill slope decreases with altitude, from around $27^{\circ}$ for lower slopes $195-400 \mathrm{~m} \mathrm{RL}$, around $23^{\circ}$ for mid slopes $400-700 \mathrm{~m} \mathrm{RL}$, to $16^{\circ}$ for the upper slopes above $700 \mathrm{~m}$ RL. Prominent surface lineaments can be located across the slides, although in areas become masked by thick slide associated debris. Trenching has revealed that the cross-slope lineaments are associated with large discontinuities within the schist (e.g., crush zones). Upslopedownslope lineaments relate to incised gullies forming the shoulders of small topographic basin structures (Beetham and Fergusson, 1990a). The Cromwell Gorge landslides lack the characteristic prominent head-scarps and hummocky topography indicative of instability. Small scarps in the head regions of the slides are only found on steep slopes falling directly into steeply incised gullies.

\section{Subsurface zoning}

Information obtained from the many drill holes and drainage tunnels allows vertical subdivision of the slide mass into four major zones, although not all four zones are necessarily present in a particular section of a landslide. Figure 1.4 from Beetham and Fergusson (1990a) and descriptions from Beetham and Fergusson (1990c) illustrate how vertical subdivisions are made and the general displacement trends that determine their appearance. 
Chaotic and bouldery debris, matrix supported comprised of large blocks of schist, sheared and crushed zones with associated clayey (gouge) seams. The schist debris crudely grades to silts and soils. Foliations within schist blocks are random in comparison to in situ schist. This zone has seen the most displacement, on the order of 10's to 100's of m.

Blocky debris, located beneath the chaotic debris and above the basal crush/shear zone, is a zone of block supported material containing large schist boulders with finer debris infilling voids, shear zones, crush zones and clayey (gouge) seams. Schist within this zone may show translation, incipient shearing, and drag folding in response to slide movements. Displacement ranges from m's to 10's of m.

Displaced schist, may be highly jointed, fractured and sheared. Joints and fractures may be infilled or open, with seams of thin gouge and abundant shear and crush zones. This zone is indicative of displacements mm's to m's in scale, and seen to transition both gradationally and abruptly in different areas to zones below.

Disturbed schist, present approaching the basal shear zone, this incipiently displaced schist contains numerous thin shear zones, with the majority of the pre-landslide failure rock mass features being preserved (e.g. crosscutting fracture zones and foliation shear zones). This zone may merge subtly into zones of similar appearance, containing material that is in a relaxed or stress-relieved state, near or at the ground surface. Downslope zones may have areas of larger scale displacements associated with landslide toe buckling (i.e., overturned schist, Figure 1.5).

In situ schist, located below the slide base, schist shows no landslide-induced displacement, but contains joints, sheared, crushed, shattered zones and faulting. 


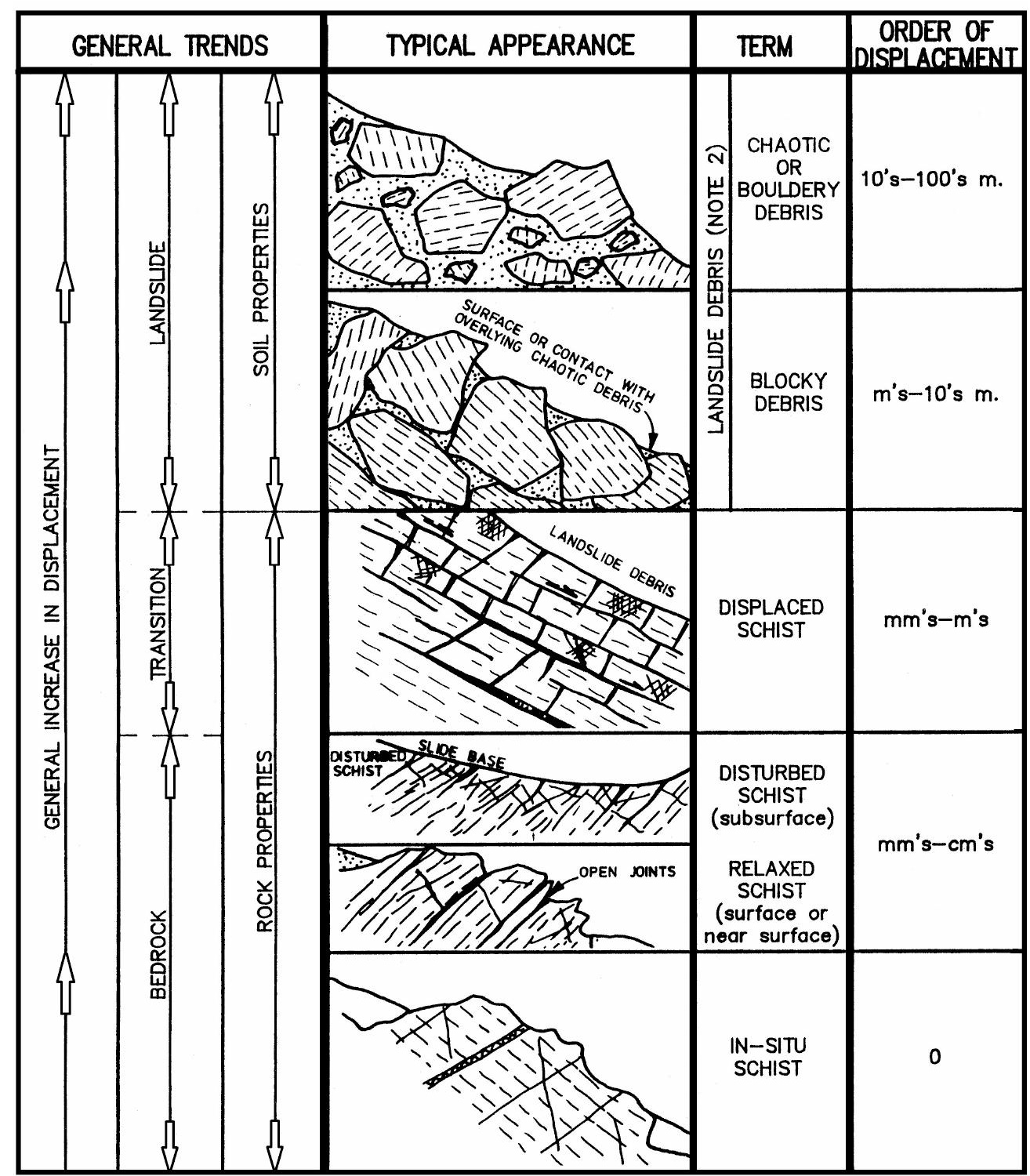

Figure 1.4: Figure from Beetham and Fergusson (1990a) showing vertical zoning within the schist landslides by displacement trends, appearance, and descriptive terminology; the figure should be viewed in conjunction with Figure 1.5

\subsection{Geoengineering of Cromwell Gorge}

During investigations and construction of the Clyde Dam it was discovered that the hill slopes consisted of large potentially unstable slow-creep schist landslides. Furthermore, it was uncovered that a major fault, the Dry River Fault, was located through the base of the dam site (Figure 1.2). The design of the dam had to be adjusted to mitigate this potential hazard, incorporating a sophisticated movable joint system. This new design feature along with the mitigation of the unstable surrounding hill slopes caused the initial completion date to be delayed, with the dam coming online in early 1993, and the budget 


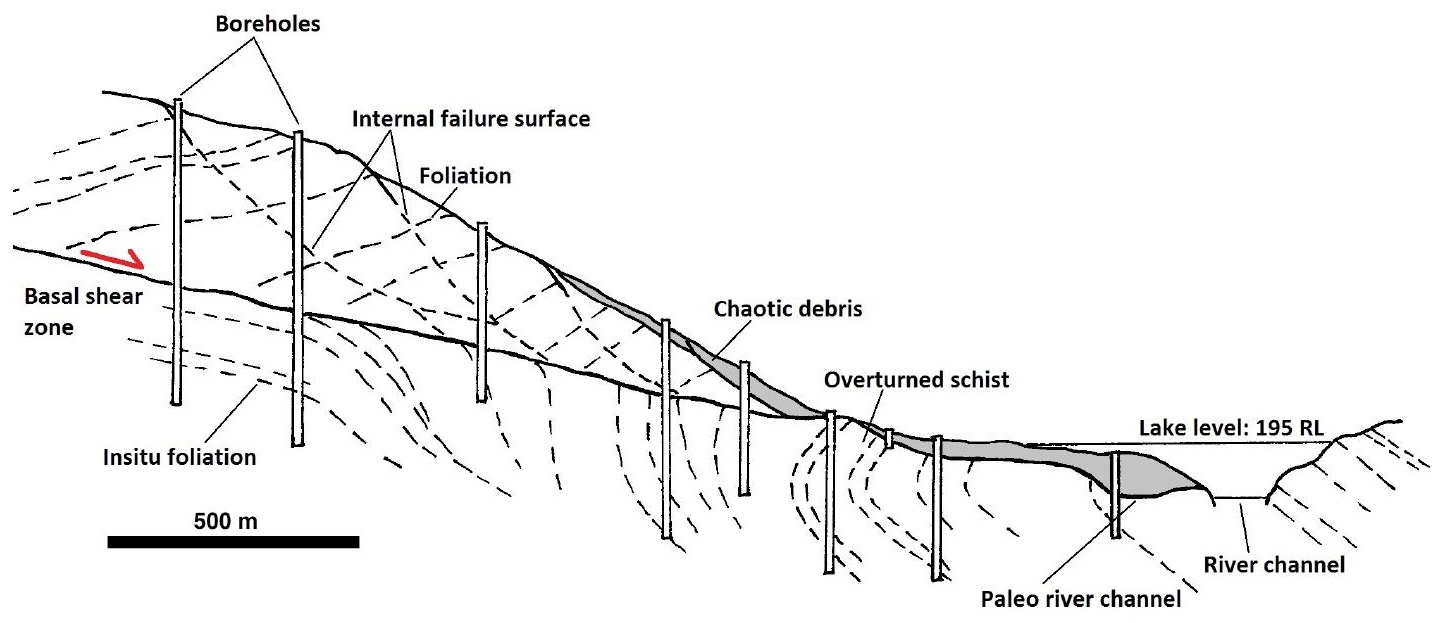

Figure 1.5: Cartoon to illustrate the internal architecture of the slow-creep schist landslides in Cromwell Gorge, and how monitoring boreholes are positioned. Note the major basal shear zone and the many internal failure surfaces. Overturned schist is attributed to toe-buckling caused by horizontal stresses, topographic stress and slide movement. Reduced Level (RL) is equivalent to metres above sea level. This figure and the three following have been constructed based on data and information presented by Beetham and Fergusson (1990a,b); Gillon and Hancox (1991) to highlight features of the landslides pertinent to this study.

to be overrun by almost an extra 50\%. Extensive geological, geophysical, geotechnical and engineering investigations were undertaken throughout Cromwell Gorge to ensure the safety and prosperity of the Clyde Dam and downstream settlements. Investigations that concentrated on landslides included:

- regional and local geological studies, including geomorphic mapping of slide areas,

- seismicity studies,

- logging of road cuttings and fill foundations,

- cored and non-cored drill holes, 560 drill holes equating to approximately 52440 $\mathrm{m}$, down-hole seismic logging,

- $62 \mathrm{~km}$ of seismic refraction and reflection surveys,

- resistivity surveys,

- 49 drainage tunnels with a combined length of $>16 \mathrm{~km}$,

- 289 trenches up to $7 \mathrm{~m}$ deep, shafts and test pit investigations,

- surface pillar, inclinometers and extensometers in drill holes, across shear zones and tension cracks to measure slide movements, 
- piezometers monitoring groundwater levels in boreholes and borehole permeability testing,

- computer modelling of groundwater flow,

- laboratory testing of groundwater, mineralogy, rock mass shear-strength, grading, and Atterberg limits of slide material (e.g. to measure irreducible water content),

- radiometric dating of landslide and surrounding terrace deposits.

The combination of the substantial geoengineering of the hillslopes and the long-term operation of monitoring equipment has produced a world class monitoring network. To date some 3500 measuring and monitoring instruments have been installed around the impounded reservoir, Lake Dunstan. From a research perspective it can also be viewed as a long-term experiment into hydrologic changes induced by earthquakes.

\subsection{Groundwater movement in the Cromwell Gorge area}

This section summarises some of the findings (from Beetham and Fergusson 1990a,b) regarding the groundwater movement through the slow-creep schist landslides, obtained via the extensive surveys, boreholes and tunnel systems. Groundwater is seen to discharge from the hill slopes of Cromwell Gorge at a substantial rate, measured by V-notch weirs in the many drainage tunnels. An important feature of the groundwater regime is the high degree of compartmentalisation within the structure of the landslides. The degree of compartmentalisation was largely uncovered by drilling, where drill hole-depth versus water-depth plots provides a graphical indication if a bore was gaining or losing groundwater at specific intervals. Core logs further aid in the interpretation of perched or confined aquifers. Compartmentalisation has been caused by the presence of impermeable (or semipermeable) layers e.g. fault gouge, generating barriers and preferential flow channels through the rock mass. Compartmentalisation occurs below and in the landslide structures, generating different groundwater pressure regimes (Beetham and Fergusson, 1990a,b; Macfarlane et al., 1991). The aquifers (or fractured reservoirs) vary laterally, being perched, confined and unconfined at different localities (Figure 1.6). Macfarlane et al. (1991) predict there is a significant, yet variable degree of interconnection between local aquifer systems; within the internal structure of the slide, in sub-basal regions, and across the basal shear zones. Drilling and tunnelling reports reveal there are areas of overpressure, suggesting that the interconnection in some areas is limited, and that permeability barriers are effective (Beetham and Fergusson, 1990a,b). In other slide areas drilling encountered cavities where drilling rods dropped unimpeded, and a 


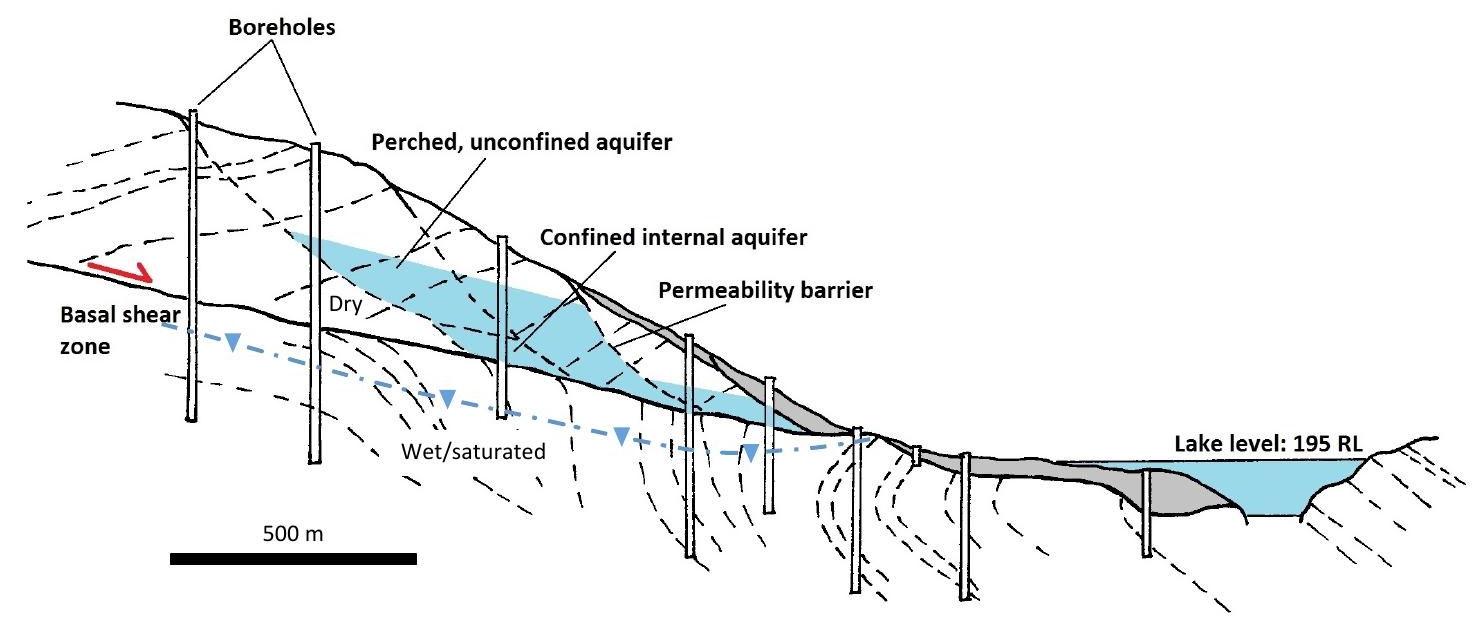

Figure 1.6: Cartoon illustrating how the internal architecture of the slow-creep schist landslides may affect the groundwater systems. Groundwater (blue) may be perched (as shown) in landslide internal zones, the blue triangles and dashed line indicated a depressed piezometric level in the sub basal groundwater. This figure was constructed based on data and information presented by Beetham and Fergusson (1990a,b); Gillon and Hancox (1991).

gush of air was in turn expelled. Tunnelling investigations in Nine Mile Downstream area illustrate the variability of a well defined basal shear zone, which in places appeared prominent and in other places was not encountered. In many slide areas water was neither confined or perched, and immediate drainage was observed through the lowering of the piezometric surface in nearby boreholes, as a result of tunnelling.

\subsubsection{Fluid sources and shallow circulation}

The Cromwell Gorge area receives a low annual rainfall and having relatively steep hill slopes around $27^{\circ}$, enables rapid runoff of rainfall. Furthermore, at low altitudes evaporation exceeds rainfall for most of the year, creating a soil-moisture deficit, which is illustrated by a powdery carbonate horizon (Beetham and Fergusson, 1990a). Recharge sources are most likely from rainfall and snowmelt occurring higher up in the surrounding ranges where precipitation is consistently higher and temperatures lower, as indicated by the soils (Mark, 1965). The slope angles are gentler with increased altitude, and at around $16^{\circ}$ water is able to pond on the undulating surface. Groundwater may enter in the upper extent of the landslide complexes where there are local horst and graben like structures reflecting extension, and features such as open tension cracks are present in the ground (Beetham and Fergusson, 1990a). It is interpreted that infiltrating groundwater travels downward, guided by clayey less permeable crush zones located adjacent to more permeable zones of relaxed and open jointed schist. Findings from 


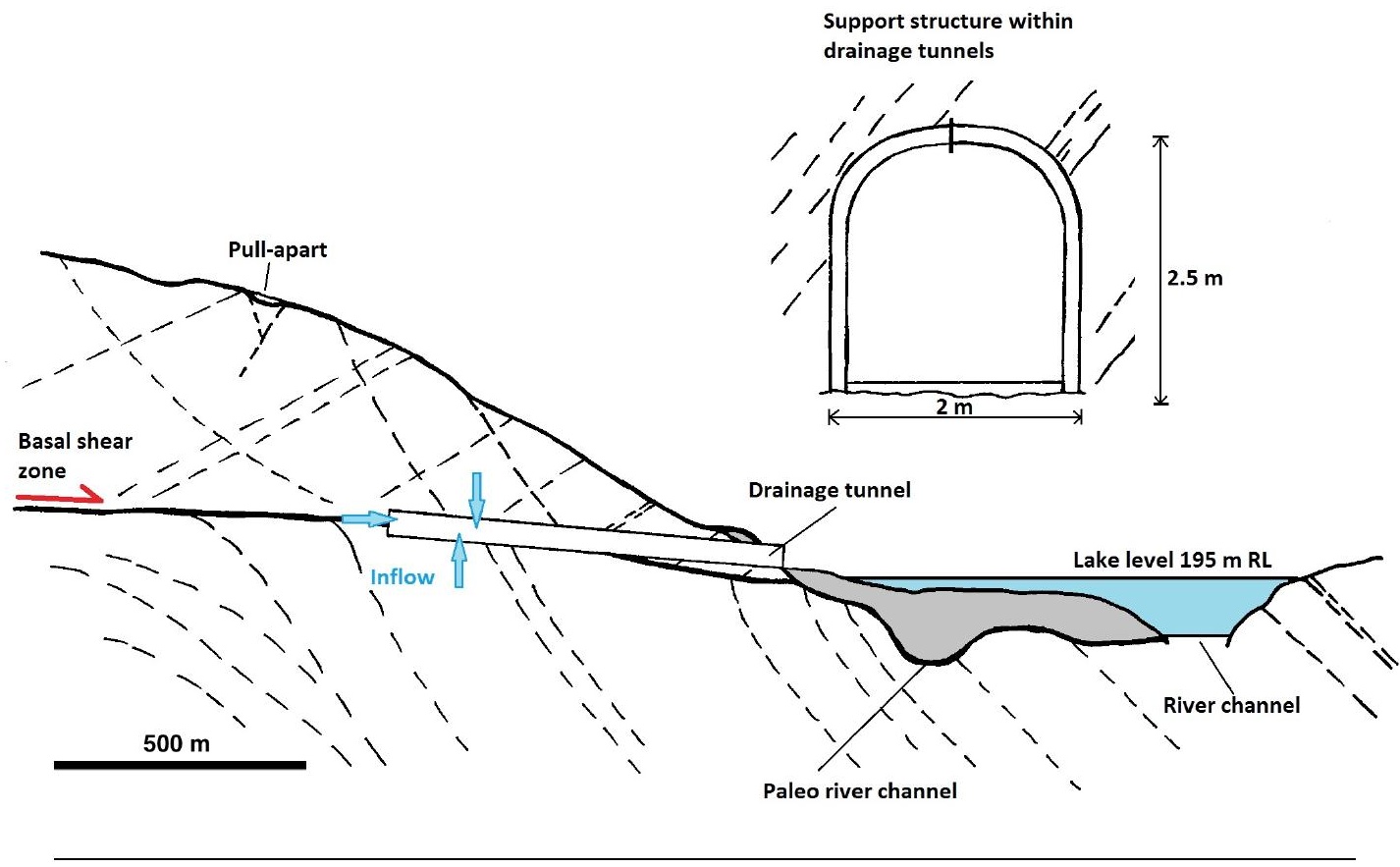

Figure 1.7: Cartoon illustrating how groundwater movement in the landslides is affected by drainage tunnels. Groundwater flows radially into tunnels. Tunnels penetrate deep within the landslides and sub basal schist. The shape of the tunnel support structure is shown by the inset. This figure was constructed based on data and information from Beetham and Fergusson (1990a,b); Gillon and Hancox (1991).

the Nine Mile Upstream Slide area suggest that infiltration into frontal perched aquifers occurs through sub basal infiltration from upslope, along cross-cutting, steeply dipping, sheared and shattered zones (Smith et al., 1990). Water chemistry revealed that old groundwater is super-saturated with dissolved calcium, which precipitates as calcite near the ground surface (Beetham and Fergusson, 1990a).

Other fluids potentially present are those of metamorphic origin, generated from the compression of hydrous minerals and dehydration reactions. Such fluids can be driven upwards predominantly by pressure and temperature gradients (Dipple and Ferry, 1992). Recharge from a metamorphic fluid source may be important on geological timescales or where hydrothermal activity is present. However, due to the shallow nature of the Cromwell Gorge landslides $(<300 \mathrm{~m})$, cool temperatures (Beetham and Fergusson, 1990b), and lack of any hot springs, metamorphic fluids are not considered significant within the context of this study. The drainage tunnels have a marked effect on the circulation of groundwater within the landslides, acting as a very effective gravity drainage system. Groundwater flows directly into the tunnel systems through the many intercepted fractures and shattered zones, and groundwater is no longer able to remain confined or perched near tunnels within large areas of the landslides. 


\subsubsection{Controls on permeability}

Many hydraulic conductivity measurements have been made in each of the outlined monitoring areas, throughout the different subsurface zones. Measurements were made using falling head tests (slug test), downhole packer tests and bail tests, being subdivided on collar elevation and drilling data into zones above or beneath the base of the landslide. Permeability $\left(\kappa\right.$ in $\left.\mathrm{m}^{2}\right)$ can be related to hydraulic conductivity $(K$ in $\mathrm{m} / \mathrm{s})$ by:

$$
\kappa=K\left(\frac{\mu}{\rho g}\right)
$$

where $\mu$ (Pa s) is the dynamic viscosity of water, $\rho$ is density $\left(\mathrm{kg} / \mathrm{m}^{3}\right)$, and $g$ acceleration due to gravity $(\mathrm{m} / \mathrm{s})$. For example, if $K$ is $5.59 \times 10^{-7} \mathrm{~m} / \mathrm{s}$ (mean value for disturbed and in situ schist, see Table 1.2), and assuming a $10^{\circ} \mathrm{C}$ water temperature, the value of $\mu$ is $1.307 \times 10^{-3} \mathrm{~Pa} \mathrm{~s}$, therefore $\kappa \approx 7.45 \times 10^{-14} \mathrm{~m}^{3}$ or $75 \mathrm{mD}$. Another useful term is the transmissivity $(T)$, which integrates the reservoir thickness $(h)$ :

$$
T=K \bar{h}
$$

Permeability testing reveals that there are highly permeable zones within and beneath the landslides. Beetham and Fergusson (1990b) attribute the more permeable zones to:

- open fractures and joints generating conduits through areas of relaxed and/or disturbed schist, roughness and curvature of shear zones may also create pull apart cavities,

- highly shattered zones of schist associated with shear zones and failure surfaces, allowing free drainage or accumulation of water,

- disturbance of schist beneath the landslides creating incipient shearing and open joints, also showing higher permeability in test results than slide materials.

In contrast are zones where the permeability is low, such as in intact schist and areas where the permeability has been substantially reduced by clayey gouge material. These zones (aquitards) that restrict the through-flow of groundwater are associated with:

- close-fractured schist where stresses are forcing fractures and joints closed, and where joints are cemented. Intact blocks of greenschist are also found in some localities, 
- movement-associated clayey gouge zones found near crush and shear zones act as near impermeable barriers,

- foliation within the schist itself preferentially creates directional flow and increasing tortuosity.

TABLE 1.2: Measured hydraulic conductivities for different subsurface zones within the landslides (upper table), sourced from Beetham and Fergusson (1990c). The corresponding calculated permeabilities are shown in the lower table.

\begin{tabular}{|c|c|c|c|}
\hline Subsurface zone & $\min (\mathrm{m} / \mathrm{s})$ & mean $(\mathrm{m} / \mathrm{s})$ & $\max (\mathrm{m} / \mathrm{s})$ \\
\hline Chaotic debris (upper layers) & - & - & - \\
Block debris and displaced schist & $4.30 \times 10^{-10}$ & $4.12 \times 10^{-07}$ & $1.70 \times 10^{-06}$ \\
Basal or internal sheared zone & $6.20 \times 10^{-10}$ & $5.46 \times 10^{-08}$ & $1.60 \times 10^{-07}$ \\
Disturbed and in situ schist & $3.10 \times 10^{-10}$ & $5.59 \times 10^{-07}$ & $5.10 \times 10^{-06}$ \\
\hline \hline Subsurface zone & $\min \left(\mathrm{m}^{2}\right)$ & $\mathbf{m e a n}\left(\mathrm{m}^{2}\right)$ & $\max \left(\mathrm{m}^{2}\right)$ \\
\hline Chaotic debris (upper layers) & - & - & - \\
Block debris and displaced schist & $5.73 \times 10^{-17}$ & $7.45 \times 10^{-14}$ & $2.27 \times 10^{-13}$ \\
Basal or internal sheared zone & $8.26 \times 10^{-17}$ & $7.28 \times 10^{-15}$ & $2.13 \times 10^{-14}$ \\
Disturbed and in situ schist & $4.13 \times 10^{-17}$ & $5.49 \times 10^{-14}$ & $6.80 \times 10^{-13}$ \\
\hline
\end{tabular}

\subsection{Hydrogeologic data set}

The hydrological dataset is comprised of 1035 instruments records that have been recording groundwater time series data since early 1990. Specialist computer software was required to view and extract hydrological data for further analysis and processing. As a result of the initial analysis of hydrological data (and other relevant monitoring equipment, see below) it became clear that to the best of our knowledge, this dataset is one of the most comprehensive, long-term, geographically concentrated hydrological datasets presently available in the world.

Instrument type can be broadly divided into two main categories: the first is piezometer groundwater level data, recorded beneath the ground surface accessed via a borehole/monitoring well. Piezometer measurements in Cromwell Gorge are either determined manually by a technician or by installed instrumentation and telemetered back to the data recorders. The second category is discharge data, recorded in tunnels by V-notch weirs and flow buckets (FL). Weirs are located near the exit of a drainage tunnel and measure the rate a volume of water flows through them i.e. litres per minute $(1 / \mathrm{min})$. Flow bucket records were investigated but contained data that were deemed unsuitable for analysis and have been excluded. This section describes the typical setup for the two hydrological data sources (piezometers and V-notch weirs). 


\subsubsection{Borehole instrumentation: Piezometers}

Boreholes selected to contain hydrologic monitoring equipment, such as piezometers, are cased $^{2}$ with galvanised steel and grouted down to a specified depth. The interval below, termed the 'filter', is packed with permeable sand allowing the groundwater pressure in the rock mass to rapidly equilibrate with the borehole. The typical setup of a standpipe piezometer is illustrated in Figure 1.8. In this example the well has been drilled to a total depth (TD) of $271 \mathrm{~m}$. Utilising the drill and core logs, the location of the filter with respect to the landslide structure can be determined; in Figure 1.8 the filter has been situated within the in situ schist, sub-basal to the landslide, and the $17.5 \mathrm{~m}$ thick filter interval is located from $142.2-124.7 \mathrm{~m} \mathrm{RL}$. The RL (reduced level) in the case of the Clyde Dam network equates to meters above sea level ( $\mathrm{m}$ asl). The borehole casing extends down into the filter but not all the way through, the filter thickness and degree of filter penetration varying between boreholes. Internal diameters of boreholes range from $90-280 \mathrm{~mm}(3.5-11 \mathrm{inch})$ throughout the gorge, and internal diameter of tubing housing piezometers ranges from $16-50 \mathrm{~mm}$ depending on piezometer type. Piezometers measure static fluid pressure (piezometric head) of the groundwater table to a specified datum: the reduced level (RL). Broadly, there are two types of piezometer systems within monitoring wells: Casagrande-type standpipe piezometers (Figure 1.8) utilise inclinometer tubing or galvanised conduit and provided much of the initial information regarding the location, extent, and behaviour of the groundwater systems (Macfarlane et al., 1991). In localities where measurements were deemed most critical, Westbay PVC multi-port piezometer systems were installed. These systems have the advantage of being more suited to fractured-rock settings, and where different slide intervals/zones are to be sampled due to complexities and uncertainties of the hydrological systems.

\subsubsection{Tunnel instrumentation: V-notch weirs}

V-notch weirs are installed in open channels in the tunnel systems near the tunnel exits, and are used to determine the discharge rate $(1 / \mathrm{min})$ of groundwater that drains under gravity from within and below the large schist landslides. The principle of a V-notch weir is that flow through the weir is related to the water depth above the V-notch (also known as the crotch). The $\mathrm{V}$-notch weir design allows for accurate changes in flow rate to be measured (Bos, 1989). The weir systems in the many drainage tunnels in Cromwell Gorge pre-calculate the groundwater flow rates into $1 / \mathrm{min}$ and are telemetered back to operations at Clyde Dam to provide real-time monitoring of groundwater discharge. A

\footnotetext{
${ }^{2}$ Often the tubing for an inclinometer is acting as well casing housing a piezometer
} 


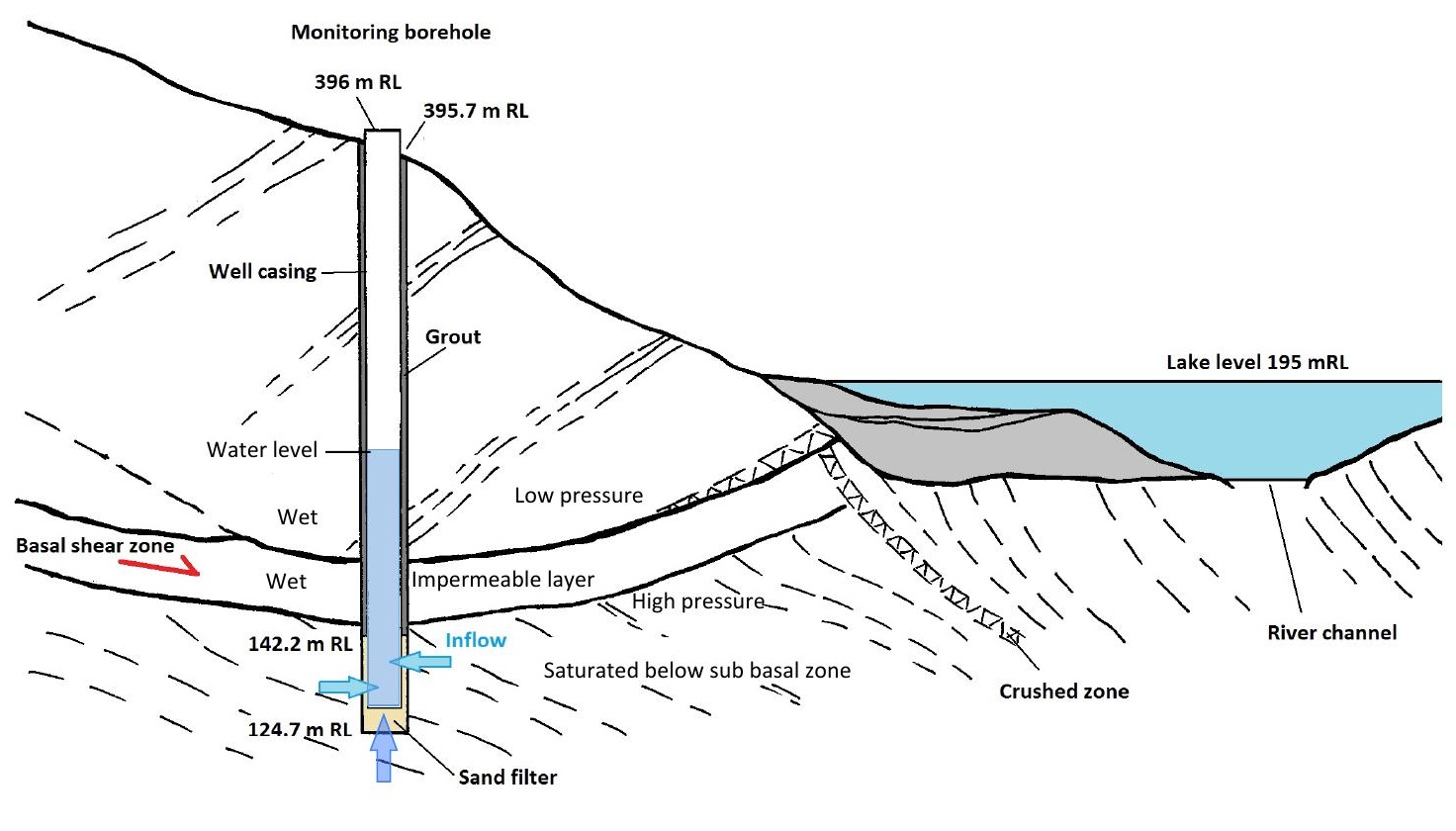

FIGURE 1.8: Schematic illustrating the typical set up for a standpipe piezometer. In the example shown the sand filter is located below the landslide, in bedrock. The example illustrates a confined aquifer, with a substantial pressure head.

total of 45 weir records were provided in the dataset from seven of the 17 known landslide areas that are present around Lake Dunstan, the reservoir that powers Clyde Dam.

Other monitoring devices installed throughout Cromwell Gorge include:

Barometers located above groundwater level in boreholes (at least one per slide area), measure the pressure exerted by the atmosphere.

Thermometers located within select boreholes below the groundwater level, measure the temperature of the groundwater, often recording diurnal and substantial annual temperature fluctuations.

Inclinometers provide direct measurements of any slide movement and deformation, often the inclinometer tubing provides the casing for a monitoring well.

Extensometers have been installed across tension cracks and the basal movement plane in select slide areas, to provide a direct measurement of any movement in specific areas.

Rain gauges have previously been located at Clyde Dam, and the closest active one (to the dam) is at Clyde Electronic Weather Station (EWS), located $\approx 1.9 \mathrm{~km}$ south. $>100$ years of rainfall data have also been recorded at Cromwell, which is closer to landslides in the upstream part of the gorge. Rain gauges provide information 
on the amount and duration of seasonal rainfall and storm events, which can be related to infiltration rate and rock mass permeability.

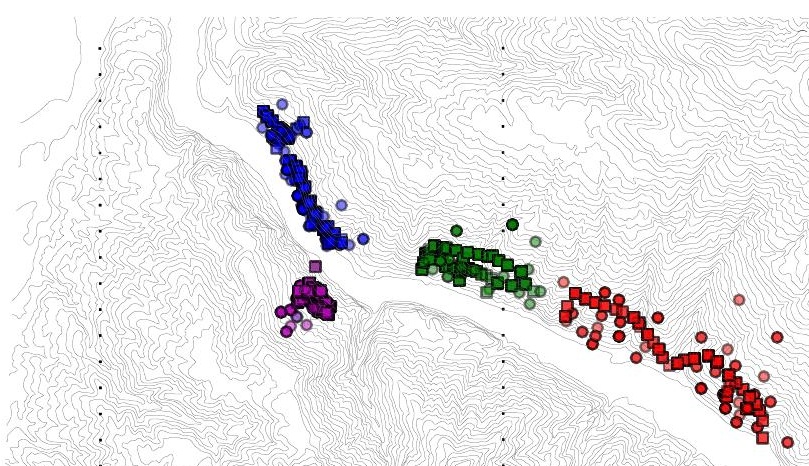

$45.1^{\circ} \mathrm{S}$

$45.15^{\circ} \mathrm{S}$

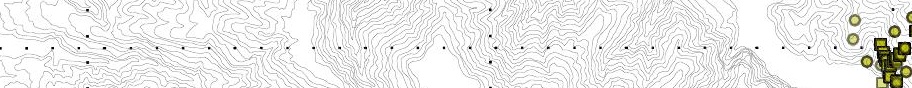

$45.1^{\circ} \mathrm{S}$

$45.15^{\circ} \mathrm{S}$

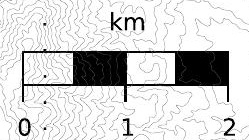

169. $2^{\circ} \mathrm{E}$

$169.25^{\circ} \mathrm{E}$

$169.3^{\circ} \mathrm{E}$

$45.2^{\circ} \mathrm{S}$

Figure 1.9: Map showing the location of the monitoring sites in Cromwell Gorge, for which data has been provided by Contact Energy ${ }^{\mathrm{TM}}$. Abbreviations are used for the seven landslide regions (see Table 1.3). The approximate extent of the landslides are shown by the dashed lines. 
TABLE 1.3: Monitoring sites from seven largest of the seventeen known landslides were provided by Contact Energy ${ }^{\mathrm{TM}}$ for this study. PZ: standpipe piezometer, PZWB: Westbay piezometer, FL: flow bucket, and WR: V-notch weir.

\begin{tabular}{|c|c|c|c|c|c|}
\hline Monitoring area/slide & Name & PZ & PZWB & FL & WR \\
\hline Cairnmuir Slide & CAI & 2 & 26 & 81 & 2 \\
Brewery Creek Slide & BRE & 50 & 16 & 191 & 25 \\
Jackson Creek Slide & JAC & 8 & 4 & 32 & 2 \\
No. 5 Slide & No.5 & 17 & 14 & 67 & 2 \\
Nine Mile Upstream & NMU & 16 & 15 & 167 & 3 \\
Nine Mile Downstream & NMD & 66 & 16 & 138 & 6 \\
Clyde Slide & CLY & 20 & 0 & 45 & 5 \\
\hline Total & 7 & 179 & 91 & 720 & 45 \\
\hline
\end{tabular}

\subsection{Seismological data set}

New Zealand has a substantial network of seismometers and strong-motion sensors. There are 51 high-performance backbone GeoNet stations, consisting of Guralp ${ }^{\text {TM }}$ CMG3ESP or Streckeisen ${ }^{\text {TM }}$ STS-2 broadband seismometers, Kinemetrics Episensor ${ }^{\text {TM }}$ strong- $^{\text {E }}$ motion accelerometers, with Quanterra ${ }^{\mathrm{TM}}$ Q330 (24-bit) data loggers. Additionally, many regional seismographs networks have been installed and used to aid the accuracy in measuring earthquake magnitude, location, acceleration, or other spectral characteristics of earthquakes. The closest GeoNet stations (seismometer and accelerometer) to Cromwell Gorge (refer to Figure 1.10) are EAZ located at the town Earnscleugh, $6.41 \mathrm{~km}$ to the south of Clyde Dam, AXZ (a temporary short period sensor L-4C3D) located at Alexandra, $9.06 \mathrm{~km}$ to the southeast of Clyde Dam, and WKZ located in Wanaka, $46.8 \mathrm{~km}$ to the northwest. Site conditions at EAZ are outcropping of schist and are deemed suitable for comparison to that of the hill slopes of Cromwell Gorge. Unfortunately EAZ has only been in operation since 01/11/2004, and does not have a record covering the entire period of monitoring since Clyde Dam was constructed. Site conditions at AXZ also appear suitable for comparison, but the site was only in operation from 07/03/1996 - 31/08/2004. WKZ opened in 03/06/2004, and is located on a thin soil layer over hard rock, which is also suitable to compare, but due to the larger distance from the gorge it is not preferred.

In this study, earthquake hypocentres and magnitudes were used to correlate the timing of earthquake-induced hydrological events, to calculate the distance, azimuth and backazimuth to the study site, and to further determine magnitude-distance relationships. The majority of centroid moment tensor solutions (CMT) or focal mechanisms for significant New Zealand earthquakes are also available, supplied through GeoNet (2013). Four focal mechanisms for older earthquakes not included in GeoNet data were sourced from various reports and publications, which include: the 1993 Fiordland (van Dissen 
et al., 1994), 1994 Arthurs Pass (Abercrombie et al., 2000), 1995 Cass (Gledhill et al., 2000), and 2001 Jackson Bay earthquakes (McGinty et al., 2005). Also stated within the GeoNet CMT data is the Dusky Sound 2009 earthquake CMT could not be determined by the national data; the solution has been provided by the United States Geological Survey (USGS).

Earthquake waveform data were downloaded from GeoNet (2013), in SAC and mini-seed formats, and ground acceleration and velocity data were calculated from strong motion sensors in spreadsheets. Earthquake records for the entire operational period of the Clyde Dam (1990 - 2014) were utilised. Other data used in conjunction with seismological data are 2D velocity structures for New Zealand regions, outlined in Chapter 2 and provided in Appendix A.

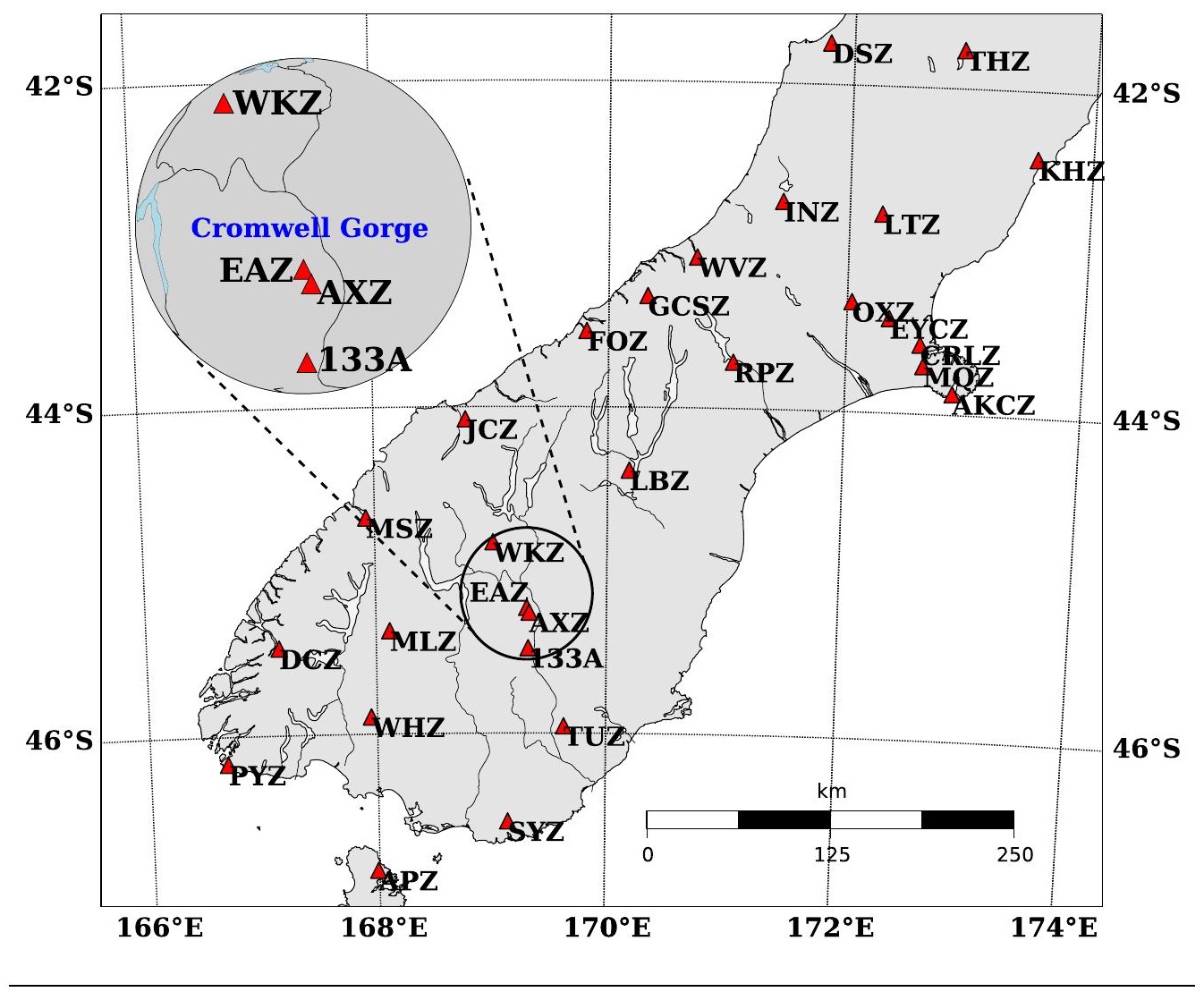

Figure 1.10: Map showing the location of the GeoNet (2013) National Network Sites (backbone stations), in southern New Zealand. Also shown are AXZ which has been decommissioned, and 133A a private site at Roxburgh Dam, operated by Contact Energy. 


\section{Chapter 2}

\section{Data and methodology}

This study utilises data extracted from a variety of industry databases including: hydrological data from Contact Energy's Clyde Dam operations; seismological data from GeoNet; climate data from NIWA; geological, geophysical and geotechnical data collected and interpreted during the development period for the Clyde Dam.

\subsection{Processing of hydrological data}

Instruments within the Clyde Dam monitoring system record time series data using New Zealand Standard time and daylight savings. Hydrological data were viewed in the first instance using Hilltop ${ }^{\mathrm{TM}}$ software, then exported and analysed using Python and Matlab. The majority of piezometer and weir records before early 1993 are dominated by the effects of groundwater drainage and filling of Lake Dunstan. These two procedures generate a great deal of high amplitude signal, masking any potential earthquake-induced signals. Analyses of hydrologic changes were performed only on data collected once the anthropogenic effects had stabilised (mid-1993).

To illustrate the above point three examples that characterise the hydrological data follow. Figure 2.1 shows water level data from piezometer DL545a located in the Nine Mile Downstream slide area (NMD). The water level during 1991 - 1993 lowered rapidly in an erratic stepwise pattern during gravity drainage by approximately $100 \mathrm{~m}$, then increases $15 \mathrm{~m}$ during lake filling, followed by a short-lived $15-20 \mathrm{~m}$ oscillation before settling in April 1993 and beginning a slow, steady rise that continues for the remainder of the recording period. The ground level and well cap are both located at $395.7 \mathrm{~m} \mathrm{RL}^{1}$, and the location of the $17.5 \mathrm{~m}$ thick sand filter is shown by the yellow band.

\footnotetext{
${ }^{1} \mathrm{RL}$ (reduced level) is a specified datum, here equivalent to sea level
} 


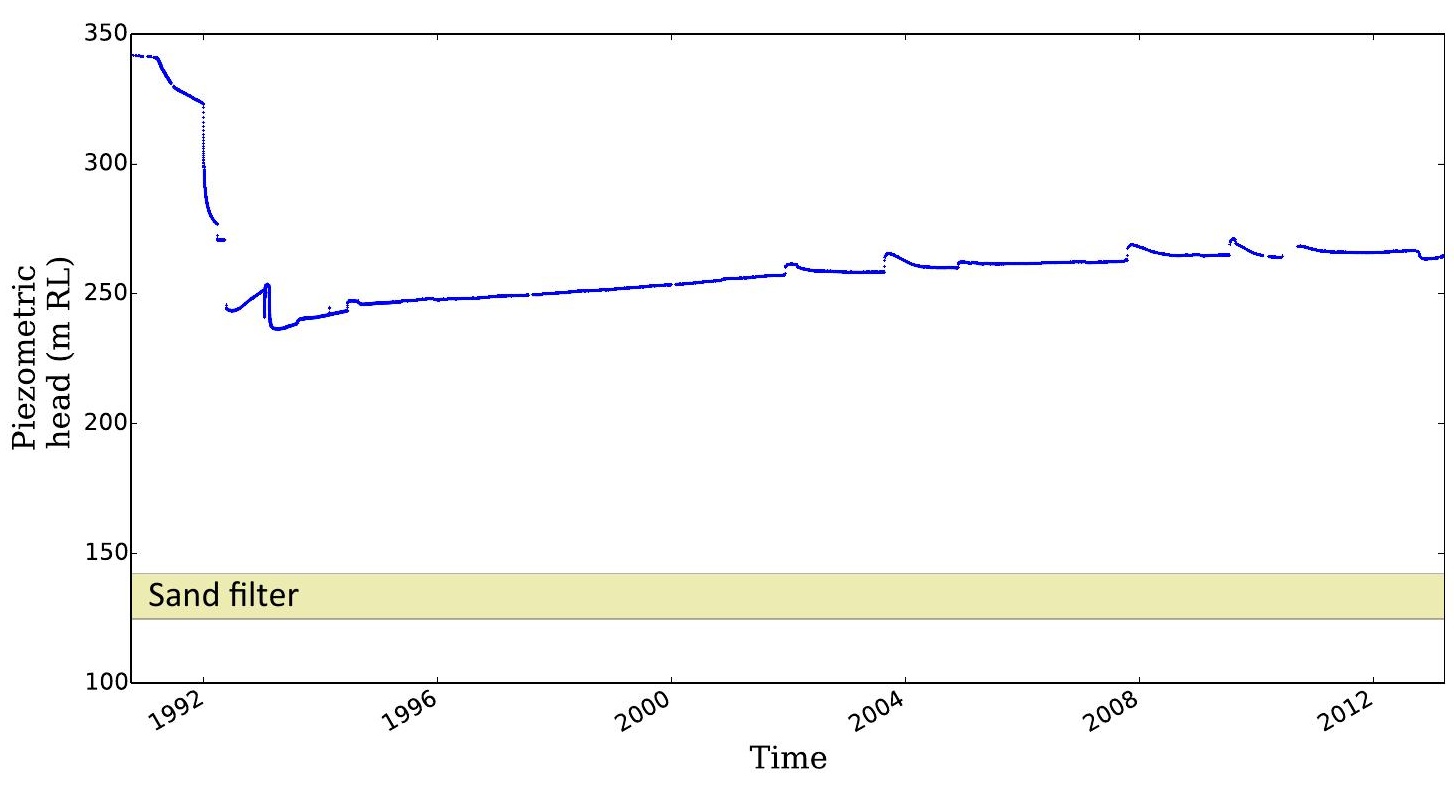

Figure 2.1: DL545a piezometer data, located in the Nine Mile Downstream (NMD) slide area (see Figure 1.9 for location). The piezometer data are shown by the blue markers, and the lower yellow interval illustrates the depth of the sand filter as shown in Figure 1.8.

The second example (Figure 2.2) shows water level data from piezometer DL1330a, also located in the Nine Mile Downstream slide area but downslope to well DL545a. The $y$-axis on the graph has been split in order to show the character of the water level data and the location of the sand filter. Much like DL545a, the groundwater is seen to be effectively drained at the beginning, but then shows small amplitude rises and falls due to the effect of lake filling and earthquakes. In this well (DL1330a) the well cap and ground level are at $202.5 \mathrm{~m} \mathrm{RL}$, just above the piezometric water level. The $9.3 \mathrm{~m}$ thick sand filter is located some $47 \mathrm{~m}$ below the piezometric level.

Similarly V-notch weir records show large fluctuations in discharge in response to initial groundwater drainage. Data from weir 556W-01 from the Nine Mile Downstream slide area are shown as an example in Figure 2.2. The flow rates during the initial drainage period are seen to surpass $1000 \mathrm{l} / \mathrm{min}$ frequently, with a maximum recorded flow around $1800 \mathrm{l} / \mathrm{min}$, but the flow rate is more stable from 1993 onwards. 
Chapter 2. Data and methodology

31
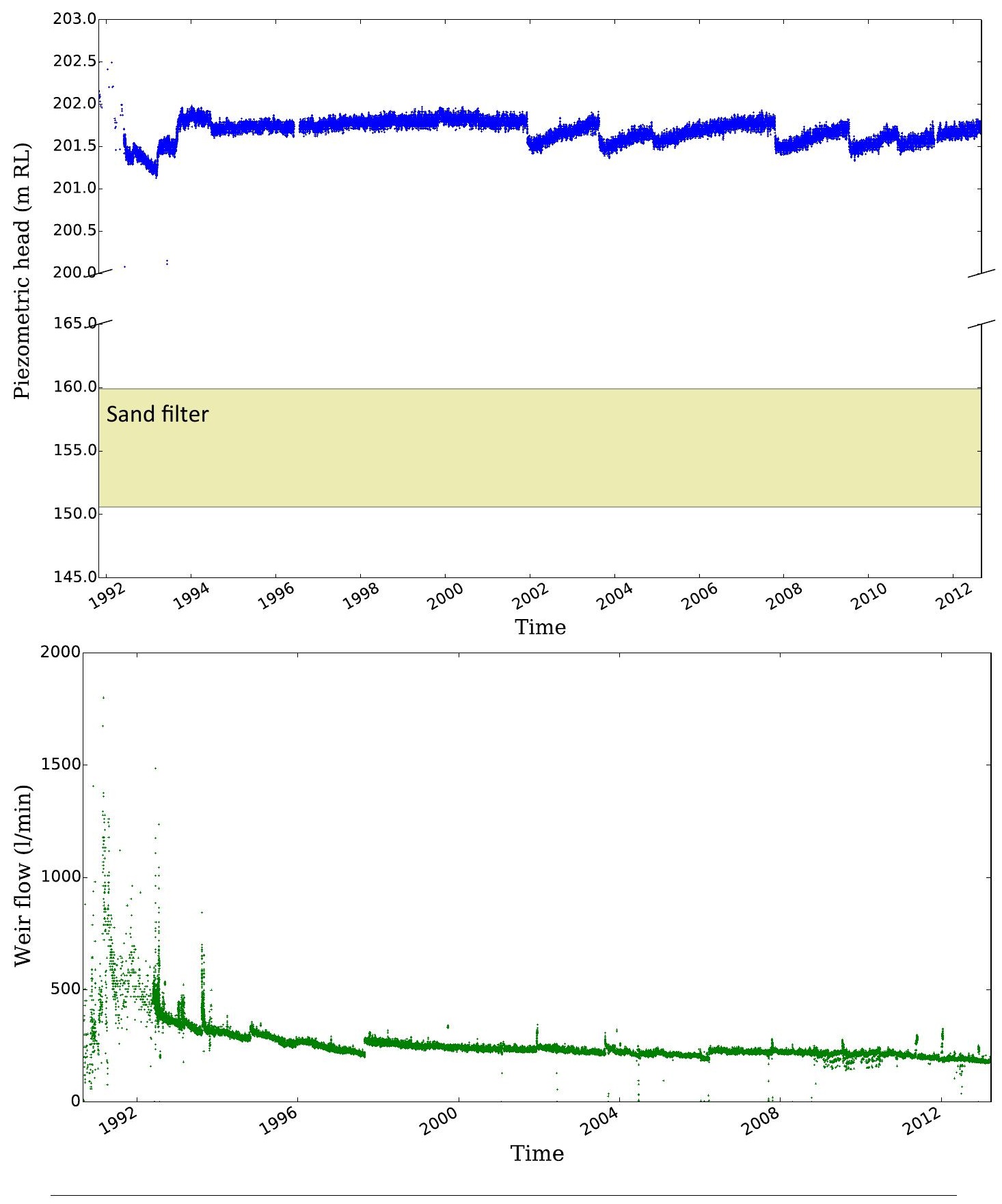

FiguRE 2.2: Upper plot shows the DL1330a piezometer record, located in the Nine Mile Downstream (NMD) monitoring area (see Figure 1.9 for location). The graph has broken y-axis in order to show both the location of the sand filter (yellow) and the piezometer data (blue). The lower plot shows the total discharge record from weir 556W-01 located near the entrance to drainage tunnel DR556, Nine Mile Downstream Slide, (see Figure 1.9 for location). As shown by the early part of the record, large volumes of water have been drained from the rock mass prior to 1993, with flow rates exceeding $1000 \mathrm{l} / \mathrm{min}$ on numerous occasions. 
In order to identify possible earthquake-induced changes to groundwater levels and discharge rates, data from monitoring sites were aligned with the New Zealand earthquake catalogue downloaded from GeoNet (2013). There were 10 earthquakes identified that potentially caused hydrological responses, being all $\mathrm{M}_{w} 6.2$ and greater, occurring at distances of 130-630 km from Cromwell Gorge.

Hydrological data were supplied in New Zealand standard time with daylight savings, so were adjusted to UTC time format. Figure 2.3 shows the alignment of piezometer records DL545a and DL1330a, V-notch weir records W5459W-01 and W556W-01 from Nine Mile Downstream Slide area, with $\mathrm{M}_{w} 5$ and greater New Zealand earthquakes overlain as bars corresponding to earthquake time and date for the period of 08/2001 - 05/2004 The height of the bars represents earthquake magnitude $\left(\mathrm{M}_{w}\right)$, shown by the righthand y-axis.

\section{Recording intervals and completeness of records}

Piezometer data are collected manually by technicians or telemetered on specified time intervals (depending on the individual well setup). Throughout the operating period (1990-ongoing) there are a few time intervals with gaps where no data have been collected. Due to the scale of the monitoring network these gaps are rarely coincident between all sites. As such, if one instrument had ceased recording, monitoring information was still collected elsewhere.

\subsubsection{Definition of an earthquake-induced hydrologic event}

This research is focussed on defining the effects earthquakes induce on the groundwater systems in the Cromwell Gorge landslides. An earthquake-induced hydrological event in the Clyde Dam monitoring boreholes and tunnels is defined as:

A period where the groundwater levels (piezometer data) or tunnel discharge rate (weir flow data) diverges significantly away from background levels, and are not associated with a rainfall event or known anthropogenic influence. Moreover, the immediate groundwater level change and discharge rate deviation must correlate to the timing of an earthquake, taking into consideration the travel time of seismic waves. 

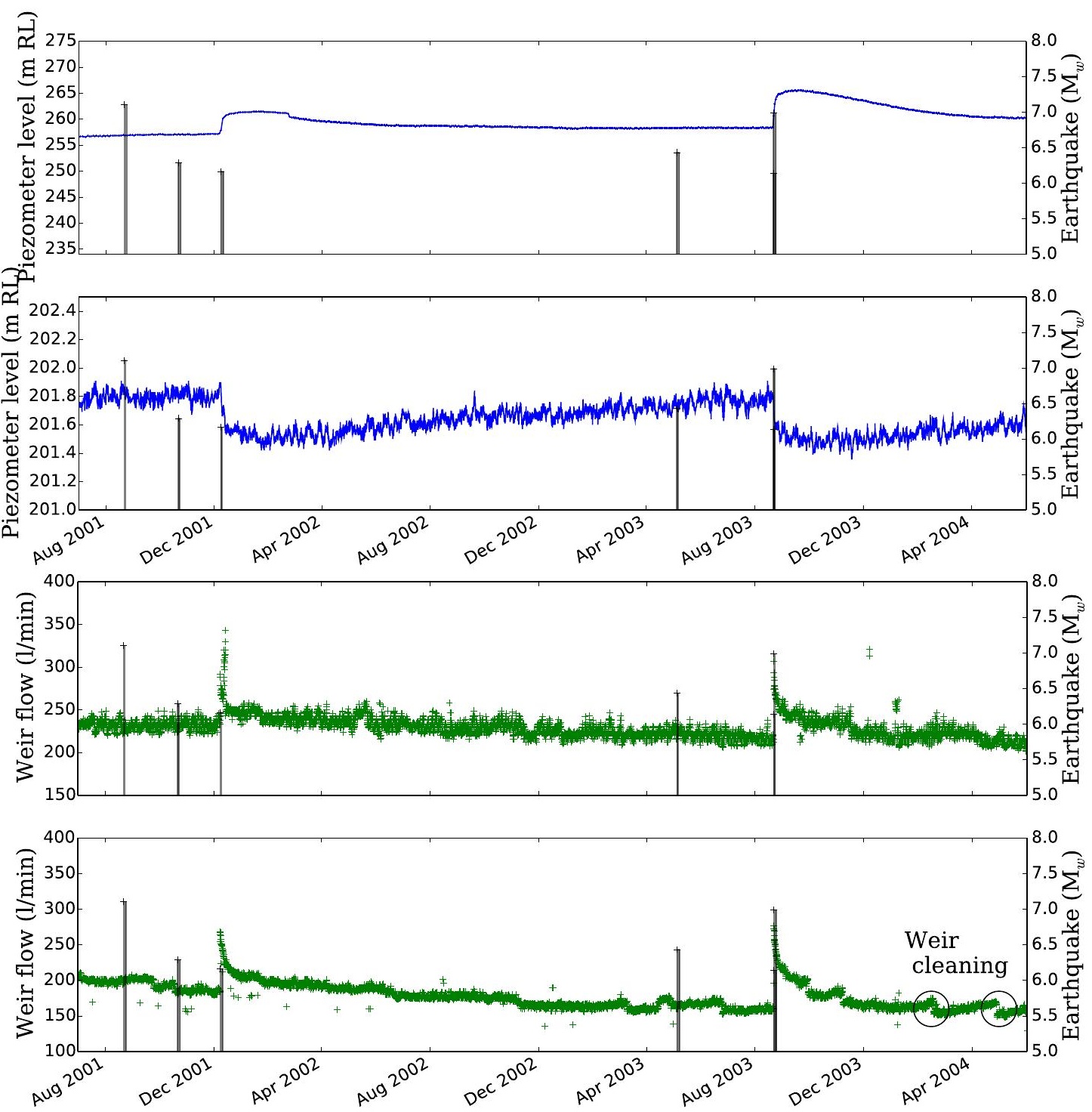

Time

Figure 2.3: Alignment of the earthquake catalogue (plotted as black bars corresponding to the right-hand y-axis) showing earthquakes for which there is a clear hydrological change and earthquakes where there is no change, with piezometer data from DL545a (blue, upper plot) and DL1330a (blue, lower plot), Nine Mile Downstream slide area. Weir data from 549W-01 (upper green plot) and 556W-01 (lower green plot) also Nine Mile Downstream slide area are also shown with the alignment of the earthquake record. Also indicated are examples of the artefacts generated from weir cleaning (maintenance).

\subsubsection{Identification of an earthquake-induced hydrologic event}

In order to clarify the earthquake-induced hydrological signals, all background signals must be identified and either excluded by filtering out from further analysis or deemed insignificant. For the majority of the data, earthquake-induced signals have a vastly different character (from other hydrological signals) and are easily distinguished in the 
data. Furthermore, earthquake-induced hydrological changes to both weir flow rates and piezometer levels in the Clyde network can be correlated together, reinforcing the identification. Immediately noticeable is that different monitoring sites behave differently to each other, some showing an increase or positive fluctuation in groundwater, and others a decrease or negative fluctuation (Figure 2.3, upper two plots). The amplitude of change in some wells is on a meter scale, while others operate on a centimetre scale. Weir discharge always shows a positive increase in response to an identified earthquake event, but increased discharge rates and volumes vary between tunnels (Figure 2.3, lower two plots).

\section{Earthquake-induced fluctuations in groundwater levels}

Piezometer data contain noise and other signals at amplitudes one or two orders of magnitude less than that of an identifiable earthquake-induced response. For example the upper plot of Figure 2.3 (DL545a) shows distinct, positive, high amplitude (metrescale) increases in groundwater level correlating to the timing of earthquakes (black bars), which are immediately far larger than the short-term variations in measurement levels and the long-term gradual increase in water level (see Figure 2.1). The second plot of Figure 2.3 (DL1330a) contains hydrological signals from barometric pressure fluctuations of around $200 \mathrm{~mm}$, with approximate 12 and 24 hour periods. In contrast, earthquake signals in both wells are at least $2-3$ times the amplitude and persist for longer periods (months-years).

\section{Earthquake-induced fluctuations in weir discharge}

Greater variation of hydrological signals exists in tunnel discharge data (measured by V-notch weirs), and those induced by earthquakes are not always the most prominent. Figure 2.3 shows part of the discharge record for 549W-01 and 556W-01 (NMD) with the earthquake record overlain as bars. Here the earthquake-induced signals are relatively large, enabling characterisation. The earthquake signals in both weir records (Figure 2.3) are still clearly identifiable as the large, positive spikes with recovery appearing to imitate a power law relation. Much like the piezometer data, nothing else within the weir data has a similar character to what are determine to be earthquake-induced.

\section{$2.2 \quad$ Identification of other influences}

Small-scale fluctuations and variability in hydrological data can be attributed to: measurement uncertainties, background water level trends, barometric and tidal strains, 
seasonal infiltration, storm events and local infrastructural maintenance and development.

\section{Background hydrological trends}

In some monitoring wells groundwater levels show a marked decrease following construction of drainage tunnels, then a gradual/slow increase over the following 20 year period. This may be attributed, for example in DL545a (NMD) by Cox et al. (2012), to processes that affect the efficiency of the drainage network in the landslide. Such long-term trends need to be removed from the data in order to understand the effects of earthquakes and quantify their response. Figure 2.4 shows an example of how this is performed: first the event is selected and removed, shown in the upper plot by the red data points, then the missing data is interpolated, rejoined, and a polynomial is fitted shown by the black line. The centre plot shows the result of subtracting the earthquake-induced event from the background trend. A similar approach has been adopted for weir discharge data. A long-term trend is identified through polynomial fit between periods before and after anomalous flow, then the period of anomalous flow is subtracted from fitted background flow. It is important to consider how the build up of sediments and/or cements on and behind weirs affects the flow rate. Figure 2.4 shows the end of the earthquake-induced flow period to be at the inflection point, the slope of the flow rate after this point has returned to pre-earthquake values, but remained high due to the increased volume of sediment and/or cement on the weir.

\section{Barometric records}

Barometers are installed in selected boreholes for pressure corrections in water levels and to aid in identifying the sensitivity of certain aquifers. Figure 2.5 shows the barometric (red) and piezometer (blue) data from a seven month period during 2001. The barometric pressure shows a negative correlation with the water level data, which confirms that the piezometer is recording pure water level data. Performing a Fourier analysis on both the barometer and piezometer data shows consistency in the frequency domain for 12 and 24 hour oscillations. The barometric fluctuation does not pose a problem in the analysis of the earthquake signal, due to the large earthquake-signal to noise/other signal ratio. 

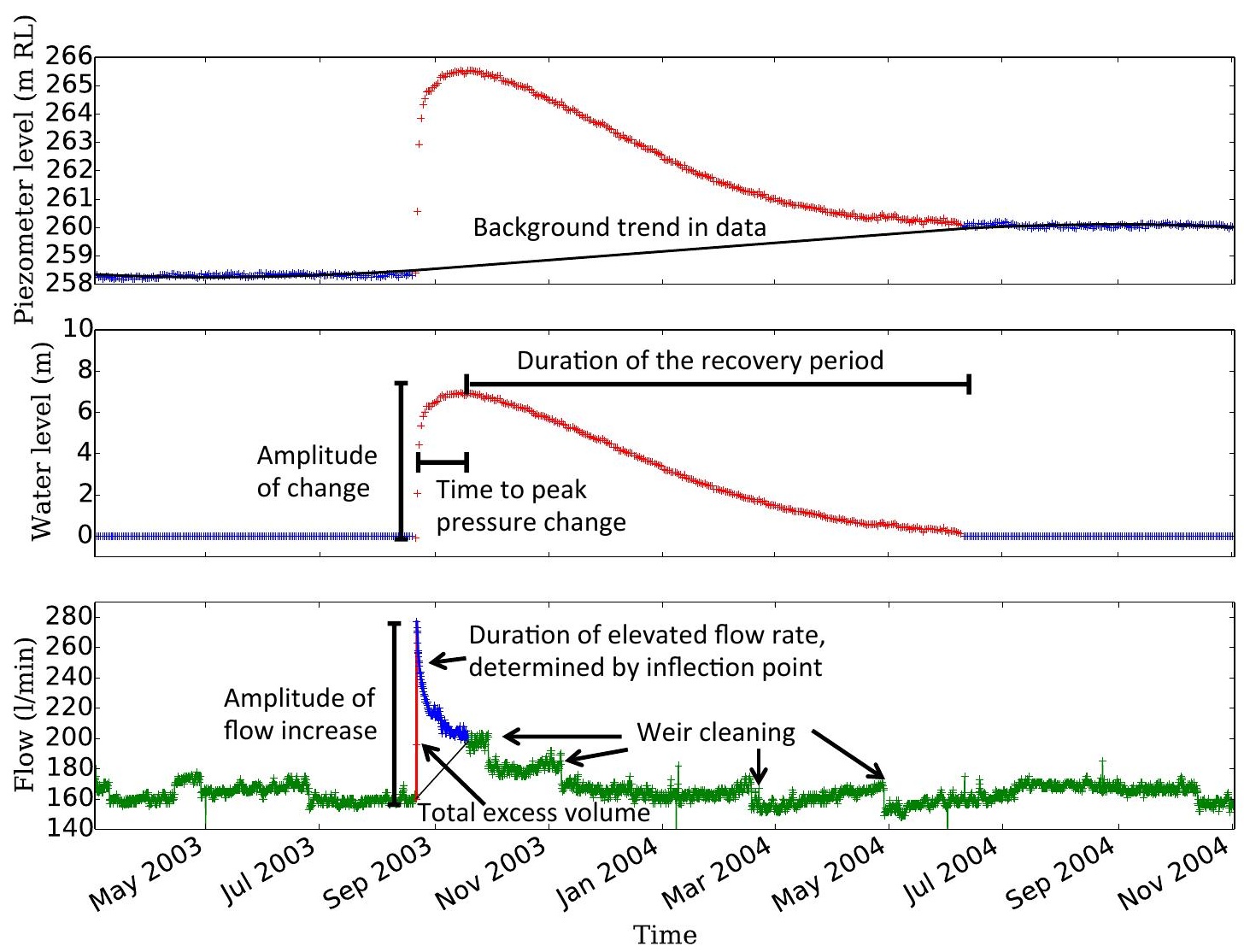

FIgURE 2.4: Upper plot shows the groundwater data with a polynomial fitted through the background trend (black line), centre plot shows the data after the background trend has been removed, with bars to indicate amplitude and duration of the induced event, lower plot shows measurements of weir discharge (measuring of hydrologic changes is outlined in Section 2.4).

\section{Identification of cyclic signals}

The periodogram in Figure 2.5, shows it is not only diurnal pressure changes that generate small rhythmic-like pulses within hydrological data. Earth tide components are identified in the frequency domain, and further analysed using Baytap08 ${ }^{\mathrm{TM}}$. No downhole strain sensors have been installed as part of the Clyde monitoring network, which would further aid in analysis and interpretation of hydrological responses to earth tide strains. Baytap08 ${ }^{\mathrm{TM}}$ (D. C. Agnew, 2008) uses a Bayesian modelling procedure (Akaike Bayesian Information Criterion, developed by H. Akaike in 1974) to analyse time-series data that may contain tidal and/or other cyclic variations. Baytap08 ${ }^{\mathrm{TM}}$ is a modified version of the original version BAYTAP-G ${ }^{\mathrm{TM}}$ developed by M. Ishiguro, Y. Tamura, T. Sato and M. Ooe, released in 1985. The current paper that describes the program and how it utilises the ABIC procedure is by Tamura et al. (1991). The functionality of Baytap $08^{\mathrm{TM}}$ is used to estimate the theoretical earth tide, then identify and compare 


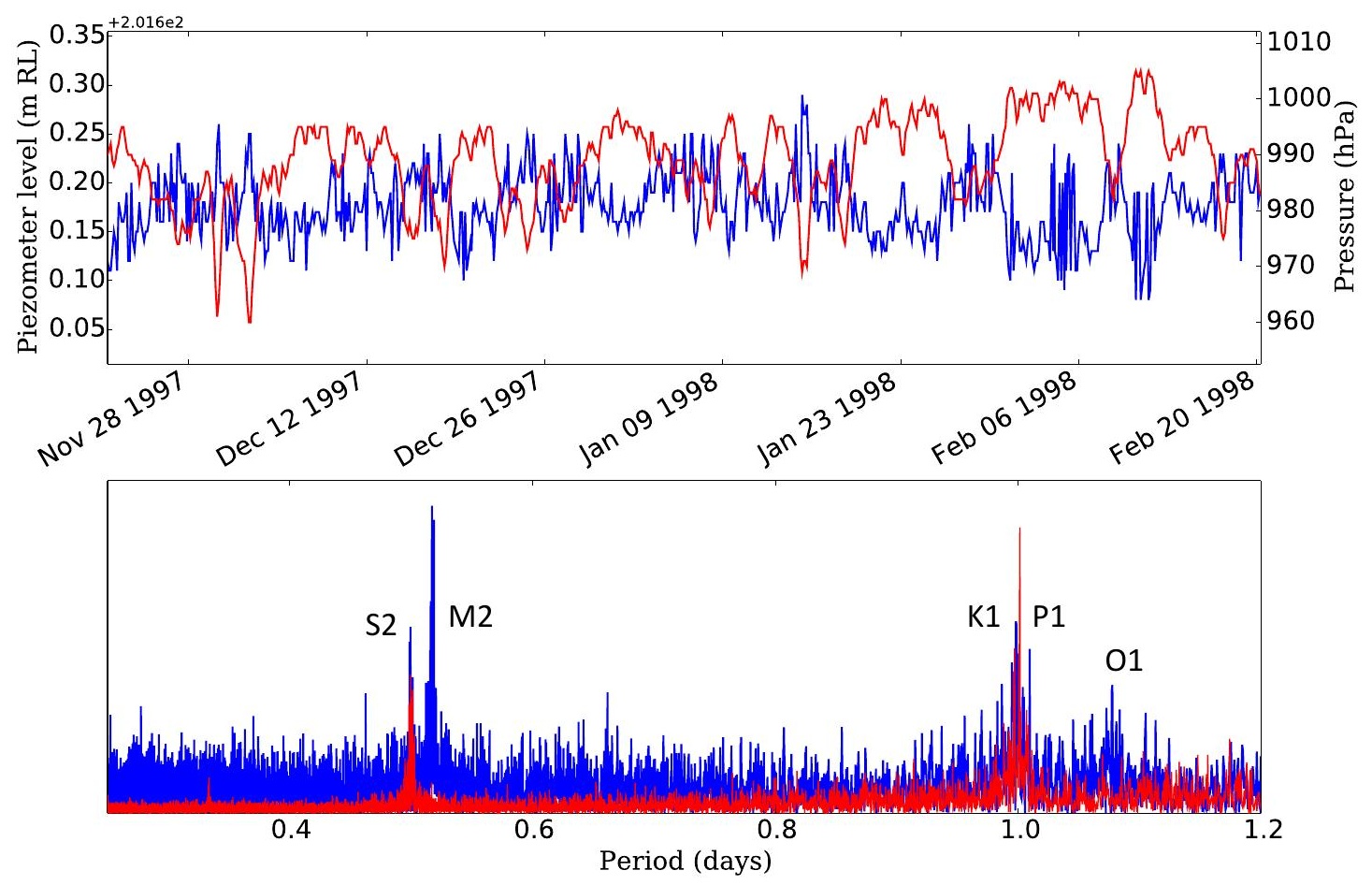

FiguRE 2.5: Figure showing the piezometer data from DL1330a (upper plot, blue), the dominant periods within the piezometric data (lower plot, blue), with the barometer data for DL1330BRM (upper plot, red), and the dominant period within the barometric data (lower plot, red), see Table 2.1 for an explanation of the earth tide nomenclature. The number at the top left corner of the figure is a scaling factor for the y-axis and an artefact of plotting.

to phases and amplitudes within hydrological data. The program is used to investigate if there are noticeable differences in phase lag between the theoretical tides and their identified influence on water levels or discharge rates before and after an earthquake. An increase or decrease in phase and/or amplitude can be interpreted as a change in the hydraulic properties e.g. permeability of the reservoir (Elkhoury et al., 2006). The functionality of the program also allows incorporation and removal of the effect from barometric pressure changes into the analysis. Due to the project time constraints and significant disorder within much of the hydrological data (i.e. missing samples and changing sampling intervals) analysis is only performed on two records: monitoring well DL1330a, NMD slide area, and weir 537W-01, No. 5 Slide. Due to changes in sampling intervals, data are further broken into sections for separate analysis. The majority of hydrological data from the landslide monitoring network are sampled at 3-hourly or greater intervals, which limits the ability to recognise the short period tides. 
TABLE 2.1: Earth tides with the larger gravity potential at 50 degrees latitude, from Wilhelm et al. (1997).

\begin{tabular}{|c|c|c|c|}
\hline Name & origin & period (day) & Gravity $\left(\mathbf{n m} / \mathbf{s}^{2}\right)$ \\
\hline Diurnal & & & \\
K1 & Sun, Moon & 0.9973 & 434 \\
O1 & Moon & 1.0758 & 309 \\
P1 & Sun & 1.0027 & 144 \\
\hline Semi-diurnal & & & 332 \\
M2 & Moon & 0.5175 & 154 \\
S2 & Sun & 0.5000 & \\
\hline
\end{tabular}

\section{Seasonal changes in groundwater levels}

Some monitoring well data show small fluctuations in water level that correlate to cycles in seasonal and mean daily temperature changes. For example, in monitoring well DL652a, Brewery Creek Slide (Figure 2.6) small increases in water level are observed during winter months and small decreases during summer months, negatively correlating to temperatures recorded by a downhole thermometer. Precipitation in the area during winter months is dominated by snowfall (Wilson and Lu, 2011), which provides a greater source of infiltration and groundwater recharge than rainfall during summer months. Temperature may exhibit certain controls on infiltration rate in association with groundwater recharge, but is not seen to affect earthquake-induced signals in any way.

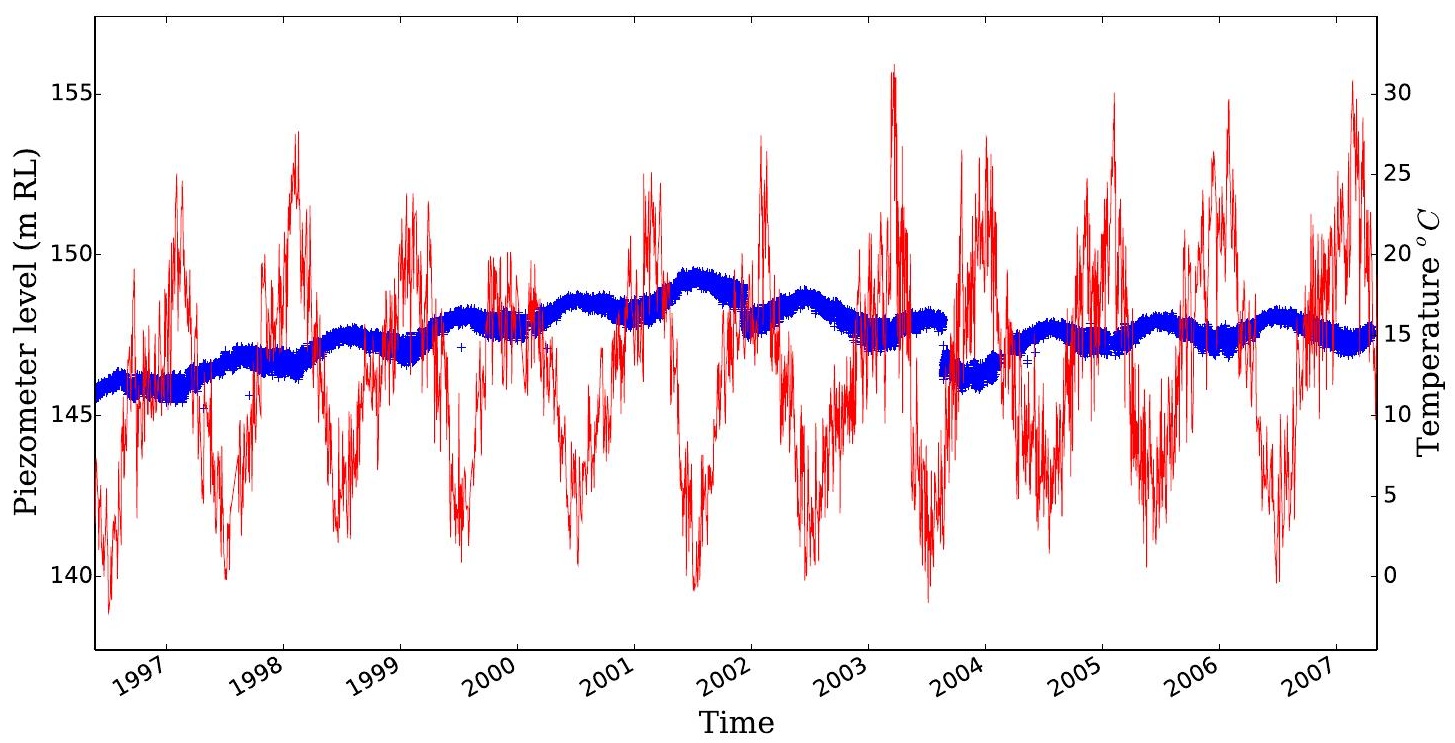

Figure 2.6: Figure showing the piezometric record (blue) of DL652 located in the Brewery Creek Slide and the temperature record (red) from DL545THM recorded in the Nine Mile Downstream Slide area. 


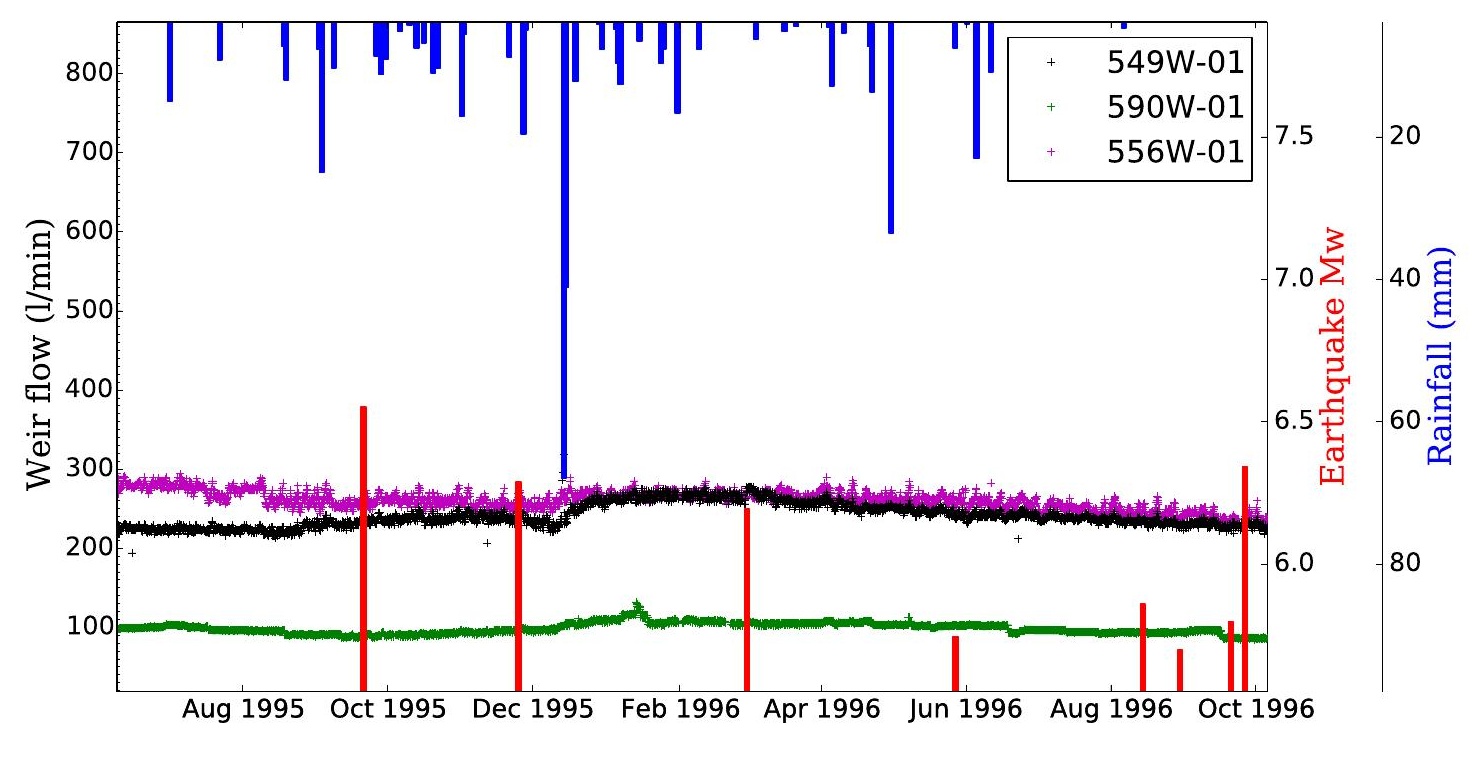

Figure 2.7: An identified storm event in the weirs 590W-01(green), 549W-01 (black), and 556W-01 (magenta) from Nine Mile Downstream Slide area (see Figure 1.9 for location), daily rainfall are shown in blue, and earthquakes through this period are shown by red bars. The rainfall is calculated for the end of the weekly period.

\section{Storm events}

Rainfall records have not been continuously recorded at one site, but a continuous rainfall record since 1991 can be created by joining two records. The first record from station 5543 located at Clyde Dam, recorded the 01/01/1991 - 29/06/2007 period, and station 12431 located at Clyde Electronic Weather Station (Figure 1.2) records 16/06/1996-ongoing. The two sites are $1.938 \mathrm{~km}$ apart and the overlapping period correlates well. Therefore, it is considered there would not be any substantial difference for the remainder of the records. Storm events are relatively rare within the data. One of the largest identified storm events was in December 1995 recorded by the weirs in the Nine Mile Downstream area (e.g., 590W-01, 549W-01 and 556W-01) shown by Figure 2.7. In this example the effect of the storm event differs in each weir, and was most distinct in weir W549W-01 (shown in black). The rainfall induced a gradual (1-2 month) rise in flow rate until peak flow is reached, followed by a slow $7-8$ month recession period. Weir flow data from 556W-01 (magenta) are similar, just more subdued than from weir $549 \mathrm{~W}-01$. The same pattern of a gradual rise in flow followed by a long recession period is recognised. Weir 556W-01 flow data (green) do not appear to be sensitive to rainfall to the same degree, a small increase in flow is observed, but appears to be truncated by weir cleaning (see Section 2.2).

Within discharge data there was a marked difference between the magnitude and temporal characteristics of an earthquake-induced event versus a storm event. Identified storm 
events showed a much greater lag-time between peak rainfall and peak flow (1-2 months) whereas the time between an earthquake and the earthquake-induced peak flow was almost instantaneous $(0-6 \mathrm{hr})$. Storm events were rarely recognised in piezometer data that recorded earthquake-induced responses, due to the effectiveness of the landslide drainage system.

\section{System maintenance: weir cleaning}

A substantial build up of calcite (Beetham and Fergusson, 1990a) and debris occurring on and behind the V-notch weirs is scraped off periodically (Whitford N. personal communication 2013). Cleaning events have been verified by engineers at Clyde Dam, and are kept as metadata in the database records. They are easily recognisable in the flow data, always being shown by immediate and repetitive drops in flow rate without any change in flow gradient. Examples are highlighted in Figure 2.3. Effects of weir cleaning have not significantly interrupted any identified earthquake-induced signals.

\subsection{Monitoring well parameters}

Monitoring wells where clear earthquake-induced hydrologic responses are observed are outlined in Table 2.2, together with parameters describing their elevation, filter interval and location within the landslide structure, and proximity to drainage tunnels. 


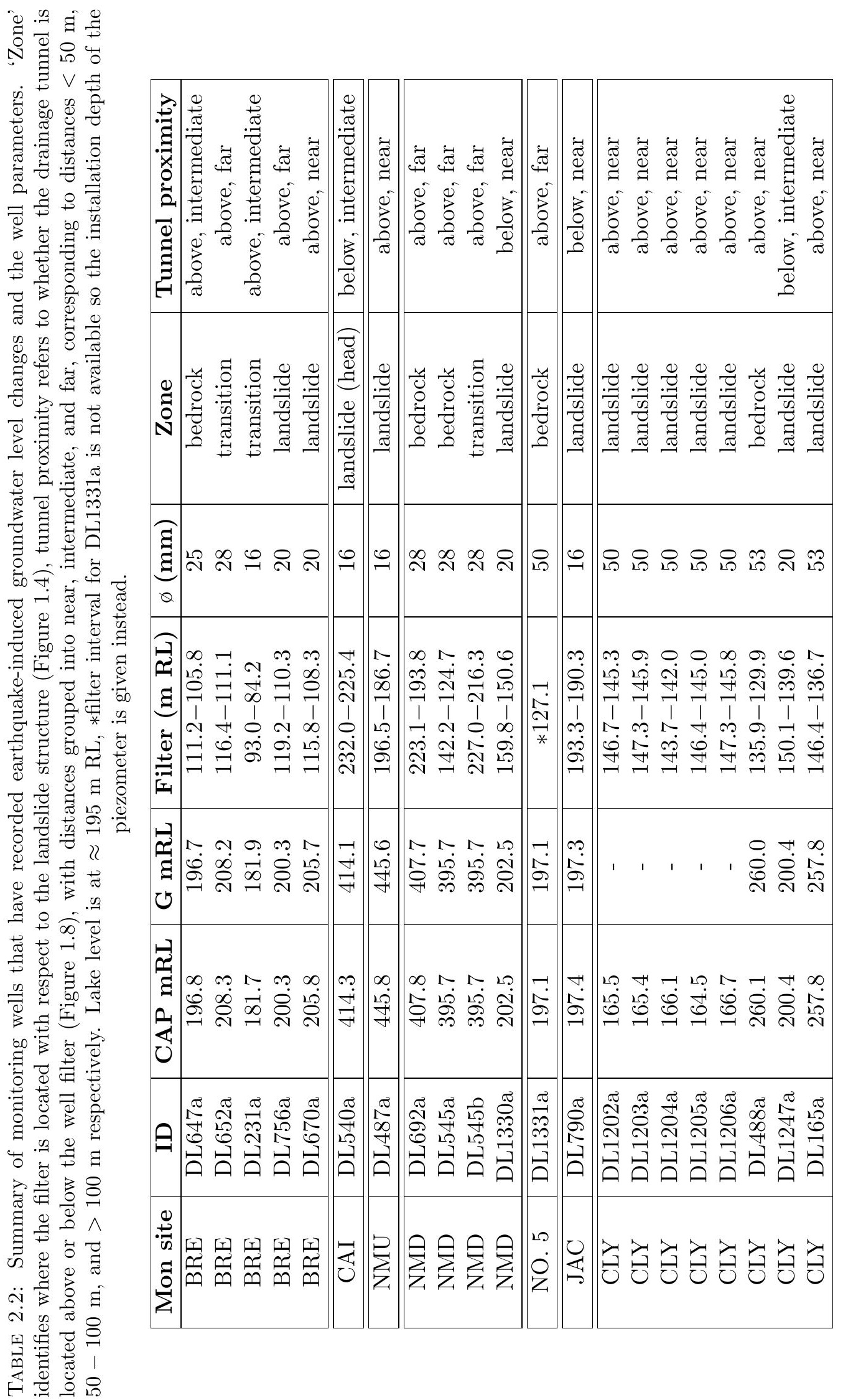




\subsection{Quantification of earthquake-induced hydrologic responses}

Monitoring data were processed to remove the effects of other hydrological signals, thus enabling quantification of the amplitude, time to peak pressure change ( $\Delta \mathrm{P}$-time), and duration of the recovery period (recovery-time) for piezometer (groundwater) level fluctuations. The recording of the initiation of earthquake-induced groundwater level fluctuations within piezometer data is dependant on the instrument sampling interval. The mean of the data for a period prior to the earthquake that best represented the water level was extrapolated to the timing of the earthquake as a measuring point. The time to peak pressure change was measured from the the initiation of water level rise to the maximum value reached, and the duration of the recovery period was taken from the maximum value reached to the inflection point of the recovery. The inflection point was determined to be the minimum point at which earthquake-induced effects have been lost to the hydrological system (Figure 2.4). Furthermore, the inflection point in the recovery of earthquake-induced weir discharge was chosen to reduce the effects of debris/cement accumulation on and behind weirs, which generated uncertainty in the flow rate. Excess discharge volumes were determined by calculating the total cumulative discharge for the period during the earthquake-induced flow, then subtracting the background cumulative discharge volumes for the same period to give the excess discharge volume (Figure 2.4).

\subsection{Processing of seismological data}

Being situated in a tectonically active region, New Zealand experiences numerous earthquakes every day, albeit the vast majority are unfelt. Analyses of 154 earthquakes of $\geq \mathrm{M}_{w} 5$ recorded since 1991 sourced via Ristau (2008); GeoNet (2013), were performed to investigate what earthquake parameters are most influential in inducing groundwater responses within the Cromwell Gorge landslides, such as:

1. Dependance on earthquake source characteristics e.g. polarity of the P-wave first arrival through analysis of earthquake take-off angles, and $\mathrm{P}$-wave angle of incidence.

2. Intensity of earthquake shaking e.g. peak ground acceleration, peak ground velocity, Arias intensity, and seismic energy density.

3. Character of the frequency bandwidth and duration of earthquake shaking in Cromwell Gorge. 


\subsubsection{Treatment of changes in the seismic network}

Due to changes in instrument type and instrument location in the GeoNet network, no continuous seismometer or strong motion record from a single instrument or site, within a suitable distance of Cromwell Gorge is available for the entire time period of hydrological monitoring. Old instruments were removed and new instruments installed at different sites, so there are changes in distance between the hydrological study site(s) and the GeoNet site, and most importantly different site conditions (e.g. exposed bedrock versus alluvium). Table 2.3 lists the closest GeoNet stations with comparable site conditions, their dates of operation and their distances to a location in centre of Cromwell Gorge (also shown in Figure 1.10). Unfortunately none of these chosen sites were in operation during the years 1993 and 1994 to record the 1993 Fiordland and 1994 Arthurs Pass earthquakes, from which significant hydrological responses were identified. Therefore, station MSZ is also included as it is the closest station (although at an unfavourable distance) that has been in operation throughout the entire monitoring period. Where data were recorded by nearby seismograms they were used preferentially; where those data were not available, other measurements were computed. The following sections describe the concepts, analytical procedures and processing steps that were undertaken in order to use disparate seismological monitoring and obtain consistent results.

TABle 2.3: GeoNet stations close to Cromwell Gorge in operation during the hydrological data recording period. Locations are shown in Figure 1.10. None of the close stations have been in operation for the total monitoring period since 1993. NB: 133A is a private strong motion site located at Roxburgh Dam, and AXZ has been decommissioned. MSZ is the nearest station to be recording throughout the entire monitoring period.

\begin{tabular}{|c|c|c|}
\hline GeoNet station & Period of operation & Distance to gorge $\mathbf{( k m )}$ \\
\hline $133 \mathrm{~A}$ & $1995 / 06 / 20-2004 / 03 / 23$ & 33 \\
AXZ & $1996 / 03 / 07-2004 / 08 / 31$ & 9 \\
WKZ & $2004 / 06 / 03-$ ongoing & 46 \\
EAZ & $2004 / 11 / 01-$ ongoing & 6 \\
\hline M $\bar{S} \bar{Z}---1-\overline{9} \overline{6} 6 / 03 / 03-$ ongoing & $12 \overline{2}$ \\
\hline
\end{tabular}

\subsubsection{Earthquake source characteristics}

\section{Earthquake location}

Hypocentres for earthquakes were obtained via GeoNet (2013) with associated error estimates. The location data for hypocentres are in WGS84. Figure 2.8 shows the epicentral location of analysed $\mathrm{M}_{w} \geq 5$ earthquakes and great circles are drawn showing the shortest path to Cromwell Gorge. 


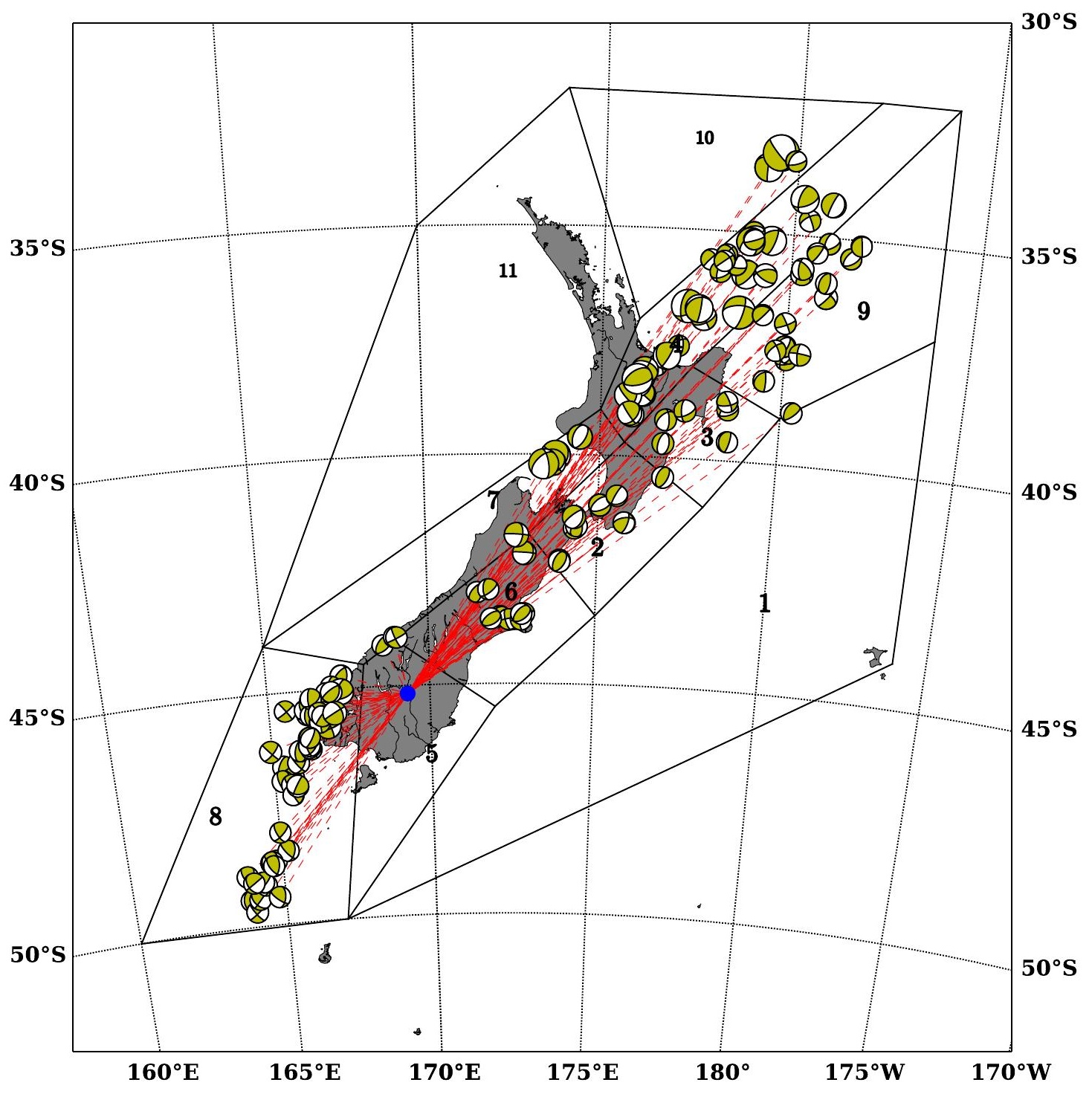

Figure 2.8: Map showing earthquakes $\left(\mathrm{M}_{w} 5\right.$ and greater) in the New Zealand region since 1991. Great circles are drawn between Cromwell Gorge (blue marker) and earthquake epicentre, represented by their lower-hemisphere focal mechanism. Data obtained via Ristau (2008); GeoNet (2013), and authors listed in Table 3.5 (Chapter 3). Also shown are the boundaries for the $2 \mathrm{D}$ velocity models used for calculating earthquake take-off angles, numbers within the different regions outlined correspond to velocity models 1: New Zealand Standard model, 2: Wellington model, 3: Hawke's Bay model, 4: Taupo model, 5: Clyde Model, 6: Central South Island model, 7: Westland model, 8: Fiordland model, 9: Hikurangi model, 10: Kermadec model, 11: Lord Howe model, 12: Vening-Meinesz model. Velocity models are also provided in Appendix A.

\section{Distance calculation}

The distance from earthquake source to site has an important bearing on the shaking intensity felt and is used in seismic energy calculations. From the earthquake hypocentres and site location, the azimuth, back-azimuth and distance to the monitoring sites are 
calculated using an Obspy function that implements algorithms to find the shortest path through a geodesic such as Earth. For detail on algorithms used in the computation of geodesics on an ellipsoid of revolution, refer to Karney (2013) and references therein.

\section{Take-off angle analysis}

An earthquake take-off angle is the angle the first P-wave ray emerges from the earthquake focus, measured from the vertical. Take-off angles are calculated for the depth of the earthquake focus with respect to a velocity model, the fastest travel-time, distance and azimuth from source to receiver. Relationships between earthquake sources and receiver sites are illustrated in Figure 2.9. Take-off angles were calculated to provide insight as to whether an earthquake's seismic wave front will impart first-motion compression or dilation at Cromwell Gorge, which in turn, may have influenced the observed hydrological responses. In order to calculate the take-off angle of an earthquake with respect to our site, Snell's law is utilised,

$$
\frac{\mathrm{V}_{1}}{\mathrm{~V}_{2}}=\frac{\sin \theta_{1}}{\sin \theta_{2}}
$$

where $V_{1}$ is the velocity of the upper medium, $V_{2}$ the velocity of the medium below, $\sin \theta_{1}$ is the angle of refraction in the upper medium and $\sin \theta_{2}$ the angle of refraction in the lower medium, and the 2D velocity models for New Zealand regions (Figure 2.8, data provided in Appendix A as used by GeoNet (2013) prior to 09/2013). Seismic wavefronts are traced through the source model for each event and then into the receiver model (Figure 2.9). For example, for a shallow earthquake the critically refracted P-wave arrival at Cromwell Gorge (or more precisely the seismometer used) is:

$$
\sin ^{-1} \frac{4.4}{8.1}=32.9^{\circ}
$$

Figure 2.9 illustrates the relationship between earthquake take-off angle (with respect to site location) and the compressional and dilatational quadrants of the focal mechanism. To be able to compare the take-off angles for all earthquakes that induce hydrological changes and those that do not, take-off angles need to be viewed on one common plot (Figure 2.10). To obtain this figure the orthogonal tensional (T), compressional (P) and null $(\mathrm{N})$ axes for selected earthquakes undergo rotation into a right-handed coordinate system, so the $\mathrm{P}$ axis aligns north, the $\mathrm{T}$ axis aligns east and the $\mathrm{N}$ axis is vertical down. Using this rotation scheme the pre-determined take-off angle and azimuth rotates by the desired amount i.e. the take-off angle and azimuth (described by a vector in an 
$X, Y, Z$ cartesian coordinate system) rotates by the desired amount around the $X, Y$, and $Z$ axes so that the $\mathrm{P}, \mathrm{T}$ and $\mathrm{N}$ axes align north, east and down, respectively. Figure 2.10 provides a visual example of how the three orthogonal focal mechanism axes and one vector can successively be rotated around a cartesian coordinate system, in order to build a composite 'normalised' focal mechanism. The following equations mathematically describe how a rotation matrix is built in order to compute each rotated take-off angle.

A matrix to describe rotation around the $x$ axis:

$$
R_{x}(\alpha)=\left(\begin{array}{ccc}
1 & 0 & 0 \\
0 & \cos \alpha & -\sin \alpha \\
0 & \sin \alpha & \cos \alpha
\end{array}\right)
$$

rotation around the $y$ axis:

$$
R_{y}(\beta)=\left(\begin{array}{ccc}
\cos \beta & 0 & \sin \beta \\
0 & 1 & 0 \\
-\sin \beta & 0 & \cos \beta
\end{array}\right)
$$

and rotation around the $z$ axis:

$$
R_{z}(\gamma)=\left(\begin{array}{ccc}
\cos \gamma & -\sin \gamma & 0 \\
\sin \gamma & \cos \gamma & 0 \\
0 & 0 & 1
\end{array}\right)
$$

The rotation matrix is the combination of these three rotations, but the outcome will depend on the order in which the rotations are made. Equation 2.6 describes a 3dimensional rotation first around the $x$-axis, the $y$-axis, and then the $z$-axis.

$$
R_{z} R_{y} R_{x}=\left(\begin{array}{ccc}
\cos \beta \cos \gamma & \cos \gamma \sin \alpha \sin \beta-\cos \alpha \sin \gamma & \cos \alpha \cos \gamma \sin \beta+\sin \alpha \sin \gamma \\
\cos \beta \sin \gamma & \cos \alpha \cos \gamma+\sin \alpha \sin \beta \sin \gamma & -\cos \gamma \sin \alpha+\cos \alpha \sin \beta \sin \gamma \\
-\sin \beta & \cos \beta \sin \alpha & \cos \alpha \cos \beta
\end{array}\right)
$$

The outcome of passing each earthquake take-off angle through the appropriate rotation matrix effectively normalises them into a common spherical coordinate system, which allows a visual comparison to be made. The angle of incidence for the head waves of seismic energy arriving at our site (Figure 2.9) are also calculated using Snell's law (equation 2.1). 


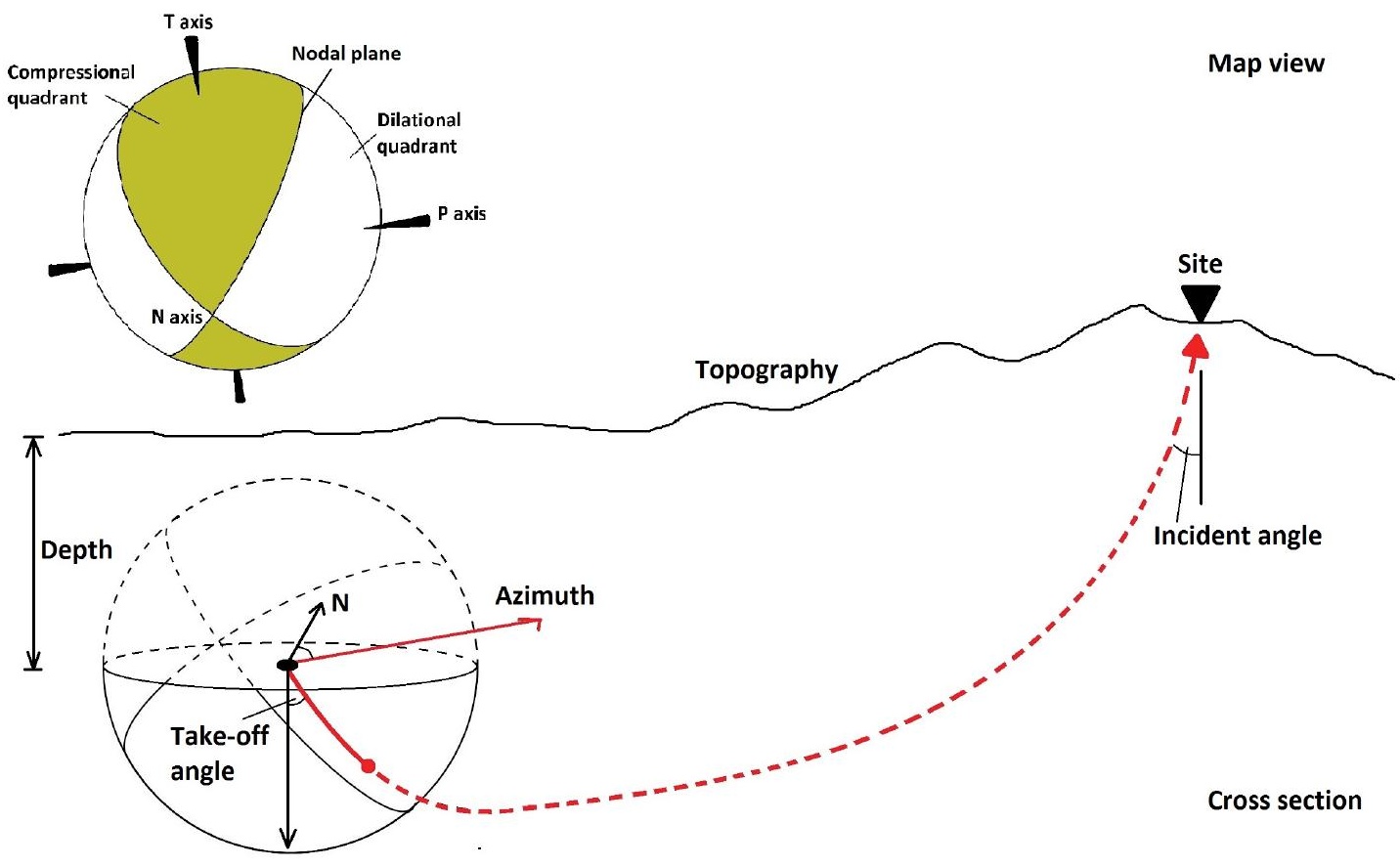

FIGURE 2.9: The upper section of the figure shows a lower hemisphere earthquake focal mechanism (in map view) with the three orthogonal axes labelled: the compressional (maximum) $\mathrm{P}$-axis is centred in the dilational quadrant (white) defined by the two nodal planes, the tensional (minimum compression) T-axis centred in the compressional quadrant (yellow) defined by the two nodal planes, and the null (intermediate compression) $\mathrm{N}$-axis is defined by the intersection of the two nodal planes. The lower section of the figure shows the same focal mechanism now rotated to a cross sectional view. From the central point of the focal sphere the earthquake take-off angle can be calculated using the depth and velocity model/travel time. The take-off angle, once plotted within the focal mechanism then reveals what quadrant the ray departed from. At the site the angle of the incoming ray (incident angle) may also be calculated using the velocity structure and travel time.

\subsubsection{Intensity and characteristics of shaking felt in Cromwell Gorge}

Perhaps the most fundamental aspect to whether or not an earthquake may induce a hydrological response is the intensity of shaking felt within the aquifer and reservoir rock (Wang and Manga, 2010). The intensity of shaking felt at a particular site can be described in terms of peak ground acceleration (PGA), peak ground velocity (PGV), Arias intensity $\left(\mathrm{I}_{a}\right)$, and seismic energy density $(e)$. PGA can be directly measured and PGV derived directly at a site by strong motion sensors. Arias intensity in the original form (Arias, 1970) utilises the recorded seismogram, and seismic energy density is a calculated term based on earthquake magnitude. 


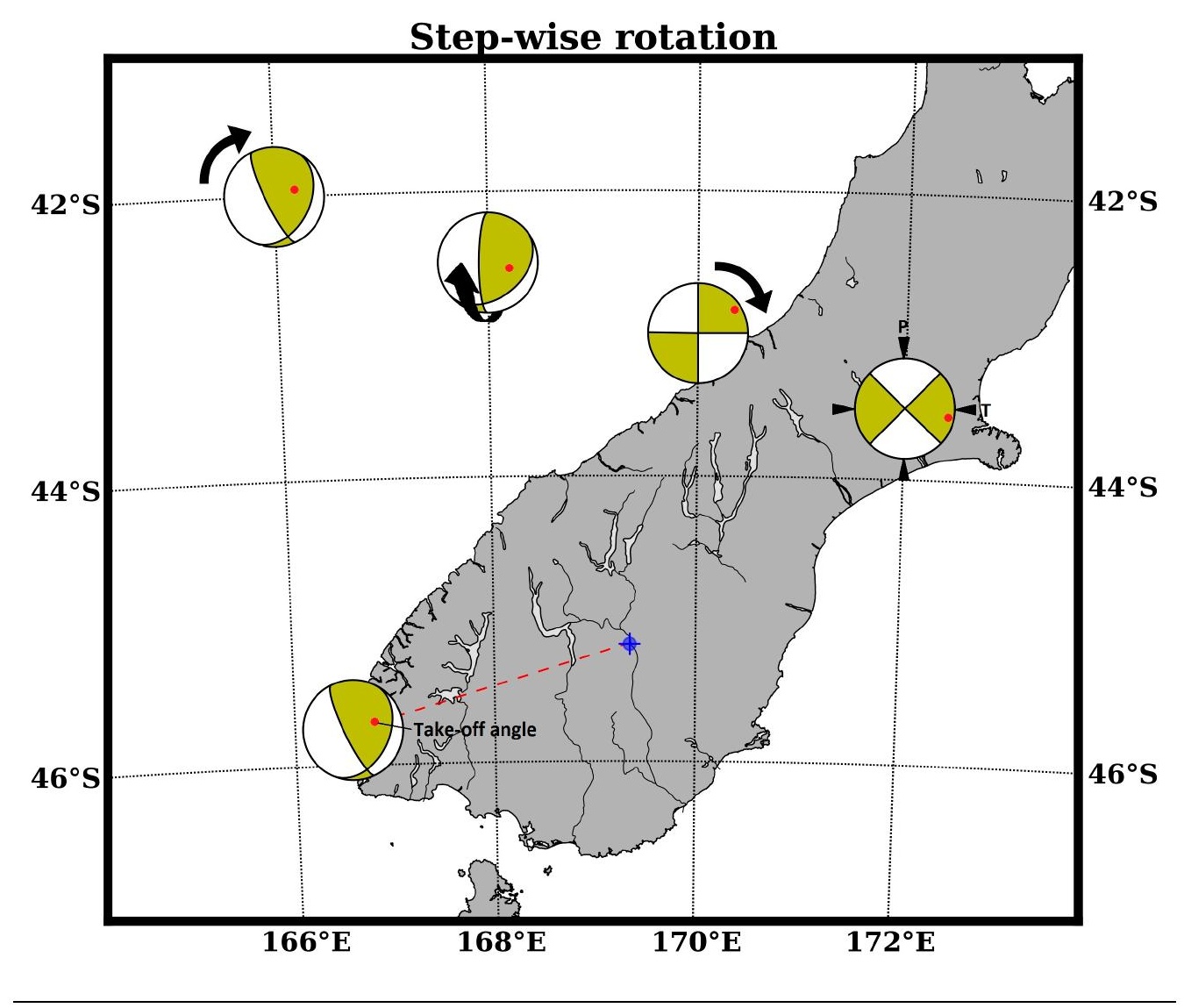

Figure 2.10: Figure illustrating the step-wise rotation of a focal mechanism (here corresponding to an earthquake in Fiordland) and the take-off vector corresponding to the Clyde Dam, into a coordinate system in which the P-axis and T-axis are oriented upward and across the page, respectively. The procession of rotation follows equations $2.3,2.4$ and 2.5 starting from the top left focal mechanism.

\section{Peak ground acceleration and peak ground velocity}

Ground moves irregularly in response to the passage of seismic waves. This movement can be described by the amplitude, velocity and acceleration of change in position as a function of time. Peak ground acceleration (PGA) is defined as the maximum acceleration experienced by the accelerometer during the passing of seismic waves. Measurements of peak ground acceleration (PGA) and derived peak ground velocity (PGV) for earthquakes inducing hydrological changes in Cromwell Gorge are available through GeoNet strong motion data catalogues. Distance-magnitude relations are developed in order to estimate PGA values within the study site based on GeoNet data. To assess the degree of uncertainty in calculated PGA, values are calculated at distances where measurements are available at EAZ e.g. for earthquakes post 01/11/2004. The developed relation used to interpolate PGA values takes the following form: 


$$
\ln (\mathrm{PGA})=c_{1}+c_{2} \mathrm{M}_{w}-c_{3} \log (D)
$$

where $c_{1}, c_{2}$ and $c_{3}$ are constants derived from the data, $\mathrm{M}_{w}$ is earthquake magnitude, and $D$ is distance. For peak horizontal ground acceleration (PGAh) $c_{1}=2.1747, c_{2}=$ $0.7653, c_{3}=-1.3983$. The interpolated PGA values are compared to the PGA attenuation model of Zhao et al. (1997) with similar results.

\section{Arias intensity}

Arias intensity further provides an estimate for the total ground motion during an earthquake, and has been used as a parameter to describe the shaking necessary to trigger landslides under certain conditions (Del Gaudio et al., 2003). The original form of Arias intensity takes into account the duration of shaking above a certain threshold, described by Arias (1970) as:

$$
\mathrm{I}_{a}=\frac{2 \pi}{g} \int_{0}^{\infty} a(t)^{2} d t
$$

where $\mathrm{I}_{a}$ is Arias intensity in units of velocity (e.g., $\mathrm{m} / \mathrm{s}$ ), $g$ is the acceleration due to gravity in $\mathrm{m} / \mathrm{s}^{2}$, and $\mathrm{a}(t)$ is the acceleration time-history in units of $g$. An empirical attenuation relationship for median Arias intensity developed by Travasarou et al. (2002), is implemented due to incomplete accelerometer records, taking the following form:

$$
\begin{array}{r}
\ln \left(\mathrm{I}_{a}\right)=c_{1}+c_{2}\left(\mathrm{M}_{w}-6\right)+c_{3} \ln \left(\mathrm{M}_{w} / 6\right)+c_{4} \ln \sqrt{\left(R^{2}+h^{2}\right)} \\
+\left(s_{11}+s_{12}\left(\mathrm{M}_{w}-6\right)\right) S_{C}+\left(s_{21}+s_{22}\left(\mathrm{M}_{w}-6\right)\right) \\
+S_{D}+f_{1} F_{N}+f_{2} F_{R}
\end{array}
$$

where: $I_{a}$ is the median Arias Intensity in $\mathrm{m} / \mathrm{s}$ (mean of the two horizontal components), $\mathrm{M}_{w}$ is the moment magnitude, $R$ in $\mathrm{km}$ is closest distance to the rupture plane, $\mathrm{S}_{C}$, and $\mathrm{S}_{D}$ are both site terms, $F_{N}$ and $F_{R}$ are terms to describe the faulting mechanism, and $c_{1}, c_{2}, c_{3}, c_{4}, h, s_{11}, s_{12}, s_{21}, s_{22}, f_{1}$ and $f_{2}$ are coefficients determined by regression analysis. 


\section{Seismic energy density and distance}

Seismic energy density $e$ as described by Wang and Manga (2010) can be defined as the maximum available seismic energy per unit volume of rock during seismic shaking; the parameter as shown by Lay and Wallace (1995), may be estimated by:

$$
e=\frac{1}{2} \sum_{i} \frac{\rho}{T_{i}} \int v_{i}(t)^{2} d t
$$

where $\rho$ is the density, $T_{i}$ and $v_{i}$ are the period and particle velocity respectively for the $i^{t h}$ mode, and summation for all modes of ground shaking. Wang (2007) and others make use of this parameter by combining it with an empirical relation for magnitude-distance, in order to estimate the energy felt at a particular site during seismic shaking:

$$
\log _{10} e=-3 \log _{10} D+1.5 \mathrm{M}_{w}-4.2
$$

where $D$ is the distance in $\mathrm{km}, \mathrm{M}_{w}$ is earthquake magnitude, and $e$ is the energy density in $\mathrm{J} / \mathrm{m}^{3}$. Seismic energy density becomes useful as it is stated to be approximately proportional to $\mathrm{PGV}^{2}$ (Ma et al., 2006), and PGV has further been described by Brodsky et al. (2003) as being proportional to the dynamic strain imposed on a system. Therefore the energy density may be a useful first-order assessment of seismic shaking intensity at a specified site. It enables comparison between hydrologic responses within Cromwell Gorge (and elsewhere) despite recording of seismic events on different seismometers.

There are limitations to the use of the seismic energy density estimate, as it is purely based on earthquake magnitude. It fails to include important earthquake parameters such as acceleration, duration of shaking, rupture directivity, seismic frequencybandwidth, and is not flawlessly transferable to all geological settings: seismic waves attenuate differently in differing geologic media, and geometric spreading varies between highly-fractured and non-fractured crustal settings (Stafford et al., 2009).

\section{Spectral analysis}

The spectral bandwidth and duration of shaking may be important factors influencing the extent to which a hydrological system may respond. It is only performed on data measured by the seismograms as it cannot be interpolated at the required resolution. As seismic waves propagate through heterogeneous media their dynamic signal changes and attenuates, due to phenomena such as energy reflection, geometric spreading, scattering and multi-pathing (de Moortel et al., 2004; Stafford et al., 2009). The spectrum of 
seismic shaking may be substantially different once the energy has travelled a great distance.

The time-frequency analysis of a random signal has been enhanced by the use of wavelet transforms, providing detailed insight into the character of transient signals (Gurley and Kareem, 1999). Computing continuous wavelet transforms of seismometer data are useful digital signal analysis techniques to investigate the spectral character of earthquakes. The continuous wavelet transform (CWT) begins with the generation of a single parent wavelet. The parent wavelet can be stretched, skewed, compressed and translated by any amount (set by the operator), which now becomes the analysing function. The CWT measures the similarities of the input data (accelerometer data) to the analysing function. The input signals become decomposed into a series of wavelet functions of different scales and positions in time and space (stretched, skewed, compressed and translated versions of the parent wavelet). This allows the resolution in time and frequency of the input signal to vary in the time-frequency domain. The CWT can provide insight into dispersive effects of wave propagation.

The Morlet wavelet function is used in the spectral analysis presented, as it provides the most accurate frequency resolution for the frequency bandwidth in which earthquakes generally occur (de Moortel et al., 2004). Other examples of parent wavelets include: Derivative of Gaussians (DoG), Paul, and Meyer wavelets. It is beyond the scope of this study to investigate the specifics of different wavelets; for further details refer to de Moortel et al. (2004); Gurley and Kareem (1999). The time-frequency representation of the CWT is presented in a scalogram (Figure 2.11). Visually the windowed CWT (scalogram) reveals a lot of information regarding the nature of non-stationary processes, such as the changes in frequency and amplitude content with time. The example in Figure 2.11 shows the CWT for the response of seismometer EAZ (east component) for the 2010 Darfield earthquake. The instrument responses are, and must be, removed prior to computing the CWT. The figure shows the seismometer data in the lower plot (with the instrument response removed), the centre plot shows the CWT scalogram using the Morlet wavelet function plotting frequency $(\mathrm{Hz})$ on the $\mathrm{y}$-axis and time (seconds) on $\mathrm{x}$-axis, the amplitude of the CWT analysis is shown by the colour bar on the right. Also shown in the far left plot is a Fourier spectrum of the same data aggregated over the whole signal. The benefit of the windowed CWT is made clearer when compared to a conventional spectrogram (refer to Appendix A), the CWT performs a much more sophisticated analysis generating a higher-resolution time-frequency representation of the signal without becoming saturated with high-amplitude frequencies (de Moortel et al., 2004). 


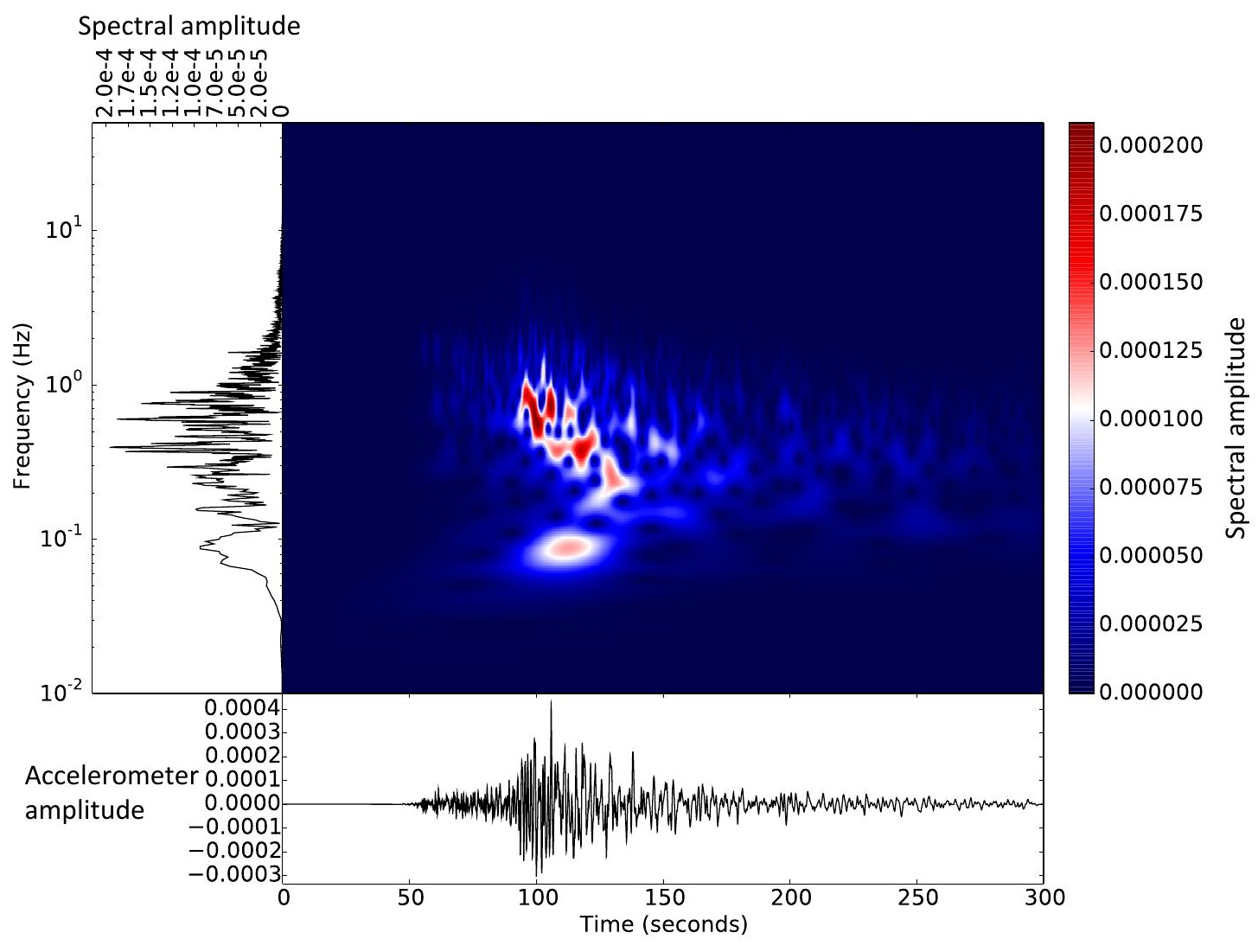

Figure 2.11: Example of the continuous wavelet transform, for the Darfield 2010 accelerometer data at EAZ (lower plot), the windowed CWT scalogram (centre), amplitude scale bar (right plot). Shown in the leftmost plot is a Fourier transform of the signal. Site responses have been removed. A time-step of 0.02 , a scaling factor of 0.05 and a wavelet function parameter of 8 are used consistently for all CWT scalograms 


\section{Chapter 3}

\section{Results}

\subsection{Hydrological responses to regional seismicity}

Initial analysis of the large hydrological dataset identified 21 piezometers reflecting groundwater aquifers exhibiting distinctive responses to earthquake shaking. Additionally, $12 \mathrm{~V}$-notch weirs, with at least one located in every landslide area, were found to record elevated discharge events in response to the same regional earthquakes. This chapter first documents and quantifies the various earthquake-induced responses in piezometer and V-notch weir data, and then analyses the earthquakes inducing the observed hydrological responses.

The earthquake-induced hydrological responses observed in the Nine Mile Creek (NMD and NMU), Clyde (CLY), and No. 5 Slide areas, are shown as examples in Figures 3.1, 3.2 and 3.3 (Other groundwater data are provided in Appendix B). In these figures raw groundwater and discharge data are shown, although weighted means are used to aid clarity where noise is prominent (e.g., DL1330a, Figure 3.1 third graph, and DL1331a Figure 3.2 bottom graph). Earthquakes are labelled and plotted with bars that correspond to earthquake magnitude, as explained in Section 2.1.2. 


\section{Magnitude $\left(\mathrm{M}_{\mathrm{w}}\right)$}

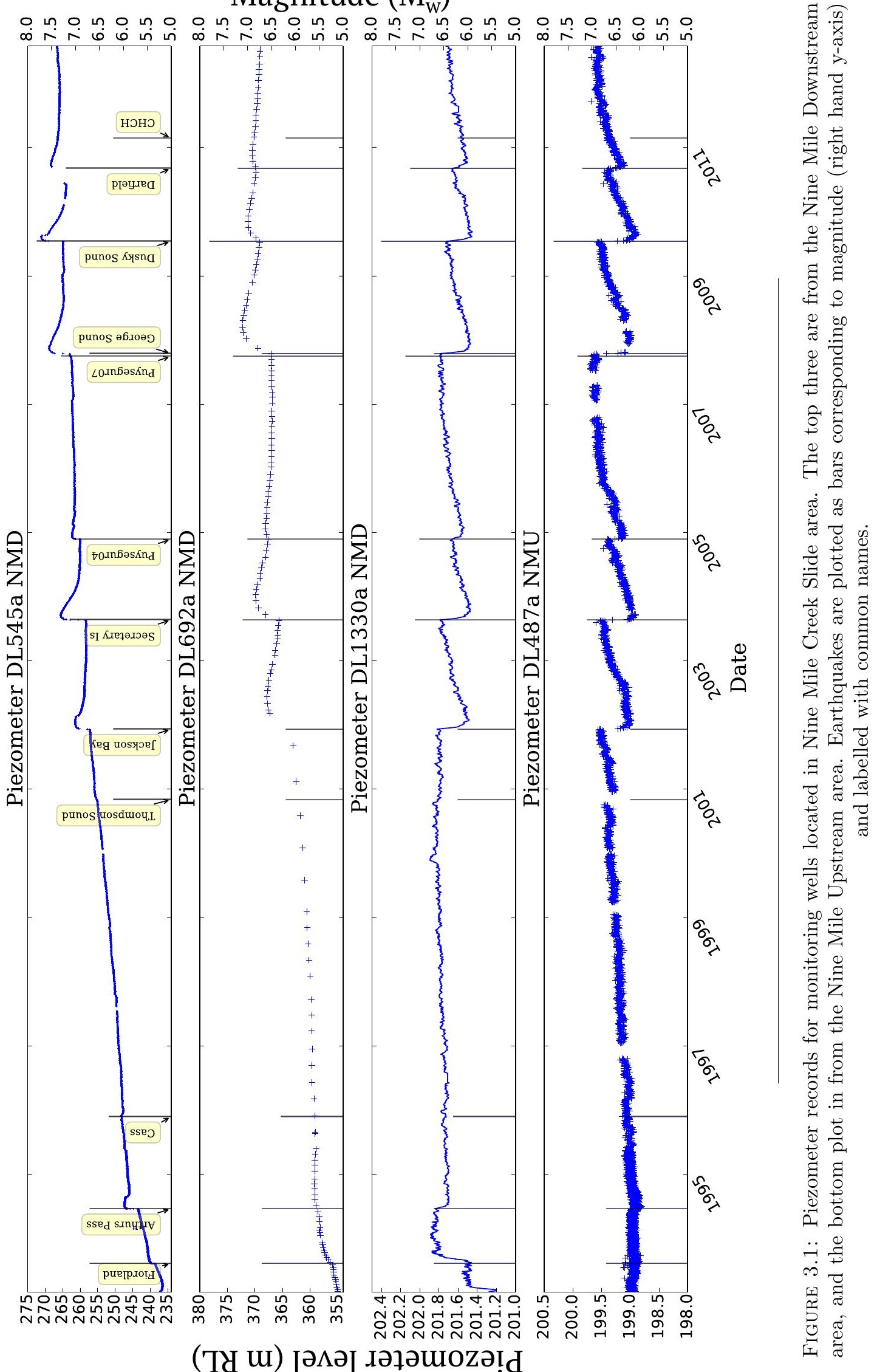




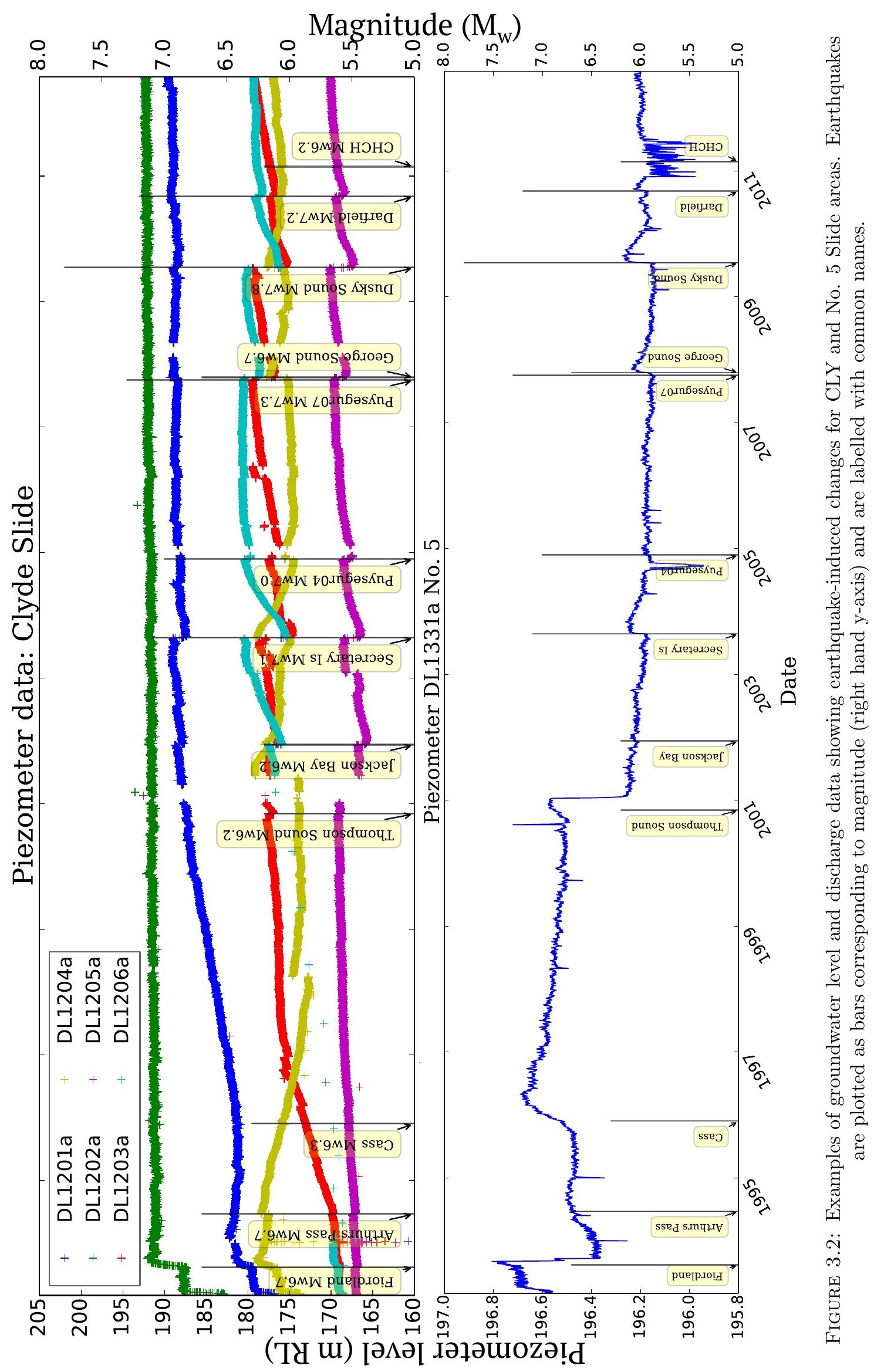




\section{Magnitude $\left(\mathrm{M}_{\mathrm{w}}\right)$}

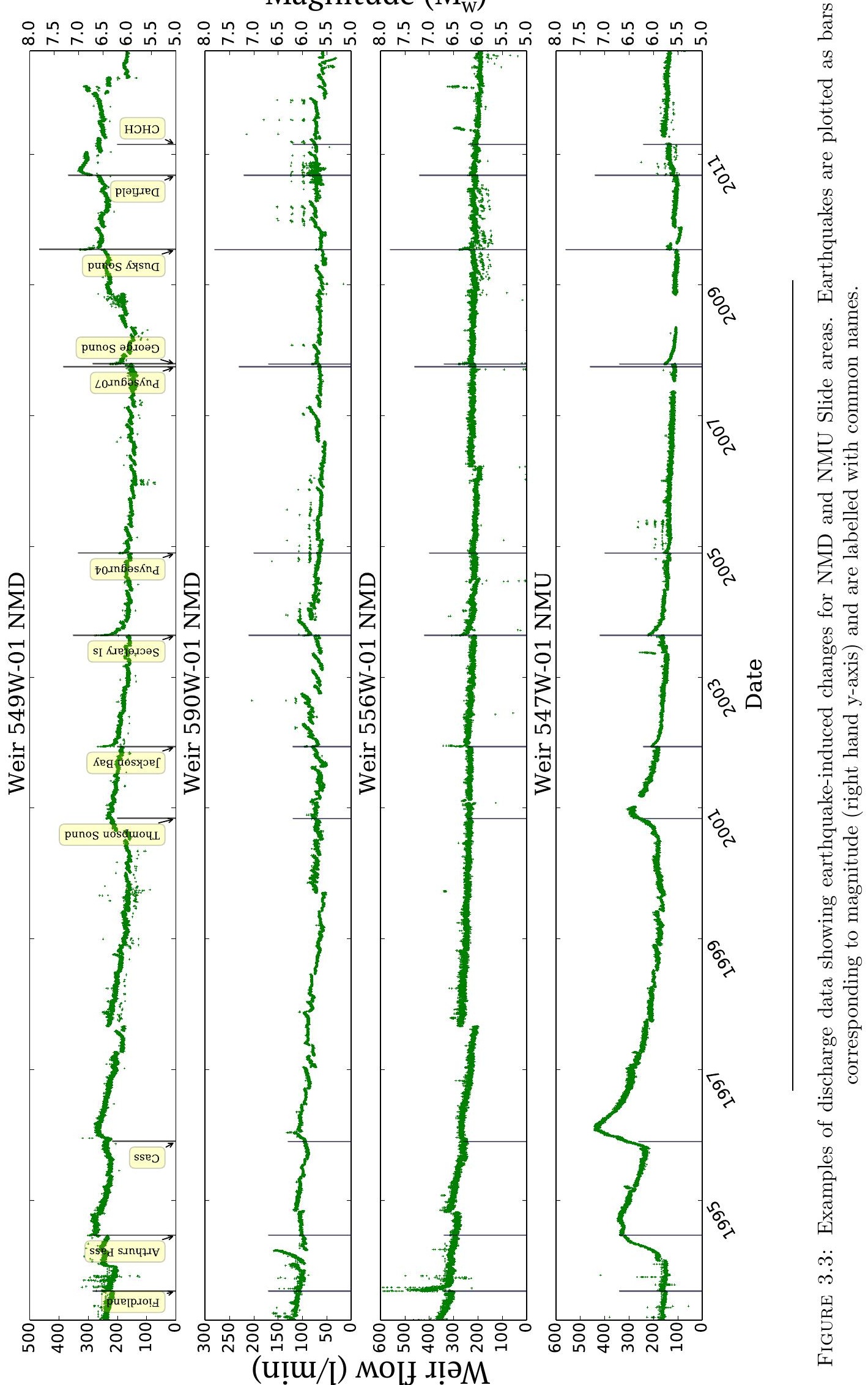




\subsubsection{Amplitude of hydrologic fluctuations}

Amplitudes of the identified hydrological responses are summarised in Table 3.2. Within each monitoring site the polarities of hydrological responses were systematic: always positive or always negative. The largest amplitudes of groundwater level changes and increases in weir flow rate were induced by the Secretary Island (2003), Dusky Sound (2009), and George Sound (2007) earthquakes, and smaller, more subdued groundwater level changes and increases in weir flow rate by the Arthurs Pass (1994), Puysegur (2004), Fiordland (1993), Puysegur (2007) and Thompson Sound (2000) earthquakes. The Jackson Bay (2001) and Darfield (2010) earthquakes generally produced a response somewhere in-between the other two groups. Variations to this pattern do exist in a few monitoring sites: for instance, weir 556W0-1 (Figure 3.3), in response to the 1993 Fiordland earthquake showed a $171 \%$ increase in discharge rate, whereas the Secretary Island, George Sound and Dusky earthquakes each induced a $30-40 \%$ increase. The discharge event induced by the 1993 Fiordland earthquake in weir 556W-01 lacks the consistent character of hydrologic responses induced by other earthquakes in 556W-01. The increase in weir flow rate induced by the 1993 Fiordland earthquake resembles that corresponding to a sudden release of perched groundwater, as observed during initial groundwater drainage (Figure 2.2). The 2001 Thompson Sound and 2007 Puysegur earthquakes are excluded from the hydrological results, due to not having produced hydrologic responses discernible in many records, and therefore, not correlatable between sites. However, they were observed to induce hydrological responses, therefore are also discussed in the analysis of earthquake parameters (Section 3.2).

The amplitudes of hydrologic responses (fluctuation) varied between individual sites for both piezometers and weirs. The largest groundwater level change of $6.94 \mathrm{~m}$ was recorded by monitoring well DL545a (Nine Mile Downstream area NMD) in response to the 2003 Secretary Island earthquake (Figure 3.1), and the smallest distinguishable groundwater level change of $0.05 \mathrm{~m}$ was recorded by DL1331a (No. 5 Slide area) in response to the 2004 Puysegur earthquake (Figure 3.2). Within each site, the amplitudes of the earthquake-induced hydrological responses were consistently of the same scale, for instance, in DL545a earthquake-induced fluctuations in groundwater level ranged from 1.29 to $6.94 \mathrm{~m}$, with the mean around $4.39 \mathrm{~m}$. In comparison, earthquake-induced groundwater levels in DL1331a fluctuated on a centimetre scale, ranging from 0.05 to $0.15 \mathrm{~m}$ with a mean of $0.09 \mathrm{~m}$, approximately 50 times smaller than that of DL545a.

Baseflow varies in different tunnels, and the earthquake-stimulated peak flow rates and total discharge volumes vary accordingly. This is predominantly due to weirs being located at the exits of tunnels of varying lengths, orientations, extent of underground drainage (probe) holes drilled, nature of subsurface groundwater flow, and groundwater 
availability (Smith et al., 1990). Longer tunnels penetrate further, and therefore have potential to drain more groundwater from the hillside: for example, the tunnel surface area of DR590 is $\approx 1.1 \times 10^{4} \mathrm{~m}^{2}$ and the baseflow recorded by weir $590 \mathrm{~W}-01$ is $\approx 87$ $1 /$ min, whereas, the surface area of DR556 $1.8 \times 10^{4} \mathrm{~m}^{2}$ and the baseflow at weir $556 \mathrm{~W}-01$ is $\approx 261 \mathrm{l} / \mathrm{min}$. Baseflow estimates determined during drier summer months are shown in Table 3.1 .

Volume calculations of earthquake-induced excess discharge provide an insight to the scale of the rock mass affected (assuming certain geological and hydrological criteria) but could only be confidently determined when data were not highly disturbed by other hydrological signals, such as rainfall and maintenance. Some drainage tunnels appeared less sensitive to rainfall events (e.g., weir 556W-01, Figure 3.3), exhibiting a delayed and subdued response, while others (e.g., 549W-01 and 547W-01, Figure 3.3) showed greater sensitivity. However, this does not appear to affect the observed sensitivity to earthquake shaking. Excess discharge volumes are only presented for Nine Mile Downstream sites (Table 3.2).

TABLE 3.1: Examples of weirs recording different baseflow discharge. Tunnel surface areas are approximates. Data used in calculations were sourced from Beetham and Fergusson (1990a,b); Jennings et al. (1991). NB: baseflow from weirs in BRE are not shown.

\begin{tabular}{|c|c|c|c|c|c|}
\hline $\begin{array}{c}\text { Monitoring } \\
\text { area }\end{array}$ & Tunnel & Weir & $\begin{array}{c}\text { Tunnel } \\
\text { surface area }\left(\mathbf{m}^{2}\right)\end{array}$ & $\begin{array}{c}\text { Slide } \\
\text { area (ha) }\end{array}$ & $\begin{array}{c}\text { Baseflow } \\
(1 / \mathrm{min})\end{array}$ \\
\hline CAI & DR580 & $580 \mathrm{~W}-01$ & $0.8 \times 10^{4}$ & 100 & 22 \\
\hline$\overline{\mathrm{NM}} \overline{\mathrm{D}}$ & $\overline{\mathrm{D}} \overline{\mathrm{R}} \overline{59}$ & $\overline{590} \overline{\mathrm{W}}-0 \overline{1}$ & $1 . \overline{1} \times 10^{4}$ & -- & $\overline{8} \overline{7}$ \\
\hline NMD & DR549 & $549 \mathrm{~W}-01$ & $1.4 \times 10^{4}$ & - & 214 \\
\hline NMD & DR556 & $556 \mathrm{~W}-01$ & $1.8 \times 10^{4}$ & - & 261 \\
\hline Total & & & $4.3 \times 10^{4}$ & 900 & 562 \\
\hline$\overline{\mathrm{NM}} \overline{\mathrm{U}}$ & $\overline{\mathrm{D}} \overline{\mathrm{R}} \overline{5} 4 \overline{7}$ & $54 \overline{7} \overline{\mathrm{W}}-0 \overline{1}$ & $2.9 \times 10^{4}$ & 300 & $1 \overline{8} \overline{3}$ \\
\hline$\overline{\mathrm{No}}-\overline{5}$ & $\overline{\mathrm{D}} \overline{\mathrm{R}} \overline{53} \overline{7}$ & $\overline{53} \overline{7} \overline{\mathrm{W}}-\overline{-01}$ & $1.1 \times \overline{1} 0^{4}$ & $\overline{1} 2 \overline{6}$ & $\overline{17} \overline{5}$ \\
\hline$\overline{\mathrm{JAC}}$ & $\overline{\mathrm{D}} \overline{\mathrm{R}} \overline{5} 4 \overline{1}$ & $54 \overline{1} \overline{\mathrm{W}}-0 \overline{1}$ & $0.4 \times 10^{4}$ & $\overline{2} \overline{3}$ & 40 \\
\hline$\overline{\mathrm{C}} \overline{\mathrm{LY}}$ & $\overline{\mathrm{D}} \overline{\mathrm{L}} \overline{5} \overline{5}$ & $\overline{55} \overline{5} \overline{\mathrm{W}}-\overline{0} \overline{1}$ & $1.3 \times \overline{1} 0^{4}$ & $\overline{1} 20$ & $\overline{12} \overline{8}$ \\
\hline
\end{tabular}




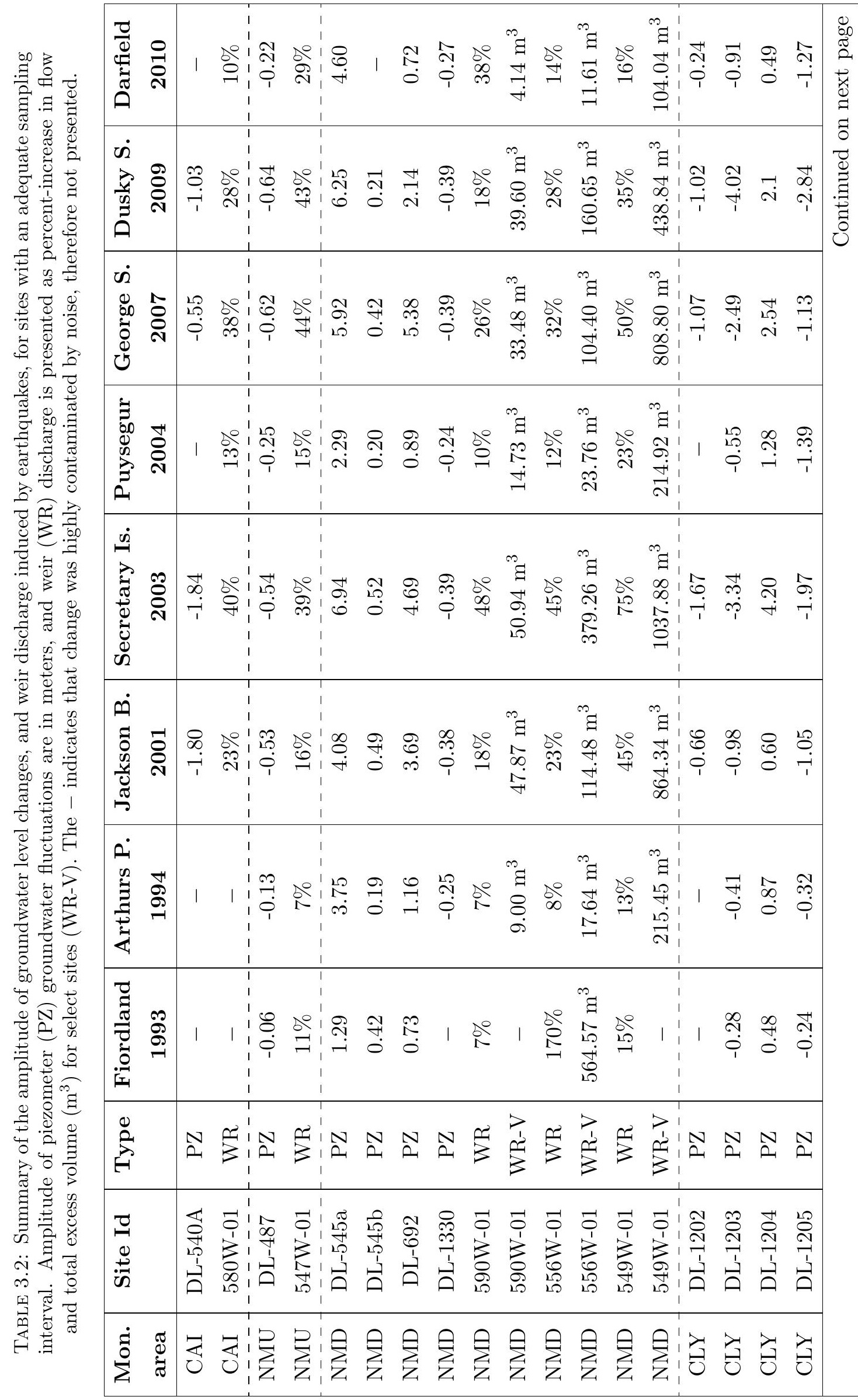


点

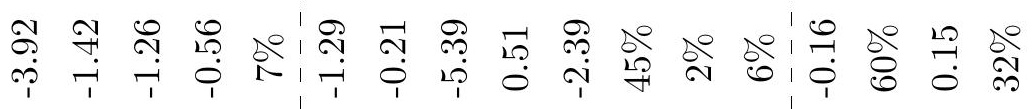

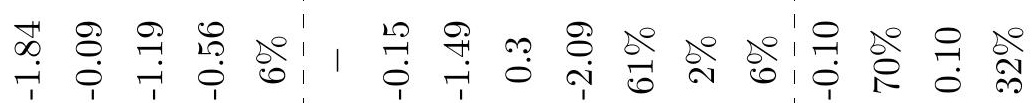

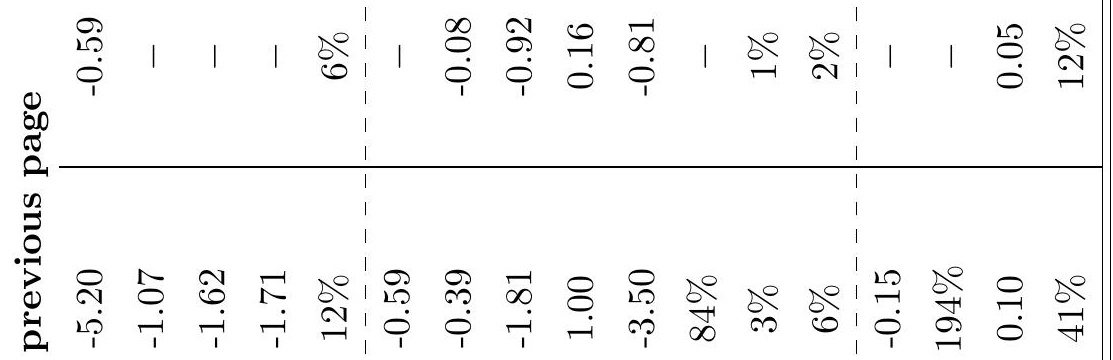

:

㟒

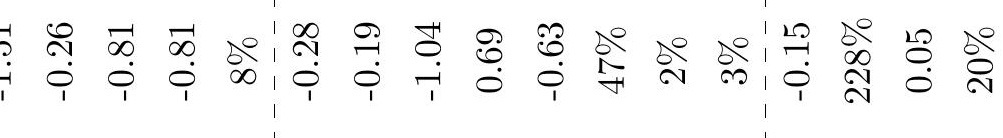

ก่

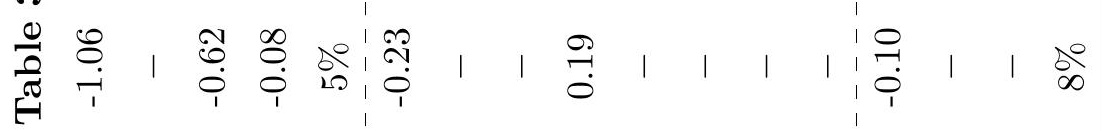

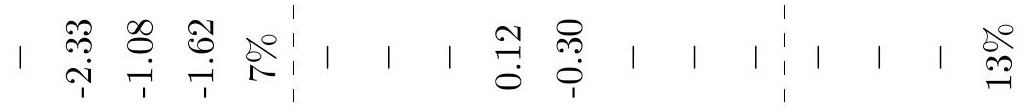

ลै ลิ ลิ ลิ

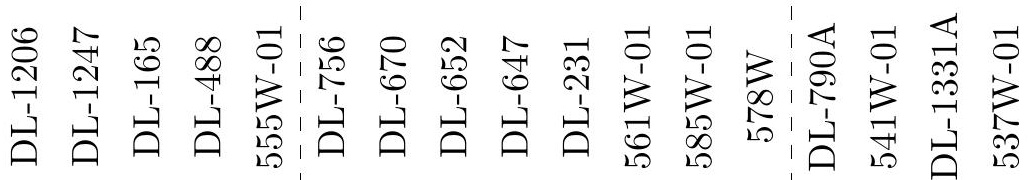

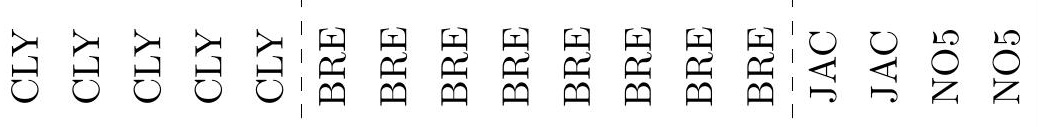




\subsubsection{Duration of hydrologic fluctuations}

\section{Piezometer data}

\section{Time to peak pressure change}

Piezometer data show the initiation of the groundwater fluctuations to have been nearcoseismic. It can only be stated as 'near' due to earthquakes occurring between sampling points. Consistency of groundwater levels were observed in the values before the earthquake, whereas post-earthquake groundwater levels were markedly different (e.g., Figure 3.1). Groundwater level data were extrapolated back to the timing of the earthquake, accounting for calculated earthquake travel-times. The time to peak pressure change ( $\Delta \mathrm{P}$-time) varied between monitoring sites, yet showed consistency at each site, for example the rise-times for DL545a, NMD were on the order of $2-3$ weeks following each earthquake whereas in DL1205a, CLY (Figure 3.2) were consistently around $3-5$ weeks. Within all monitoring sites, there was a delay to peak pressure change followed by a long, slow recovery period. Table 3.3 provides a summary of the time scales involved for identified groundwater level fluctuations.

\section{Recovery-time}

The amount of time taken for groundwater levels to recover to pre-stimulated levels also varied, but similarly showed a high degree of consistency between each site. A proportion of variation was attributed to where the end of the recovery periods were determined. In some wells recovery periods were masked when other hydrological signals become prominent (e.g., DL1330a Figure 3.1). The timescales of recovery were usually of the order of $0.7-1.2$ years, but in some instances lasted for $>3$ years: for example, the response in DL1330a to the 1994 Arthurs Pass $\mathrm{M}_{w} 6.7$ earthquake, Figure 3.1. In some monitoring wells (notably DL1330a NMD and DL487a NMU, Figure 3.1), the total recovery period never fully ended, and was truncated by the next earthquake. However, the inflection point was always achieved, which was the chosen point of recovery. Of note, the time of peak pressure change and recovery time of groundwater level changes showed little dependancy on the amplitude of change across all monitoring sites: that is, sites that fluctuated on a metre scale have timescales of change and recovery in close agreement to those of sites that changed on a centimetre scale. 
TABLE 3.3: Summary of the time to peak pressure change and recovery-time for earthquake-induced groundwater level changes (piezometer fluctuation), polarity of response, and scale of amplitude of response. Sampling interval (Interval ${ }_{s}$ ) is presented in hours with a range shown where the sampling interval changes at a site.

\begin{tabular}{|c|c|c|c|c|c|}
\hline Piezometer & $\begin{array}{c}\text { Interval }_{s} \\
(\mathrm{hr})\end{array}$ & Polarity & $\begin{array}{l}\text { Scale of } \\
\text { response }\end{array}$ & $\begin{array}{l}\Delta \text { P-time } \\
\text { (weeks) }\end{array}$ & $\begin{array}{c}\text { Recovery-time } \\
\text { (years) }\end{array}$ \\
\hline BRE & & & & & \\
\hline DL652a & $1-3$ & $-\mathrm{ve}$ & $\mathrm{m}$ & $0.5-1.5$ & $0.5-0.7$ \\
\hline DL231a & $6-100+$ & $-\mathrm{ve}$ & $\mathrm{m}$ & $0.5-1.5$ & $0.6-0.8$ \\
\hline DL670a & $1-3$ & $-\mathrm{ve}$ & $\mathrm{cm}$ & $0.5-1.5$ & $0.5-0.7$ \\
\hline DL647a & $24-100$ & $+\mathrm{ve}$ & $\mathrm{cm}$ & $4.0-8.0$ & $0.7-1.0$ \\
\hline DL756a & $1-3$ & $-\mathrm{ve}$ & $\mathrm{cm}$ & $1.0-2.0$ & $0.3-0.7$ \\
\hline${ }^{-} \overline{\mathbf{C}} \overline{\mathbf{A}} \overline{\mathbf{I}}{ }^{-}$ & & & & & \\
\hline DL540a & $1-100$ & - ve & $\underline{m}$ & $10.0-15.0$ & $0.8-1.5$ \\
\hline${ }^{-} \overline{\mathrm{NM}} \overline{\mathrm{M}} \overline{\mathrm{D}}^{-}$ & & & & & \\
\hline DL545a & $1-24$ & $+\mathrm{ve}$ & $\mathrm{m}$ & $2.0-3.0$ & $0.7-1.0$ \\
\hline DL545b & $1-24$ & $+\mathrm{ve}$ & $\mathrm{cm}$ & $2.0-3.0$ & $0.7-1.0$ \\
\hline DL1330a & $1-3$ & $-\mathrm{ve}$ & $\mathrm{cm}$ & $8.0-9.0$ & $0.7-1.2$ \\
\hline DL692a & $1-100+$ & $+\mathrm{ve}$ & $\mathrm{m}$ & $10.0-17.0$ & $0.7-1.2$ \\
\hline$\overline{\mathbf{N}} \overline{\mathbf{M}} \overline{\mathbf{U}}{ }^{-}$ & & & & & \\
\hline DL487a & $6-24$ & - ve & $\mathrm{cm}$ & 6.0-7.0 & $0.7-1.2$ \\
\hline$\overline{\mathrm{No}} \overline{5} \overline{5}^{-}$ & & & & & \\
\hline DL1331a & $1-3$ & + ve & $\mathrm{cm}$ & $3.0-5.0$ & $0.7-1.2$ \\
\hline$\overline{\mathbf{J A C}}$ & & & & & \\
\hline DL790a & $0.16-3$ & $-\mathrm{ve}$ & $\mathrm{cm}$ & $0.5-1.5$ & $0.3-0.7$ \\
\hline$-\overline{C L Y} \bar{Y}^{-}$ & & & & & \\
\hline DL1202a & $1-3$ & $-\mathrm{ve}$ & $\mathrm{cm}$ & $3.0-5.0$ & $0.7-1.2$ \\
\hline DL1203a & $1-3$ & $-\mathrm{ve}$ & $\mathrm{m}$ & $3.0-5.0$ & $0.7-1.2$ \\
\hline DL1204a & $1-3$ & $+\mathrm{ve}$ & $\mathrm{m}$ & $0.5-1.5$ & $0.7-1.2$ \\
\hline DL1205a & $1-3$ & $-\mathrm{ve}$ & $\mathrm{m}$ & $3.0-5.0$ & $0.7-1.2$ \\
\hline DL1206a & 1-100 & $-\mathrm{ve}$ & $\mathrm{m}$ & $0.5-1.5$ & $0.7-1.2$ \\
\hline DL488a & $48-100+$ & $-\mathrm{ve}$ & $\mathrm{cm}$ & $2.0-3.0$ & $0.7-1.2$ \\
\hline DL165a & $48-100+$ & $-\mathrm{ve}$ & $\mathrm{m}$ & $2.0-3.0$ & $0.8-1.5$ \\
\hline DL1247a & $48-100+$ & $-\mathrm{ve}$ & $\mathrm{cm}$ & $2.0-3.0$ & $0.7-1.2-$ \\
\hline
\end{tabular}

\section{Weir data}

\section{Time to peak flow rate}

The majority of weir data were sampled at 1 hour intervals for the first few years of monitoring, then reduced to 3 hourly intervals. Much like groundwater level responses, the initiation of earthquake-stimulated increases in discharge were near-coseismic throughout the slide areas. The discharge responses showed an abrupt rise to peak flow rate, occurring in the first or second sampling interval $(0-6$ hours). The rise to peak flows were on a much shorter timescale than the groundwater level changes. 


\section{Post earthquake recession}

The time taken for earthquake-induced discharge events to return to pre-stimulated flowrates, also varied consistently throughout the majority of monitoring sites, and typically ranged from $10^{1}-10^{2}$ hours (weeks-month). Build-up of carbonate and sediment on and behind weirs must be taken into account when determining the point of total-recovery from earthquake-induced flow. The flow-rate may not return to the pre-stimulated rate, due to an excess volume of debris generating an elevated, false reading. The point of recovery was again determined by the inflection point, in order to overcome this effect. The majority of earthquake-induced weir flow data are presented as percentrises, rather than total volume calculated. Comparing the slope of the discharge rate before an earthquake, to the slope after earthquake-stimulated discharge had reduced, provided a means to investigate longer-term or potentially permanent changes to the hydrologic conductivity and permeability of the rock mass (e.g. Wang et al. 2004). There appeared to be no significant deviation in the generalised slope of the discharge rate once earthquake-induced flow had diminished, suggesting that any potential changes to the hydraulic properties governing the hydrologic responses were only temporary, and operating on the time scales of the observed responses. 


\subsubsection{Distribution of hydrological responses}

As outlined in Section 3.1.1 the polarities of groundwater fluctuations observed in monitoring wells were consistently positive or negative at individual sites. Discharge responses to earthquakes always showed an increase in flow rate. Figure 3.4 shows the locations of monitoring wells and weirs that recorded these fluctuations. In Figure 3.4, circles represent the locations of monitoring boreholes, and squares the locations of tunnel V-notch weirs and flow buckets. Symbols are colour coded for sites showing negative fluctuations in blue and positive fluctuations in red. The extent of the tunnels is indicated by the closely spaced black squares. Other monitoring wells are shown by smaller black/grey circles. On the larger landslides, such as Nine Mile Creek (NMU, NMD), Brewery Creek (BRE), and Clyde (CLY) slides (refer to Figure 3.4) the majority of monitoring wells are located in the lower slide sections, due to the greater importance of monitoring movement in these areas. Smaller slides like Cairnmuir, Jackson Creek, and No. 5 slides, also have monitoring wells in upslope areas: for example, Cairnmuir Slide has wells located in the slide head region.

No clear pattern emerges in the polarities of groundwater level change with respect to the site area, elevation, or landslide. Within the lower sections of the landslides, wells in comparable locations recorded both positive or negative groundwater level changes. There does appear to be a general relationship to tunnel proximity, although this is not exact (e.g. Clyde Slide, Figure 3.4). Wells further away from tunnels showed positive fluctuations and, conversely, wells close to tunnels showed negative fluctuations. As boreholes were drilled to different depths and monitor groundwater from different subsurface zones, it is crucial to compare the landslide structure in conjunction with tunnel proximity (summarised in Table 2.2). Subsurface zones were identified by means of drilling logs and borehole-depth versus water-depth plots (e.g., Jennings et al. 1991), by methods outlined in Clyde Dam development reports and related publications (e.g., Beetham and Fergusson 1990a,b; Macfarlane et al. 1991). Earthquake-induced groundwater gains were common in wells that monitor groundwater from sub-basal slide regions and are located $\approx 50 \mathrm{~m}$ or greater away from drainage tunnels. Wells that observed earthquakeinduced groundwater losses are always located close to drainage tunnels $(\leq 50 \mathrm{~m})$ and commonly tap landslide internal groundwater. 

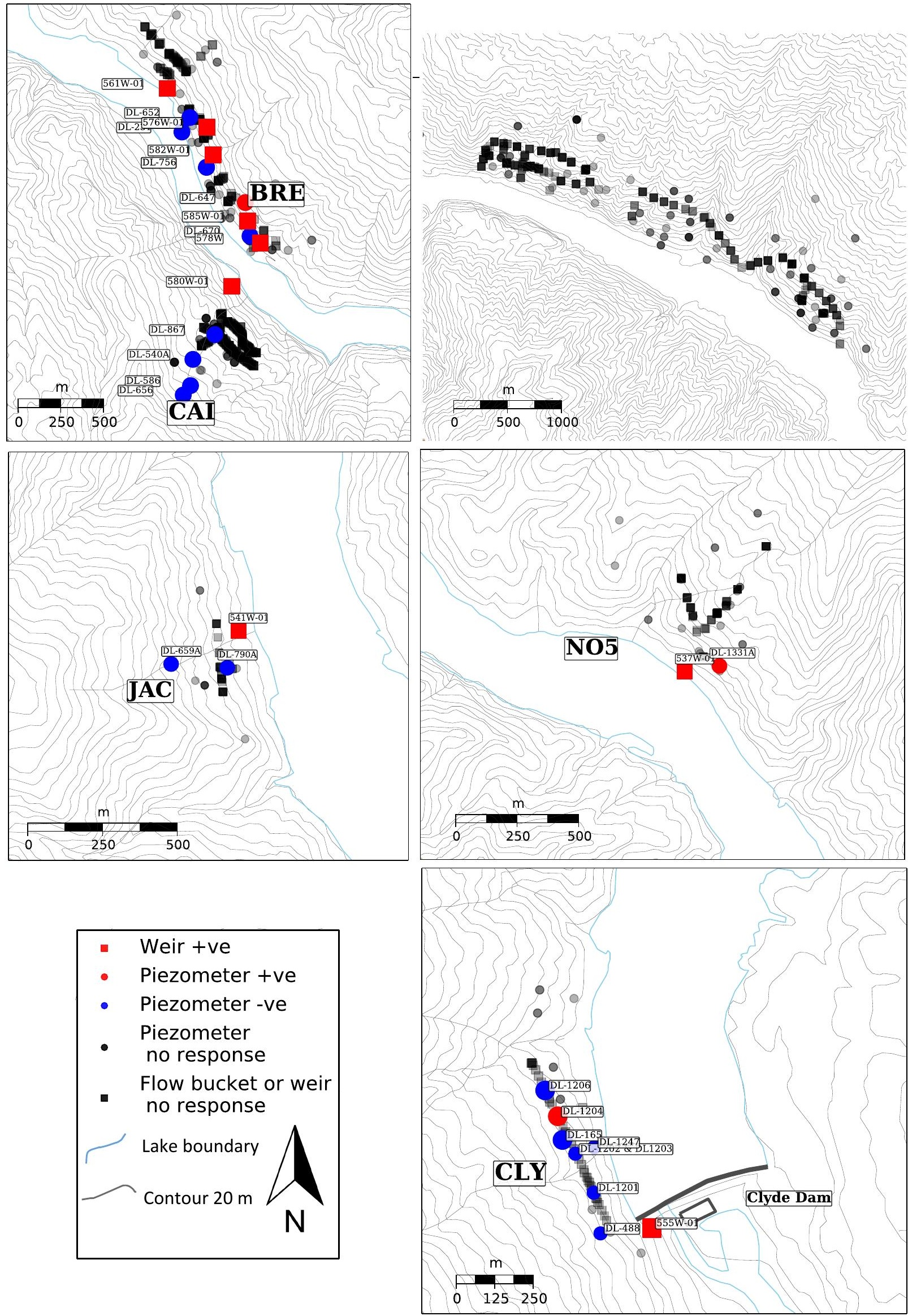

FiguRE 3.4: Maps showing the geographic distribution of observed earthquake-induced groundwater level changes and discharge increases, for monitoring areas in Cromwell Gorge. From the top left: BRE, NMU and NMD, JAC, NO. 5, and CLY. Blue markers reflect negative and red markers positive piezometer and weir responses, black/grey: no response. Marker sizes are scaled to the amplitude of response. Lake level is at 195 $\mathrm{mRL}$ and contours are at $20 \mathrm{~m}$ intervals. Location information for monitoring areas are shown in Figure 1.9 (Section 1.9) 


\subsubsection{Analysis of cycles within data}

Cyclic signals were observed in many records but due to sampling inconsistencies and unfavourable length of sampling intervals (Table 3.3), analysis has proven difficult. Two records that have strong oscillatory signals with 3-hourly sampling intervals are piezometer record DL1330a from the Nine Mile Downstream Slide area, and weir 537W-01 located in drainage tunnel DR537, No. 5 Creek Slide. Monitoring wells have long been reported to fluctuate in response to earth tides (e.g., Beresnev and Johnson (1994); Wang and Manga (2010); Elkhoury et al. (2006)), but springs and mountain streams less so. Tunnel weir data recorded throughout Cromwell Gorge tunnel systems may be unique. In other tunnels, specialised instrumentation has observed earth tide-induced changes in strain (Agnew, 1986). Drainage tunnel systems may behave differently from natural systems, and some ambiguity remains in the exact cause of cyclic oscillation. The oscillations in flow-rate recorded by weir $537 \mathrm{~W}-01$ No. 5 Slide have a remarkable character, and for time spans where background flow was low, are nearly free of other hydrological signals.

\section{Monitoring well DL1330a}

The water level data recorded by DL1330a contains clear cycles at periods of c. 0.50, 0.52, 0.99, 1.07 days, shown in Figure 2.5 (Section 2.2). Other cycles were present but are not prominent and only the strongest were focused on for analysis. The peaks in the periodogram (Figure 2.5) are interpreted to be mixed affects of diurnal tide groups O1, K1, P1, semi-diurnal M2 and S2 (Table 2.1), and barometric pressure. However, in order to clarify the O1, K1, P1 and S2 cycles, the effects of daily barometric fluctuations must be removed. The functionality of Baytap $08^{\mathrm{TM}}$ is used to compute the barometric efficiency, and remove its effect on the groundwater levels. The barometric efficiency appeared relatively large in DL1330a, and the program appears to have removed a large proportion of effects (for which a test is performed, see Appendix C), but there are some variations. For this reason, and the large sampling intervals the O1 and M2 tides appeared most appropriate for analysis.

The analysis conducted to date shows the degree of general variation in phase is large, and abnormal changes to phase lags from tidal-induced fluctuations (O1, M2, or other) after any earthquakes are not clear. Logical explanations include: the natural variations in phase are large within the data and are caused by other hydrologic and/or hydraulic effects, the parameters chosen in the analysis are insufficient for the large sampling interval, and the degree of missing data is greater than anticipated. 


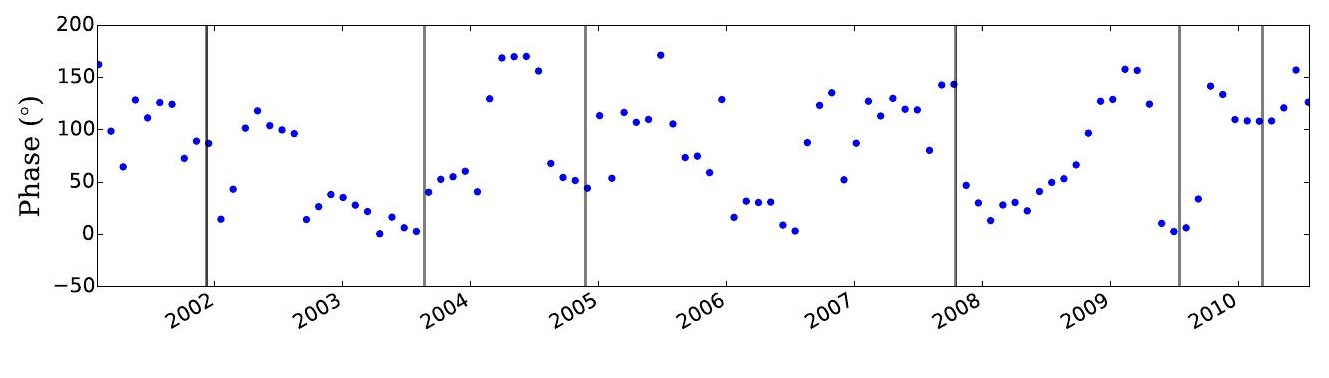

Figure 3.5: Phase changes (M2) in DL1330a, the timing of earthquakes are shown by grey bars.

\section{Discharge past weir 537W-01}

Cycles present in the weir data differ from those found in monitoring wells, with the most prominent cycles only at periods of 12 and 24 hours. Investigation into the cause of these cycles lead to comparison with barometer data (Figure 3.6, upper plot), which shows negative correlation as expected, but the match is not absolute and many inconsistencies can be observed. Moreover, there are discrepancies in the barometric efficiency such as larger pressure changes ( $2-5$ times that of the daily change) occurring over 5 10 day periods which had little influence on the flow rate in comparison to the daily cycles in discharge. Instead, the weir data show a higher degree of correlation with the local temperature record, shown in Figure 3.6 (lower plot). The cycles in flow rate were observed all year round (summer and winter), therefore are determined not to be associated with snow melt or freeze-thaw cycles, that might be restricted to the colder months. It is postulated that the cycles may be caused by thermal stresses, but it is not understood how such consistency is found throughout the seasons. Frequency analysis shows direct matches to S1 and S2 frequencies, leaving the question: if the system is sensitive to the effect of gravity from the sun, why is there an absence of lunar cycles? The M2, O1 and K1 (Moon+sun) cycles all have greater gravitational potential (Wilhelm et al., 1997). We suggest the signal is thermally driven, but ambiguity remains in the actual causal mechanism. Nevertheless, noticeable $2-3$ hour phase lags between temperature records and weir flow rate were present at times which, if dependent on the hydraulic properties of the rock mass, may become altered during an earthquake. Baytap0 $08^{\mathrm{TM}}$ can analyse data with respect to any specified sinusoids, thus enabling a test of this hypothesis.

Earthquakes that have induced substantial increases in flow prove difficult to analyse, due to the rapid increase in flow completely saturating any other signals. However, data from weir 537W-01 show the No. 5 Slide hydrologic system to only have responded with large (signal-saturating) increases in flow to earthquakes at certain times. For 

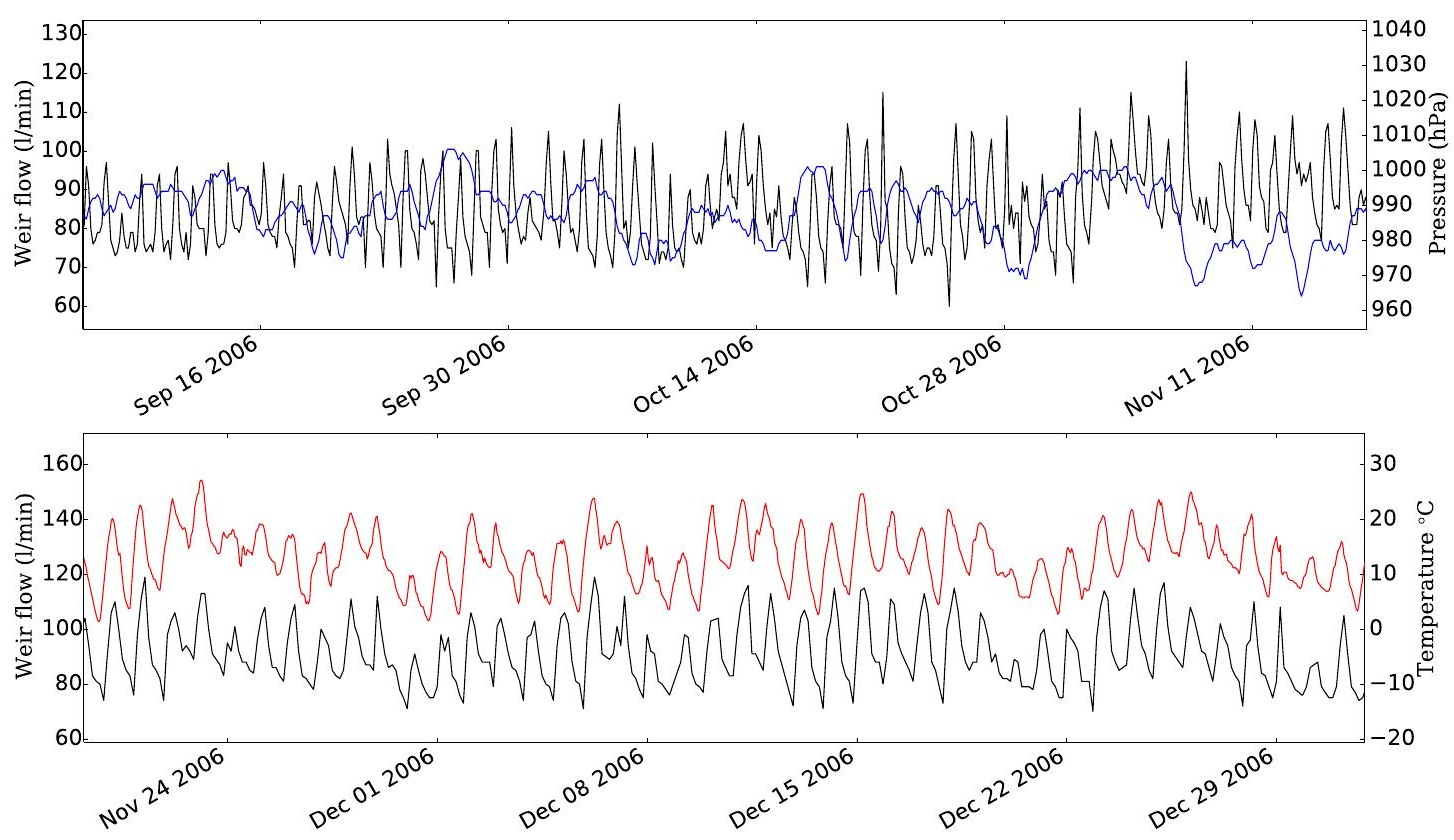

Figure 3.6: Flow rate data from weir 537W-01 (No. 5 Slide) are shown by the black line in both plots, the upper plot shows barometer data in blue (recorded at the site), and the lower plot shows local temperature in red (sourced from NIWA).

example, when flow was low, earthquakes did not appear to be coupled with a large increase in flow and the character of the daily cycles was maintained. The two most substantial alterations in phase lag detected are those associated with the 2003 Secretary Island and 2009 Dusky Sound earthquakes, illustrated in Figure 3.7. The RMS errors $(0.01-0.1)$ returned by Baytap $08^{\mathrm{TM}}$ suggest these are real and not artefacts of the calculations. The figure shows the measured phase lags between the discharge data and the theoretical sinusoid, with earthquakes shown by grey bars. The upper plot shows a substantial, rapid decrease in phase lag following the 2003 Secretary Island earthquake, that recovers approximately over a week. The data are shown for a short time period, and are interpreted to show no permanent, or longer lasting hydraulic changes. The phase lag appears to have a natural degree of variation within the amplitude of change, and thus, what appears only as a partial recovery from the rapid onset of earthquakeinduced phase lag reduction, is back to well within the natural variation in phase.

The data for the Dusky Sound earthquake are shown during the onset of winter, and there are possibilities that increases in phase lag (e.g. early June and mid July) were influenced by snow fall. Therefore, the rapid decrease in phase lag during the 2009 Dusky earthquake may be a response to snow melt, although this is unlikely during mid July in Central Otago. The recovery period appears to be prolonged, although the data are within the natural degree of variation, and not unusual. 

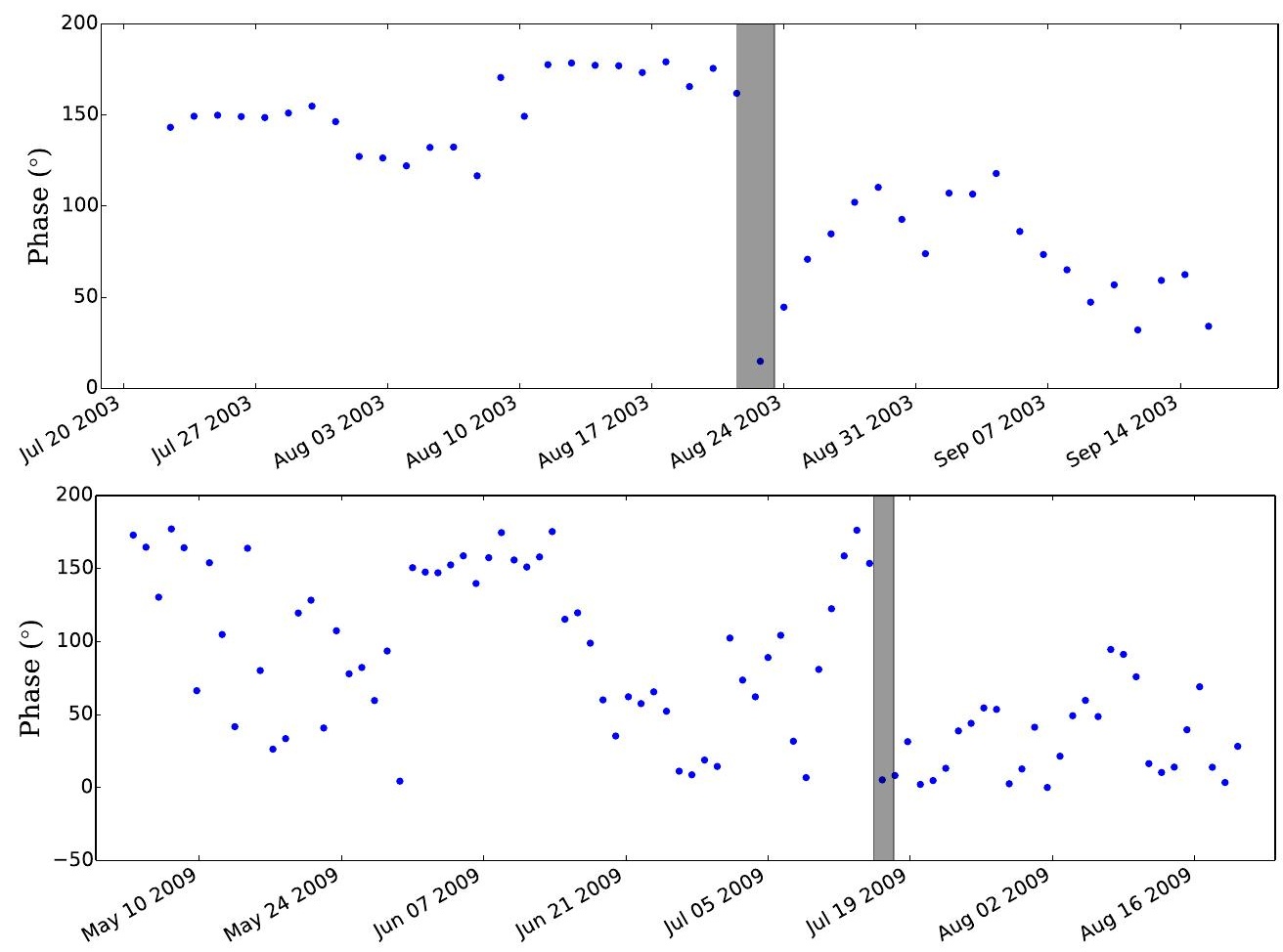

Figure 3.7: Results from analysis using Baytap08 $8^{\mathrm{TM}}$ for the phase in cyclic flow past weir 537W-01, No. 5 Slide in comparison to a 24 hour (period) sinusoid, for the 2003 Secretary Island and 2009 Dusky Sound earthquakes. The blue data points show the phase lag in degrees and the timing of the earthquakes is shown by the grey bars (differences in the width of the bars is an artefact of the figure).

A decrease in phase lag is interpreted as an increase in hydraulic conductivity or permeability (Elkhoury et al., 2006). An increase in these hydraulic properties may enable flow from the rock mass to be quicker, therefore reducing the phase lag time. There were few observed changes in phase amplitude outside of the natural variation, which suggests the volume of available water is limited on short timescales (weekly) and the storativity of the system is large, or the data analysis methods are insufficient. Due to lack of consistent results and time constraints of this project, the analysis of tidal and/or other cyclic signals were not pursued any further. A more substantial analysis would require interpolating and resampling data, but was deemed beyond the scope of this study.

\subsubsection{Characteristic groundwater response in hydrological data}

Piezometer and weir data showed high degrees of consistency between different monitoring sites, for the relative amplitudes of groundwater level changes, weir flow rate increases, time to peak pressure changes and recovery times shown in Figures 3.8 and 3.9. 
The graphs in Figure 3.8 show groundwater level changes in metres and weir flow rate changes as a percent increase for representative sites located in different landslides. It is shown that different sites consistently operated within different scales of response, some changing on a centimetre-scale and others on a metre-scale. The effect of this is removed by normalising the amplitude of each site to a maximum of 1 (for the eight earthquakes shown). Consistent trends emerge with respect to which earthquakes induce larger responses in piezometer data and weir data (further shown by Figure 3.9). The lower right graph in Figure 3.8 compares the absolute values for amplitudes of groundwater level changes and weir flow increases by plotting one against the other. Various combinations are shown, and there is general agreement between weir and piezometer data. However, greater scatter is found when comparing piezometer sites that exhibit metre-scale changes. The lower left plot in Figure 3.8 shows the time to peak pressure change and recovery time for monitoring sites from the Nine Mile Downstream slide. The graph shows two proportional reductions in time to peak pressure change and recovery time for two of the earthquakes ( 4 and 7, refer to Table 3.4) that produced some of the larger hydrological changes. Earthquakes 4 and 7 correspond to the 2003 Secretary Island and 2009 Dusky Sound earthquakes. Figure 3.8 shows the 2003 Secretary Island and 2009 Dusky Sound earthquakes producing consistently larger piezometer level changes, yet have relatively shorter time to peak pressure change and recovery time. 

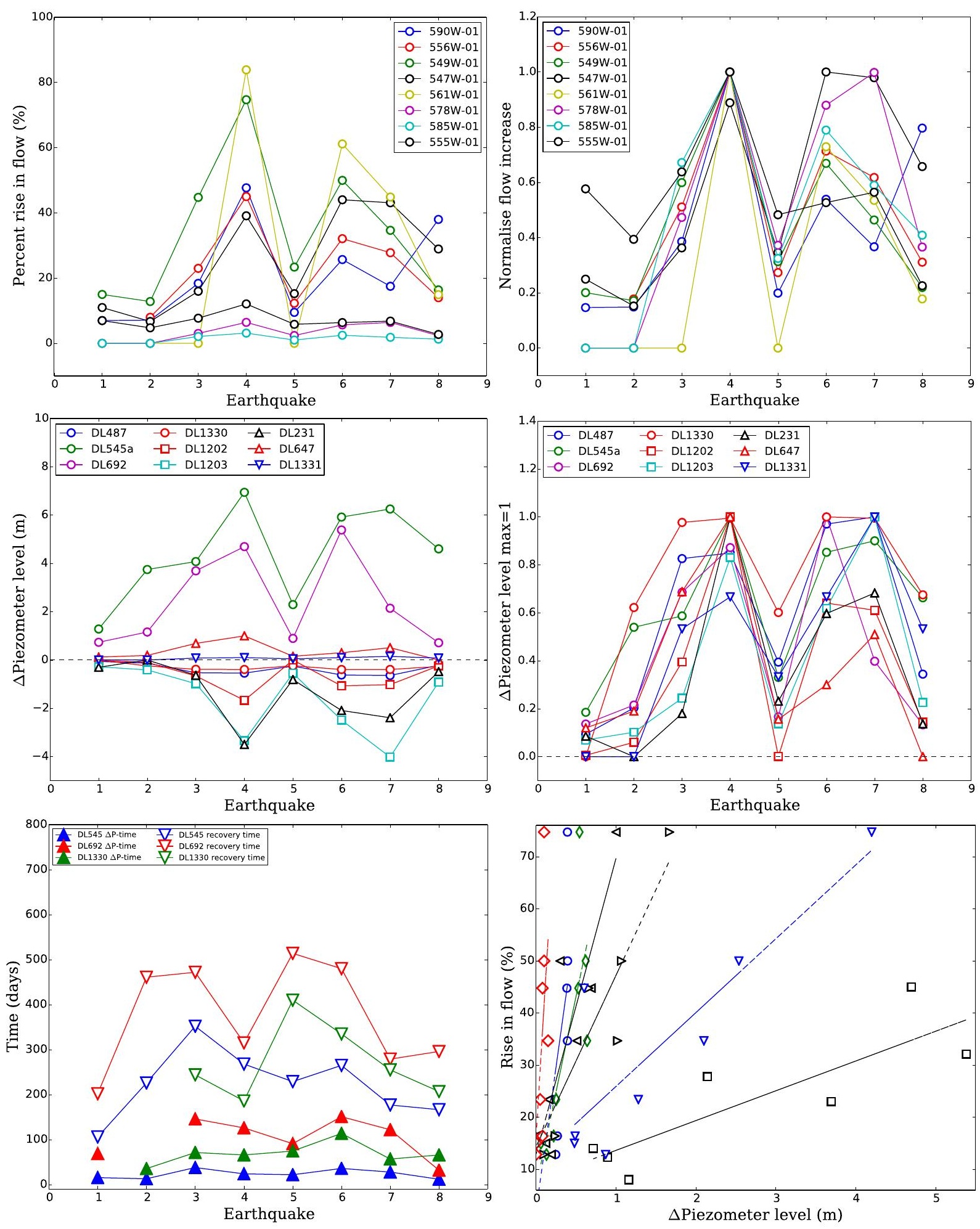

Figure 3.8: Top left graph shows the magnitude of the rise in weir flow as a percent for earthquakes inducing a hydrological response in chronological order (1-8 as shown in Table 3.4), top right graph shows the weir data normalised to max $=1$. The centre left graph shows piezometer level changes plotted against the earthquakes, the centre right graph shows the piezometer level changes normalised to $\max =1$. The lower left graph plots the time to peak pressure change ( $\Delta$-P-time) and the recovery time for the piezometers in NMD in chronological order. The lower right graph plots piezometer level changes against the magnitude of weir flow increase as a percent for selected combinations. The figure illustrates the consistent character of hydrologic changes between different monitoring sites shown in Figure 3.4. 


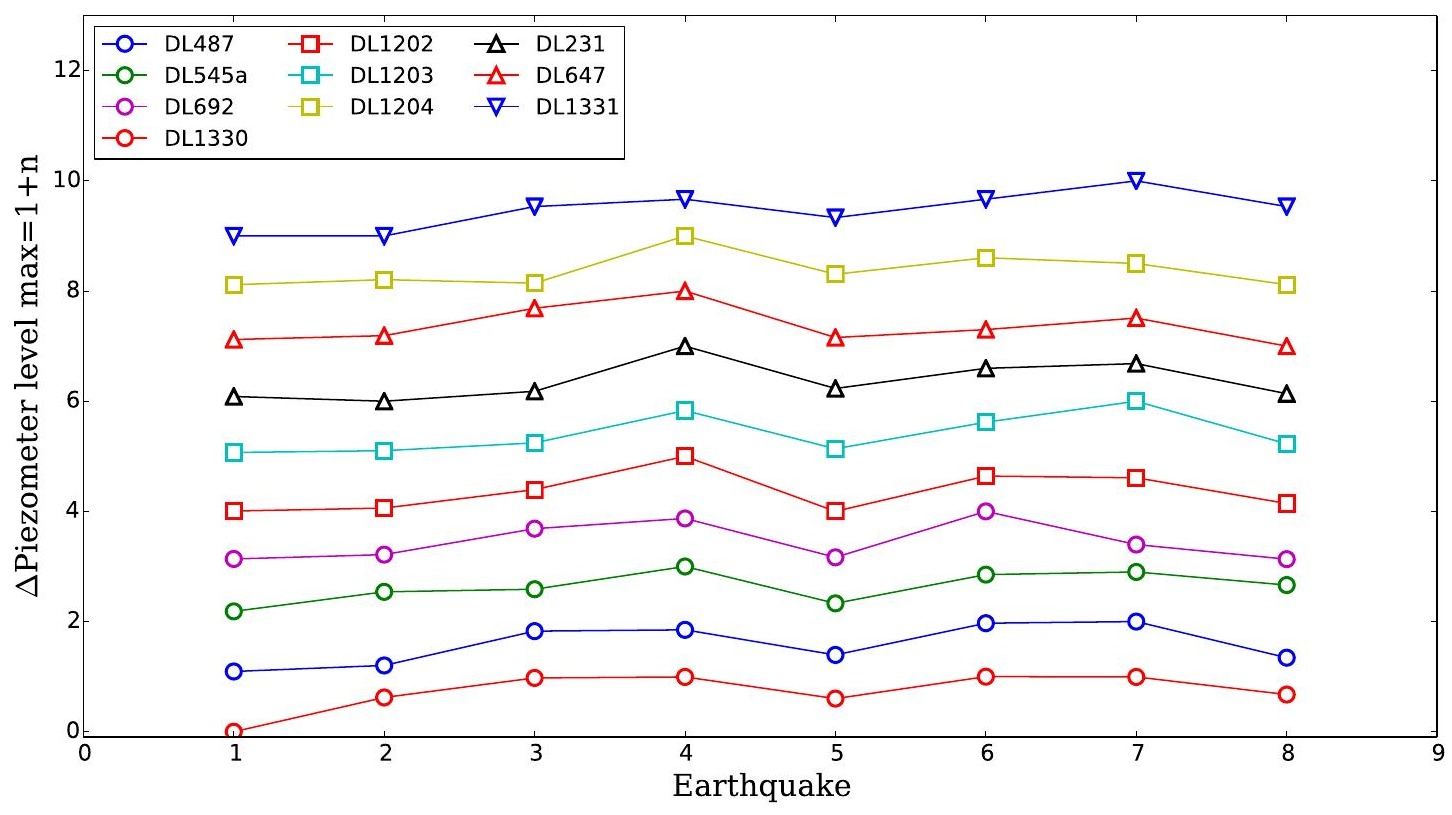

Figure 3.9: The graph shows the amplitude of groundwater level changes for different monitoring wells for earthquakes in chronological order (1-8 as shown in Table 3.4), that are representative of the overall trends in the amplitude of hydrological responses. The amplitudes are scaled for each site to $\max =1$ and plotted as $\max =1+n$ where $n$ is the site. The figure further illustrates the consistent character of hydrologic changes between different monitoring sites shown in Figure 3.8.

Earthquake-induced groundwater fluctuations were extracted from surrounding data (i.e. other hydrological signals, Section 2.2), in order to compare the character of the fluctuations between different monitoring sites. A test was performed to aid comparison of groundwater level changes and to visualise the similarities between different monitoring sites, in which the extracted data were normalised, first in terms of polarity, then amplitude and duration. Certain site conditions, other hydrological signals, general noise, and measurement uncertainty have generated small variations within the tailing end of the recovery periods. To minimise these uncertainties, groundwater fluctuations were re-normalised by 'time to half recovery'. Plotting the results from this test (Figure 3.10), enables visualisation in the similarities of how groundwater levels at different sites change, and subsequently recover. Furthermore, the comparison reveals many of the responses are so similar in character, that it suggests very similar, if not the same, mechanisms were working. This is expected, due to the congruent nature of the schist landslides throughout the gorge. 

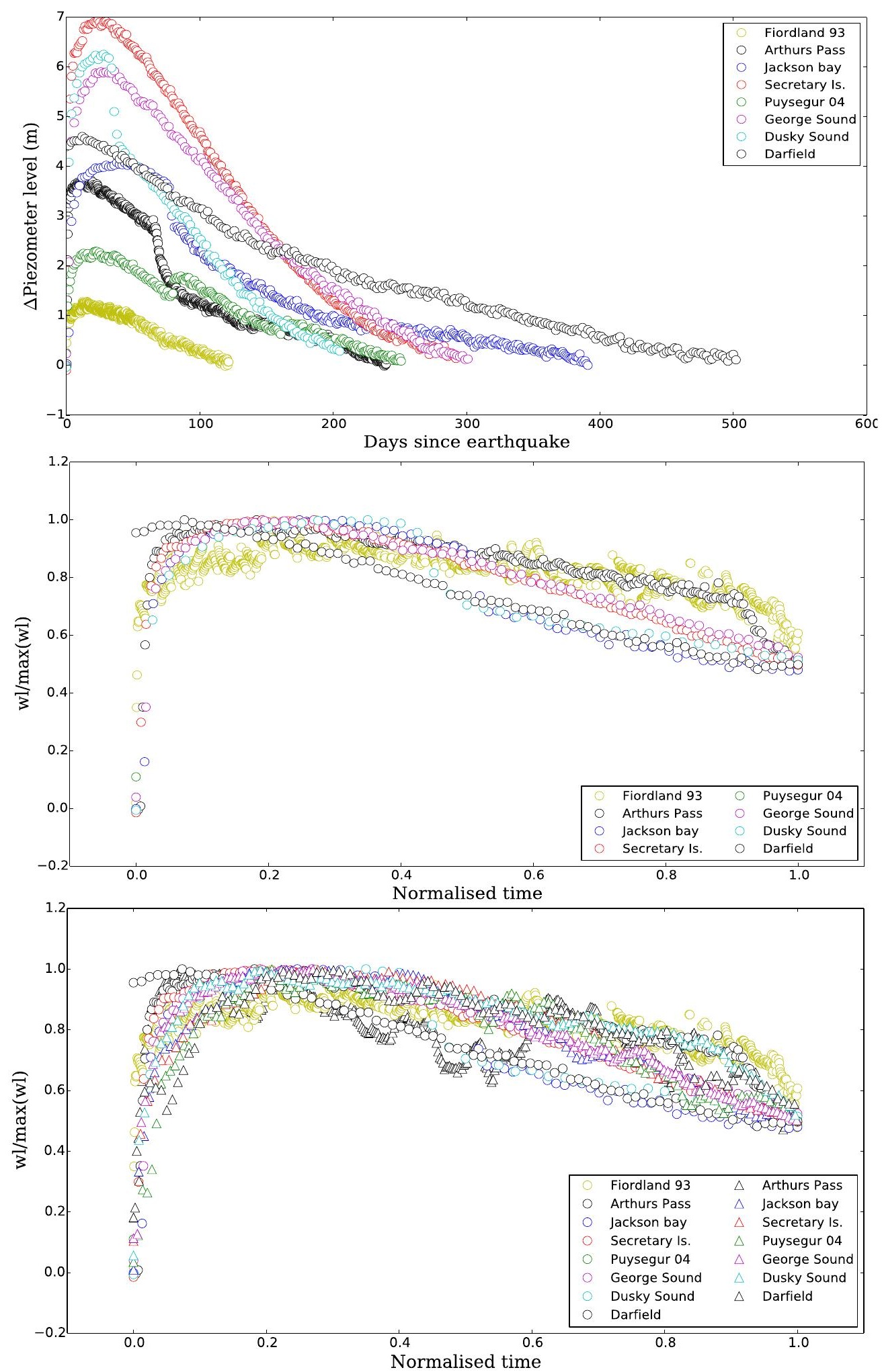

FIgURE 3.10: The top graph shows the piezometer level changes in well DL545a (Figure 3.1 after processing, see Chapter 2) plotted since the time of the earthquakes. The centre graph shows the same piezometer level changes normalised to maximum amplitude $=1$ and by time to half recovery $=1$. The lower graph shows the same normalised data for DL545a and also the data for DL1330a (Figure 3.1) after the polarity has been flipped and the same processing applied. The figure illustrates the consistent character of hydrologic changes between different monitoring sites. 


\subsubsection{Modelling of groundwater level fluctuations}

The shapes of the groundwater level fluctuations (shown in Figure 3.10) are very similar to that presented by Roeloffs (1998) for the water level response in the B.V. monitoring well near Parkfield, California that was induced by the 28/06/1992 $\mathrm{M}_{w} 7.3$ Landers earthquake, which occurred at an epicentral distance of $433 \mathrm{~km}$ away from the well. Roeloffs (1998) modeled the groundwater response in terms of the diffusion of an abrupt coseismic pore-pressure increase occurring near to the well. Although the B.V. well and the Cromwell Gorge wells appear to be operating on different timescales (B.V. recovered on the order of weeks, Cromwell Gorge wells repeatedly recovered on the order of one year), the similarities of the shapes of the responses suggests the Cromwell Gorge data can be modelled in a similar fashion.

Close examination of the finer differences in the groundwater level fluctuations, generated by individual earthquakes, were of a consistent pattern throughout all monitoring sites (Figure 3.9). Within the scale of amplitude (i.e. m- or cm-scale changes) of each site certain earthquakes consistently induced larger responses and therefore have steeper recovery curves than smaller amplitude fluctuations. Figure 3.11 shows examples of the two end member groups for wells DL545a (m-scale positive responses) and DL1330a (cm-scale negative responses), Nine Mile Downstream Slide. The amplitudes of the hydrological responses are scaled to a maximum of 1 , with negative responses from DL1330a turned positive, only the recovery phase is shown. In order to model the curves with different amplitudes, a model of damped harmonic oscillation is introduced according to which

$$
\frac{d^{2} x}{d t^{2}}+2 \zeta \omega_{0} \frac{d x}{d t}+\omega_{0}^{2} x=0
$$

where $\zeta$ and $\omega_{0}$ are the damping ratio and angular frequency respectively, $x$ represents the amplitude and $t$ the duration. The damped harmonic oscillator is an appropriate model to consider as it provides a means of distinguishing different amplitudes of the groundwater level change and small differences in recovery time between different monitoring sites. Proportionally smaller amplitude fluctuations (groundwater level changes) are in agreement with heavily over-damped oscillation: if $\zeta>1$ the system behaves over-damped and returns to its steady state slowly and without oscillation, if $\zeta=1$ the system is termed critically damped, and it returns as quickly as possible without oscillation, and if $\zeta<1$ the system is under-damped and will show oscillation.

In Figure 3.11 curves of over-damped harmonic oscillation are fitted as an example, the red, black and green curves have damping ratios $(\zeta)$ of 2, 9 and 11, respectively (critical 
damping at $\zeta=1)$, with angular frequency $\left(\omega_{0}\right)$ at 0.0075 . The fit of the curves is good for both monitoring sites. Best fit damping parameters and corresponding angular frequencies were determined by a log-likelihood function (Appendix D, Figures D.1). Damping ratios and angular frequencies for the modelled recovery periods are presented in Table 3.4 for mean values between the DL545a and DL1330a modelled data, and a graphical representation in Figure 3.11 (lower plot). In Figure 3.11 the models are positive and only the recovery periods are shown. The aim of future work is to incorporate these 'initial models' into a more comprehensive model incorporating the time to peak pressure change, similar to that presented by Roeloffs (1998).

TABLE 3.4: Statistically determined best fit values for damping ratios and angular frequencies based on damped harmonic oscillation, for monitoring boreholes DL545a and DL1330a. Italics indicate earthquakes for which hydrologic response could not be modelled due to insufficient data. Number refers to earthquake order in Figure 3.8

\begin{tabular}{|c|c|c|c|}
\hline Number & Earthquake & Damping ratio $(\zeta)$ & Angular frequency $(\omega)$ \\
\hline 1 & Fiordland 1993 & 4.5 & 0.056 \\
2 & Arthurs Pass 1994 & 10.9 & 0.035 \\
- & Thompson Bay 2000 & - & - \\
3 & Jackson Bay 2001 & 2.8 & 0.033 \\
4 & Secretary Island 2003 & 1.81 & 0.024 \\
5 & Puysegur 2004 & 8.1 & 0.043 \\
- & Puysegur 2007 & - & - \\
6 & George Sound 2007 & 2.92 & 0.018 \\
7 & Dusky Sound 2009 & 1.66 & 0.028 \\
8 & Darfield 2010 & 4.39 & 0.020 \\
\hline
\end{tabular}



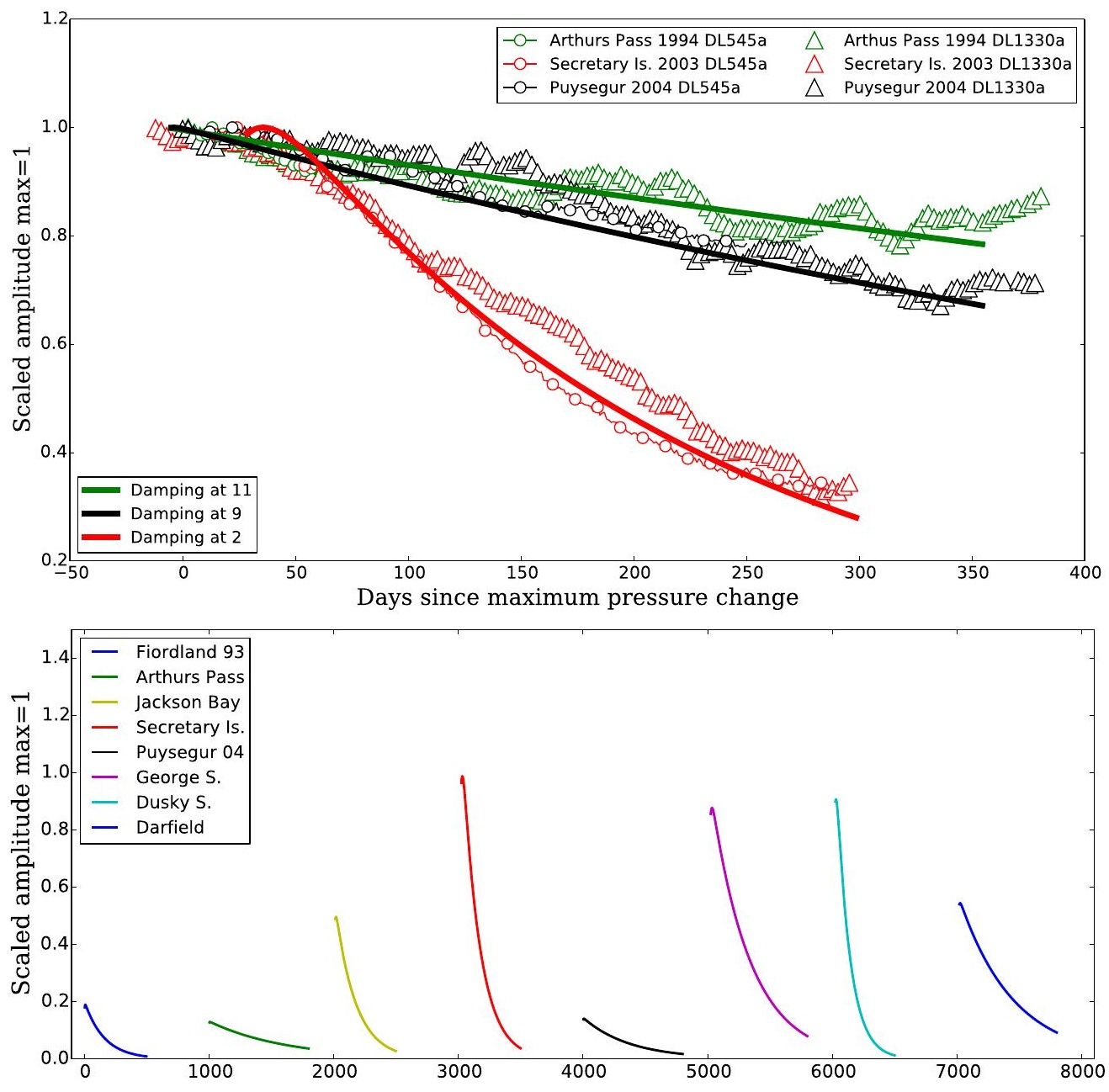

FiguRE 3.11: Upper graph: selected groundwater level fluctuations from monitoring sites DL545a shown by ' $\bigcirc$ ' and DL1330a shown by ' $\Delta$ ' (Figure 3.1), coloured by different earthquakes, normalised in terms of polarity, and amplitude scaled to max=1 for every curve, only the recovery is shown. Solid lines represent modelled damped harmonic oscillation, colour coordinated to the damping ratios shown, the number of data points is reduced for clearer plotting. Lower graph shows modelled (damped harmonic oscillation, Table 3.4) groundwater fluctuations, scaled to maximum amplitude of Secretary Island=1, plotted in chronological order of earthquakes (1-8 Table 3.4).

Note: only the recovery periods are modelled and are shown as absolute values. 


\subsection{Earthquakes that have induced hydrological responses}

Throughout the $>20$ year recording period, ten earthquakes were observed to have induced substantial hydrological responses within the Cromwell Gorge landslides (Figure 3.12). Of the ten induced hydrologic responses, eight were consistently correlated between different sites (examples shown in Figures 3.1, 3.2, and 3.3). Hydrological systems in various landslides appear to have very similar triggering sensitivities, and only responded to earthquakes that were either large enough, or close enough, to impart the minimum stress change required to alter hydrologic conditions. Central Otago is a region of relatively low seismicity and thus it is unsurprising that few local earthquakes have occurred during the monitoring period, and those that occurred were small in magnitude, $\left(\mathrm{M}_{w} 3\right.$ or less $)$.

The earthquakes that have induced discernible hydrologic responses were all regional events ranging from $\approx 130-630 \mathrm{~km}$ away, and of magnitudes $\mathrm{M}_{w} 6.2-7.8$ (summarised in Table 3.5). Distal earthquake sources (that is: a tele-seismic source) were investigated but no induced hydrological responses were identified. The first earthquake to induce a hydrologic response, seen throughout the monitoring system, was the 1993 Fiordland earthquake. However, the effects cannot be clearly identified in all piezometer and weir records, due to large amplitude signals generated by the effects of prolonged landslide drainage and lake filling. All subsequent earthquakes (with the exception of the 2007 Puysegur earthquake) occurred after lake filling and induced clear, correlatable hydrologic fluctuations between sites. The 2007 Puysegur earthquake, despite being of a large magnitude $\left(\mathrm{M}_{w} 7.3\right)$, occurred at a distance of c. $630 \mathrm{~km}$, too great to produce more than a faint signal in a few favourable piezometer records. Furthermore, the earthquake also occurred just before the closer, yet smaller $\left(\mathrm{M}_{w} 6.7, \approx 170 \mathrm{~km}\right) 2007$ George Sound earthquake, which induced one of the three largest hydrological responses. Other than in this case, earthquake-induced hydrologic responses were not observed to occur on top of those previously existing. Many of the earthquakes studied were followed by numerous and (some) large aftershocks. Due to the observed timescales of groundwater level time to peak pressure changes, it is possible that aftershocks may have contributed to the relative amplitude of hydrological responses. Discharge records were sampled at a consistently higher resolution and succumbed to, and recovered from, the effects of earthquakes on shorter timescales, also showing no direct evidence of aftershock-driven hydrological responses. The intervals between successive hydrological responses were generally greater than one year. 


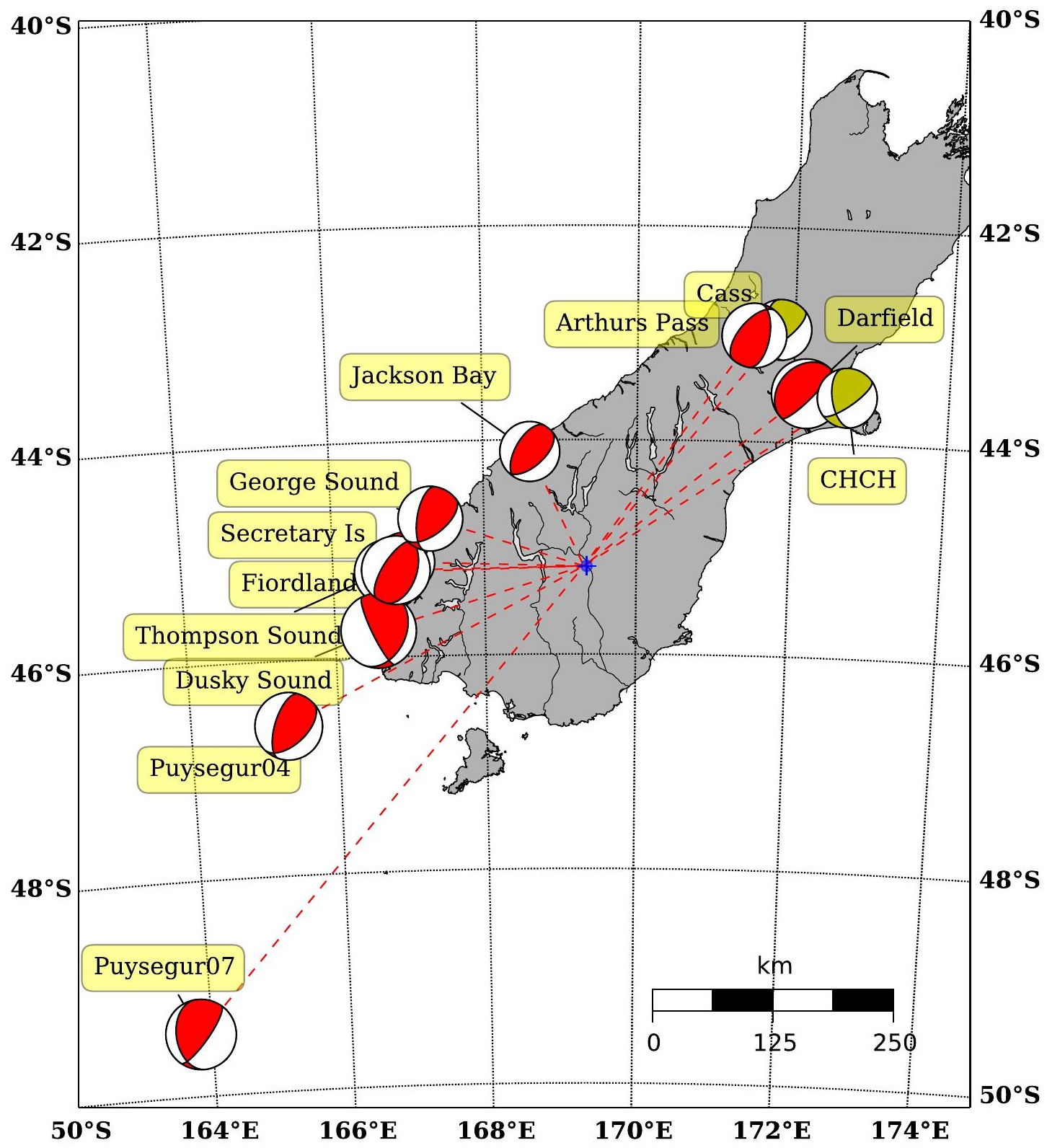

FiguRE 3.12: Map showing the geographic distribution of the ten earthquakes that have induced hydrological responses within the landslides located in Cromwell Gorge. Also shown are the 1995 Cass and 2011 Christchurch earthquakes that interestingly did not induce a response but may have been expected to. Lower hemisphere focal mechanisms are shown. 


\begin{tabular}{|c|c|c|c|}
\hline 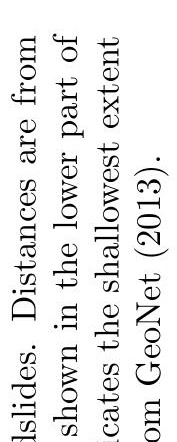 & 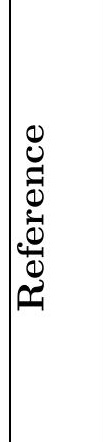 & 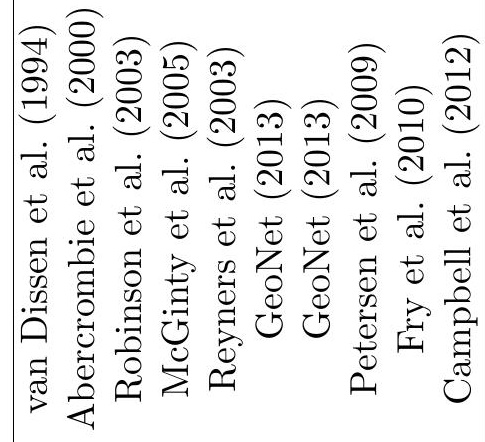 & 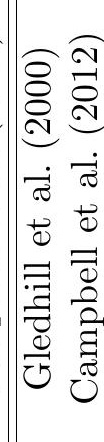 \\
\hline 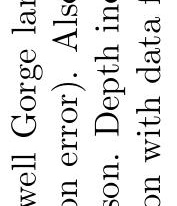 & 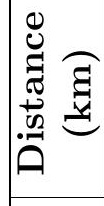 & 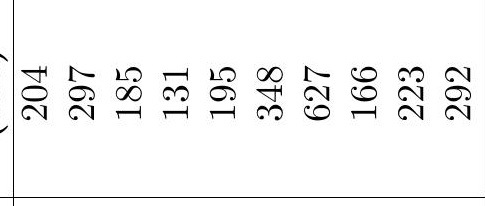 & 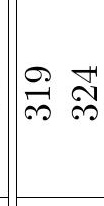 \\
\hline 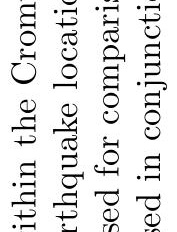 & $\frac{n}{\infty}$ & 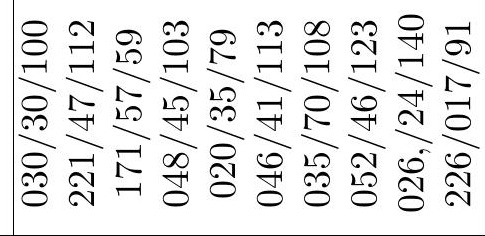 & 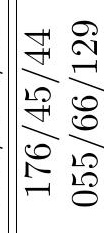 \\
\hline 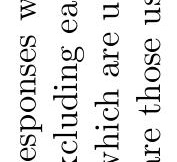 & 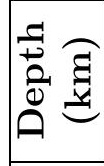 & एक & $\sim r$ \\
\hline 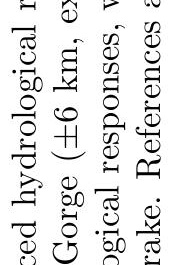 & 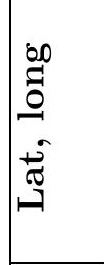 & 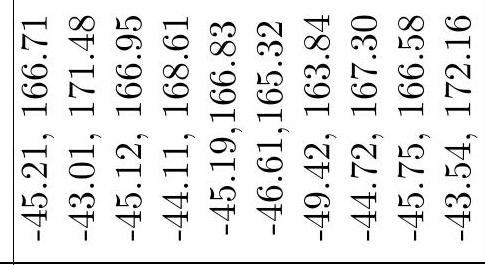 & 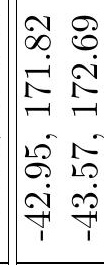 \\
\hline 要完: & $\sum^{3}$ & 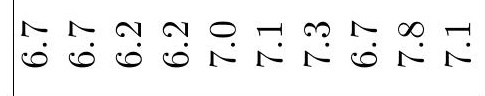 & 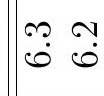 \\
\hline 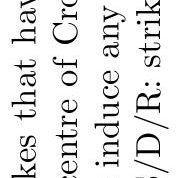 & $\theta$ & 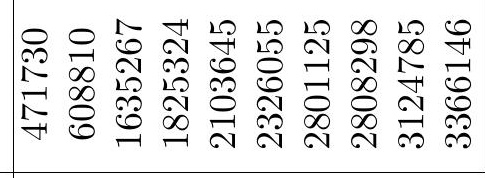 & 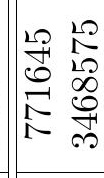 \\
\hline 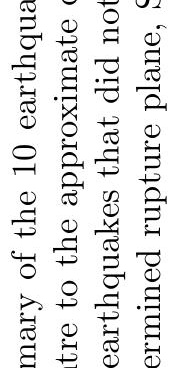 & 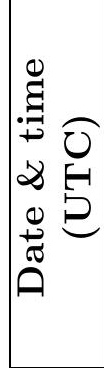 & 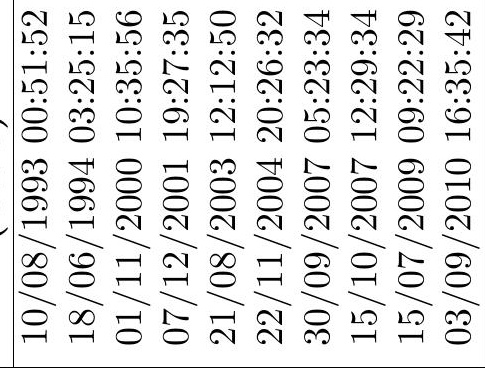 & 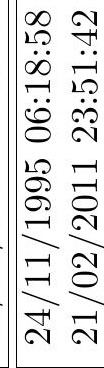 \\
\hline 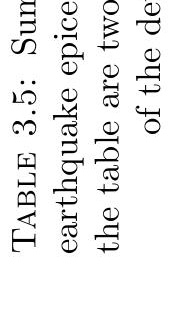 & 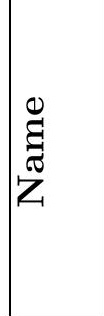 & 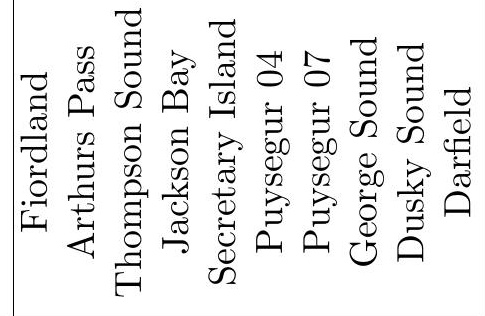 & 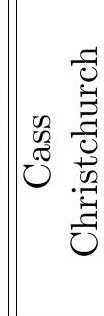 \\
\hline
\end{tabular}




\subsubsection{Source characteristics of earthquakes inducing hydrological re- sponses}

\section{Geographic distribution of earthquakes}

Earthquakes that have induced hydrological responses within the Cromwell Gorge landslides were distributed in the mid-lower South Island and offshore regions, from the west to southwest. The majority occurred in the Fiordland region (Figure 3.12), and were shallow subduction related earthquakes associated with the Pacific-Australian plate boundary. The 1994 Arthurs Pass and 2010 Darfield earthquakes, in contrast, are not associated with the Puysegur subduction zone. From Cromwell Gorge, earthquake backazimuths ranged from southwest to west, to northeast. No significant earthquakes during the operation of the Clyde Dam to date have originated from the south or east quadrants. The earthquakes listed in Table 3.5, shown in Figure 3.12, all had focal mechanisms characteristic of reverse faulting, with the exception of Christchurch which had a substantial component of strike-slip movement. Two possible fault planes are provided by each focal mechanism solution. The actual rupture plane may be illuminated by the aftershock distribution (e.g., Abercrombie et al. 2000; Gledhill et al. 2000), or determined by the known geometry of the faulting or plate interface system. For the focal mechanisms located around the Fiordland region, the likely rupture planes are those dipping shallow to moderately-shallow and eastward. The likely rupture planes for the earthquakes occurring around the Central South Island are more ambiguous and are inferred to be reactivated normal faults that formed during the Cretaceous (Campbell et al., 2012).

\section{Focal depth}

The depth of the earthquakes ranged from $4 \mathrm{~km}$ to $24 \mathrm{~km}$ (Table 3.5), and uncertainties in the depth estimates are larger than those for epicentre location. Nevertheless they are robust and it can be stated that the earthquakes that induced hydrological responses in Cromwell Gorge were predominately shallow, upper crustal, and did not originate from the deep lower crust. It is postulated that a large deep earthquake would induce a significant hydrological response, but one has not occurred within close enough proximity of Cromwell Gorge during the monitoring period.

\subsubsection{Earthquake take-off angles with respect to Cromwell Gorge}

Earthquake take-off angle analyses yielded an interesting relation between the style of first-motion shaking and triggering of hydrologic changes within Cromwell Gorge 
landslides. Figure 3.13 illustrates the take-off angles for $154 \mathrm{M}_{w}>5$ regional earthquakes at epicentral distances of $130-1678 \mathrm{~km}$, with respect to Cromwell Gorge, that occurred during the monitoring period 1993-2013 (first motion data obtained via Ristau 2008; GeoNet 2013). The take-off angles are plotted on a spherically rotated, first-motion, focal mechanism (described in Section 2.5.2). Earthquakes that have induced hydrological changes are shown by red marker symbols, blue markers show earthquakes with no observed effect. Marker size is scaled by seismic energy density (see Section 3.2.2). The compressional $(\mathrm{P})$ and dilational $(\mathrm{T})$ axes are labelled, and their corresponding quadrants coloured grey and white respectively. From the figure it can be seen that the majority of earthquakes that induced hydrological effects had take-off angles originating from the compressional quadrant, or very near the nodal plane, and favour the outer regions of the plot. The uncertainties in the earthquake depths allow the 2001 Jackson Bay earthquake (red, labelled JB in the figure) to fall even closer to the nodal plane, and the 2007 George Sound earthquake (red, labelled G) to fall within the compressional quadrant. For comparison of earthquakes that did not induce any observable hydrologic responses, the 2011 Christchurch earthquake (blue, labelled $\mathrm{CH}$ ) originates from clearly within the dilational quadrant, and the 1995 Cass earthquake (blue, labelled C) is from within the compressional quadrant, but lies near the null axis.

Incident angles for P-waves arriving at Cromwell Gorge were also calculated for the same set of $\mathrm{M}_{w}>5$ earthquakes. The angles of incidence were shown to arrive steeply in to Cromwell Gorge and cluster from $47^{\circ}-57^{\circ}$, indicating that the seismic wave fronts traveled along the Moho-crust interface (Smith E. G. C. personal communication 2013). No substantial relation can be drawn between incident P-wave angles and whether or not an earthquake induced hydrological responses in Cromwell Gorge landslides.

\subsubsection{Earthquake shaking characteristics in Cromwell Gorge}

Two crucial parameters controlling earthquake-induced dynamic and static stress changes, at a specific location, are the magnitude of the earthquake and distance from source to site. A measure of the shaking intensity is desired within the study site in order to compare the different effects of earthquakes on the hydrological systems.

\subsubsection{Measures of shaking intensity}

Instrument type and instrument location changes to the GeoNet seismometer network during the period 1993 - 2012 mean that a complete earthquake record from a single seismometer site close to Cromwell Gorge is not available. As outlined in Section 2.5.1, 


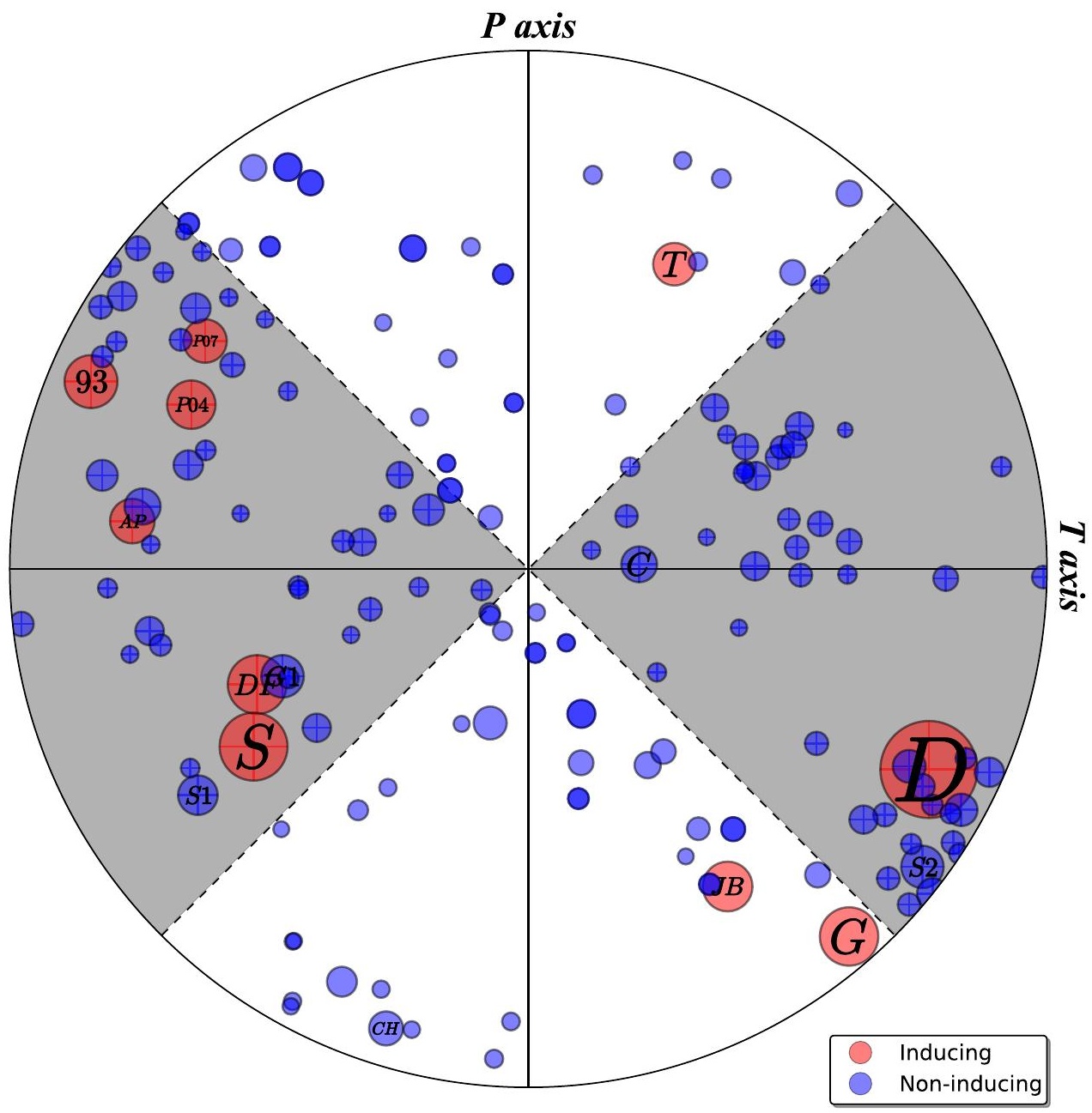

FIGURE 3.13: A spherically rotated lower hemisphere focal mechanism plotting earthquake take-off angles for $154 \mathrm{M}_{w}>5$, marker size is scaled by seismic energy density (see Section 3.2.2. Earthquakes that have induced hydrologic changes are shown by red markers, and those that have not by blue markers. Earthquakes in Table 3.5 are labelled with the abbreviations 93: Fiordland 1993, AP: Arthurs Pass 1994, C: Cass 1995, T: Thompson Sound 2000, JB: Jackson Bay 2001, S: Secretary Island 2003, P04: Puysegur 2004, P07: Puysegur 2007, G: George Sound 2007, D: Dusky Sound 2009, DF: Darfield 2010, CH: Christchurch 2011. Substantial aftershocks are labelled by the initial of the main earthquake, followed by a number e.g. S1=first discernible aftershock following the Secretary Island earthquake. Compressional and dilatational focal quadrants are shaded grey and white, respectively and the $\mathrm{T}$ and $\mathrm{P}$ axes are labelled.

interpolation of earthquake parameters such as peak ground acceleration and Arias intensity need to be undertaken in order to complete the catalogue of earthquakes inducing hydrological responses in Cromwell Gorge landslides. Results from the developed method for interpolation of PGA and the model proposed by Travasarou et al. (2002) for median Arias intensity are shown in Table 3.6 and Figure 3.14. PGA values for six earthquakes in Table 3.6 measured by GeoNet provide a means of assessing the uncertainty in the 
PGA model, and the more complex Zhao et al. (1997) alternative (used for comparison). Both models show similar results, relating to the large input distances. Results are presented from our developed PGA model. The model provides quite accurate estimates for PGA values for many of the earthquakes, but as with the model of Zhao et al. (1997), values for Dusky Sound earthquake are consistently overestimated. This is due to the large $\mathrm{M}_{w} 7.8$ of the 2009 event, but the analysis of seismological properties indicates very little high frequency content and oceanward (southwest) rupture directivity (Fry et al., 2010), accounting for the relatively low measured PGA values (at EAZ). A small overestimate in the value for the 2007 Puysegur earthquake is also apparent, but due to unmeasurable hydrological responses in many hydrological data, the earthquakeinduced hydrological response from the 2007 Puysegur earthquake was excluded from further analysis. Furthermore, the comparison of measured strong motion data (PGA and derived PGV, Table 3.6) suggests that the calculated median Arias intensity and the seismic $e$ parameter overestimate the value for the Dusky Sound earthquake and underestimate the value for the 2007 George Sound earthquake. The calculation of median Arias intensity for earthquakes with reverse/thrust faulting mechanisms appears scaleable to that of the calculated PGA values (Figure 3.21), but differs when other faulting mechanisms are introduced (e.g., strike-slip for Christchurch 2011). 


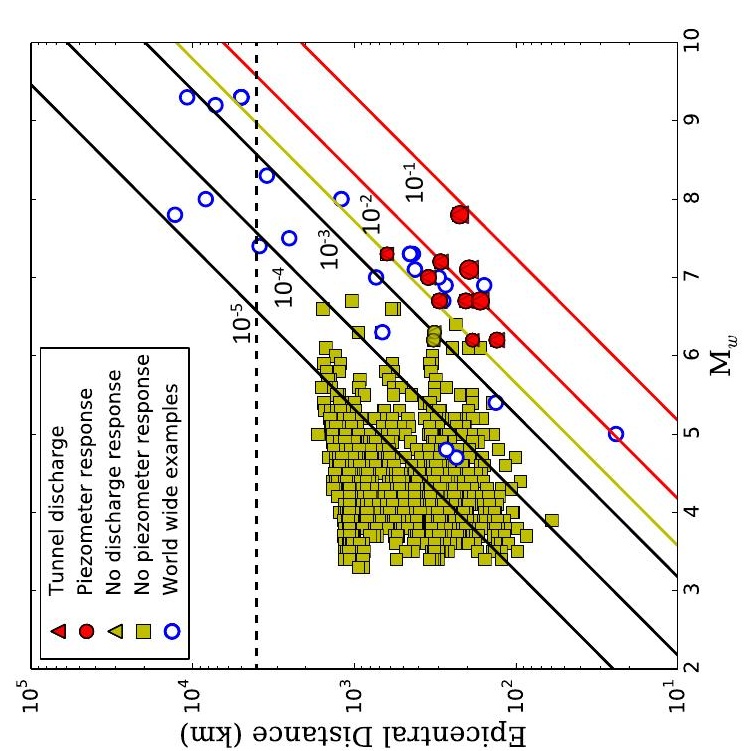

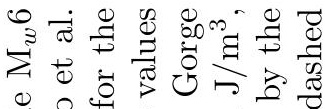

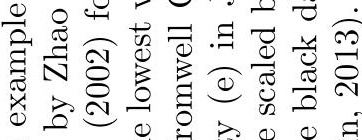
สี ठठठ

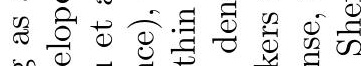

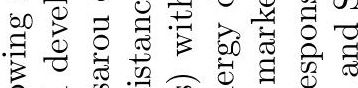

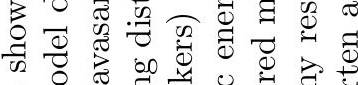
w

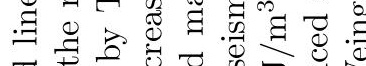

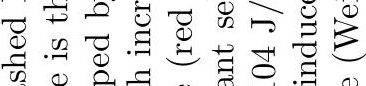

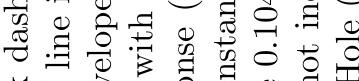

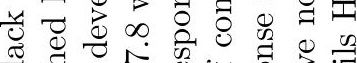

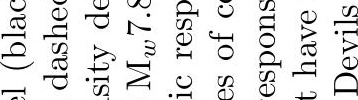

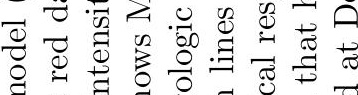

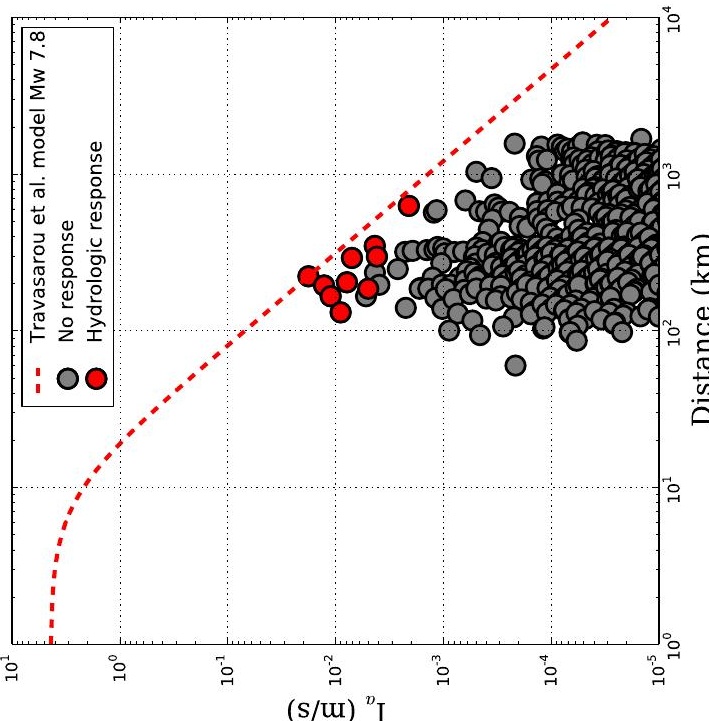

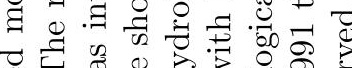

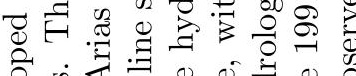
定

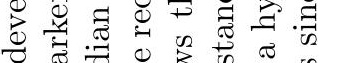

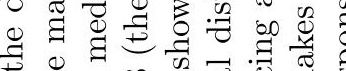

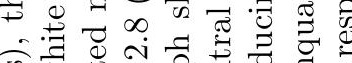
की

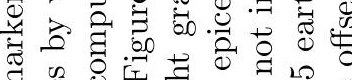
द 0 .

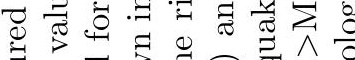

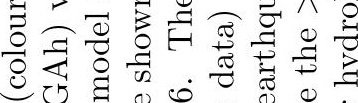

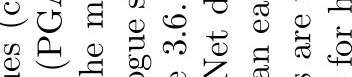
पू

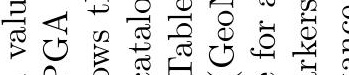

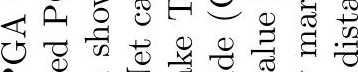
Ð च क ठ

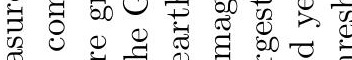
ॠ द्व

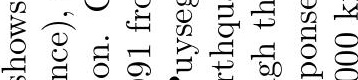

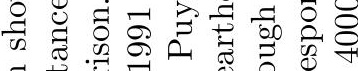

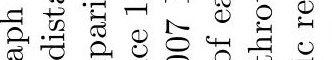

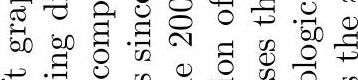

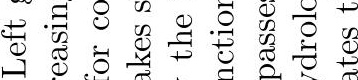

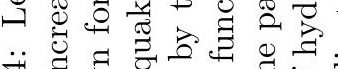

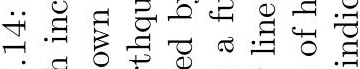

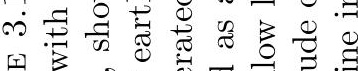

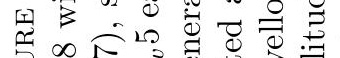

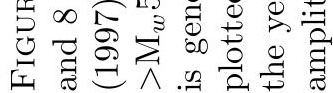




\subsubsection{Seismic energy density}

The seismic energy density parameter (e) after Wang (2007), is defined to be the total seismic energy in $\mathrm{J} / \mathrm{m}^{3}$ available to do work on a unit volume of rock. It allows the observed hydrological responses in Cromwell Gorge landslides to be compared to representative effects previously reported (e.g., Manga et al. 2012; Weingarten and Shemin 2013). The far right graph in Figure 3.14 plots measured earthquake magnitude versus epicentral distance with lines of constant $e$. The earthquakes in Table 3.5 that have induced hydrologic responses are shown by the red coloured markers for all sites in Tables 3.1, and 2.2, and are scaled by the amplitude of the hydrological responses. The values are shown in Table 3.6 and range from 0.18 to $1.58 \mathrm{~J} / \mathrm{m}^{3}$ for the $\mathrm{M}_{w} 6.2$ Thompson Sound 2000 and $\mathrm{M}_{w} 7.8$ Dusky Sound earthquakes, respectively. Yellow markers indicate earthquakes that did not induce any hydrological responses, including the 1995 Cass and 2011 Christchurch earthquakes (for comparison), and blue circles illustrate selected worldwide events compiled in Wang and Manga (2010). Due to the close proximity of individual monitoring sites in each slide area, data points are clumped together. Figure 3.14 shows that the monitored hydrological systems within the Cromwell Gorge landslides are not particularly sensitive to earthquake stimulation, when compared to that recently reported in Devils Hole, Death Valley National Park, Nevada, USA (Weingarten and Shemin, 2013). There, $e$ values as small as $10^{-6} \mathrm{~J} / \mathrm{m}^{3}$ stimulated hydrological responses in a fractured carbonate groundwater system, and produced hydroseismographic oscillations. In Devils Hole there appears to be an $\approx 4000 \mathrm{~km}$ threshold for producing coseismic offsets in water level (Weingarten and Shemin, 2013), shown in Figure 3.14 by the dashed line.

\subsubsection{Shaking intensity and the amplitude of hydrologic response}

Ten values of PGA, seismic e and Arias intensity provide a means of comparing the shaking intensity with the amplitude of hydrologic changes. Figure 3.15 shows the results for the three shaking intensity parameters PGA (left column), seismic $e$ (centre column) and Arias intensity (right column) plotted against the measured hydrological responses, scaled to $\max =1$ and averaged. There is a general association in the greater amplitudes of groundwater level changes (top row, blue) with PGA, seismic $e$ and Arias. Increases in weir flow (percent-rises and calculated volumes) show a more consistent increase with greater PGA, $e$ and Arias. However, the over estimate of $e$ and Arias for the Dusky Sound earthquake is clear. The times to peak pressure changes ( $\Delta \mathrm{P}$-time) show a general increase with greater PGA, $e$ and Arias, but are more scattered with $e$ and Arias. The recovery times, although scattered, all show a general decrease in time with increasing PGA, $e$ and Arias. The scatter is greater with the PGA values. 

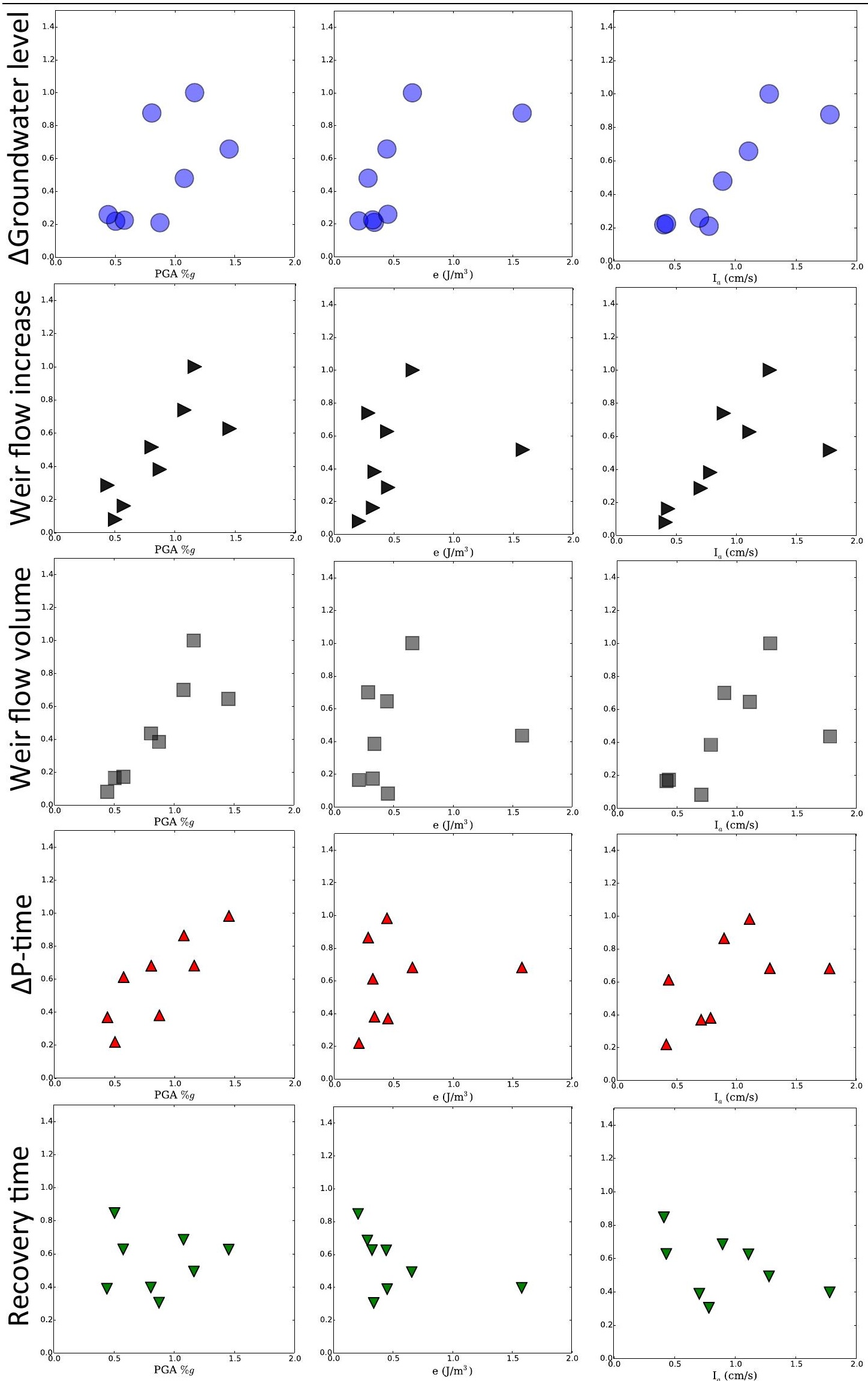

FiguRE 3.15: Earthquake shaking intensity parameters PGA (left column), seismic e (centre column) and Arias (right column) plotted against mean amplitude of induced hydrological response, time to peak pressure and recovery time with $\max =1$ from Table 3.2 for earthquakes in Table 3.6. 
TABLE 3.6: Summary of shaking intensity for earthquakes inducing hydrological changes in Cromwell Gorge landslides. Seismic energy $(e)$ is calculated after Wang (2007), PGA are values recorded at EAZ, $\mathrm{PGA}^{\dagger}$ are the calculated values, and $\mathrm{I}_{a}$ expresses median Arias intensity, as described by Travasarou et al. (2002). Italics show earthquakes inducing hydrologic responses that were not readily correlated between sites, or where data were missing and are excluded from the hydrological results. Cass 1995 and Christchurch 2010 earthquakes are shown for comparison.

\begin{tabular}{|c|c|c|c|c|c|c|}
\hline Earthquake & ID & $\begin{array}{c}\mathbf{e} \\
\left(\mathbf{J} / \mathbf{m}^{3}\right)\end{array}$ & $\begin{array}{c}\text { PGA } \\
(\% g)\end{array}$ & $\begin{array}{c}\mathbf{P G A}^{\dagger} \\
(\% g)\end{array}$ & $\begin{array}{c}\text { PGV } \\
(\mathbf{c m} / \mathbf{s})\end{array}$ & $\begin{array}{c}\mathbf{I}_{a} \\
(\mathbf{c m} / \mathbf{s})\end{array}$ \\
\hline Fiordland 1993 & 471730 & 0.339 & - & 0.875 & - & 0.784 \\
Arthurs Pass 1994 & 608810 & 0.208 & - & 0.505 & - & 0.413 \\
Thompson Sound 2000 & 1635267 & 0.182 & - & 0.693 & - & 0.497 \\
Jackson Bay 2001 & 1825324 & 0.286 & - & 1.079 & - & 0.897 \\
Secretary Is. 2003 & 2103645 & 0.658 & - & 1.165 & - & 1.28 \\
Puysegur 2004 & 2326055 & 0.325 & 0.266 & 0.578 & 0.612 & 0.433 \\
Puysegur 2007 & 2801125 & 0.194 & 0.097 & 0.287 & 0.082 & 0.209 \\
George Sound 2007 & 2808298 & 0.444 & 1.454 & 1.313 & 1.498 & 1.11 \\
Dusky Sound 2009 & 3124785 & 1.580 & 0.807 & 1.796 & 1.299 & 1.78 \\
Darfield 2010 & 3366146 & 0.452 & 0.442 & 0.716 & 0.593 & 0.705 \\
\hline \hline Cass 1995 & 771645 & 0.104 & - & 0.341 & - & 0.226 \\
Christchurch 2011 & 3468575 & 0.088 & 0.136 & 0.342 & 0.165 & 0.193 \\
\hline
\end{tabular}




\subsubsection{Spectral characteristics}

Scalogram plots using the continuous wavelet transform (CWT) have provided a useful way of visualising the transient signals of passing seismic energy. The results allow comparison of the frequency spectrum through time for earthquakes that induced hydrological effects and earthquakes that did not. Furthermore, the CWT aids comparison between the spectral character for earthquakes that induced differing (subtle and not so subtle) hydrological responses. Based on the illuminated spectral characteristics, the earthquakes listed in Table 3.5 were divided into five broad categories. This is complicated because of the need to consider different seismometer stations, as the site response can be very influential. However, each site will have maintained a high degree of relative accuracy, and fortunately, Geonet station EAZ (2004-ongoing), had recorded the six most recent earthquakes in Table 3.5, which covers the different groupings of hydrological responses: large, intermediate or subdued in amplitude, and the more subtle, faster or slower $\Delta \mathrm{P}$-time and recovery-time.

The five categories determined by differences in spectral characteristics of shaking EAZ, AXZ and MSZ were:

1. Earthquakes that imparted high-spectral amplitudes over broad (1.5-2 orders of magnitude) frequency bandwidth shaking, over a long, $25+$ second duration.

2. Earthquakes that had high-spectral amplitudes across moderately broad (1 order of magnitude) frequency bandwidth, over a short, less than 25 second duration.

3. Earthquakes that had moderate-spectral amplitudes over a broad (1.5-2 orders of magnitude) frequency bandwidth, over a long, 20+ second duration.

4. Earthquakes that had moderate-spectral amplitudes across a moderately broad (1 order of magnitude) frequency bandwidth, over a short, less than 20 second duration.

5. Earthquakes that had very low spectral amplitudes (at the site of investigation) with broad or narrow bandwidth over a short or long duration. Coincidently earthquakes under this category generally had not induced any noticeable hydrologic responses, with the exception of Puysegur 2007 for which the reasons are noted, and are used for comparative purposes.

Justification for this categorisation is presented in the following sections. Figure 3.16 shows seismograms for George Sound and Dusky Sound recorded by EAZ, and Jackson Bay and Secretary Island recorded by AXZ, to aid visualisation of the CWT, and to 

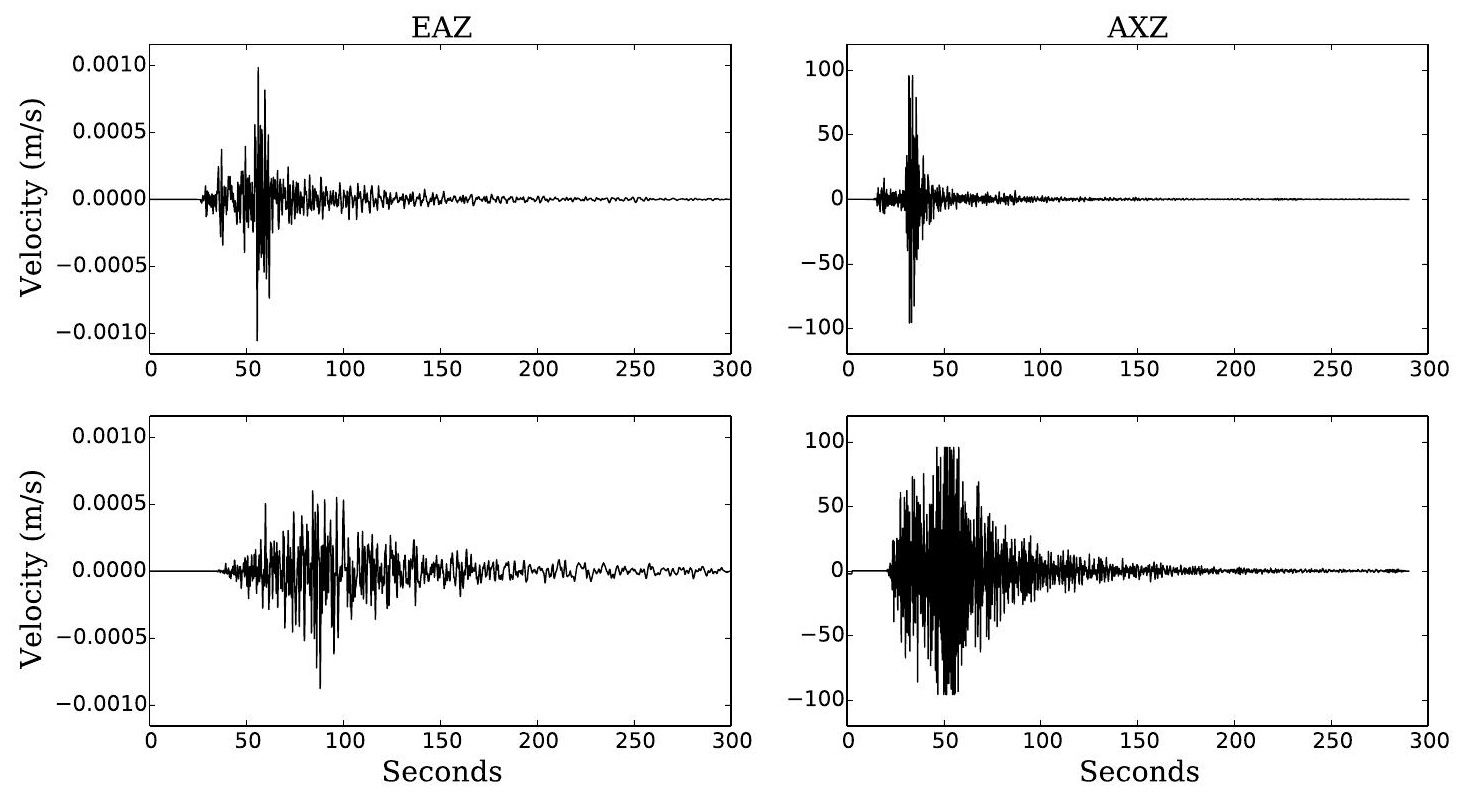

FIGURE 3.16: Examples of seismographs recorded at broadband sensor EAZ (left column) and short period sensor AXZ (right column), east component. Top left: George Sound 2007, bottom left: Dusky Sound 2009, top right: Jackson Bay, bottom right: Secretary Island 2003. Instrument responses have been removed.

show that differences in duration of these two categories of earthquakes are not artefacts of the CWT processing.

\section{EAZ}

Earthquake spectra recorded at EAZ are plotted in Figure 3.17, the CWT amplitudes $(\mathrm{m} / \mathrm{s})$ are shown by the colour bar and for each plot have been scaled according to the maximum amplitude of all six transforms. The amplitude scaling was adjusted to aid visual clarity for earthquakes with lower amplitudes: such is, as the maximum CWT amplitude of the colour bar was 0.0053 (occurring in the George Sound earthquake) is now $0.0053-0.002$. The foremost differences between earthquake spectra are in the amplitude. Dusky Sound and George Sound produced high amplitudes, and Darfield and Puysegur 2004 had moderate to low amplitudes. In the figure Christchurch and Puysegur 2007 show very low amplitudes, hardly registering when scaled on the amplitude scheme (illustrating category 5). The 2010 Christchurch earthquake did not induce any hydrologic responses, and Puysegur 2007 only did in one piezometer record, within the noise bracket. Also worth noting is that the frequency scale on the Christchurch plot is lower in comparison to the others. The second most striking features are the differences in duration and frequency bandwidth of shaking, most dramatically illustrated by comparing the George Sound and Dusky Sound earthquakes. The shaking during George Sound appears to have been highly concentrated with the vast majority of high amplitude shaking passing in $\approx 20$ seconds, with pronounced frequencies 

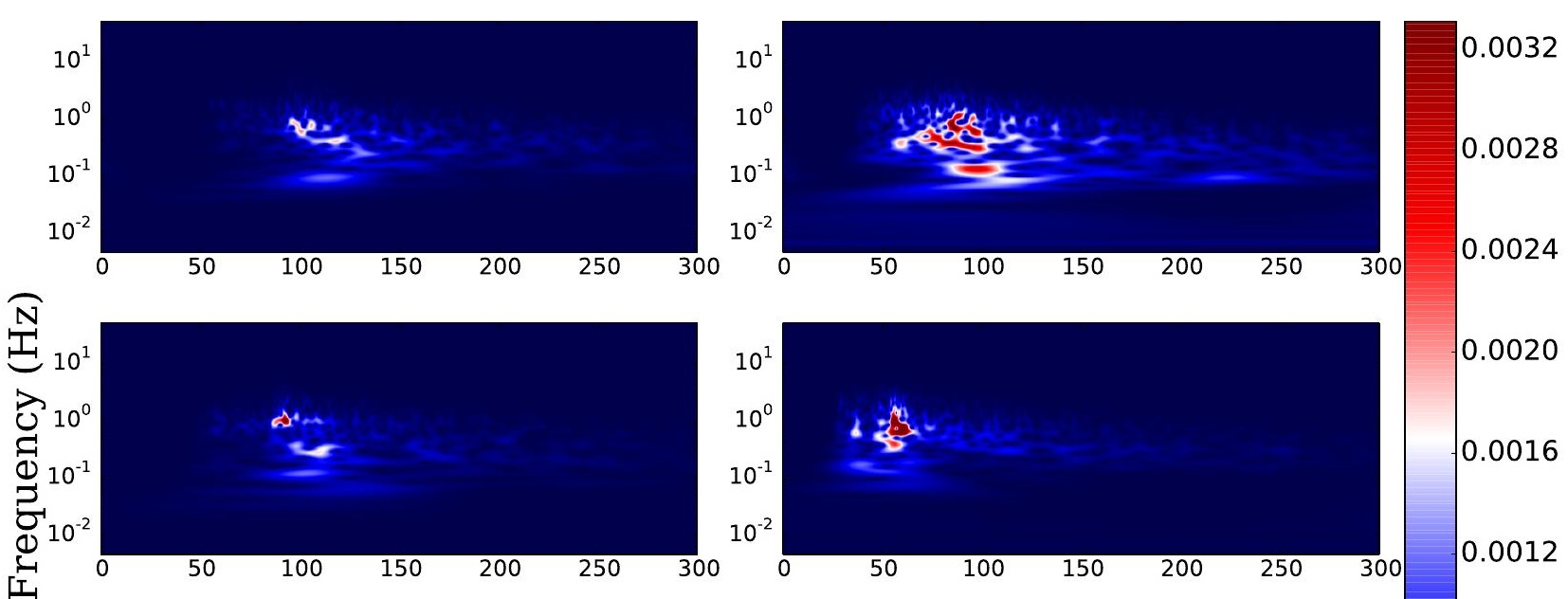

0.0020

0.0016
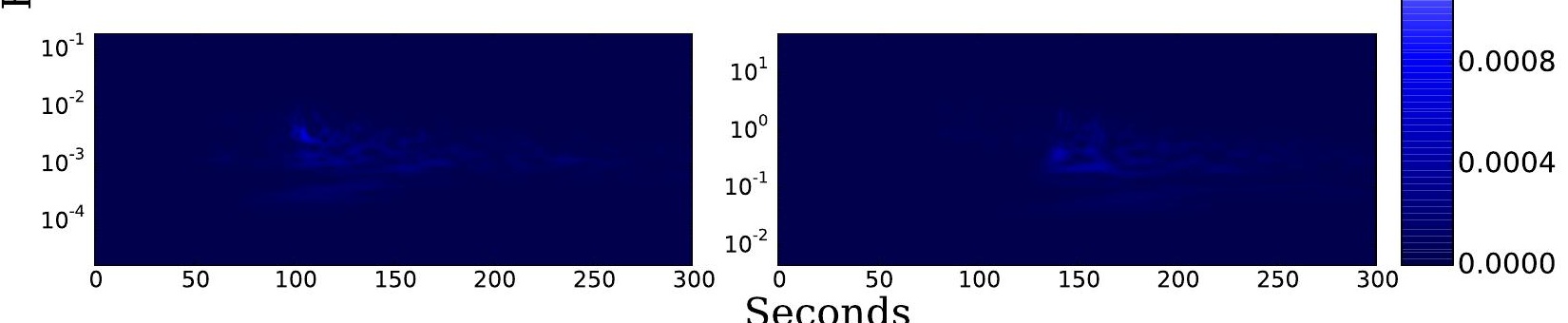

0.0012

Figure 3.17: Scalogram plots of Continuous wavelet transform for six earthquakes recorded by Geonet Station EAZ, east component. Top left: Darfield 2010, top right: Dusky Sound 2009, centre left: Puysegur 2004, centre right:George Sound 2007, bottom left: Christchurch 2011, bottom right: Puysegur 2007. NB: Christchurch 2011 and Puysegur 2007 only appear faintly on this amplitude scale but are shown to illustrate category five.

around $50 \times 10^{-2}-10 \mathrm{~Hz}$. However, Dusky Sound shows a broader frequency range of $50 \times 10^{-2}-20 \mathrm{~Hz}$, and a far longer duration of higher amplitude shaking occurred, lasting > 50 seconds. Differences are more subtle between Darfield 2010 and Puysegur 2004 earthquakes, i.e. the amplitudes of shaking are quite similar, with Puysegur slightly higher. The main difference is that Darfield contained more lower-frequency shaking, distributed around 3-10 Hz, while Puysegur 2004 centred its higher amplitude shaking around $10 \mathrm{~Hz}$, with some lower amplitude shaking at $2 \mathrm{~Hz}$.

\section{AXZ}

AXZ (operational 1996/03/07 - 2004/08/31) captured the Jackson Bay 2001 and Secretary Island 2003 earthquakes (Figure 3.18), but unfortunately has no record of the Thompson Sound 2000 earthquake. Amplitudes are scaled to the maximum recorded (Secretary Island) and adjusted to visually promote lower amplitudes. The CWT for Jackson Bay reveals a concentrated frequency range $10 \times 10^{-2}-50 \times 10^{-2} \mathrm{~Hz}$, with the higher amplitude shaking lasting $\approx 10$ seconds, whereas Secretary Island contained high amplitude shaking lasting $\approx 50$ seconds, with frequencies $10 \times 10^{-2}-10 \times 10^{-3}$ 


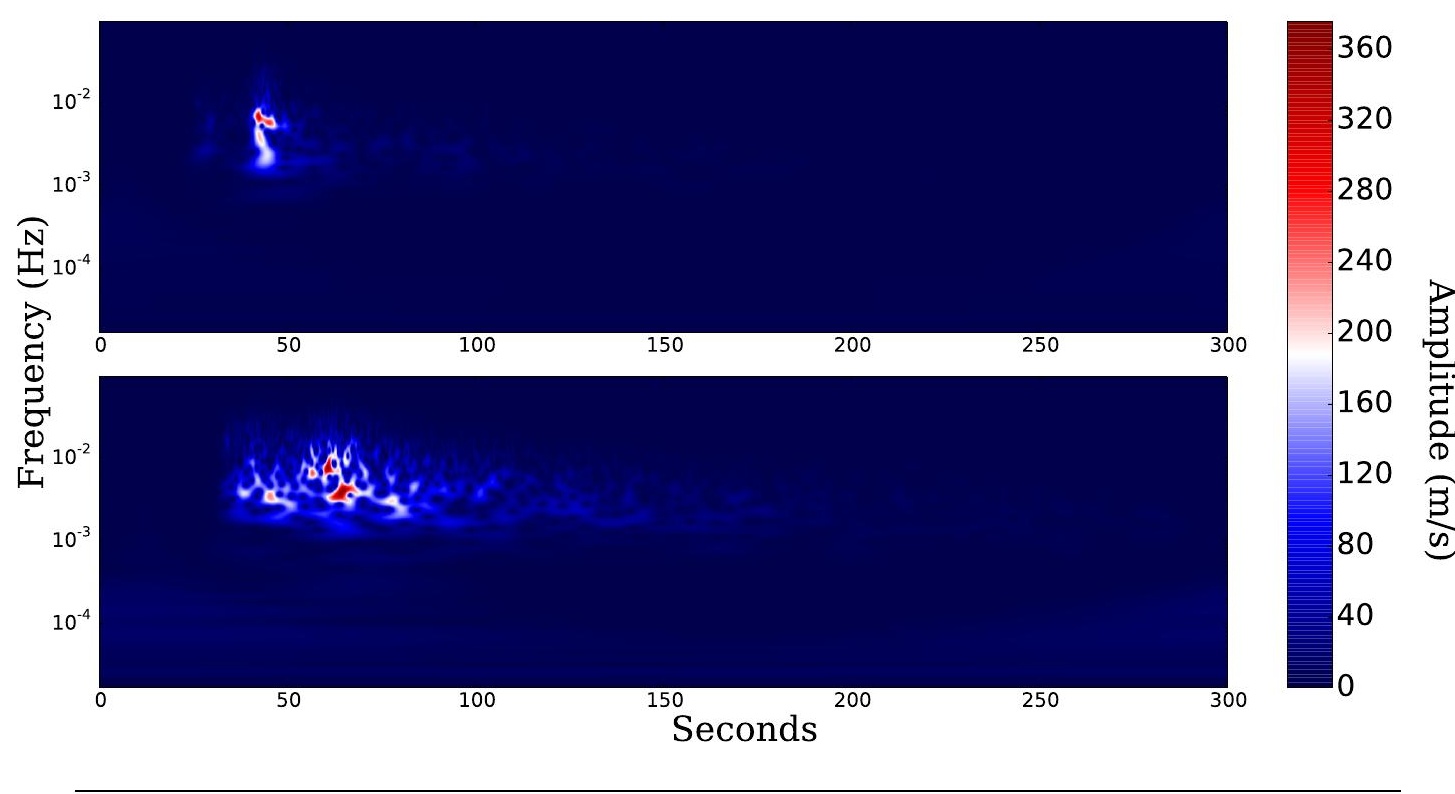

Figure 3.18: Scalogram plots of Continuous wavelet transform for the 2001 Jackson Bay (upper plot) and the 2003 Secretary Island (lower plot) earthquakes recorded at GeoNet Station AXZ, east component.

$\mathrm{Hz}$ throughout. The long durational shaking over a broad frequency range of Secretary island is similar to that of Dusky Sound (Figure 3.17).

The instrument response at AXZ is showing a strong influence in the results, the spectral amplitudes are greater, and the frequencies appear to be scaled consistently lower than earthquakes recorded at EAZ. These differences in instrument response were also confirmed by computing Fourier spectrums for the seismograms. Despite this, it is believed that the spectra recorded at each seismometer show a high degree of relative accuracy. The transient shaking characteristics of the Jackson Bay and Secretary Island earthquakes appear to show resemblance to that of George Sound and Dusky Sound earthquakes, respectively.

\section{MSZ}

To investigate the consistency in spectral character, and to further complete the catalogue of earthquakes inducing hydrological effects, data from Geonet station MSZ, one of the longest running seismometer sites are incorporated. MSZ had recorded all earthquakes throughout the Clyde Dam operating period, but it is located in Milford Sound, Fiordland, and is too far away to be representative of the shaking that was felt within Cromwell Gorge. Nevertheless, in the absence of other data, it is used to provide insight into the spectral characteristics of the Fiordland 1993, Arthurs Pass 1994, Cass 1995, and Thompson Sound 2000 earthquakes (Figures 3.19 and 3.20). Additionally comparing one earthquake at two differing seismometer sites helps confirm aspects of the time-frequency representation. As an example, the Secretary Island earthquake is 


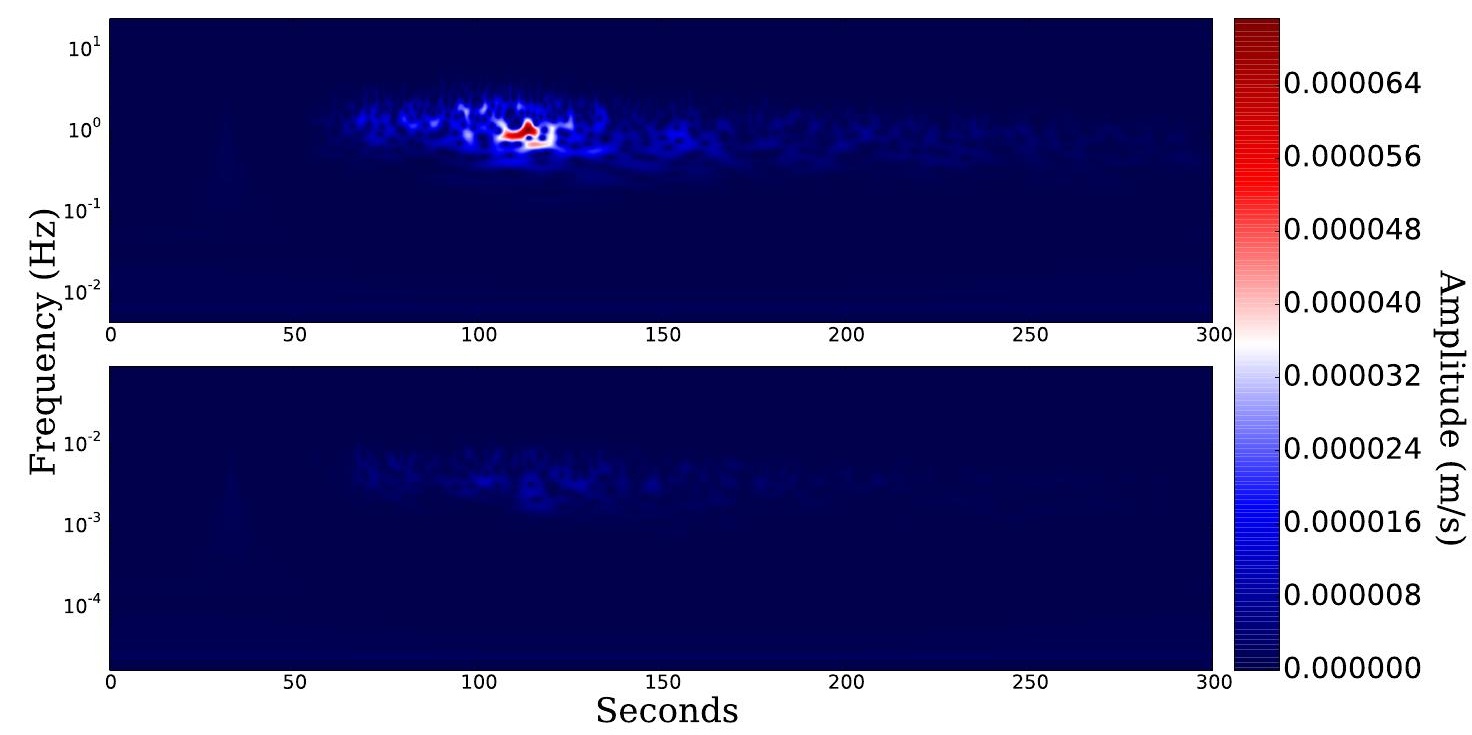

Figure 3.19: Scalogram plots of Continuous wavelet transform for two earthquakes: the 1994 Arthurs Pass (upper plot) and 1995 Cass (lower plot), recorded by Geonet Station MSZ, east component. NB: Cass 1995 only faintly registers on this amplitude scale shown to illustrate category 5 .

shown in Figure 3.18 (AXZ) and again in Figure 3.20 (MSZ) where the long-duration, broad frequency bandwidth character of the signal appears to be consistent between both MSZ and AXZ data.

The continuous wavelet transform representation of the George Sound, Dusky Sound, Jackson Bay and Secretary Island earthquakes allows determination of two spectral categories. The first, defined by Dusky Sound and Secretary Island earthquakes has longduration, high-amplitude shaking, exhibiting a broader frequency bandwidth (low to high frequency range) that evolves with duration (Figures 3.17 and 3.18). The second, under which George Sound and Jackson Bay lie, is defined by short-duration, highamplitude with a concentrated time-frequency representation (Figures 3.17 and 3.18). A third category can be defined by the Puysegur 2004, Darfield 2010, Arthurs Pass 1994 and Fiordland 1993 earthquakes which had intermediate-duration of shaking with lower amplitudes over a moderate bandwidth (Figures 3.17, 3.19 and 3.20). The Arthurs Pass earthquake induced notable hydrological responses within Cromwell Gorge landslides, equivalent to that of the Puysegur 2004 earthquake. The spectral content of the Arthurs Pass earthquake recorded at MSZ shows a lower frequency dominance in comparison to other earthquakes, although the amplitude of the signals recorded at MSZ cannot be directly compared, due to reduced epicentral distance to the Fiordland region earthquakes. It is inferred to be due to a combination of PGA values and frequency content, that the spectral amplitudes for the Arthurs Pass earthquake, if recorded at the location of EAZ, would be comparable to the Puysegur 2004 earthquake. In support of the Arthurs Pass 


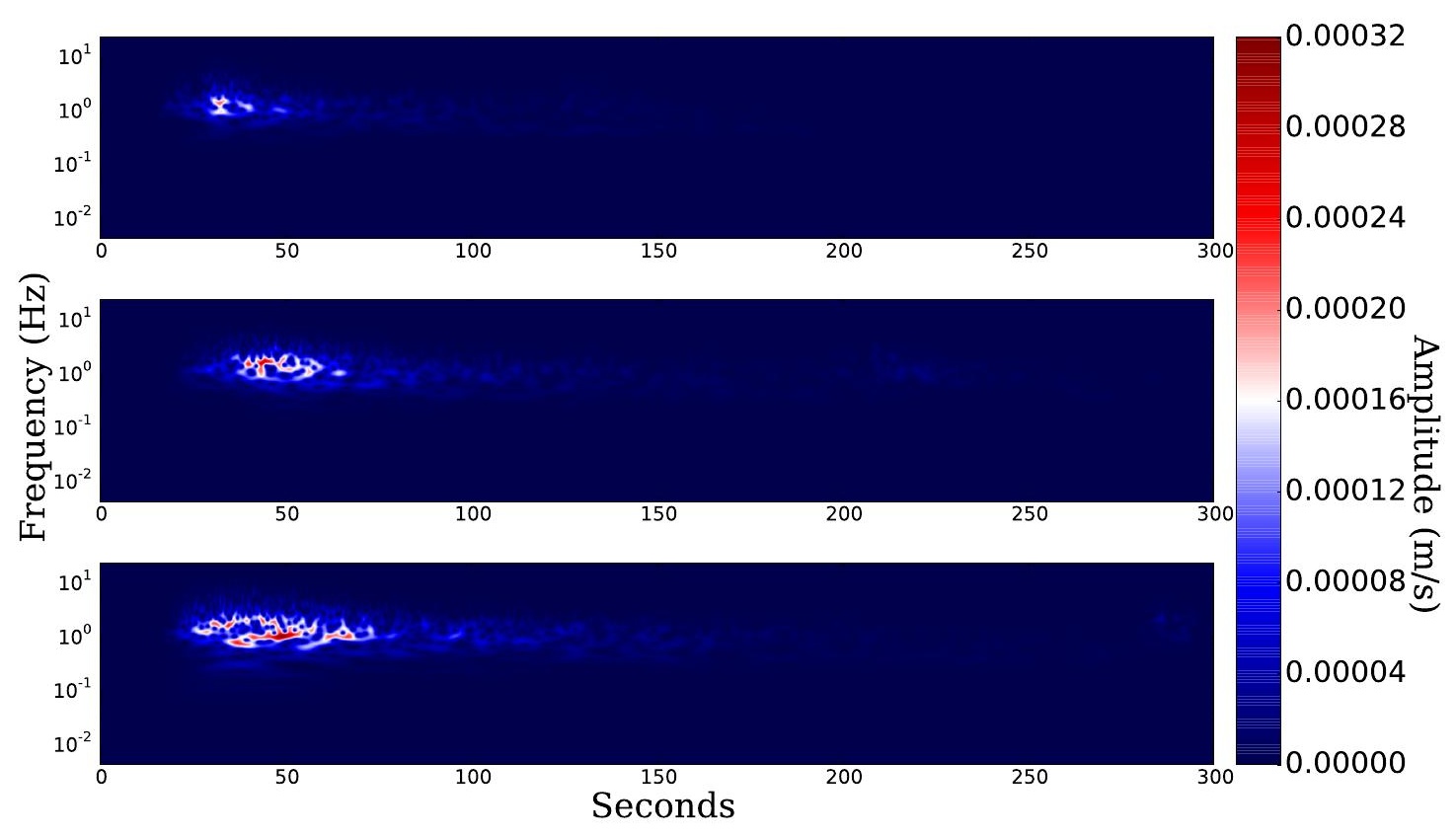

Figure 3.20: Scalogram plots of Continuous wavelet transform for the 2000 Thompson Sound (upper plot), 1993 Fiordland (centre plot), and 2003 Secretary Island (lower plot) earthquakes, recorded by Geonet Station MSZ, east component. NB: there is a large bias in the CWT amplitude when compared to Arthurs Pass and Cass earthquakes in Figure 3.19, due to the reduced epicentral distance between MSZ and Fiordland region earthquakes.

earthquake generating strong low-frequency content, are the two Fourier amplitude spectrums shown by Gledhill et al. (2000) to compare the Arthurs Pass 1994 and Cass 1995 earthquakes. The two spectrums were recorded at the Christchurch Police Station and used to investigate why the PGA values were so similar (in Christchurch), for differing magnitude earthquakes, $\mathrm{M}_{w} 6.7$ and $\mathrm{M}_{w} 6.2$. The Thompson Sound earthquake had low spectral amplitudes, over a short duration, and alone defines a fourth category. The fifth and final category is defined by earthquakes which had such low spectral amplitudes that they barely register when scaled to that of another category, i.e. the Cass 1994, Puysegur 2007, and Christchurch 2011 earthquakes (Figures 3.17 and 3.20). Importantly, no one category (with exception of category 4, Thompson Sound) was defined by a single seismometer station.

\subsection{Summary of results}

Earthquake stimulation caused the piezometers to record fluctuations in groundwater levels, which then gradually returned to pre-earthquake levels (e.g. Figures 3.1 and 3.10). 
TABLE 3.7: A summary of earthquake parameters and induced hydrologic responses. TOA is take-off angle quadrant with C: compressional, D: dilational, NP: near nodal plane, and N: near null axis, PGA: combination of measured and calculated values from Table 3.6 (horizontal), SC: spectral character as defined in Section 3.2.2.4, HA: relative hydrologic amplitude at each site (S: small, M: medium, L: large), $\zeta, \omega_{0}$ : damping ratio and angular frequency.

\begin{tabular}{|c|c|c|c|c|c|c|c|c|}
\hline Earthquake & $\mathbf{M}_{w}$ & TOA & $\begin{array}{c}\mathbf{e} \\
\left(\mathbf{J} / \mathbf{m}^{3}\right)\end{array}$ & $\begin{array}{c}\text { PGA } \\
(\% g)\end{array}$ & $\begin{array}{c}\mathbf{I}_{a} \\
(\mathrm{~cm} / \mathrm{s})\end{array}$ & SC & HA & $\zeta, \omega_{0}$ \\
\hline Fiordland 1993 & 6.7 & $\mathrm{C}$ & 0.339 & 0.875 & 0.748 & 3 & $\mathrm{~S}-\mathrm{M}$ & $4.5,0.056$ \\
\hline Arthurs P. 1994 & 6.7 & $\mathrm{C}$ & 0.208 & 0.505 & 0.413 & 3 & $\mathrm{M}$ & $10.9,0.035$ \\
\hline Thompson S. 2000 & 6.2 & $\mathrm{D}$ & 0.182 & 0.693 & 0.514 & 4 & $\mathrm{~S}$ & - \\
\hline Jackson B. 2001 & 6.2 & $\mathrm{D}(\mathrm{NP})$ & 0.286 & 1.079 & 0.897 & 2 & M & $2.8,0.033$ \\
\hline Secretary Is. 2003 & 7.0 & $\mathrm{C}$ & 0.658 & 1.165 & 1.28 & 1 & $\mathrm{~L}$ & $1.81,0.024$ \\
\hline Puysegur 2004 & 7.1 & $\mathrm{C}$ & 0.325 & 0.577 & 0.433 & 3 & M & $8.1,0.043$ \\
\hline Puysegur 2007 & 7.3 & $\mathrm{C}$ & 0.194 & 0.097 & 0.209 & 5 & $\mathrm{~S}$ & - \\
\hline George S. 2007 & 6.7 & NP & 0.444 & 1.454 & 1.110 & 2 & $\mathrm{~L}$ & $2.97,0.018$ \\
\hline Dusky S. 2009 & 7.8 & $\mathrm{C}$ & 1.580 & 0.807 & 1.780 & 1 & $\mathrm{~L}$ & $1.66,0.028$ \\
\hline Darfield 2010 & 7.1 & $\mathrm{C}$ & 0.452 & 0.442 & 0.705 & 3 & $\mathrm{M}$ & $4.39,0.020$ \\
\hline Cass $\overline{1995}$ & $\overline{6} . \overline{3}$ & $\overline{\mathrm{C}} \overline{(\mathrm{N})}$ & $0 . \overline{104}$ & $0.3 \overline{1}$ & $\overline{0} . \overline{2} 2 \overline{6}$ & $\overline{5}$ & - & ----- \\
\hline CHCH 2011 & 6.3 & $\mathrm{D}$ & 0.088 & 0.163 & 0.193 & 5 & - & - \\
\hline
\end{tabular}

The groundwater level changes were not instantaneous and exhibited delays in peak pressure change (refer to Table 3.3). No coseismic oscillation was observed on the timescales predicted for the passage of earthquake surface waves (c. $5-13$ min for earthquakes at distances of $1080-2820 \mathrm{~km}$, Brodsky et al. 2003), due to the 3 hour and longer sampling intervals in effect at the times of significant earthquakes, although it is possible that the landslide hydrologic systems are sensitive enough to record these oscillations. Tunnel weirs recorded earthquake-induced increases in discharge that showed short delays of $0-6$ hours before maximum flow was achieved (Figures 2.3 and 3.3). Peak flows were reached more quickly than peak pressure changes in wells, and elevated flow rates also returned to initial levels more rapidly. Hydrologic responses in piezometer data showed mixed polarity of response between different well sites but within each site were systematic: that is, monitoring wells that experience positive piezometric fluctuations always showed positive fluctuations and vice versa (Figure 3.8). Furthermore, it appeared that sensitive wells are responsive to the same earthquakes: if an earthquake induced a response in one site it will have induced a response in other sensitive sites. The amplitudes of groundwater level changes within each site were consistent in scale but varied between sites, from metre-scale to centimetre-scale changes (i.e., $10^{-1}$ to $10^{-2} \mathrm{~m}$ ), and importantly were $1-2$ orders of magnitude greater than surrounding hydrological signals and variation. Although hydrological noise obscured some responses and not every piezometer had recorded usable hydrologic data, the large, comprehensive, long-term dataset has enabled the characteristic hydrologic response of the Cromwell Gorge landslides to 

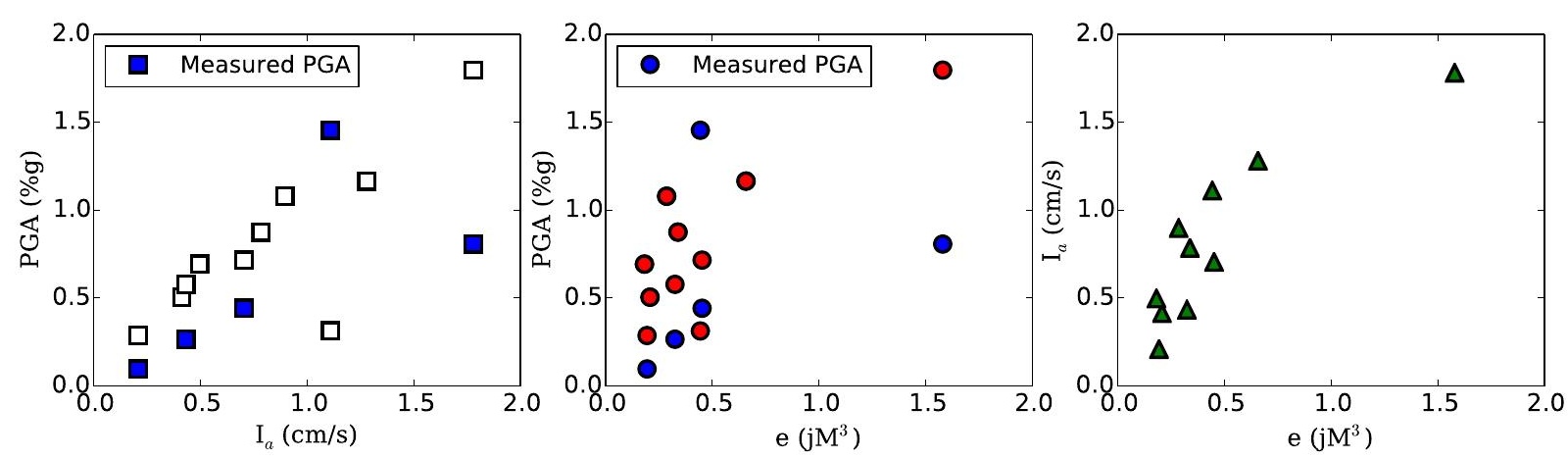

FIGURE 3.21: Comparison of measured PGA, calculated PGA, seismic energy density and Arias intensity values for the 10 earthquakes listed in Table 3.7. The left graph plots Arias against calculated horizontal PGA (white) and measured horizontal PGA (blue) values at EAZ, the centre graph plots seismic $e$ against the same PGA values, and the third graph plots seismic $e$ against Arias.

be determined. There appears to be no dependancy in the polarity or amplitude of groundwater level change on earthquake focal mechanism and earthquake take-off angle (Figure 3.13).

The amplitude of hydrological responses shows a general association with earthquake shaking characteristics, more so with calculated values for PGA, Arias intensity and seismic $e$, rather than measured PGA (Figure 3.15). The measured and calculated earthquake shaking intensities horizontal PGA, seismic $e$ and Arias intensity do not appear to be consistent with each other (Figure 3.21). This is because seismic $e$ and the adopted Arias calculation (Travasarou et al., 2002) are based on the magnitude of the earthquake $^{1}$ and there appears to be an over-estimate in the calculated values for the $\mathrm{M}_{w} 7.8$ Dusky Sound 2009 earthquake, and a smaller underestimate in the values for the $\mathrm{M}_{w} 6.7$ George Sound 2007 earthquake. The Dusky Sound earthquake was considered to have anomalously low shaking intensities for its large $\left(\mathrm{M}_{w} 7.8\right)$ magnitude (Fry et al., 2010), reflected in the measured PGA value. Calculated values cannot replace measured values, but are required to complete the earthquake catalogue. Therefore, the preferred measure to describe the earthquake shaking intensity for earthquakes that induced hydrological response is the combination of measured PGA and calculated PGA values. In many monitoring wells the two largest hydrological changes do not clearly associate with larger PGA values (Figures 3.14 and 3.15). Larger hydrologic responses (Groundwater level change and tunnel flow rate) show greater association with earthquakes of spectral category (SC) 1, that shake over a broad frequency bandwidth and over a long (> 25 s) duration (e.g., Figures 3.17, 3.18 and 3.22). Furthermore, proportionally reduced time to peak pressure changes and recovery times also appear to associate with

\footnotetext{
${ }^{1}$ Arias method also incorporates some site conditions
} 
earthquake shaking over broad frequency bandwidths and a long duration i.e., $\mathrm{SC}=1$

(Figures 3.8, 3.14 and 3.22).
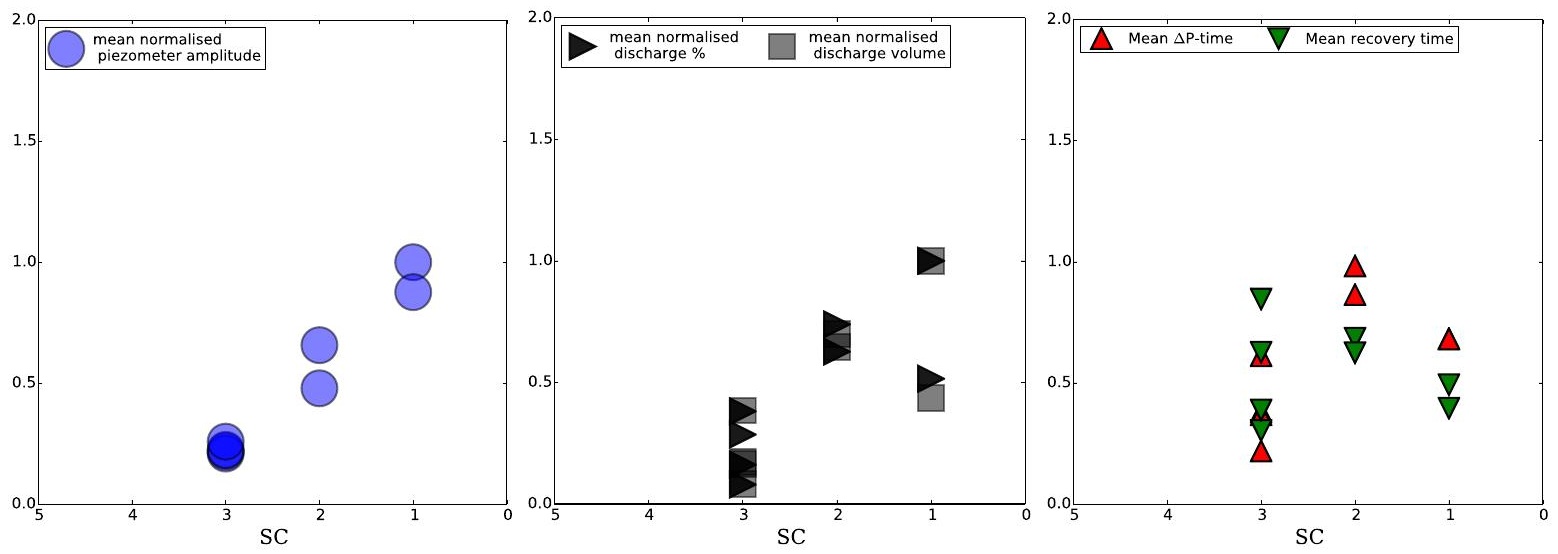

Figure 3.22: Figures showing the mean amplitude of groundwater level changes, weir flow rate increases and $\Delta \mathrm{P}$-time and recovery time with $\max =1$, plotted against spectral category (SC) for earthquakes Table 3.7, outlined in Section 3.2.2.4. 


\section{Chapter 4}

\section{Discussion}

\subsection{Key observations}

Observations on the highly-monitored, geoengineered groundwater systems within the Cromwell Gorge landslides show that the effects of earthquake shaking between 1992 and late 2013 induced changes in groundwater levels and tunnel discharges. Connecting these field-scale observations to causal mechanisms operating at a pore or fracture scale is a difficult process and may not be solved with the current resolution of groundwater and landslide monitoring, and earthquake instrumentation. Nevertheless, a number of key observations have been made:

1. Intermediate and far-field earthquakes induced temporary hydrologic changes, that were manifest as large (m-scale) and small (cm-scale) changes to groundwater levels, and elevated discharge from drainage tunnels (Figures 3.1, 3.2 and 3.3, Table 3.2). 10 earthquakes were observed to have induced hydrologic changes during the $>20$ year monitoring period; there appeared to be no amassing development in the earthquake-induced hydrological responses (Figures 3.1, 3.2 and 3.3).

2. The earthquake-induced groundwater level changes had mixed polarity, but changes were always systematic at each site (Table 3.2) and consisted of a delay to peak pressure change in the order of weeks, followed by a long slow recovery in the order of a year (Table 3.3, Figure 3.8). V-notch weirs always observed increases in flow in response to the 10 earthquakes (Figure 3.8), and showed a delay to peak flow rate of $0-6$ hours, and a recovery period that lasted two weeks to one month.

3. Earthquake-induced responses in groundwater levels did not appear to occur on top of those previously existing (although one possible exception was noted) until 
a substantial portion $(60-70 \%)$ of recovery had occurred. In the sites studied rainfall events did not affect recovery time in monitoring wells. Monitoring wells appeared to be either sensitive to rainfall or to earthquakes but not both. Heavy rainfall events were observed in many tunnel systems (Figures 2.7 and 3.3); the transient of rainfall-induced discharge associated with these events consisted of a slow rise to peak weir flow (requiring months), followed by a long drawn out recession period (lasting years); significantly longer than, and characteristically different from observed earthquake-induced changes.

4. Sufficiently large volumes of carbonate and/or sediments were mobilised from the rock mass in tunnels to warrant periodic (3-4 monthly) cleaning of weirs (e.g., Figure 2.3). Previous geological investigations suggest old groundwater is supersaturated with dissolved calcite (Beetham and Fergusson, 1990a).

5. There were no obvious influences on hydrological responses with regard to seasonality, even though Central Otago experiences quite a continental climate, and substantial ice/snow cover occurred during winter months (e.g. Figure 2.6).

6. Many shallow wells were observed to be sensitive to small strains induced by earth tides and barometric pressures (e.g., Figure 3.5), suggesting low compressibility of the monitored aquifer. Deeper wells generally had insufficient sampling intervals to detect these effects but appeared to be insensitive. Additionally, some weirs had recorded similar cyclic increases in flow rates (Figure 3.6), which appear to correlate with temperature records (Figure 3.6), possibly reflecting thermal stresses. Following the earthquakes that induced the groundwater level changes and weir flow rate changes, there were observed decreases in phase lag between the theoretical earth tides and temperature data with the hydrological data, in piezometer data DL1330a and weir 537W-01, respectively (Figures 3.5 and 3.7).

7. Long-term piezometer levels have exhibited one of three responses to the geoengineering and filling of Lake Dunstan. All piezometer levels lowered and partially recovered, then 1) maintained a constant level (i.e. flatlined), 2) gradually increased, or 3) gradually lowered (see Figures 3.1 and 3.2). Nine of the 21 studied piezometer records showed that it was not until a certain degree of recovery from the initial gravity drainage (i.e. groundwater suppression) that compartmentalised, landslide internal groundwater systems become responsive to earthquakes. Of the remaining 12 piezometers five are monitoring sub basal groundwater and seven are monitoring landslide internal groundwater, and were observed to be responsive to earthquakes immediately after the effects of lake filling had stabilised. 
8. The amplitude and transient nature of earthquake-induced responses were seen to vary within the characteristic response of the site: different earthquakes consistently induced proportionally different responses (Figures 3.8 and 3.14).

The ramifications of these observations below are explored below.

\subsection{Characteristic hydrological responses}

The seven landslide groundwater systems responded to the 10 earthquakes in a characteristic manner (key observations 1 and 2, e.g., Figures 3.8, 3.10, 3.11, and 4.1). To recapitulate, earthquake-induced groundwater level changes showed a delay in the time to peak pressure change on the order of $2-5$ weeks, and a subsequent recovery period on the order of approximately one year. Earthquake-induced changes in weir flow were near-instantaneous and maximum flow was reached in $0-6$ hours, followed by a comparatively long recession period on the order of one month.

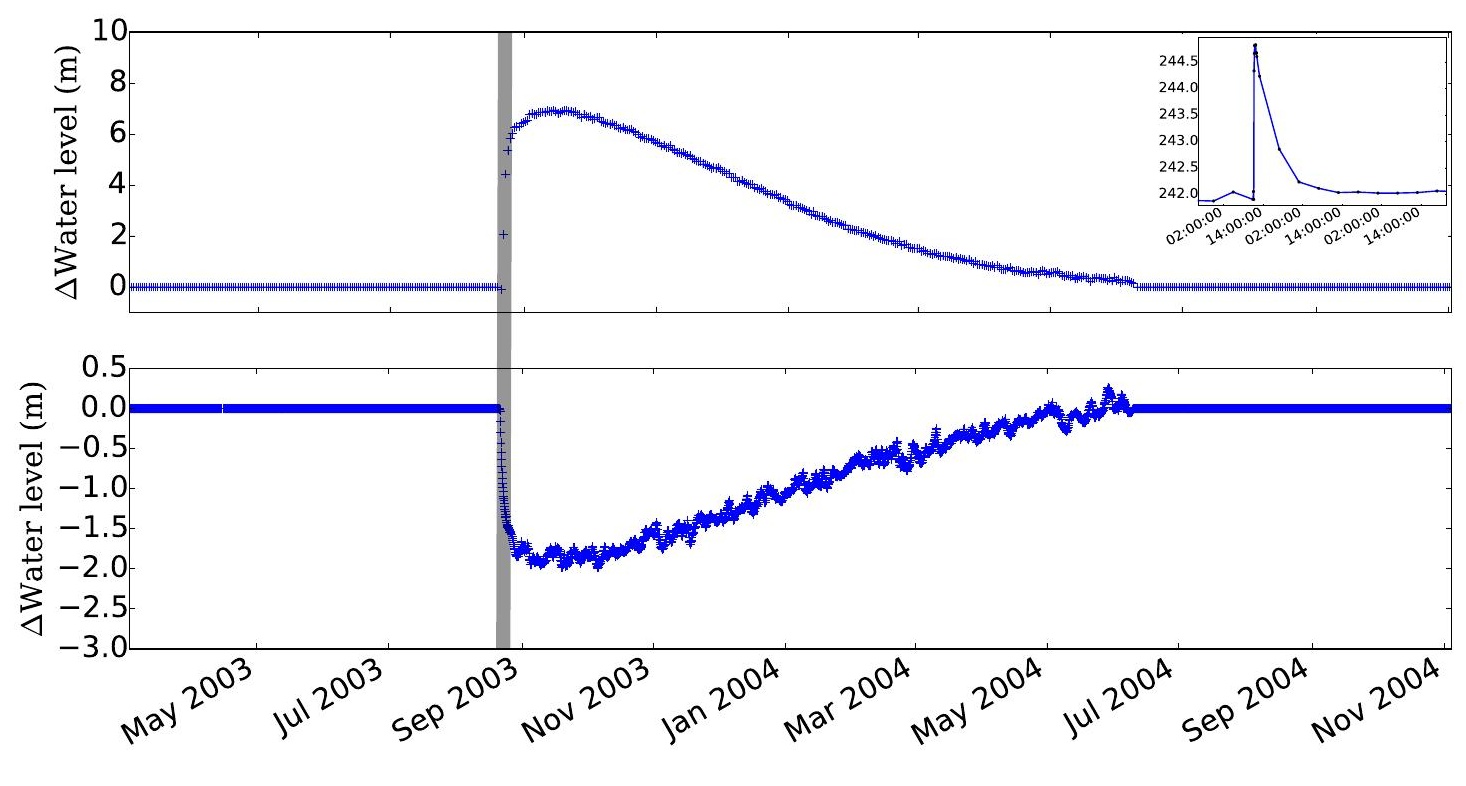

Figure 4.1: The figure shows the characteristic earthquake-induced groundwater level response. The upper plot shows the response in well DL545a NMD of nearly $7 \mathrm{~m}$ and the lower plot shows the response in DL1205a CLY of nearly $-2 \mathrm{~m}$ to the 2003 Secretary Island earthquake (timing of the earthquake is shown by the grey bar). These two monitoring wells are $>10 \mathrm{~km}$ apart, on opposite sides of Lake Dunstan and measure groundwater from different landslide subsurface zones (Table 2.2). The inset on the upper plot shows the $>2.5 \mathrm{~m}$ falling head test in DL545a conducted over a $24 \mathrm{hr}$ period on $25 / 02 / 1994$, where water was poured into the well and allowed to drain. 
Within the characteristic earthquake-induced groundwater level changes, there were consistent differences in the amplitude of response, time to peak pressure change and recovery time between sites, induced by the same earthquakes (Figures 3.8 and 3.11). The characteristic earthquake-induced tunnel discharge response also showed consistently higher amplitudes of response for the same earthquakes. It is unclear how sensitive the groundwater systems are to earthquake shaking as a consequence of their extensive geoengineering. The results reveal sensitivity increases and decreases.

The variations in polarity and scale of groundwater level changes (e.g., Figures 3.1 and 3.8) support findings of the initial geological investigations (Beetham and Fergusson, 1990a), namely that the groundwater systems within and below the many slow-creep schist landslides are complex and compartmentalised, with aquifers residing at multiple levels and under differing pressure regimes (Table 2.2 and Figure 3.4). Earthquakeinduced discharge and groundwater level changes were markedly different in character from each other (e.g. Figure 2.3) and this possibly reflects the influence of tunnel systems.

Previous geological and geotechnical investigations have established that the permeability structure is highly anisotropic, dominated by hydraulically conductive fracture zones with permeability barriers of clayey (gouge) material and blocks of intact schist (Beetham and Fergusson, 1990a). The scales of fracture zones are large in comparison to that of monitoring well casings (often co-situated with inclinometers or extensometers) and sand filters are many orders of magnitude more permeable than the surrounding rock mass (Beetham and Fergusson, 1990a). Furthermore, the piezometer data contain the initial slug-tests (i.e., falling head test) that were used to provide a measure of the hydraulic conductivity (Section 1.8.2). The falling head test illustrated in the inset in Figure 4.1 that was conducted in DL545a (NMD) over a $24 \mathrm{hr}$ period on 25/02/1993, shows rapid recovery from a $2.5 \mathrm{~m}$ increase in piezometer level on the order of 12 hours. Therefore, changes in the groundwater level in monitoring wells were deemed to be driven by groundwater moving through the rock mass and/or changes in groundwater pressures, not merely small-scale leakage into monitoring wells. A key difference in the settings of monitoring wells and tunnel weirs with respect to fracture systems, shear zones, and intact schist is that tunnels are essentially open systems in which groundwater flows away from the landslide, whereas wells monitor groundwater that is in a closed (or semi-closed) system within or beneath the landslide.

\subsection{Sensitivity to earthquake stimulation}

Earthquakes that induced the observed hydrological responses ranged in their source parameters (location, focal mechanism, $\mathrm{M}_{w}$ ) and shaking characteristics, suggesting that 
the only requirement for inducing hydrologic changes within the landslides is to surpass some threshold in shaking intensity. Initial investigations addressed whether there was dependance on earthquake source characteristics, such as the polarity of the P-wave first arrival, in order to induce hydrological responses (Figure 3.13). It was observed that Cromwell Gorge is located within the compressional quadrant or near the nodal plane for the earthquakes that induced the largest hydrological responses within each site (e.g. Secretary Island, George Sound and Dusky Sound earthquakes, Figure 3.13). However, for other earthquakes that induced hydrological responses, Cromwell Gorge is located well within the dilatational quadrant: for instance, the Thompson Sound earthquake. It is concluded that the polarity of $\mathrm{P}$-wave arrivals (i.e. position on a focal sphere) has no consistent bearing on the ability of an earthquake to induce hydrologic responses or alter the polarity of hydrologic responses in Cromwell Gorge landslides.

In Section 3.3 it was shown that the preferred measure of earthquake intensity at Cromwell Gorge is PGA, being a combination of measured and calculated values, as the parameter is interpreted to be more representative of the earthquake dynamic shaking than with the calculated seismic energy density and the calculated median Arias intensity. Figure 4.2 shows measured horizontal PGA values at EAZ since installation; the red circles represent earthquakes that induced hydrological responses, blue circles no response and the red triangles show calculated PGA values for the earthquakes which induced hydrological responses (i.e., pre EAZ). The smallest measured PGA value (at EAZ, Puysegur Trench 2007, $\mathrm{M}_{w} 7.3$ ) inducing a hydrologic response was $0.097 \% \mathrm{~g}$ (Table 3.7, and shown again in Figure 4.2), derived PGV $0.082 \mathrm{~cm} / \mathrm{s}$, and peak dynamic stress $^{1}$ of $0.007 \mathrm{MPa}$. Figure 4.2 shows that measured PGA values greater than that from the Puysegur 2007 earthquake have been reached. With reference to the third observation alone, these measured PGA values appear to fall inside the characteristic duration of the previous earthquake-induced groundwater level response. It is unclear why no increases in tunnel discharge were observed for these earthquakes. By way of contrast, the 2011 Christchurch earthquake $\left(\mathrm{M}_{w} 6.3\right)$ produced a greater measured PGA $(0.163$ $\% g$ ), and calculated peak dynamic stress change (0.029 MPa), but was not observed to induce any hydrological response. The empirical decay laws governing calculations of seismic energy density and median Arias intensity suggest the degree of shaking from the Christchurch earthquake was smaller.

In comparison to the sensitivities of other reported fractured, hard-rock hydrological systems (e.g. Weingarten and Shemin 2013), the monitored geoengineered groundwater systems in Cromwell Gorge landslides were not observed to be uniquely sensitive to

\footnotetext{
${ }^{1}$ Although oversimplified, peak dynamic stress is assumed proportional to PGV (Elkhoury et al., $2006)$, and calculated by: $\mathrm{PGV} \times$ shear modulus $\left(3 \times 10^{10} \mathrm{~Pa}\right) /$ shear wave velocity $(3.5 \mathrm{~km} / \mathrm{s})$
} 


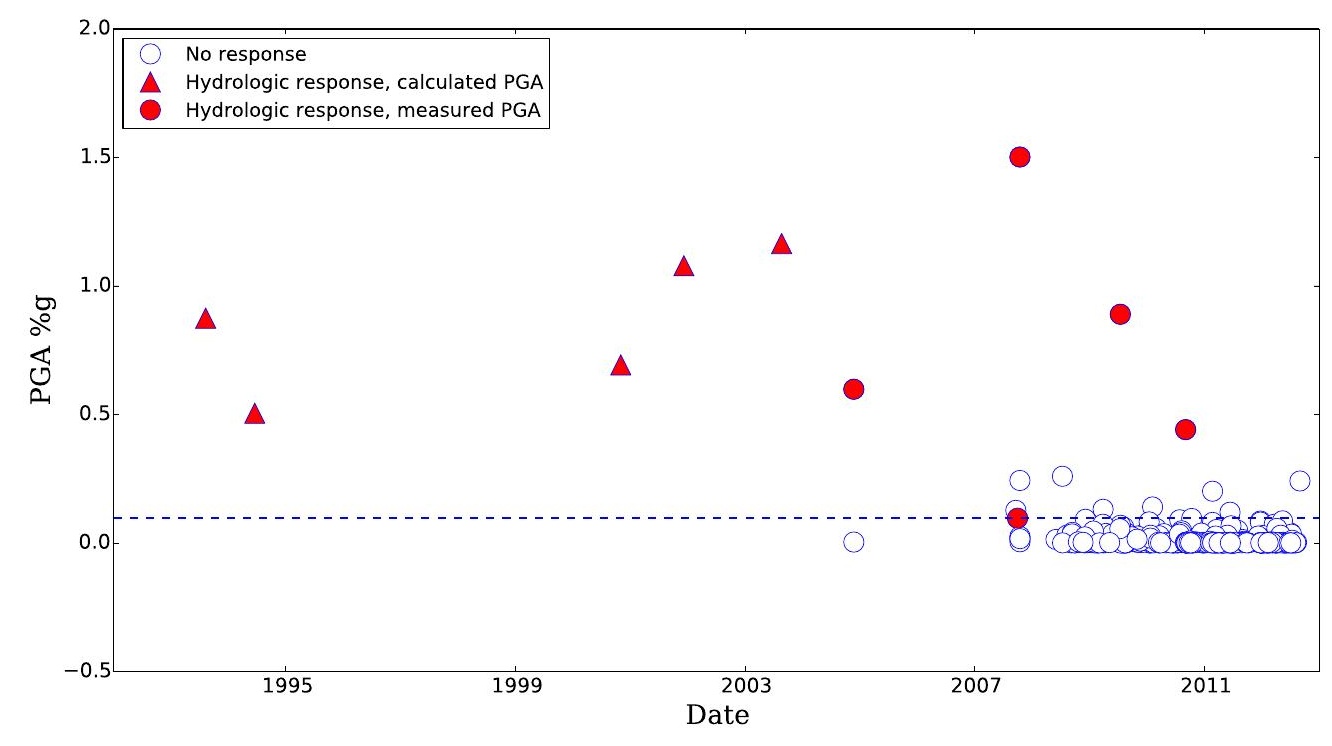

Figure 4.2: Horizontal PGA values measured at EAZ shown by circles for earthquakes that have induced hydrological responses are shown by red markers and those that did not by white/blue markers, the 2007 Puysegur earthquake has a dashed line through its PGA value $(0.097 \% \mathrm{~g})$. The red triangles are calculated horizontal PGA values (Section 3.2.2.1) for earthquakes that induced a hydrologic response pre EAZ (1994).

small degrees of earthquake shaking (Figure 3.14). Whilst the thresholds for earthquakerelated hydrological responses are similar to international observations, the amplitudes of some groundwater level changes were substantially greater (nearly $7 \mathrm{~m}$ ) and are at the extremes of international examples (Manga et al., 2012).

The spectral characteristic of earthquake shaking revealed by the continuous wavelet transform (Section 3.2.2.4, and Figure 3.17), show that the hydrological responses were larger and on proportionally shorter time scales when earthquake shaking occurred at high spectral amplitudes, over a broad frequency bandwidth and for a long (25 - 50 s or longer) duration (Figure 3.15 and Table 3.7). This suggests that the hydrological systems are more sensitive (i.e., have greater responses) to broad bandwidth, long-duration earthquake shaking than narrow bandwidth, short-duration shaking.

\subsection{What governs the response of the hydrological system?}

Some piezometers recorded groundwater level changes that were positive and on a metrescale (e.g., DL545a NMD), and some piezometers recorded groundwater level changes that were negative and only of a few centimetres (e.g., DL1330a). The time to peak pressure change and recovery time for opposing polarities of response, and both scales of amplitude of change (centimetre and metre) were consistent at all monitoring sites 
(Figures 3.8 and 4.1). This suggests a similar process is occurring at different monitoring well sites throughout the c. $20 \mathrm{~km}$ long gorge. Earthquake-induced weir flow was only observed to increase and reached peak flow rate then recovered more rapidly than monitoring well data, but was also consistent between different weir sites (different tunnels). The hydrologic responses throughout the landslides repeated and were systematic, therefore reflecting systematic changes in hydrological conditions within the rock mass, which in turn may reflect systematic changes to hydraulic properties, such as permeability.

\subsubsection{Summary of mechanisms}

Numerous mechanisms have been previously employed to explain transient hydrological observations at other localities around the earth, many of which centre around the enhancement of hydraulic properties such as permeability (e.g., Brodsky et al. 2003). Permeability enhancement can be either permanent or transient and permeability is considered to be a dynamic and ever-evolving hydraulic property (Wang and Manga, 2010). Recent stress models by Upton and Sutherland (2014) suggest that shallow crustal permeabilities are governed by a proximity to brittle failure.

Gradual long-term hydrological changes were observed in both monitoring well and tunnel weir data, and include gradually increasing or decreasing groundwater levels and gradual reductions in tunnel baseflow discharge. These observations suggest the landslide hydrological systems are capable of permanent changes. No earthquake-induced effects were observed to be long-term, and thus, mechanisms that embody temporary earthquake-induced changes to the hydraulic properties of the hydrologic system, such as permeability, are favoured. Mechanisms that have been evoked in order to explain hydrologic responses to earthquakes at other locations are listed in Table 4.1, with predictions of hydrologic responses for the geoengineered groundwater systems in Cromwell Gorge landslides.

Using the key observations (Section 4.1) some mechanisms can be quickly eliminated, for example, a coseismic elastic strain change (Jonsson et al., 2003) is expected to show correlation in the polarity of groundwater level changes and tunnel discharge with the sign of elastic strain change, but observations show that the polarity of hydrological responses is dependent on the aquifer properties and is always positive or negative regardless of the sign of elastic strain change. Furthermore, the effect of earthquake-induced changes in volumetric strain at far-field distances have diminished to the degree that large changes in groundwater level are not plausible (Roeloffs, 1998; Brodsky et al., 2003). However, the Cromwell Gorge landslides are not static objects (i.e. landslides dictate the rock 
mass has already failed) and have shown varying degrees of displacement (Beetham and Fergusson, 1990a; Macfarlane, 2009). It is possible that small changes in volumetric strain may be occurring beyond the resolution of the monitoring equipment that are a result of earthquake dynamic shaking.

Permanent enhancement of permeability (Manga and Rowland, 2009) does not seem likely, due to the observed recovery of both groundwater levels and elevated discharge occurring with no amassing variation through the $>20$ year monitoring period. Similarly, internal rupture and micro-fractures (Wang et al., 2004) dictate permanent changes to the rock mass, therefore permanent hydrological changes are expected to follow. Permanent earthquake-induced hydrological changes were not observed.

Consolidation of rock masses were observed in some landslide areas following initial groundwater drainage (Beetham and Fergusson, 1990a), which was on the order of $1 \times 10^{6}$ $\mathrm{m}^{3}$ of groundwater by mid 1991 (Jennings et al., 1991). The amount of consolidation from the removal of groundwater was reflected in the degree of ground level subsidence, and was locally on the order of a few centimetres (Beetham and Fergusson, 1990a). Permanent reduction in piezometer levels and tunnel discharge were a result of the assisted groundwater drainage. Given that much consolidation has already occurred, earthquake-induced consolidation (Manga et al., 2003) does not seem likely and permanent earthquake-induced hydrological changes were not observed. Furthermore, the amount of earthquake-induced ground water discharge is very small in comparison to the permanent removal of the volume that only caused centimetre scale consolidation (i.e. $1 \times 10^{3} \mathrm{~m}^{3}$ versus $1 \times 10^{6} \mathrm{~m}^{3}$ ).

Increases in hydraulic head (Manga and Rowland, 2009) were observed in response to storm events in some wells (i.e., increased groundwater levels), and storm events were correlated with increases in tunnel discharge (Figure 2.7). The character of the rainfall-induced hydrologic responses were markedly different to the earthquake-induced hydrologic response (key observation three). It is interpreted that recharge from rainfall produces an increase in the groundwater levels without altering the hydraulic properties of the hydrologic system. Therefore, an increase in groundwater level alone seems unlikely and cannot explain the contrasting character between earthquake-induced hydrologic responses and those induced by rainfall.

There were observed cyclic changes to groundwater levels and weir flow rate in some monitoring areas (key observation six). Following the logic outlined by Elkhoury et al. (2006); Manga et al. (2012), if the landslide groundwater aquifers contained a gaseous phase that was released under earthquake stimulation (Beresnev and Johnson, 1994; Manga et al., 2012), there would be no observed responses in groundwater level changes and discharge increases to the small strains induced by earth tides and thermal stresses. 
Instead cyclic changes to groundwater levels and weirs flow rates were observed, implying the Cromwell George landslide aquifers have low compressibility. Furthermore, there were no reports of a gaseous phase in the groundwater (Beetham and Fergusson, 1990c).

Two mechanisms from Table 4.1 remain as likely candidates to explain the observed earthquake-induced hydrological responses, which are: 1) a transient permeability enhancement (e.g., Roeloffs 1998; Brodsky et al. 2003; Elkhoury et al. 2006; Manga and Rowland 2009) and 2) a coseismic increase in pore pressure (e.g., Roeloffs 1998; Beresnev and Johnson 1994; Faoro et al. 2012). Both these mechanisms embody temporary changes to hydrologic systems, with the ability for change and recovery dependent on the amount of earthquake-stimulation and the hydraulic properties of the rock mass, such as permeability, porosity, storativity, diffusive properties, and ability to re-clog pores and fractures (Manga et al., 2012). Neither mechanism may fully explain all the observations, in particular why some monitoring wells record metre-scale groundwater level changes and others centimetre-scale changes, when they are both engaged by the same degree of earthquake shaking. 
TABLE 4.1: Mechanisms previously presented in the relevant literature to explain earthquake-induced hydrological changes, discussed with respect to the groundwater systems in the Cromwell Gorge landslides.

\begin{tabular}{|c|c|c|}
\hline $\begin{array}{l}\text { Mechanism } \\
\text { for change }\end{array}$ & $\begin{array}{l}\text { Weir discharge } \\
\text { prediction }\end{array}$ & $\begin{array}{l}\text { Groundwater level } \\
\text { prediction in wells }\end{array}$ \\
\hline $\begin{array}{l}\text { Coseismic elastic } \\
\text { strain change }\end{array}$ & $\begin{array}{l}\text { Correlation with the sign of } \\
\text { volumetric strain change, dif- } \\
\text { ferent pattern in decay depen- } \\
\text { dent on sign, possible perma- } \\
\text { nent changes in flow }\end{array}$ & $\begin{array}{l}\text { Correlation with the sign of } \\
\text { volumetric strain change, am- } \\
\text { plitude reflecting the degree } \\
\text { of change, possible permanent } \\
\text { changes in water level }\end{array}$ \\
\hline $\begin{array}{l}\text { Enhanced perme- } \\
\text { ability }\end{array}$ & $\begin{array}{l}\text { Sharp increase in flow, decay } \\
\text { dependent on hydraulic head, } \\
\text { permanent changes amassing } \\
\text { with each earthquake }\end{array}$ & $\begin{array}{l}\text { +ve or - ve change in water } \\
\text { level, potentially permanent } \\
\text { changes amassing with each } \\
\text { earthquake }\end{array}$ \\
\hline $\begin{array}{l}\text { Transient perme- } \\
\text { ability enhance- } \\
\text { ment }\end{array}$ & $\begin{array}{l}\text { Sharp increase in flow, decay } \\
\text { influenced by hydraulic pres- } \\
\text { sure head and ability to heal } \\
\text { (power law decay Elkhoury } \\
\text { et al. 2011) }\end{array}$ & $\begin{array}{l}\text { +ve or -ve changes in wa- } \\
\text { ter level depending on hydro- } \\
\text { logic conditions, gradual re- } \\
\text { turn dependent on degree of } \\
\text { enhancement (i.e. amplitude) } \\
\text { and ability to heal }\end{array}$ \\
\hline Consolidation & $\begin{array}{l}\text { Sharp increase in flow, poten- } \\
\text { tially followed by a reduction, } \\
\text { permanent changes }\end{array}$ & $\begin{array}{l}\text { Longer-term changes in water } \\
\text { level, permanent changes, and } \\
\text { potential landslide movement }\end{array}$ \\
\hline $\begin{array}{l}\overline{\text { Internal }} \text { rupture } \\
\text { or micro-fracture }\end{array}$ & $\begin{array}{l}\text { Longer-term increases in } \\
\text { flow, potentially permanent } \\
\text { changes }\end{array}$ & $\begin{array}{l}\text { Potentially permanent } \\
\text { changes to water levels, } \\
\text { possible landslide movement }\end{array}$ \\
\hline $\begin{array}{l}\overline{\text { Hydraulic }} \text { head } \\
\text { change }\end{array}$ & $\begin{array}{l}\text { Increases and decreases in } \\
\text { flow at the rate of sys- } \\
\text { tem diffusivity, recovery gov- } \\
\text { erned by diffusivity, hydraulic } \\
\text { head, drainage efficiency and } \\
\text { recharge, i.e. rainfall event }\end{array}$ & $\begin{array}{l}\text { +ve or - ve changes in wa- } \\
\text { ter level governed by system } \\
\text { diffusivity, recovery governed } \\
\text { by system diffusivity and hy- } \\
\text { draulic head }\end{array}$ \\
\hline $\begin{array}{l}\text { Coseismic pore } \\
\text { pressure increase }\end{array}$ & $\begin{array}{l}\text { Sharp increase in flow fol- } \\
\text { lowed by exponential de- } \\
\text { cay dependent on diffusivity } \\
\text { (Faoro et al., 2012) }\end{array}$ & $\begin{array}{l}\text { Sharp increase in water level, } \\
\text { the amplitude dependent on } \\
\text { aquifer properties, decay de- } \\
\text { pendent on pressure partition- } \\
\text { ing (fracture-matrix) and ma- } \\
\text { trix diffusivity }\end{array}$ \\
\hline $\begin{array}{l}\overline{\text { Removal of }} \text { or } \\
\text { gaseous phase }\end{array}$ & $\begin{array}{l}\text { Increases in flow rate followed } \\
\text { by recession periods that are } \\
\text { longer for higher amplitude } \\
\text { changes }\end{array}$ & $\begin{array}{l}\text { Water level decreases, in- } \\
\text { creased sensitivity to small } \\
\text { strains induced by earth tides } \\
\text { and barometric pressures. }\end{array}$ \\
\hline
\end{tabular}




\subsubsection{Polarity of groundwater level responses}

Monitoring wells that showed opposing polarity of groundwater level change may only be situated a few 100 metres away from each other and may be of similar or different depth (Figure 3.4, Table 2.2). Wells that monitor groundwater from sub basal slide regions recorded groundwater increases (e.g., DL545a, DL692), whereas wells monitoring landslide internal groundwater recorded either groundwater level increases or decreases (e.g. DL1330a, DL1331a). The observed systematic variation in the polarity of groundwater level changes further illustrates the degree of groundwater compartmentalisation, with confined, unconfined and perched groundwater found within each landslide complex (Beetham and Fergusson, 1990a). It is suggested that the hydrologic responses were induced by dynamic stress changes, through the passage of seismic waves from the intermediate to far-field earthquakes, and the polarity and scale of amplitude of the hydrological responses directly reflects a changes in aquifer properties and local groundwater conditions. An increase or decrease in groundwater level appears to depend on at least three aquifer properties:

1. The local availability of groundwater and connectivity of transmissive fracture zones.

2. The subsurface zone within or below the landslide where the groundwater is located, relating to perched, confined, or unconfined groundwater.

3. The proximity of the groundwater aquifer to drainage tunnels.

Previous studies (e.g. Roeloffs 1998) have interpreted an earthquake-induced transient rise in groundwater level to reflect either a coseismic decrease in groundwater discharge near the monitoring well, or an abrupt increase in pore pressure and subsequent diffusion. Groundwater level changes in Cromwell Gorge landslides were both positive and negative (key observation two), and maintained a consistent temporal character (time to peak pressure change and recovery time). The results from this study suggest that groundwater may be lost by a coseismic increase in discharge, or gained by a coseismic decrease in discharge occurring near the monitoring well. However, consistencies in the temporal character between different monitoring sites suggest a somewhat consistent hydraulic property may be in operation e.g. diffusion (Manga et al., 2012). Therefore, an abrupt increase in pore pressure and subsequent diffusion (Roeloffs, 1998) may be more likely, and groundwater loss may reflect negative pressures existing below perched aquifers, enhanced by the intervention of the drainage systems e.g. tunnels. 


\subsubsection{Polarity of groundwater discharge in tunnels}

Earthquake-induced increases in discharge in tunnels were observed to be always positive (e.g. Figures 3.3 and 3.4). The excess volume that was discharged reflects the size and effectiveness of the drainage tunnels and localised availability of groundwater (Tables 3.1 and 3.2). Other influences include: the portion of confined or unconfined aquifers penetrated, the tunnel overburden and storativity of the different landslide areas and subsurface zones (encountered by tunnels). The tunnel overburden broadly dictates the distance from groundwater source (e.g. rainfall) to drainage system, and a larger overburden may hold more groundwater. Larger fracture zones are inherently more connected and have a greater storage capacity than smaller, less connected fracture zones. What is apparent in the weir data is that the character of earthquake-induced discharge events are very similar between tunnels. The similarities indicate that all tunnel systems are operating in the same (or very similar) manner, despite large differences in baseflow and fracture variation. Because earthquake-induced discharge was positive and similar between different drainage tunnels it is considered to be influenced by three main factors:

1. The position of the tunnel with respect to perched, confined, and unconfined groundwater gradients i.e. the tunnel is below these levels.

2. Connectivity and size of fractures intersected.

3. Upon earthquake stimulation some mechanism(s) rapidly increases groundwater flow into the tunnels systems.

To add context to the source of tunnel groundwater, the excess groundwater volume expelled past weir 549W-01 (DR549, NMD) induced by the Secretary Island earthquake of $1040 \mathrm{~m}^{3}$, is approaching half the volume of an olympic sized swimming pool (2500 $\mathrm{m}^{3}$ ). If $1040 \mathrm{~m}^{3}$ is divided by the surface area of tunnel DR549 c. $1.4 \times 10^{4} \mathrm{~m}^{2}$, then 0.074 $\mathrm{m}^{3}$ of excess water is required to be expelled per $\mathrm{m}^{2}$ of tunnel. Assuming a homogeneous rock mass with $0.1 \%$ porosity, the excess volume of water requires $\geq 74 \mathrm{~m}$ of matrix connectivity in every direction, not including baseflow. In contrast, if $1 \%$ porosity is assumed then approximately $7 \mathrm{~m}$ is required. The permeability structure of the landslides (Beetham and Fergusson, 1990a) suggests that the majority of this volume of water would be expelled from large fracture zones, therefore the surface area of the tunnel that effectively expels groundwater should be reduced in the calculation. However, the storativity (described as the effective porosity) of large fracture zones intersected by drainage tunnels may also be greater than $1 \%$. The degree of rock mass relaxation and dilation around tunnels (Beetham and Fergusson, 1990a) may have increased hydraulic properties, such as storativity and permeability in the vicinity of tunnels. In light 
of the previously determined permeability structure, the above calculations and the approximate one month recession period in earthquake-induced tunnel discharge events, it is suggested that the release of groundwater is not controlled by poroelastic effects (i.e. release of near-tunnel surface stored water), although they may contribute.

\subsubsection{Amplitude of hydrological response}

An important and relevant question with respect to the large landslides that surround the reservoir of a hydroelectric dam, is why some monitoring wells respond with groundwater fluctuations on a metre scale, whereas others only at a centimetre scale? Changes in groundwater levels can be equated to changes in pore pressures $\left(P_{f}\right)$, which if large enough may reduce effective stresses $\left(\sigma_{n}^{\prime}\right)$ in the rock mass to levels insufficient in resisting shear stress (Sibson, 2001) shown by

$$
\sigma_{n}^{\prime}=\left(\sigma_{n}-P_{f}\right)
$$

where $\sigma_{n}$ is the normal stress essentially resisting failure from shear stress (Sibson, 2001). Stress investigations on in situ schist during the Clyde Dam development stages were performed through hydrologic fracturing experiments (Beetham and Fergusson, 1990a). Results yielded northwest-southeast maximum horizontal stress orientation (near-normal to the Dunstan Fault Zone), with the magnitude of maximum horizontal stress: $\mathrm{S}_{h \max }$ 23-24 MPa, approximately six times greater than the vertical: $\mathrm{S}_{v} 3^{-}$ $4 \mathrm{MPa}$ (Thomson, 1993). Stress orientations are anticipated to rotate substantially from the in situ measurements when approaching landslide internal zones. Monitoring well DL545a (Figure 3.1) monitors sub basal groundwater in in situ schist (Beetham and Fergusson, 1990c), the background pressure head in DL545a shown in Figure 2.1 is approximately equivalent to $1.07 \mathrm{MPa}$ of fluid pressure (calculated via well known hydrological equations). It can be calculated that in DL545a a $5 \mathrm{~m}$ increase in water level equates to a c. $0.050 \mathrm{MPa}$ increase in pore pressure at the depth of the well's filter (assuming a unit weight of water at $10^{\circ} \mathrm{C}$ of $9.8 \mathrm{kN} / \mathrm{m}^{3}$ ). Using Equation 4.1 this relates to a potential decrease in effective stress $\left(\sigma_{n}^{\prime}\right)$ of $0.05 \mathrm{MPa}$.

The amplitude and recovery time of the groundwater level changes were modelled with a damped harmonic oscillator (Section 3.1.6). The modelled damping parameters $(\zeta)$ (Table 3.4) are all over-damped, ranging from approximately $\zeta=2$ to $\zeta=11$ and have corresponding angular frequencies $\left(\omega_{0}\right)$ that dictate how fast each model returns (discussed further in Section 4.4.5). The modelled over-damped harmonic oscillation suggests that 
the landslide hydrologic systems respond differently to different degrees of earthquakeinduced shaking: that is, they can more effectively resist hydrologic changes induced by smaller amounts of earthquake shaking than they can resist hydrologic changes from larger amounts of earthquake shaking. The modelled damping parameters (Table 3.4) are interpreted as the ability of the hydrologic system to resist changes induced by earthquake shaking.

The larger groundwater level changes and tunnel discharge correlated to earthquakes with larger shaking intensities such as PGA, Arias and seismic e, but also favoured longduration $(25-50+\mathrm{s})$, broad bandwidth shaking (i.e., spectral category one, outlined by Section 3.2.2.4). The landslide hydrological systems appear more susceptible too, i.e. have less ability to resist $(\zeta<3)$ high intensity (PGA $>1 \%$ ) , long-duration $(25-50+$ s) shaking, which suggests there may be a greater changes in hydraulic properties (such as permeability) associated with this style of earthquake shaking.

\subsubsection{Duration of the hydrologic recovery}

The recovery transients of earthquake-induced responses in groundwater levels and elevated tunnel discharge are different in duration and in character (key observation two). The consistent character of the timescales in both types (but not between) of hydrologic responses suggest hydrological conditions (e.g. hydraulic properties such as diffusivity and permeability) are similar between monitoring sites of the same type.

\section{Groundwater level recovery}

The results from this study demonstrate that the duration of earthquake-induced groundwater level changes (time to peak pressure change and subsequent recovery) are not governed by the amplitude or polarity of the change (Figures 3.8, 3.10, 3.14 and Tables 3.2 and 3.3).

As mentioned in Section 4.4.4, the damped harmonic oscillator model enables the damping parameter $(\zeta)$ and the angular frequency $\left(\omega_{0}\right)$ to be used to describe how effectively the landslide hydrologic systems can resist changes induced by earthquake shaking. The modelled recovery period is determined by $\omega_{0}$ (Table 3.7 ), a smaller $\omega_{0}$ dictates a proportionally longer return of the model. It has been proposed that the consistent character of the recovery periods for groundwater level changes is suggestive that a relatively uniform process is occurring that governs the rate of recovery (e.g. diffusion or consistent rate of permeability recovery). The small $\omega_{0}$ range of the modelled recovery period (0.018-0.056) also suggests some common process. 
Throughout the landslide structures there is evidence of carbonate cements (Hewitt and Fergusson, 1990) and clayey sediments, and old groundwater was previously measured to be supersaturated with dissolved calcite (Beetham and Fergusson, 1990a). Cements and sediments build up in tunnel systems, and weirs require periodic cleaning to maintain accuracy of flow measurements (N. Whitford personal communication 2014, Figure 2.3). It has been suggested by Cox et al. (2012) that clay weathering and mineral precipitation are occurring within the Cromwell Gorge landslides, which may cause an amassing decrease in drainage efficiency. For example, the background water level in DL545a, NMD (Figure 3.1) was observed to have steadily risen approximately $25 \mathrm{~m}$ over a 20 year period. The timescales of recovery from earthquake-induced groundwater level changes in DL545a were far shorter (c. 1 year) and did not appear in well DL545a to affect the long-term rise, therefore may not be governed by the same processes as the long-term rise.

A final observation that may offer insight into what governs the recovery of groundwater level changes is the observed recovery from rainfall-induced groundwater level change that was observed in other monitoring wells not presented (note key observation 3 ). The duration of observed recovery from rainfall-induced increases in groundwater levels was longer than most earthquake-induced groundwater level changes, showing a gradual rise to peak groundwater level increase in the order of months. The subsequent recovery periods were also longer, suggesting that the mechanisms that allow recovery of rainfallinduced groundwater level change work more slowly than those that govern recovery from earthquake-induced groundwater level changes.

A question was left open in section 1.3, regarding how far-field earthquake dynamic stresses may induce and sustain elevated groundwater pressures (i.e. groundwater levels) in different hydrological systems. The analysis of groundwater level changes in the Cromwell Gorge landslides suggests it is the hydrological systems themselves that sustain the elevated fluid pressures, not the earthquakes. The earthquakes may induce changes to the hydrological systems (e.g. changes to hydraulic properties such as permeability), but the amplitude and duration of changes (the observed response) in the landslides reflect local aquifer properties and settings, such as the movement of perched and sub basal groundwater.

\section{Discharge recession}

The recession periods from earthquake-induced peak discharge in tunnel weirs were shorter than the recovery period of groundwater level changes in monitoring wells (key observation 2, e.g, Figure 2.4), and appeared similar to a power law relation as suggested 
by Elkhoury et al. (2011). In some weir data (e.g., 590W-01, 556W-01 Figure 3.3), during earthquake-induced elevated discharge, there appeared to be an increased need to clean the weirs, suggestive of an increase in the build-up of sediments and/or carbonates during earthquake-induced flow rate increase. An increase in the need for weir cleaning was not apparent during storm events which suggests that larger quantities of sediments and/or cements were expelled as a result of earthquake shaking, not just as a result of greater flow from increased hydraulic head (i.e. rainfall). This observation supports the previously stated mechanism for permeability enhancement through earthquake-induced entrainment and subsequent removal of pore clogging particulates (Brodsky et al., 2003).

\subsection{Conceptual model for groundwater movement}

Figure 4.3 shows the developed conceptual model to explain the movement of geoengineered groundwater through the Cromwell Gorge landslides. The upper figure shows the position of three monitoring wells A, B and C. Wells A and B monitor perched, landslide internal groundwater, that upon earthquake stimulation may transfer from an upslope compartment to a downslope compartment. This scenario provides explanation for matching $\Delta \mathrm{P}$-times between different wells in some slide areas. In the model the two $\Delta$ P-times (well $\mathrm{A}$ and well $\mathrm{B}$ ) would be controlled by the earthquake-induced groundwater transfer through the fracture zone (shown in inset $\mathrm{B}$, lower model). Well $\mathrm{C}$ monitors sub basal groundwater that is confined (or semi-confined) by an impermeable sub basal shear zone. Earthquake shaking may increase groundwater flow into these areas faster than it can flow out (transferred from upslope regions), in which case the wells would record a large increase in groundwater levels due to an increase in confined groundwater pressure. Alternatively, the sub basal groundwater zone may be depressed (from assisted drainage) and the well would record the filling up of the sub basal zone aided by a steep hydraulic gradient (further caused by assisted drainage downslope). In this scenario the groundwater is returning to the pre-drainage equilibrium piezometric levels (shown by the blue dashed arrow) but the drainage systems impedes this.

The lower model in Figure 4.3 shows groundwater flow through fracture zones into a drainage tunnel; the $\mathrm{V}$-notch weir is located near the exit. Inset A rotates the plane of view by 90 degrees and shows how tunnels have intersected large conductive fracture zones. Inset B (at a fracture-scale) illustrates flow through the fracture zones with greater flow through large fractures, smaller flow through smaller fractures and possible diffusive flow from the matrix into the fractures (Faoro et al., 2012). Flow through fractures may become increased during earthquake shaking by entrainment and removal of fracture clogging particulates (e.g. Brodsky et al. 2003). Earthquake-induced fracture 
flow into tunnels may exhaust readily available groundwater supplies quickly, due to fractures being more conductive closer to tunnel surfaces as a result of tunnel-induced rock mass relaxation (Beetham and Fergusson, 1990a). However, results show that groundwater supplies cannot become completely exhausted. The conceptual model suggests that once flow through larger fracture begins to reduce, flow through smaller fractures may help maintain elevated discharge rates.

The conceptual model suggests the many different groundwater level changes (polarity and amplitude) reflect the transfer of perched and sub basal groundwater between different landslide compartments. The ability to transfer groundwater from one compartment to the next is dictated by the highly fractured, anisotropic permeability structure (Beetham and Fergusson, 1990a). The rapid increase in earthquake-induced tunnel discharge may be due to proportional increases in flow, in both large and small fractures. The decay in flow rate is rapid in comparison to monitoring wells, as large fractures truncated by the tunnel may quickly exhaust readily available groundwater supplies, yet elevated smaller-volume flow is maintained by smaller fractures. Although the groundwater systems are undoubtedly more complex than the conceptual model portrays, the mechanism(s) that govern the earthquake-induced increase in groundwater flow may be a transient increase in permeability in fracture zones, due to the entrainment and removal of blockages (Roeloffs, 1998; Brodsky et al., 2003; Manga and Rowland, 2009; Elkhoury et al., 2006, 2011).

In the model the large groundwater level changes and/or increases in confined groundwater pressures are sustained for long periods (i.e. on the order of one year), due to the aquifer's hydrological conditions and the recovery of the aquifer's hydraulic properties. 

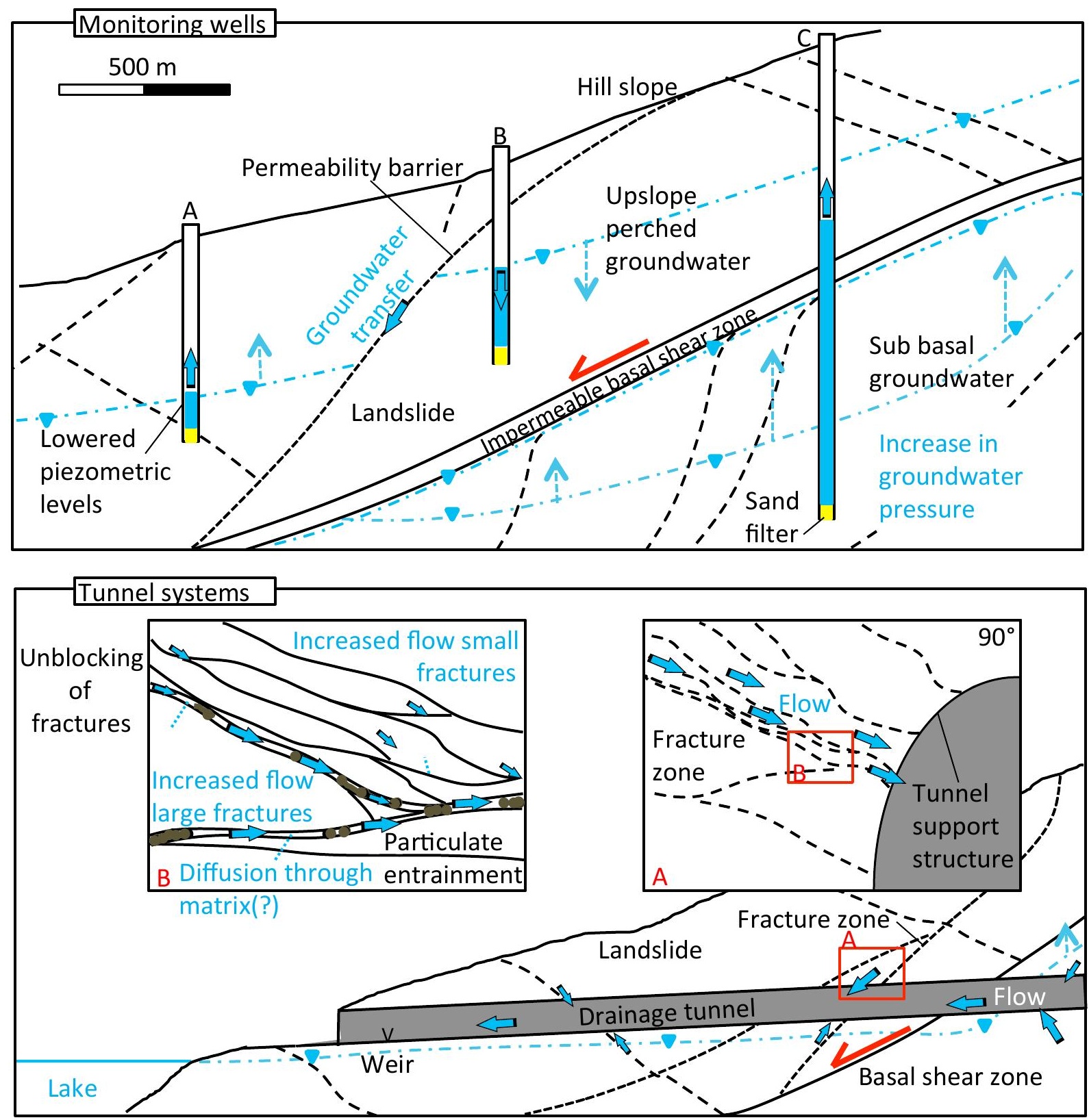

Figure 4.3: Conceptual model to illustrate how geoengineered groundwater moves through the schist landslides. The upper figure shows the position of three monitoring wells/boreholes, wells labelled A and B monitor perched landslide internal groundwater that upon earthquake stimulation may transfer from an upper compartment to a lower compartment, this scenario provides explanation for matching $\Delta \mathrm{P}$-times between different wells. Well $\mathrm{C}$ monitors sub basal groundwater that records an increase in confined groundwater pressure. The lower figure shows the flow into tunnel systems through large conductive fracture zones. Inset A rotates the view 90 degrees and shows how the tunnels have truncated fracture zones. Inset B, at a fracture-scale shows high-volume flow through large fractures, smaller-volume flow through small fractures and possible diffusive flow from the matrix into the fractures. All flow regimes may increase upon earthquake stimulation. The scale bar in the upper figure approximates the size with a degree of vertical exaggeration. 


\subsection{Geoengineering, landslide movement and earthquake- induced effects}

The long-term effect of the landslide management systems on the groundwater movement can be observed through the long-term trends in tunnel discharge and piezometer levels (key observation seven). Some weirs that recorded a long-term decrease in baseflow are 556W-01 NMD and 547W-01 NMU (Figure 3.3). The long-term reduction in tunnel baseflow may be interpreted in several ways, such as an overall decrease in drainage efficiency (i.e. less water is able to drain) or the drainage systems are further exerting control (i.e. there is less water to drain). The long-term rainfall record shows from approximately 2001 - 2010 there were less frequent, large storm events and post 2010 an overall increase in rainfall has occurred. Some weirs have recorded a rise in baseflow (e.g. 590W-01, NMD) post 2010, suggesting some hydrological systems respond more slowly than others to recharge, or assisted drainage has become more effective in some areas.

Long-term piezometer levels have responded in one of three ways to the drainage system (key observation seven). These long-term trends are not observed to be altered by earthquake shaking. Long-term decreases in groundwater levels suggest the drainage systems are continuing to exert control on the groundwater systems, maintaining safety for the dam. Increases in piezometer levels can reflect an increase in unconfined groundwater level or an increase in pore pressures, and suggest a decrease in drainage efficiency. The results from this study show there were systematic large and small groundwater level responses and increases in tunnel discharge induced by dynamic earthquake shaking. The results suggest that the consistent character of the hydrological responses is reflective of consistent changes in hydrological conditions, that are governed by consistent changes in hydraulic properties, in particular permeability and diffusivity of the schist landslides. Moreover, and perhaps more importantly, in view of the geographical location of this study, are that the earthquakes and the earthquake-induced hydrological responses are having no observed affect on the stability of the landslides or creating changes to the large-scale drainage systems.

However, heavy and/or prolonged rainfall has previously been correlated to increased creep in some active portions of slide areas (Macfarlane, 2009). These active portions are well-known by the engineers at Clyde Dam and are monitored closely. Landslide movement (e.g. accelerated creep) dictates volumetric strain change, for example dilatation in landslide head regions and compression in the lower slopes (Hutchinson, 1994). Elsewhere, it is possible that the dynamic stresses imposed by far-field earthquakes could be causing small changes in volumetric strain associated with landslide creep, beyond 


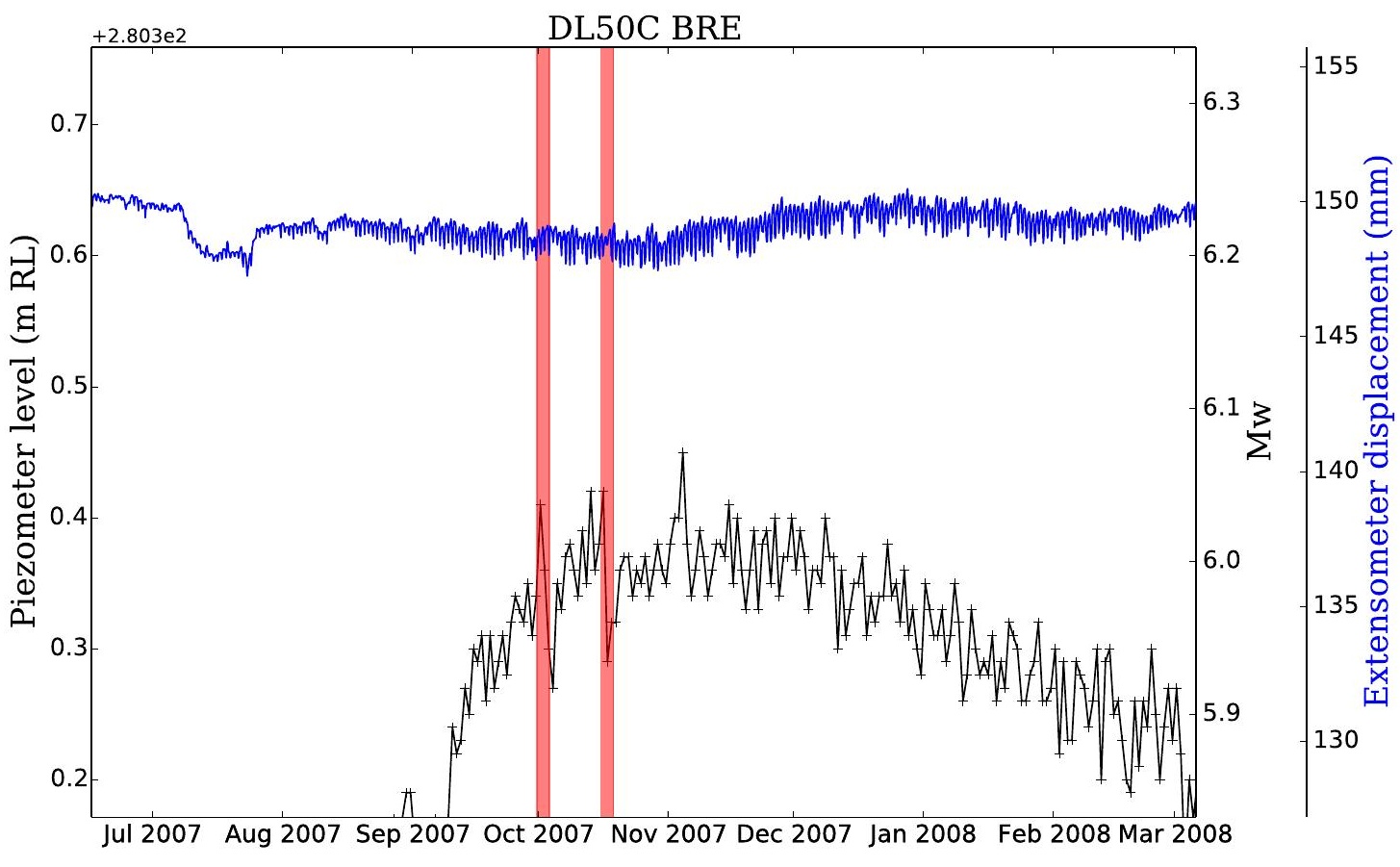

Figure 4.4: Piezometer data from DL50C (black), and local extensometer data (blue) from the Brewery Creek Slide area active portion, showing two possible reductions in water level in response to the 2007 Puysegur and 2007 George Sound earthquakes (red bars), on top of a rainfall-induced increase in piezometer level. The blue extensometer displacements show no movement induced by the two earthquakes.

the resolution of the monitoring infrastructure. Small-scale changes in volumetric strain on the order of $10^{-6}$ are all that is required to produce hydrological responses (Manga et al. 2012).

\subsubsection{Monitoring well DL50C and rainfall}

Monitoring well DL50C is located in a known active portion of the Brewery Creek Slide. DL50C monitors an isolated, compartmentalised, perched, low permeability aquifer that showed no influence from filling Lake Dunstan (Macfarlane, 2009). Macfarlane (2009) identified when the piezometric groundwater levels measured in well DL50C exceed c. $280 \mathrm{~m}$ RL, accelerated landslide creep occurs in the Brewery Creek Active Portion (measured by a local extensometer BRERX-01). The increased creep events measured by extensometers and inclinometers were seen to trail behind piezometer levels, confirming that the rise in piezometer levels are not caused by the landslide movement (Macfarlane, 2009). DL50C shows the rainfall-induced high groundwater levels take a period of months to dissipate, and the accelerated creep (when occurring) follows suit. 


\section{Potential effects from dynamic shaking}

Investigation of DL50C data suggests the aquifer being monitored has low sensitivity to earthquake-induced shaking, and only two earthquake-induced groundwater level changes are observed and correlate to the 2007 Puysegur Trench and 2007 George Sound earthquakes. Figure 4.4 shows the two groundwater level changes to be subtle but different from the rest of the hydrological signals within the piezometer data, and no movement is seen on extensometer BRERX-01 (shown in blue) in response to the earthquakes or earthquake-induced hydrological responses. Figure 4.4 also shows the groundwater level is rising due to groundwater infiltration in response to rainfall. The Puysegur 2007 earthquake (first red bar) induced a $0.08 \mathrm{~m}$ rise immediately followed by a $0.15 \mathrm{~m}$ fall. The 2007 George Sound earthquake (second red bar) induced a similar pattern $(0.05 \mathrm{~m}$ rise $0.15 \mathrm{~m}$ fall) but there was more distinct offset in the background trend of approximately $0.05 \mathrm{~m}$. The amplitude of the earthquake-induced groundwater level changes is small in comparison to that induced by rainfall.

These two earthquake-induced groundwater level changes (Figure 4.4) are uncharacteristic compared to other sites (Table 3.3, e.g., Figure 3.8), most likely due to the high sensitivity of the aquifer to rainfall. Earthquake shaking in this instance (Figure 4.4) has reduced the rising rainfall-induced piezometer level and brought the active portion further away from accelerated failure, albeit by a very small amount. Whether this is a common occurrence remains unknown, but it is suggestive that under the right groundwater conditions (e.g. a perched, compartmentalised aquifer undergoing an increase in groundwater levels) the earthquake-induced hydrological response may actually increase the slope stability by lowering groundwater levels.

\subsection{Shallow crustal permeability}

The Cromwell Gorge landslides are large (23-900 ha), comprised of highly disturbed Otago Schist, ranging from c. 10-270 m metres in thickness (Table 1.1), and are known only to move by slow flexural creep (Beetham and Fergusson, 1990a; Macfarlane, 2009; Halliday, 2010). However, landslides are stress relief features i.e. the rock mass has already failed due to imposed stresses e.g. topographic stress (Halliday, 2010; Upton and Sutherland, 2014). Failure of the rock mass is a result of stresses surpassing some threshold governed by the strength of the rock mass (Hoek and Brown, 1997). Rock mass failure in southern New Zealand is associated with topographic stresses (Upton and Sutherland, 2014) and the regional stress field (Reyners et al., 2002). Permeability and permeability barriers in hard rock settings are associated with the degree of rock 
damage e.g. fractures and fracture filling gouge (Hoek and Brown, 1997; Brodsky et al., 2003), and in the Cromwell Gorge landslides rock damage is abundant (Beetham and Fergusson, 1990a).

Permeability testing, carried out during development for the Clyde Dam (e.g. Beetham and Fergusson 1990a,b,c; Smith et al. 1990) found that permeabilities measured below the sub basal failure zones (i.e. in situ schist) were higher than permeabilities measured in landslide internal zones (Table 1.2). Additionally, through tunnelling and drilling operations it was found that the sub basal aquifers often contained confined, over-pressured groundwater (Beetham and Fergusson, 1990a). Upton and Sutherland (2014) propose that permeability (in the upper crust) associates with a proximity to rock mass failure, and that topographic loading (although only contributing $<50 \%$ of the stress required for failure) may guide where this failure occurs. This conceptual framework may explain why zones underneath the landslides have higher permeabilities.

Cromwell Gorge landslides can be broadly divided into shallower zones that have undergone repeated rock-failure (i.e. landslide internal zone) and deeper zones that have not failed in the same translational context but are considered disturbed (i.e. sub basal in situ schist). Results from this study show that the shallow-crustal groundwater aquifers contained in both these two broadly defined zones responded to earthquake shaking by temporary changes in groundwater levels and release of groundwater through tunnels. Monitoring wells in both zones recorded the same characteristic groundwater level response, of a $2-5$ week delay to peak pressure change followed by c. 1 year recovery period. All monitoring wells investigated have shown an amount of permanent groundwater level suppression in response to the drainage infrastructure. Whether the landslide groundwater systems now have heightened sensitivity to the effects induced by earthquakes is yet to be uncovered. However, observations of how some monitoring wells only record earthquake-induced groundwater responses once partial groundwater recovery from the drainage-suppressed groundwater levels have been achieved, suggests that the landslide hydrologic systems are more responsive to earthquake shaking when groundwater levels are significantly higher.

\subsection{Extraneous variables that may have contributed to the results}

\section{Hydrological influences}

It cannot be dismissed that seasonality could have played a role in the ability for the landslides to respond hydrologically. For example, the 2007 George Sound earthquake 
occurs during spring, and the 2003 Secretary Island and 2009 Dusky Sound earthquakes during late winter. There is however, no evidence for a reduced (or increased) availability of groundwater in piezometer data or tunnel baseflow, and temperature probes show no prolonged cooling after hydrologic responses in winter. Furthermore, greater groundwater availability provides no explanation for the proportional differences in recovery times.

The supersaturation of groundwater with dissolved calcite (Beetham and Fergusson, 1990a) may have an influence on the groundwater movement through fracture zones in the landslides, and also on the groundwater flow through the monitoring wells' sand filters. Up to date groundwater geochemistry and geochemistry of precipitated calcite may add clarity on the source(s) of groundwater.

\section{Seismological influences}

Earthquake directivity may show influence on calculated PGA values and determine frequency bandwidth of spectral characteristics. At present no means of assessing these effects for earthquakes not recorded at EAZ are known, but it is considered that technical reports and publications on individual earthquakes (refer to Table 3.5 for list of publications used) would have alluded to potential directivity if detectable (e.g., Fry et al. 2010). Velocity models used in the analysis of earthquake source characteristics are $2 \mathrm{D}$ and therefore, are not fully integrated like $3 \mathrm{D}$ velocity models. Influences of Pwave first motion take-off angles were not considered deterministic, although intriguing in comparison to previously reported findings (e.g. Manga et al. 2003), and may have a greater influence than concluded. Seismometer site conditions are observed to have strong influences on the seismometer signals (Smith E. G. C., personal communication, 2013). However, this is not anticipated to change the classification of spectral characteristics (Section 3.2.2.4), as they do not rely on comparisons between sites, and each seismometer site is considered to maintain a high degree of relative accuracy. 



\section{Chapter 5}

\section{Conclusions}

This chapter summarises the main findings of the study, followed by direction for future research.

\subsection{Main findings}

- A sophisticated, extensive and diverse groundwater monitoring network records hydrological behaviour of geoengineered groundwater systems within deep seated, slow-creep schist landslides in Cromwell Gorge, Central Otago. The monitoring network is spatially concentrated on the seven landslide groundwater systems. Data from 270 borehole piezometers and 45 underground V-notch weirs were scanned for hydrological responses to earthquakes over a 22 year monitoring period (1991-2013). Earthquake-induced hydrological responses were observed in 21 piezometers and $12 \mathrm{~V}$-notch weirs records, making this dataset one of the most comprehensive, long-term, multiple earthquake hydrology datasets currently available in the world.

- The hydrological responses induced by the 10 earthquakes were temporary, and show the groundwater systems within Cromwell Gorge landslides are sensitive to the transient effects of earthquake shaking from distances categorised as intermediateand far-field. The groundwater systems responded in a characteristic manner, consistently to each earthquake. Piezometer data from monitoring wells $10-260 \mathrm{~m}$ deep recorded delays to peak pressure changes generally in the order of $2-5$ weeks, followed by a long slow recovery in the order of one year (Figure 4.1). V-notch weirs recorded sharp increases in flow rate with maximum flows reached in $0-6$ hours, then comparatively long recovery over periods in the order of one month. 
Earthquake-induced groundwater level changes were always positive or always negative, and are interpreted to reflect systematic responses at each monitoring site. Earthquake-induced changes to tunnel discharge always involved increases in weir flow rate. The tunnel drainage systems have created an open system from which groundwater is lost during faster responses in groundwater discharge than the semi-closed system monitored by wells to the dynamic shaking of earthquakes.

All observed earthquake-induced responses were temporary with clear recovery to pre-earthquake conditions. By way of contrast, some permanent or longer-term changes have occurred, and are still occurring, in response to drainage infrastructure and rainfall recharge of groundwater.

- Different monitoring sites recorded different amplitudes of hydrological response (e.g. $\Delta$ groundwater level), yet they maintained the same character of response to different earthquakes. Some wells exhibited metre-scale increases or decreases in groundwater levels, whereas changes at other well sites were limited to centimetrescale changes. Importantly, the duration of observed response was not governed by the amplitude of response: large amplitude responses recovered on the same timescales as small amplitude responses. It is concluded the scale of the amplitude (metres or centimetres) and polarity (+ve or -ve) of hydrologic response is dependant on aquifer setting, such as whether the groundwater is confined, unconfined or perched, which the drainage systems may have altered. The consistency in the scale of time to peak pressure change and recovery time throughout monitoring wells suggests the recovery of groundwater level changes are dependent on some form of consistent hydraulic property, such as diffusion or geochemical permeability recovery, that occurs in the fracture zones dictating the permeability structure.

- The earthquakes that induced the hydrological responses were large $\left(\geq \mathrm{M}_{w} 6.2\right)$, regional $(130-630 \mathrm{~km})$ and relatively shallow $(<30 \mathrm{~km})$. At these distances the effects of earthquake static stress changes have decayed more than the earthquake dynamic stress changes. Therefore, it is likely that the hydrological responses were induced by the earthquake dynamic stresses (i.e. transient passage of seismic waves) rather than static changes to the regional stress field. Calculated earthquake take-off angles for the earthquakes that induced the proportionally larger hydrologic responses in Cromwell Gorge landslides departed from the compressional quadrant or were near the nodal plane of the earthquake focus. However, other earthquakes inducing a hydrological response locate Cromwell Gorge in the dilatational quadrant, therefore it is concluded that the polarity of the P-wave first arrival has no bearing on the ability for an earthquake to induce a hydrological response or determine the polarity of groundwater level change. The landslide hydrologic systems are not exceptionally sensitive to small degrees of earthquake 
shaking when compared to other hydrological systems and responses reported in the international literature. The smallest measured horizontal PGA value of 0.097 $\% g$ observed to induce a hydrologic response was from the $\mathrm{M}_{w} 7.3$ Puysegur 2007 earthquake. The hydrological response was very small and only detectable in a few favourable piezometers. Furthermore, it was superseded 15 days later by the hydrological response to the much larger measured PGA of $1.45 \% \mathrm{~g}$ from the $\mathrm{M}_{w} 6.7$ George Sound earthquake. The George Sound earthquake produced one of the largest groundwater level changes observed in the monitoring network, up to 6 $\mathrm{m}$. The largest groundwater level change was $6.9 \mathrm{~m}$ in DL545a following the 2003 $\mathrm{M}_{w}$ 7.0 Secretary Island earthquake (calculated PGA $1.17 \% \mathrm{~g}$ ).

- Within the characteristic earthquake-induced hydrological responses of groundwater level change and tunnel discharge, different earthquakes consistently induced proportionally different amplitudes of hydrological response (groundwater level change and tunnel discharge), time to peak pressure change, and recovery time of the response. A damped harmonic oscillator model is used to compare the proportionally different groundwater level changes. The damping parameter $(\zeta)$ and angular frequency $\left(\omega_{0}\right)$ enables a comparison of how the landslide groundwater systems can resist hydrological change from the different shaking intensities and styles of earthquake shaking. The hydrological systems are more effective at resisting change $(\zeta>>3)$ when the shaking intensities are low $(\mathrm{PGA}<0.8 \% g)$ and the shaking is occurring on a narrow frequency bandwidth over a short duration $(<25$ s). Moreover, the hydrological systems are less effective at resisting change $(\zeta<3)$ from earthquakes shaking with PGA values $>0.8 \% \mathrm{~g}$, on a broad frequency bandwidth and over a long $\left(25-50 \mathrm{~s}\right.$ or longer) duration. The angular frequency $\left(\omega_{0}\right)$ of the modelled groundwater level change reflects the duration of the recovery time, and shows that the landslide hydrological systems recover proportionally quicker ( $\zeta: \omega_{0}$ ratio is reduced) when earthquake shaking is also over a broad frequency bandwidth and long ( $25-50 \mathrm{~s}$ or longer) duration.

- The largest hydrological changes at each monitoring site are not conclusively driven by greater shaking intensities (PGA, PGV, Arias, and $e$ ). It is concluded that the earthquake shaking intensity has to overcome a certain threshold to induce a hydrological response (e.g. PGA c. $0.2 \% \mathrm{~g}$ ), above which the amplitude of the hydrological response will not alone be determined by the shaking intensity (e.g., PGA) but more so by the duration and frequency bandwidth of earthquake shaking.

- A conceptual model is presented to explain earthquake-induced groundwater movement throughout the landslides in Cromwell Gorge. The model illustrates that 
groundwater level changes in compartmentalised aquifers can be a result of groundwater transfer between aquifers, occurring along fracture zones that become more conductive during earthquake shaking. In confined sub basal groundwater systems where depressed piezometric levels can occur as results of drainage, the increases in groundwater level may be a result of either an increase in groundwater pressure or an increase in hydraulic head. Both result from increased groundwater flow into the sub basal aquifer through fractures. The conceptual groundwater model associates larger amplitude earthquake-induced hydrological responses, and proportionally reduced time to peak pressure change and recovery time, to greater changes in the hydraulic properties of the landslide aquifers. The model suggests that greater groundwater flow is achieved through relatively greater unblocking of fracture networks, through the transient permeability enhancement mechanism that has been previously outlined (e.g. Roeloffs 1998; Brodsky et al. 2003; Elkhoury et al. 2006, 2011). Furthermore, the recovery phase of groundwater level changes may be dependant on the hydrologic systems' ability to recover from enhancement of hydraulic properties (e.g. permeability), through re-blocking of fractures (e.g. particulate accumulation and/or geochemical precipitation), or redistribution of pressure (Manga et al., 2012).

\subsection{Directions for future research}

This study showed that groundwater systems can be difficult to compare even when similar in nature and close to each other. Earthquake-induced hydrological responses are interpreted to reflect hydrological changes occurring within the hydrological systems. These hydrological changes appear to reflect hydraulic changes of the reservoir/rock mass properties, such as permeability, and in the case of the Cromwell Gorge landslides are temporary. In order to further understand potential hydraulic changes and further narrow down the search for the causal mechanism(s) in operation, more data and higher resolution monitoring (e.g. decrease in sampling interval of hydrological and nonhydrological monitoring equipment) are required. Complementary data would include: downhole strain meters, geochemistry of groundwater and suspended particulates, and of course (although regrettably) more large earthquakes.

Future work will include a more comprehensive statistical analysis of the observed patterns in groundwater level changes, in order to increase confidence and further quantify the hydrologic variations. Hydrological data (monitoring wells and tunnel weirs) in which small fluctuations induced by small strains from earth tides and thermal stresses 
are observed, can be interpolated and resampled to provide a consistent long-term sampling interval, followed by a more detailed analysis in the effect earthquakes have on the timing of these small tidal induced changes (e.g., $\Delta$ phase lag).

This study worked on the premise that the earthquakes that induced hydrological responses, which occurred at intermediate and far-field distances of between $130-630 \mathrm{~km}$, were at distances such that the dynamic stresses associated with the passage of seismic waves were considerably greater than earthquake-related static stresses (Manga et al., 2012). Static stress changes associated with each earthquake have not been modelled as part of this study. However, other studies (e.g. Fry et al. 2010, Zhan et al. 2011) suggest the associated static stress changes are indeed small, and less than the peak dynamic stresses suggested by measured PGV values (Table 3.6), but may be large enough to also induce hydrological responses (e.g. strains $>10^{-6}$, Manga et al. 2012). Further work could be done to model the static stresses of each earthquake, in order to test the extent to which static stress changes at source may result in stresses of different sign or amplitude in Cromwell Gorge. In all likelihood, however, there could also be locally induced stresses changes (and strains) of similar magnitude associated with small shifts in the landslides, albeit at a scale insufficient to be detected by the monitoring equipment, but also of sufficient magnitude $\left(>10^{-6}\right)$ to induce hydrological responses. More careful assessment of the landslide strain monitoring, and potentially a change to the methodology, might elucidate strains at this level in future studies.

Compiling the large hydrological dataset obtained from Contact Energy is an ongoing project and will require a purpose built system allowing it to be efficiently accessed by others. The initial platform in making this large dataset accessible was developed during this study. 



\section{Appendix A}

\section{Data to accompany the methodology}

\section{A short note regarding the use of industry collected data}

The monitoring strategy was designed for assessing the stability of the landslides and not with research ideals in mind. The study has had to work with available data, without control on recording procedures e.g. sampling rate. Significant problems encountered in this study include: the size of the dataset and therefore how to realistically cope with it in the allowable timeframe. Furthermore, the sheer size of the dataset and the specialised data format(s) and metadata were not easily reassembled.

TABLE A.1: New Zealand 2D velocity models used for calculating earthquake takeoff angles, angles of incidence, and ray tracing as outlined in chapter 4 . The number corresponds to the map region on Figure 2.8

\begin{tabular}{|l|l|l|}
\hline Depth & \multicolumn{1}{|c|}{ Model region } & Number \\
\hline $\begin{array}{l}\text { Depth } \\
(\mathrm{km})\end{array}$ & $\begin{array}{l}\text { NEW ZEALAND STANDARD MODEL } \\
\left(\mathrm{km} \mathrm{s}^{-1}\right)\end{array}$ & No. \\
\hline 0 & 5.5 & 3.3 \\
12 & 6.5 & 3.7 \\
33 & 8.1 & 4.6 \\
\hline \hline Depth & WELLINGTON MODEL & No. \\
$(\mathrm{km})$ & $\left(\mathrm{km} \mathrm{s}^{-1}\right)$ & 2 \\
\hline 0 & 4.4 & 2.54 \\
0.4 & 5.63 & 3.16 \\
5 & 5.77 & 3.49 \\
15 & 6.39 & 3.5 \\
\hline \multicolumn{2}{|c|}{ Continued on next page }
\end{tabular}


Table A.1 - continued from previous page

\begin{tabular}{|c|c|c|}
\hline $\begin{array}{l}25 \\
35 \\
45\end{array}$ & $\begin{array}{l}6.79 \\
8.07 \\
8.77\end{array}$ & $\begin{array}{l}3.92 \\
4.8 \\
4.86\end{array}$ \\
\hline $\begin{array}{l}\text { Depth } \\
(\mathrm{km})\end{array}$ & $\begin{array}{l}\text { HAWKE'S BAY MODEL } \\
\left(\mathrm{km} \mathrm{s}^{-1}\right)\end{array}$ & $\begin{array}{l}\text { No. } \\
3\end{array}$ \\
\hline 0 & 5.5 & 3.3 \\
\hline 12 & 6.5 & 3.7 \\
\hline 33 & 8.1 & 4.6 \\
\hline $\begin{array}{l}\text { Depth } \\
(\mathrm{km})\end{array}$ & $\begin{array}{l}\text { TAUPO MODEL } \\
\left(\mathrm{km} \mathrm{s}^{-1}\right)\end{array}$ & $\begin{array}{l}\text { No. } \\
4\end{array}$ \\
\hline 0 & 3 & 1.7 \\
\hline 2 & 5.3 & 3 \\
\hline 5 & 6 & 3.5 \\
\hline 15 & 7.4 & 4.3 \\
\hline 33 & 7.78 & 4.39 \\
\hline 65 & 7.94 & 4.51 \\
\hline 96.4 & 8.08 & 4.52 \\
\hline $\begin{array}{l}\text { Depth } \\
(\mathrm{km})\end{array}$ & $\begin{array}{l}\text { CLYDE MODEL } \\
\left(\mathrm{km} \mathrm{s}^{-1}\right)\end{array}$ & $\begin{array}{l}\text { No. } \\
5\end{array}$ \\
\hline 0 & 4.4 & 2.6 \\
\hline 0.5 & 6 & 3.3 \\
\hline 12 & 6.5 & 3.7 \\
\hline 33 & 8.1 & 4.6 \\
\hline $\begin{array}{l}\text { Depth } \\
(\mathrm{km})\end{array}$ & $\begin{array}{l}\text { CENTRAL SOUTH IS MODEL } \\
\left(\mathrm{km} \mathrm{s}^{-1}\right)\end{array}$ & $\begin{array}{l}\text { No. } \\
6\end{array}$ \\
\hline 0 & 5.5 & 3.3 \\
\hline 12 & 6.5 & 3.7 \\
\hline 33 & 8.1 & 4.6 \\
\hline $\begin{array}{l}\text { Depth } \\
(\mathrm{km})\end{array}$ & $\begin{array}{l}\text { WESTLAND MODEL } \\
\left(\mathrm{km} \mathrm{s}^{-1}\right)\end{array}$ & $\begin{array}{l}\text { No. } \\
7\end{array}$ \\
\hline 0 & 5.5 & 3.3 \\
\hline 12 & 6.5 & 3.7 \\
\hline 33 & 8.1 & 4.6 \\
\hline $\begin{array}{l}\text { Depth } \\
(\mathrm{km})\end{array}$ & $\begin{array}{l}\text { FIORDLAND MODEL } \\
\left(\mathrm{km} \mathrm{s}^{-1}\right)\end{array}$ & $\begin{array}{l}\text { No. } \\
8\end{array}$ \\
\hline 0 & 5.5 & 3.3 \\
\hline
\end{tabular}


Table A.1 - continued from previous page

\begin{tabular}{|l|l|l|}
12 & 6.5 & 3.7 \\
33 & 8.1 & 4.6 \\
\hline \hline Depth & HIKURANGI MODEL & No. \\
$(\mathrm{km})$ & $\left(\mathrm{km} \mathrm{s}^{-1}\right)$ & 9 \\
\hline 0 & 5.5 & 3.3 \\
12 & 6.5 & 3.7 \\
33 & 8.1 & 4.6 \\
\hline \hline Depth & KERMADEC MODEL & No. \\
$(\mathrm{km})$ & $\left(\mathrm{km} \mathrm{s}^{-1}\right)$ & 0 \\
\hline 0 & 5.5 & 3.3 \\
12 & 6.5 & 3.7 \\
33 & 8.1 & 4.6 \\
\hline \hline Depth & LORD HOWE MODEL & No. \\
$(\mathrm{km})$ & $\left(\mathrm{km} \mathrm{s}^{-1}\right)$ & 11 \\
\hline 0 & 5.5 & 3.3 \\
12 & 6.5 & 3.7 \\
33 & 8.1 & 4.6 \\
\hline \hline Depth & VENING-MEINESZ MODEL & No. \\
$(\mathrm{km})$ & $\left(\mathrm{km} \mathrm{s}^{-1}\right)$ & 12 \\
\hline 0 & 5.5 & 3.3 \\
12 & 6.5 & 4.6 \\
33 & 8.1 & \\
\hline \hline
\end{tabular}

Visual comparison between a conventional spectrogram (i.e. sinusoid function) and the continuous wavelet transform (i.e. Morlet wavelet function) 


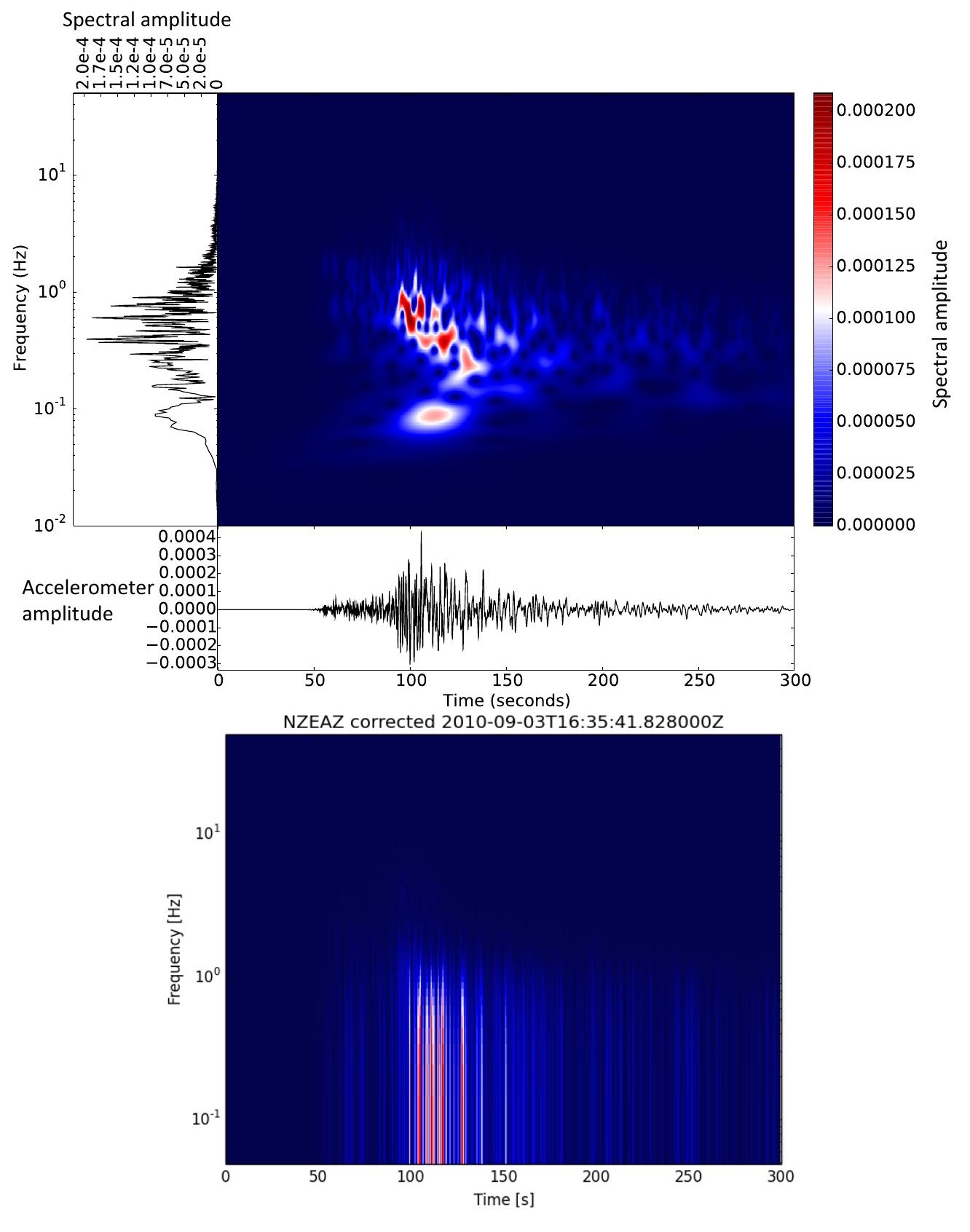

Figure A.1: Example of the continuous wavelet transform (upper plot) for the Darfield 2010 accelerometer data at EAZ (as shown in Chapter 2), and a more conventional FFT spectrogram for the same earthquake (lower plot). Instrument response was removed prior to processing. A scale resolution factor of 0.05 and a time-step of 0.02 are used for the CWT processing, and a window length of 0.02 is used for the FFT spectrogram. 
Appendix B

Piezometer and weir data:

Cromwell Gorge landslides 
Appendix B. Hydrological data

132

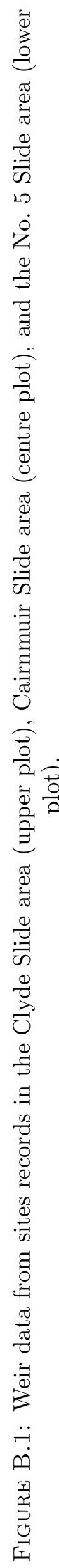




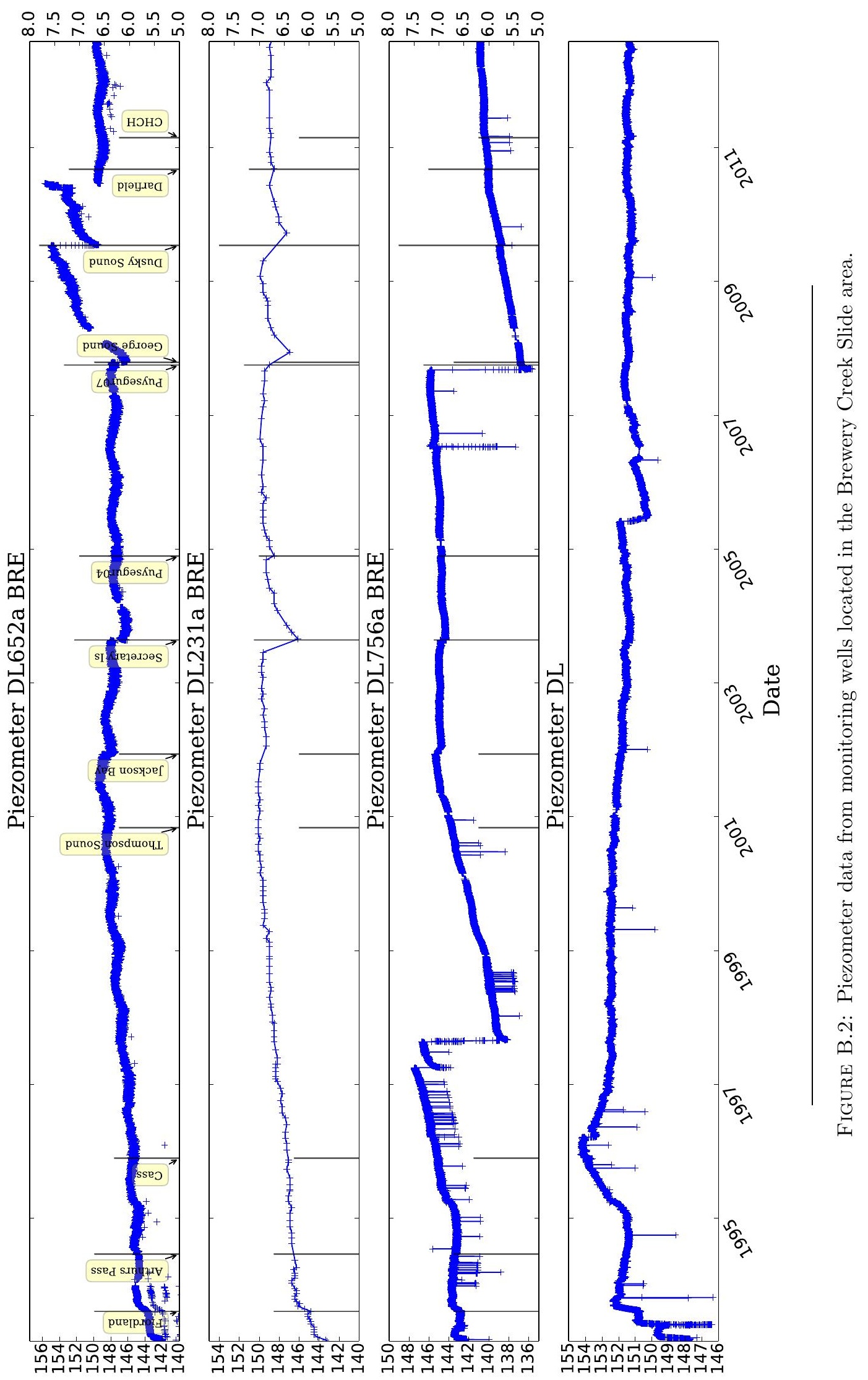




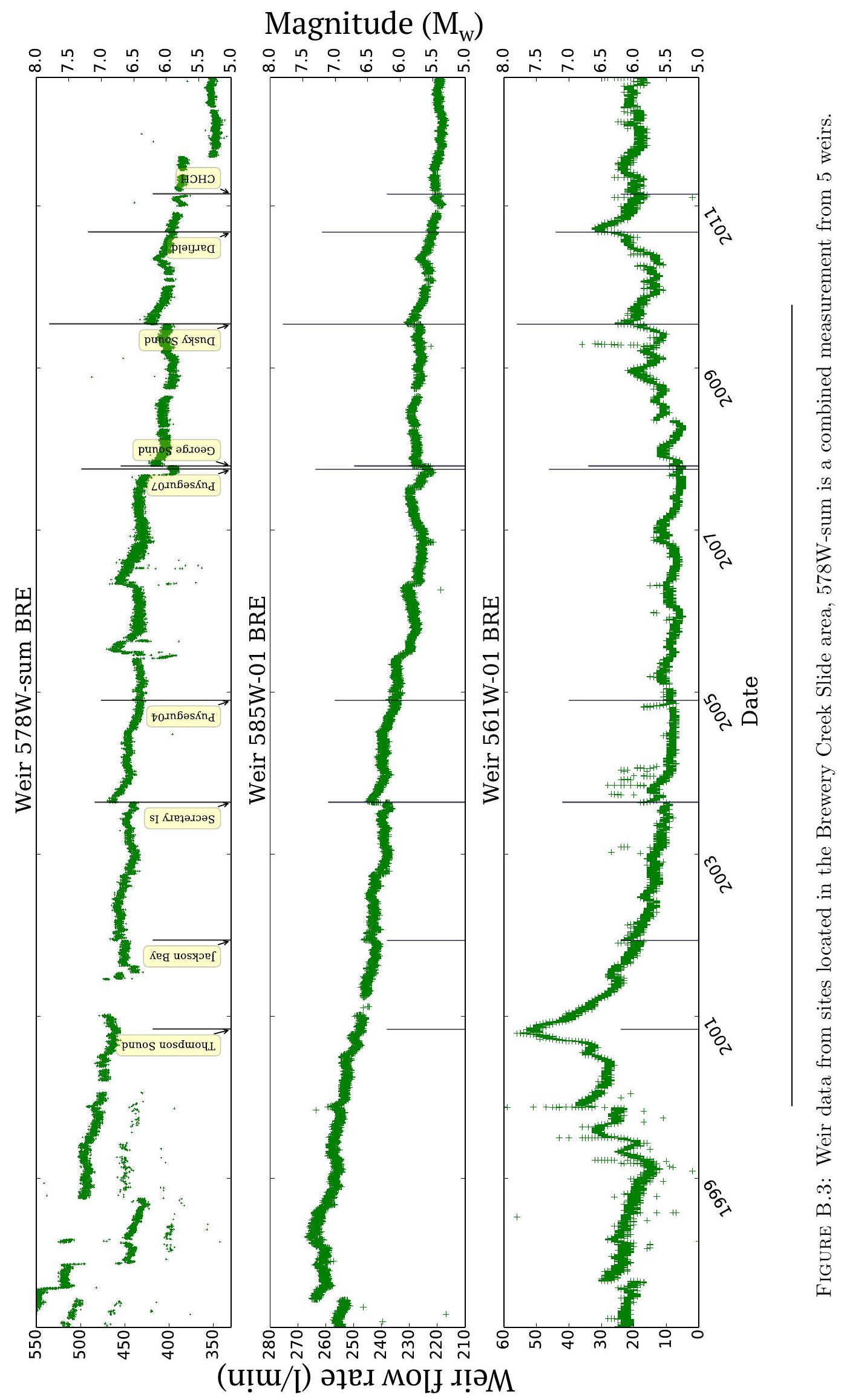




\section{Magnitude $\left(\mathrm{M}_{\mathrm{w}}\right)$}

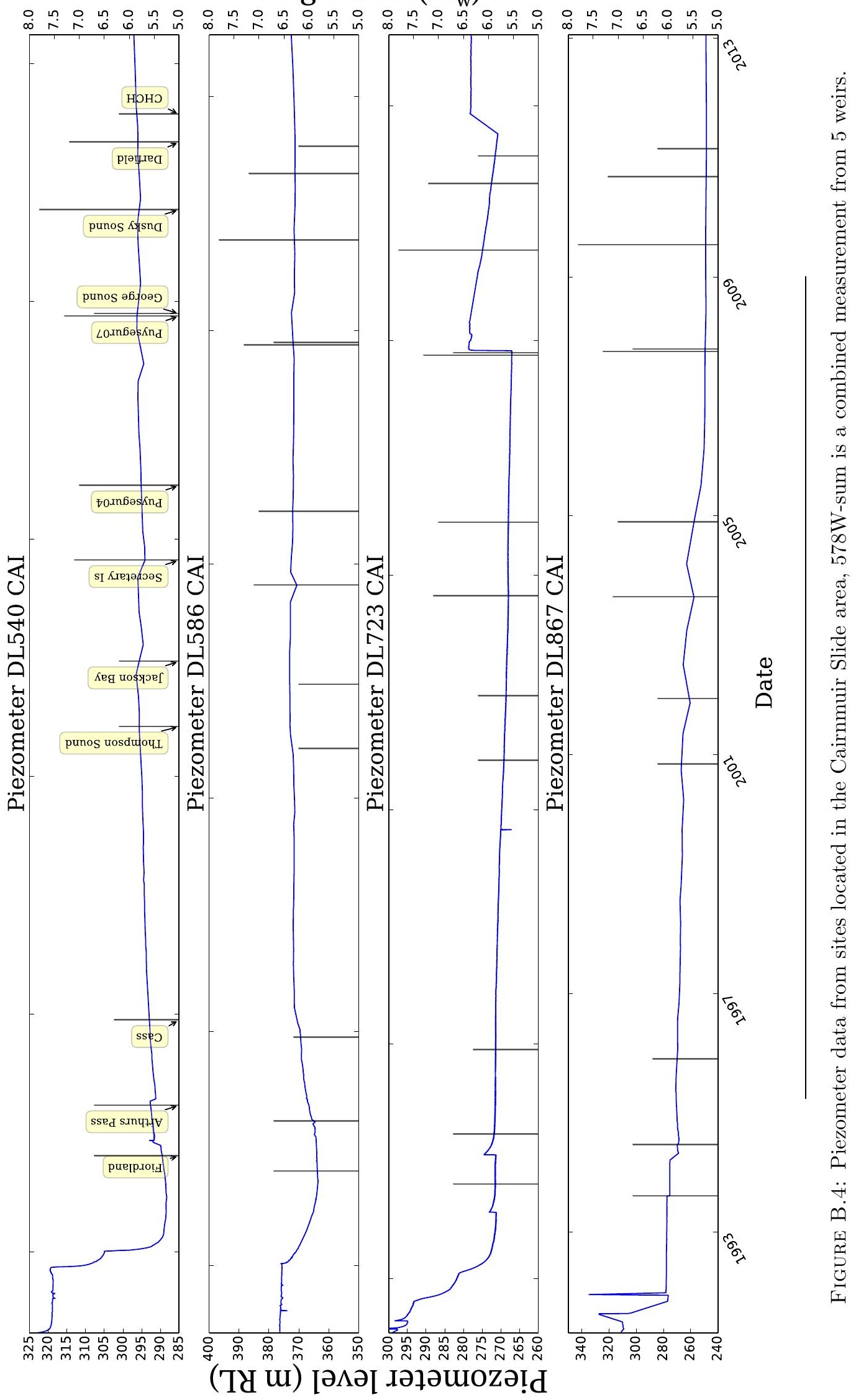




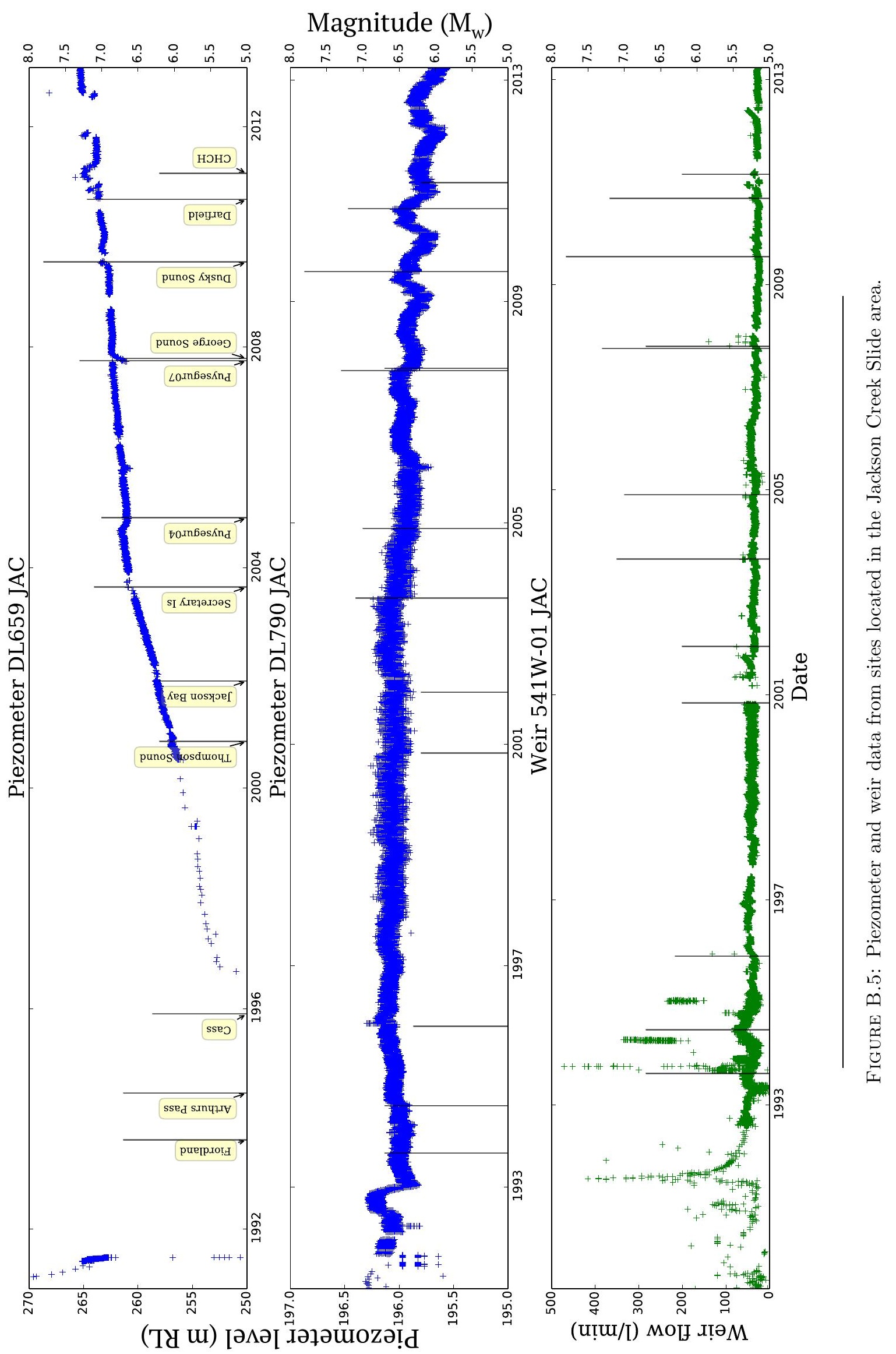




\section{Appendix C}

\section{Removal of barometric effects: a test}

To test if Baytap08 ${ }^{\mathrm{TM}}$ has successfully removed the daily barometric pressure highs and lows that cause oscillations in monitoring well DL1330, NMD, Baytap08 is used to compute the phase differences between theoretical earth tides and piezometer data. Phase differences are then compared to phase differences between water level data with barometric effects removed, and to water level data with barometric effects included. Figure C.1 shows the phase lag of the water level with barometric effects (red) to calculated M2 earth tide, and the phase lag of the piezometer data (to the M2 tide) after Baytap08 has removed the barometric effects (blue); it can be seen that the program has removed a great deal, notably where there are large differences. However, where there are small differences water level data appears to still follow the barometric trend. 


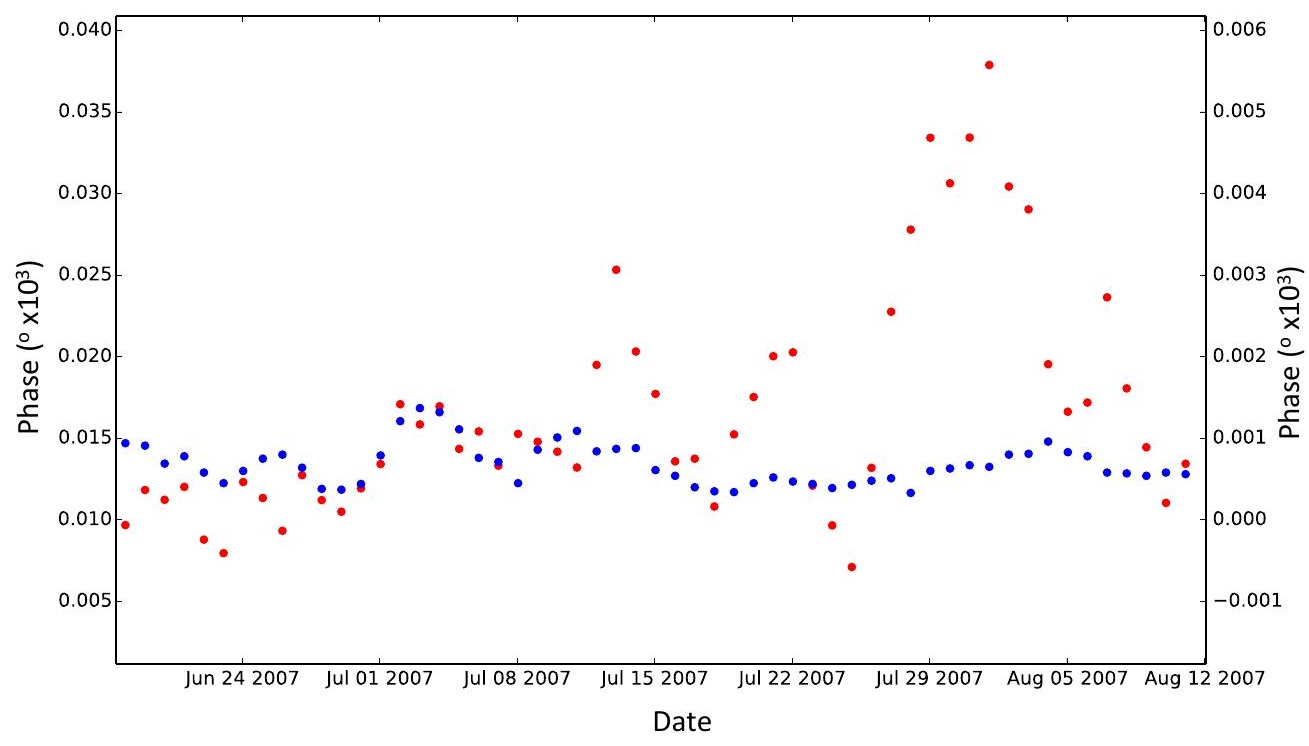

Figure C.1: Test to see if Baytap08 ${ }^{\mathrm{TM}}$ has removed the barometric effects in DL1330a water level data. The blue markers show data after the barometric effects are removed, and the red shows the same data without the effects removed. 


\section{Appendix D}

\section{Assessment of uncertainties}

\section{Log-likelihood plots}

Four examples of log-likelihood plots for determining damping ratio and angular frequency are presented in Figures D.1 and D.2. The log likelihood function fits curves of best-fit using the damped harmonic oscillation model to the data, and returns the corresponding damping parameters and angular frequencies using a gaussian distribution. 

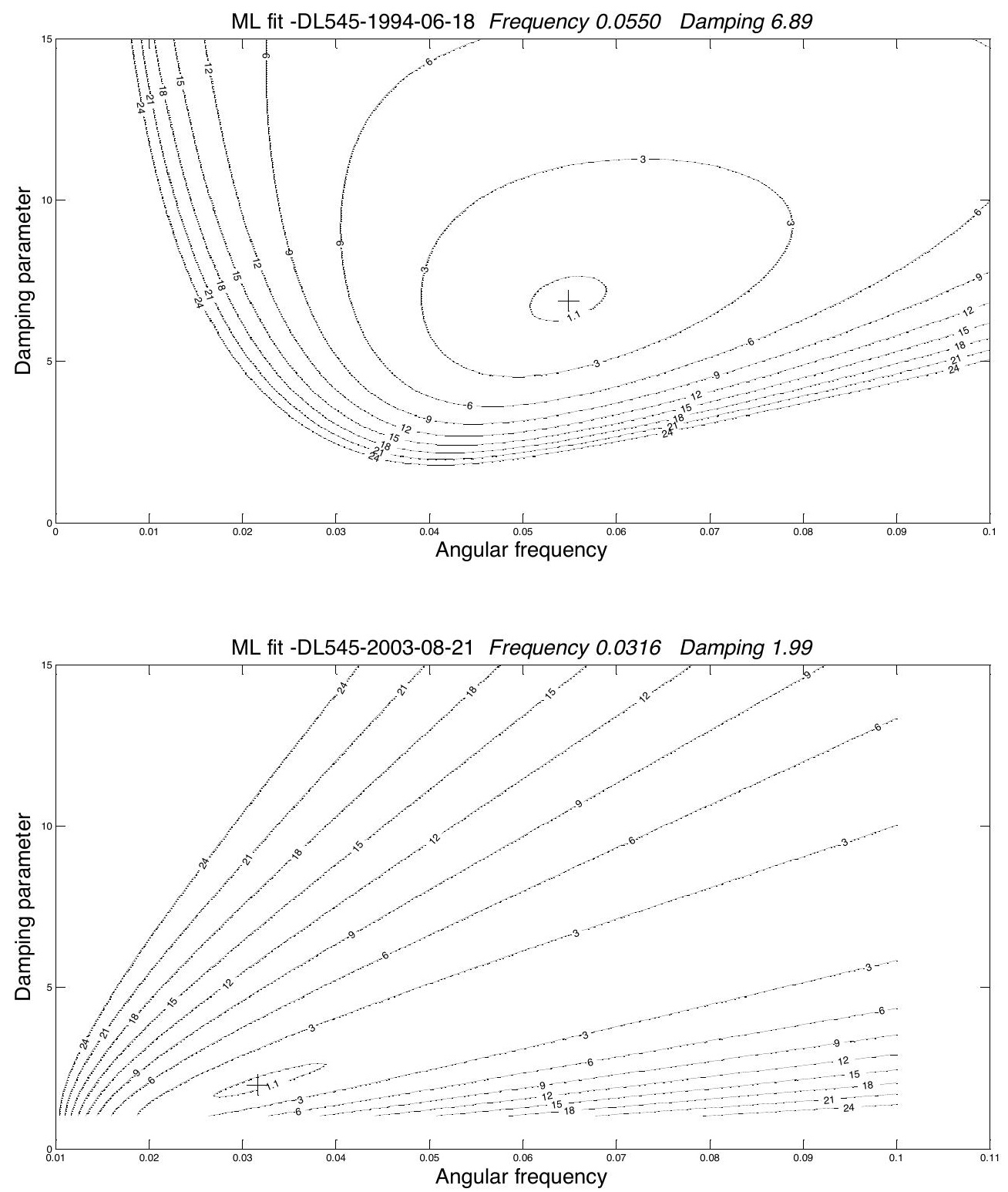

FiguRE D.1: Examples of log-likelihood plots in determining damping ratio angular frequency in DL545a. 

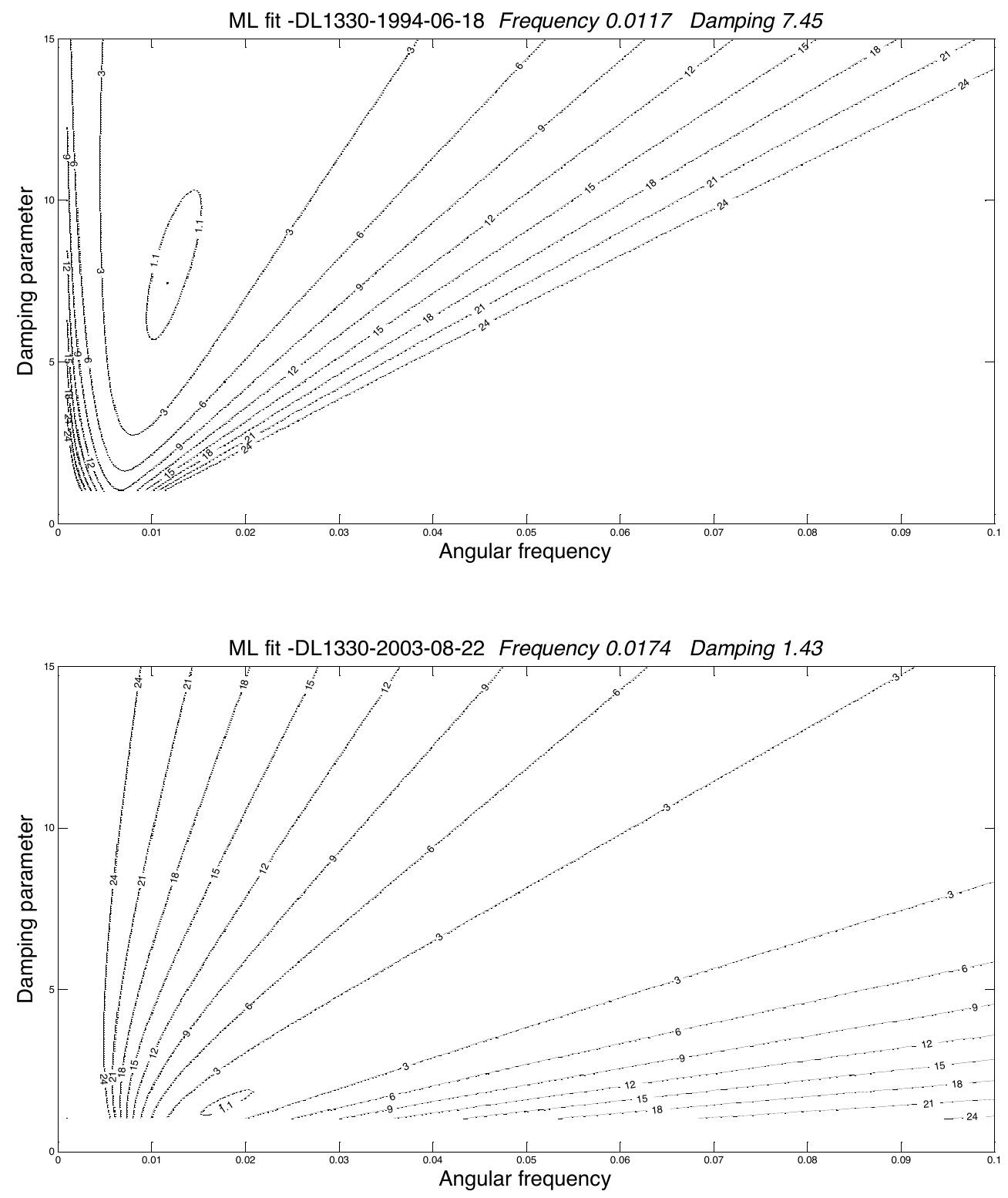

FiguRE D.2: Examples of log-likelihood plots in determining damping ratio angular frequency in DL1330a. 



\section{Bibliography}

Abercrombie, R., Webb, T., Robinson, R., and McGinty, P. (2000). The enigma of the Arthur's Pass, New Zealand, earthquake 1. Reconciling a variety of data for an unusual earthquake sequence. Journal of Geophysical Research, 105(B7):119-137.

Agnew, D. C. (1986). Strainmeters and tiltmeters. Rev. Geophys, 24:579-624.

Arias, A. (1970). A measure of earthquake intensity. In: Hansen, R.J. (Ed.), Seismic Design for Nuclear Power Plants, MIT Press, Cambridge, MA, pages 438-483.

Beca Engineering (2004). Christchurch Liquefaction Study. Stage - IV, page 31.

Beca Engineering (2005). Christchurch Liquefaction Study. Stage - IV (Addendum Report), page 13 .

Beetham, R. and Fergusson, D. (1990a). Clyde Power Station Reservoir, Nine Mile Slide (Downstream) Engineering Geological Assessment. Unpublished Contract Report EGI 89/041, DSIR, held at Clyde Dam landslides Library, 1A, Text and Photographs.

Beetham, R. and Fergusson, D. (1990b). Clyde Power Station Reservoir, Nine Mile Slide (Downstream) Engineering Geological Assessment. Unpublished Contract Report Report EGI 89/041, DSIR, held at Clyde Dam Landslides Library, 1B, Figures.

Beetham, R. and Fergusson, D. (1990c). Clyde Power Station Reservoir, Nine Mile Slide (Downstream) Engineering Geological Assessment. Unpublished Contract Report EGI 89/041, DSIR, held at Clyde Dam Landslides Library, 2, Appendices A-F.

Beresnev, I. A. and Johnson, P. A. (1994). Elastic-wave stimulation of oil production: A review of methods and results. Society of Exploration Geophysicists, 59(6):1000-1017.

Blanchard, F. and Byerly, P. (1935). A study of a well gauge as a seismograph. Bulletin of the Seismological Society of America, 25:313-321.

Bos, M. (1989). Discharge measurement structures. Publication 20, International Institute for Land Reclamation and Improvement, Wageningen, The Netherlands. 
Brodsky, E. E., Roeloffs, E., Woodcock, D., Gall, I., and Manga, M. (2003). A mechanism for sustained groundwater pressure changes induced by distant earthquakes. Journal of Geophysical Research, 108 (B8)(2390):doi:10.1029/2002JB002321.

Brown, L. and Weeber, J. (1992). Geology of the Christchurch urban area: scale 1:50,000. GNS Science. Institute of Geological and Nuclear Sciences 1:50,000 geological map 1, page $104 \mathrm{p}$. and 1 folded map.

CAE (1997). Risk and realities. A multi-disciplinaryapproachtothe vulnerability of lifelines to natural hazards based on the work of the Christchurch Engineering Lifelines Group. Christchurch, Centre for Advanced Engineering, University of Canterbury, ISBN 0-908993-12-9.

Campbell, J., Pettinga, J., and Jongens, R. (2012). The tectonic and structural setting of the 4th September 2010 Darfield (Canterbury) earthquake sequence, New Zealand. New Zealand Journal of Geology and Geophysics, 55(3):155-168, doi: 10.1080/00288306.2012.690768.

Cox, S., Rutter, H., Sims, A., Manga, M., Weir, J., Ezzy, T., White, P., Horton, T., and Scott, D. (2012). Hydrological effects of the M W 7.1 Darfield (Canterbury) earthquake, 4 September 2010, New Zealand. New Zealand Journal of Geology and Geophysics, 55(3):231-247.

Cox, S., Strong, D., Reyes, A., and Sutherland, R. (2010). Earthquake-related thermal responses at Copland warm spring. abstract, Geoscience Society of New Zealand miscellaneous publication 129A. Wellington, Geoscience Society of New Zealand, Auckland(21-24):72.

Cubrinovski, M., Bray, J., Taylor, M., Giorgini, S., Bradley, B., Wotherspoon, L., and Zupan, J. (2011). Soil liquefaction effects in the central business district during the February 2011 Christchurch earthquake. Seismological Research Letters, 82(6):893904.

Cubrinovski, M. and Green, R. A. (2010). Geotechnical reconnaissance of the 2010 Darfield earthquake. Bulletin of the New Zealand Society for Earthquake Engineering, 43(4):243-320.

Dandekar, A. Y. (2013). Petroleum reservoir rock and fluid properties. CRC Press, Taylor and Francis Group, second edition edition.

de Moortel, I., Munday, S. A., and Hood, A. W. (2004). Wavelet analysis: The effect of varying basic wavelet parameters. Solar Pysics, 222:203-228. 
Del Gaudio, V., Pierri, P., and Wasowski, J. (2003). An approach to time-probabilistic evaluation of seismically induced landslide hazard. Bulletin of the Seismological Society of America, 92(2):557-569.

Dipple, G. and Ferry, J. (1992). Fluid flow and stable isotopic alteration in rocks at elevated temperatures with applications to metamorphism. Geochimica et Cosmochimica Acta, 56:3539-3550.

Elkhoury, J., Brodsky, E., and Agnew, D. (2006). Seismic waves increase permeability. Nature, 441(7097):1135-8.

Elkhoury, J. E., Niemeijer, A., Brodsky, E. E., and Marone, C. (2011). Laboratory observations of permeability enhancement by fluid pressure oscillation of in situ fractured rock. Journal of Geophysical Research, 116(B02311):doi:10.1029/2010JB007759.

Faoro, I., Elsworth, D., and Marone, C. (2012). Permeability evolution during dynamic stressing of dual permeability media. Journal of Geophysical Research, 117(B01310):doi:10.1029/2011JB008635.

Fry, B., Bannister, S., Beavan, J., Bland, L., Bradley, B., Cox, S., Cousins, J., Gale, N., Hancox, G., Holden, C., Jongens, R., Power, W., Prasetya, G., Reyners, M., Ristau, J., Robinson, R., Samsonov, S., Wilson, K., and the GeoNet team (2010). The Mw 7.6 Dusky Sound Earthquake of 2009: Preliminary Report. Bulletin of the New Zealand Society for Earthquake Engineering, 43(1):24-40.

GeoNet (2013). The New Zealand Seismometer Network. Sponsored EQC, GNS Sciences, and LINZ.

Gillon, M. D. and Hancox, G. T. (1991). Cromwell Gorge landslides - A general overview. Landslides, Bell (ed.).

Gledhill, K., Ristau, J., Reyners, M., Fry, B., and Holden, C. (2011). The Darfield (Canterbury, New Zealand) Mw 7.1 earthquake of September 2010: A preliminary seismological report. Volume 82(3).

Gledhill, K., Robinson, R., Webb, T., Abercrombie, R., Beavan, J., Cousins, J., and Eberhart-phillips, D. (2000). The Mw 6.2 Cass, New Zealand, earthquake of 24 November 1995: reverse faulting in a strike-slip region. New Zealand Journal of Geology and Geophysics, 42:255-269.

Gurley, K. and Kareem, A. (1999). Applications of Wavelet Transforms in Earthquake, Wind and Ocean Engineering. Engineering Structures, 21:149-167.

Hainzl, S., Kraft, T., Wassermann, J., Igel, H., and Schmedes, E. (2006). Evidence for rainfall-triggered earthquake activity. Geophysical Research Letters, 33. 
Halliday, G. (2010). Large-scale toppling of schist in North-West Otago, Southern Alps, NZ; a precursor to rockslides and rock avalanches. Geologically Active, Williams et al. (eds).

Hewitt, A. and Fergusson, D. (1990). Soil Features Relevant to Shallow Mass Movement in the Nine Mile Creek Slide, Cromwell Gorge, Otago. DSIR Land and Resources Contract Report 90/8, held at Clyde Dam Landslides Library.

Hill, D., Reasonberg, P., Michael, A., Arabez, W., Beroza, G., Brumbaugh, D., Brune, J., Castro, R., Davis, S., dePolo, D., Ellsworth, W. L., Gomberg, J., Harmsen, S., House, L., Jackson, S. M., Johnston, M. J. S., Jones, L., Keller, R., Malone, S., Munguia, L., Nava, S., Pechmann, J. C., Sanford, A., Simpson, R. W., Smith, R. B., Stark, M., Stickney, M., Vidal, A., Walter, S., Wong, V., and Zollweg, J. (1993). Seismicity remotely triggered by the magnitude 7.3 Landers, California, earthquake. Science, 260:1617-1623.

Hoek, E. and Brown, E. (1997). Practical estimates of rock mass strength. International Journal of Rock Mechanics and Mining Sciences, 34(8):1165-1186, ISSN 1365-1609, http://dx.doi.org/10.1016/S1365-1609(97)80069-X.

Hutchinson, J. N. (1994). Some aspects of the morphological and geotechnical parameters of landslides, with examples drawn from italy and elsewhere. Geologica Romana, 39(15):1-14.

Jennings, D., Newton, C., Beetham, D., and Smith, G. (1991). Stabilization of the Nine Mile Creek schist landslide complex. Landslides, Bell (ed.), Balkema, Rotterdam.

Jonsson, S., Segall, P., Pedersen, R., and Bjornsson, G. (2003). Post-earthquake ground movements correlated to pore-pressure transients. Nature, 424(6945):174-9.

Kaiser, A., Holden, C., Beavan, J., Beetham, D., Benites, R., Celentano, A., Collett, D., Cousins, J., Cubrinovski, M., Dellow, G., Denys, P., Fielding, E., Fry, B., Gerstenberger, M., Langridge, R., Massey, C., Motagh, M., Pondard, N., McVerry, G., Ristau, J., Stirling, M., Thomas, J., Uma, S., and Zhao, J. (2012). The Mw 6.2 Christchurch earthquake of February 2011: Preliminary report. New Zealand Journal of Geology and Geophysics, 55(1):67-90.

Karney, C. F. (2013). Algorithms for geodesics. Journal of Geodesy, 87(1):43-55.

Kilb, D., Gomberg, J., and Bodin, P. (2002). Aftershock triggering by complete Coulomb stress changes. Journal of Geophysical Research, 107(B4)(2060):doi:10.1029/2001JB000202. 
King, C.-Y., Zhang, W., and Zhang, Z. (2006). Earthquake-induced groundwater and gas changes. Pure and Applied Geophysics, 163:633-645.

Lay, T. and Wallace, T. (1995). Modern Global Seismology. Academic Press, San diego.

Ma, L., Wang, T., Yin, B., Wang, W., Huang, J., and Zhang, C. (2006). Exploratory statistical analysis with the data of various observations around Tangshan Well Y. Ogata, K.Z. Nanjo and T. Iwata. Proceedings of The 4th International Workshop on Statistical Seismology.

Macfarlane, D. (2009). Observations and predictions of the behaviour of large, slowmoving landslides in schist, Clyde Dam reservoir, New Zealand. Journal of Engineering Geology, 109:5-15.

Macfarlane, D., Pattle, A. D., and Salt, G. (1991). Nature and identification of Cromwell Gorge landslide groundwater systems. Landslides, Bell (ed.), Balkema, Rotterdam.

Manga, M., Beresnev, I., Brodsky, E. E., Elkhoury, J. E., Elsworth, D., Ingebritsen, S. E., Mays, D. C., and Wang, C.-Y. (2012). Changes in permeability caused by transient stresses: field observations, experiments, and mechanisms. Rev. Geophys, 50(RG2004):doi:10.1029/2011RG000382.

Manga, M., Brodsky, E. E., and Boone, M. (2003). Response of streamflow to multiple earthquakes. Geophysical Research Letters, 30(5, 1214):doi:10.1029/2002GL016618.

Manga, M. and Rowland, J. C. (2009). Response of Alum Rock springs to the October 30, 2007 Alum Rock earthquake and implications for the origin of increased discharge after earthquakes. Geofluids, 9:237-250.

Mark, A. (1965). Vegetation and Mountain Climate, in R.G. Lister, and R.P. Hargreaves (eds) Central Otago. New Zealand Geographical Society.

Markley, M. and Norris, R. (1999). Structure and neotectonics of the Blackstone Hill anitform, Central Otago, New Zealand. New Zealand Journal of Geology and Geophysics, 42:205-218.

McGinty, P., Robinson, R., and Webb, T. (2005). The 2001 ML 6.2 Jackson Bay earthquake sequence, South Island, New Zealand. New Zealand Journal of Geology and Geophysics, 48(2):315-324.

Mortimer, N. (2000). Metamorphic discontinuities in orogenic belts: example of the garnet-biotite-albite zone in the Otago Schist, New Zealand. International Journal of Earth Sciences (Geologische Rundschau), (89):295-306. 
Mortimer, N. and Sibson, R. (2003). Otago Schist Structure and Exhumation. Geological Society of New Zealand Miscellaneous Publication, Field Trip 3:116B ISBN 0-908678$97-5$.

Petersen, T., Ristau, J., Beavan, J., Denys, P., Denham, M., Field, B., Holden, C., McCaffrey, R., Palmer, N., Reyners, M., Samsonov4, S., and team, T. G. (2009). The Mw 6.7 George Sound earthquake of October 15, 2007: response and preliminary results. Bulletin of the New Zealand Society for Earthquake Engineering, 42(2):129141.

Polak, A., Elsworth, D., Liu, J., and Grader, A. (2004). Spontaneous swithcing of permeability changes in a limestone fracture under net dissolution. Water Resources Research, 40(W03502):doi:10.1029/2003WR002717.

Quigley, M., Dissen, R. V., Litchfield, N., Villamor, P., Duffy, B., Barrell, D., Furlong, K., Stahl, T., Bilderback, E., and Noble, D. (2012). Surface rupture during the 2010 Mw 7.1 Darfield (Canterbury) earthquake: Implications for fault rupture dynamics and seismic-hazard analysis. Geology, 40(1):55-58.

Reyners, M., McGinty, P., Cox, S., Turnbull, I., O’Neill, T., Gledhill, K., Hancox, G., Beavan, J., Matheson, D., McVerry, G., Cousins, J., Zhao, J., Cowan, H., Caldwell, G., Bennie, S., and the GeoNet team. (2003). The Mw 7.2 Fiordland Earthquake of August 21, 2003: Background and Preliminary Results. Bulletin of the New Zealand Society for Earthquake Engineering, 36(4):233-248.

Reyners, M., Robinson, R., Pancha, A., and McGinty, P. (2002). Stress and strains in a twisted subduction zone-fiordland, new zealand. Geophysics Journal International, 148:637-648.

Ristau, J. (2008). Implementation of routine regional moment tensor analysis in New Zealand. Seismological Research Letters, 79(3):400-415, doi: 10.1785/gssrl.79.3.400.

Robinson, R., Webb, T., McGinty, P., Cousins, J., and EberhartPhillips, D. (2003). The 2000 Thompson Sound earthquake, New Zealand. New Zealand Journal of Geology and Geophysics, 46(3):331-341, DOI: 10.1080/00288306.2003.9515013.

Roeloffs, E. (1998). Persistent water level changes in a well near Parkfield, California, due to local and distant earthquakes. Journal of Geophysical Research, 103(B1):869889.

Segall, P. (1989). Earthquakes triggered by fluid extraction. Geology, 17:942-946.

Sibson, R. H. (2001). Seismogenic Framework for Hydrothermal Transport and Ore Deposition. Society of Economic Geologists Reviews, 14:25-50. 
Smith, G., Crampton, N., and McDowell, B. (1990). Clyde Power Station Reservoir - Nine Mile Slide (Upstream) Geological Assessment. Unpublished Contract Report NZGS Report EGI 89/014, held at Clyde Dam Landslides Library.

Stafford, P. J., Berrill, J. B., and Pettinga, J. R. (2009). New predictive equations for Arias intensity from crustal earthquakes in New Zealand. Journal of Seismology, 13:31-52, DOI 10.1007/s10950-008-9114-2.

Tamura, Y., Sato, T., Ooe, M., and Ishiguro, M. (1991). A procedure for tidal analysis with a Bayesian information criterion. Geophysics Journal International, 104:507-616.

Terzaghi, K. (1925). Erdbaumechanik auf bodenphysikalischer Grundlage. Leipzig u. Wien, F. Deuticke.

Thomson, R. (1993). Clyde Dam Engineering Geological Completion Report. Unpublished Contract Report C-1992/18 Clyde Power Project. Held in GNS Science library www.gns.cri.nz, 1: Text and Appendices.

Travasarou, T., Bray, J., and Abrahamson, N. (2002). Empirical attenuation relationship for arias intensity. Earthquake Engineering and Structural Dynamics, 32(7):1133-1155.

Turnbull, I. (1987). Sheet 133 Cromwell: Geological Map of New Zealand. DSIR, Wellington, New Zealand, 1:63,360, Map and Notes.

Turnbull, I., Mortimer, N., and Craw, D. (2001). Textural zones in the Haast Schist - a reappraisal. New Zealand Journal of Geology and Geophysics, 44:171-183.

Turnbull, I. M. (2000). (Compiler) Geology of the Wakatipu Area. Institute of Geological and Nuclear Sciences Limited, Lower Hutt, New Zealand.

Upton, P. and Sutherland, R. (2014). High permeability and low temperature correlates with proximity to brittle failure within mountains at an active tectonic boundary, Manapouri Tunnel, Fiordland, New Zealand. Earth and Planetary Science Letters, 389:176-187.

USGS (2014). Hydroogic Response in Well 27F2 SOW 019 to Worldwide Earthquakes. van Dissen, R., Cousins, J., Robinson, R., and Reyners, M. (1994). The Fiordland Earthquake of 10 August, 1993, A Reconnaissance Report Covering Tectonic Setting, Peak Ground Acceleration, and Landslide Damage. Bulletin of the New Zealand Society for Earthquake Engineering, 27(2).

Wang, C.-Y. (2007). Liquefaction beyond the near field. Seismological Research Letters, 78:512-417. 
Wang, C.-Y. and Manga, M. (2010). Earthquakes and Water. Springer Heidelberg Dordrecht London New York.

Wang, C.-Y., Manga, M., Wang, C.-H., and Chen, C.-H. (2012). Transient change in groundwater temperature after earthquakes. Geology, page doi: 10.1130/G32565.1.

Wang, C.-Y., Wang, C.-H., and Manga, M. (2004). Coseismic release of water from mountains - evidence from the $1999(\mathrm{Mw}=7.5)$ Chi-Chi, Taiwan, earthquake. Geology, 32:769-772.

Weingarten, M. and Shemin, G. (2013). Insights into water level response to seimic waves: a 24-year high-fidelity record of global seismicity at Devils Hole. Geophysical Research Letters, page doi: 10.1002/2013GL058418.

Wilhelm, H., Zurn, W., and Wenzel, H. (1997). Tidal phenomena, volume 66 of Lecture notes in earth sciences. Springer.

Wilson, S. and Lu, X. (2011). Rainfall recharge assessment for Otago groundwater basins. Otago Regional Council Private Bag 1954, 70 Stafford St, Dunedin 9054, pages ISBN 978-0-478-37621-0.

Wood, B. (1962). Sheet 22 - Whakatipu: Geological Map of New Zealand, 1:250000. DSIR, Wellington, New Zealand.

Wotherspoon, L. M., Pender, M. J., and Orense, R. P. (2012). Relationship between observed liquefaction at Kaiapoi following the 2010 Darfield earthquake and former channels of the Waimakariri River. Engineering Geology 125.

Zhao, J. X., Dowrick, D. J., and McVerry, G. H. (1997). Attenuation of Peak Ground Accelerations in New Zealand earthquakes. Bulletin of the New Zealand Society for Earthquake Engineering, 30(2):133-158. 